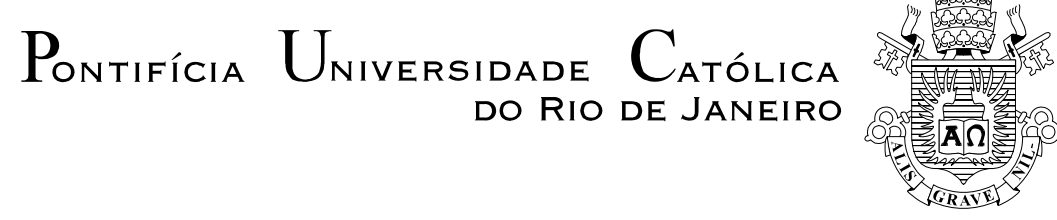

Isabel Horowicz Kallmann

O Financiamento do Sistema Único de Saúde:
um estudo crítico

Dissertação de Mestrado

Orientador: Prof. Florian Fabian Hoffmann Co-orientador: Profa ${ }^{\text {.Nadia de Araujo }}$ 


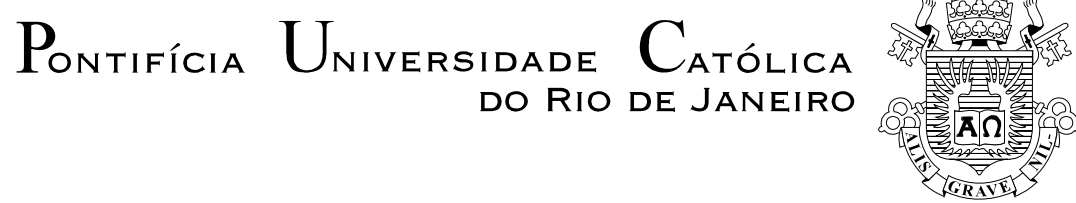

Isabel Horowicz Kallmann

\title{
O Financiamento do Sistema Único de Saúde: um estudo crítico
}

Dissertação apresentada como requisito parcial para obtenção do grau de Mestre pelo Programa de Pósgraduação em Direito do Departamento de Direito da PUC-Rio. Aprovada pela Comissão Examinadora abaixo assinada.

\author{
Prof. Florian Fabian Hoffmann \\ Orientador \\ Departamento de Direito - PUC-Rio \\ Profa. Nadia de Araujo \\ Co-orientador \\ Departamento de Direito - PUC-Rio
}

Prof. José Ribas Vieira

Departamento de Direito - PUC-Rio

Profa. Élida Graziane Pinto Ministério Público de Contas do Estado de São Paulo

Prof ${ }^{a}$. Letícia de Campos Velho Martel

Prof. Augusto César Pinheiro da Silva

Vice-Decano Setorial de Pós-Graduação do

Centro de Ciências Sociais - PUC-Rio

Rio de Janeiro, 24 de abril de 2018. 
Todos os direitos reservados. É proibida a reprodução total ou parcial do trabalho sem autorização da universidade, da autora e do orientador.

\section{Isabel Horowicz Kallmann}

Graduou-se em Direito no ano de 2000 pela Pontifícia Universidade Católica do Rio de Janeiro - PUC-Rio; Membro do Ministério Público do Estado do Rio de Janeiro (MPRJ) desde o ano de 2010, designada desde 2016 para atuar em Promotorias de Justiça de Tutela Coletiva da Saúde.

Ficha Catalográfica

Kallmann, Isabel Horowicz.

O Financiamento do Sistema Único de Saúde: um estudo crítico / Isabel Horowicz Kallmann; Orientador: Florian Fabian Hoffmann - Rio de Janeiro: PUC, Departamento de Direito, 2018.

$182 f ; 30 \mathrm{~cm}$

Dissertação (mestrado) Pontifícia Universidade Católica do Rio de Janeiro, Departamento de Direito, 2018.

Inclui referências bibliográficas.

1. Direito - Teses. 2. Brasil. 3. Saúde. 4. Sistema Único de Saúde. 5. Financiamento. 6. Alocação de Recursos Públicos. 7. Acesso. 8. Equidade. 9. Eficiência. I. Hoffmann, Florian Fabian. II. Pontifícia Universidade Católica do Rio de Janeiro. Departamento de Direito. III. Título. 


\section{Agradecimentos}

Aos meus familiares e amigos, pela compreensão nos momentos em que não estive presente por conta dos estudos e pelo companheirismo nos momentos em que larguei os livros e o computador.

Ao Ministério Público do Estado do Rio de Janeiro, por ter me oportunizado ocupar o cargo de Promotora de Justiça de Tutela Coletiva da Saúde Pública no meu Estado, permitindo-me concretizar a minha missão neste mundo.

Aos meus orientadores, pela experiência transmitida e pelo constante incentivo.

À PUC-Rio e à CAPES, pelos auxílios sem os quais este estudo não teria sido possível.

Por fim, aos fervorosos combatentes em prol do movimento da Saúde Coletiva, aqueles que permanecem firmes em seus ideais mesmo quando o sistema parece colapsar. Deles tirei (tiro) minha inspiração. 


\section{Resumo}

Kallmann, Isabel Horowicz; Hoffmann, Florian Fabian. O Financiamento do Sistema Único de Saúde: um estudo crítico . Rio de Janeiro, 2018. 182p. Dissertação de Mestrado - Departamento de Direito. Pontifícia Universidade Católica do Rio de Janeiro.

O presente estudo parte da insistente indagação sobre os motivos da falência das redes públicas brasileiras de atenção à saúde. Apesar de instituído na Constituição da República de 1988 como um sistema público de saúde que se pretende de cobertura integral e acesso universal, o Sistema Único de Saúde (SUS), na prática, não avançou neste sentido. Pelo contrário, são enormes as desigualdades em saúde no Brasil. O objetivo deste estudo é demonstrar que uma das principais chaves para a superação desta adversidade se encontra na forma como as ações e serviços públicos de saúde no Brasil são financiadas. Afirma-se que o atual modelo de financiamento do SUS apresenta ineficiências e promove iniquidade. No primeiro capítulo são apresentados os aspectos do direito à saúde sob a ótica global, buscando traçar um panorama dos conceitos e tendências desta área do conhecimento. O segundo capítulo discute o conflito entre a infinitude das demandas de saúde e a escassez de recursos para supri-las, procurando destacar a importância do equilíbrio entre as dimensões da equidade e da eficiência durante o exercício da tarefa de alocação de recursos sanitários. O terceiro e o quarto capítulos tratam propriamente do financiamento do SUS. O terceiro capítulo se ocupa com o padrão dos gastos públicos, tornando evidente que os governos brasileiros historicamente se imiscuem da responsabilidade de promover o financiamento adequado das ações e serviços públicos de saúde. O quarto e último capítulo aborda um outro aspecto problemático do financiamento do SUS, qual seja, a ausência de um pacto interfederativo que promova a colaboração mútua entre os entes federativos, situação que prejudica a harmonia do sistema.

\section{Palavras-chaves}

Brasil; Saúde; Sistema Único de Saúde; Financiamento; Alocação de Recursos Públicos; Acesso; Equidade; Eficiência. 


\section{Abstract}

Kallmann, Isabel Horowicz; Hoffmann, Florian Fabian (Advisor). Financing the Brazilian Sistema Único de Saúde (Unified Health System): a critical study. Rio de Janeiro, 2018. 182p. Dissertação de Mestrado - Departamento de Direito, Pontifícia Universidade Católica do Rio de Janeiro.

This research explores the persistent question regarding the reasons for the failure of the Brazilian Public Health System. Although the Brazilian Constitution of 1988 envisioned its Unified Health System (Sistema Único de Saúde) to become an universal system intended to guarantee full access and coverage for all, in practice this concept has never materialized. On the contrary, there are enormous inequalities on the delivery of health in Brazil. This research aims to demonstrate that methods of financing are one of the key elements to overcome such arduous situation. It is asserted that the current health financing model in Brazil is inefficient and ultimately promotes inequality. The first chapter reflects on aspects related to "right to health" from a global perspective, mapping the key concepts and tendencies of Global Health. The second chapter deliberates on the conflict between the infinite demand for health and the scarcity of resources to fulfill such demand, them, highlighting therefore the great importance of achieving a balance between equity and efficiency when conducting the task of allocating health resources. The third and the fourth chapters are addressed to the financing of the Brazilian's Unified Health System. The third chapter considers the Brazilian pattern of public health spending, in order to demonstrate that, historically, Brazilian governments evaded their responsibility of providing adequate health financing. The fourth and last chapter examines another problematic aspect of the public health financing in Brazil, which is the lack of cooperation between the federal units, the absence of such inter-federal covenant is believed to be detrimental to the health system as it impacts on its harmony and unity.

\section{Keywords}

Brazil; Health; Unified Health System; Financing; Public Resources Allocation; Access; Equality; Efficiency. 


\section{Sumário}

$\begin{array}{ll}\text { Introdução } & 10\end{array}$

1 Sistemas de Saúde no Contexto Internacional 13

1.1 Parâmetros e marcos regulatórios supranacionais do direito fundamental à saúde

1.1.1 Definição de saúde $\quad 13$

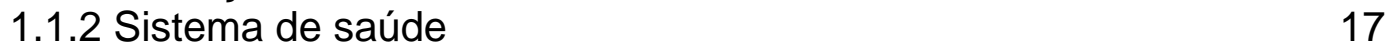

1.1.3 Financiamento da saúde 20

1.2 Tendências da saúde global 22

1.3 Financiamento equitativo do direito à saúde: compartilhamento de encargos sociais e progressividade $\quad 35$

1.4 Modelos de financiamento $\quad 42$

1.4.1 Modelo de seguro social (germânico - modelo Bismarck) 44

1.4.2 Modelo de seguridade social (anglo-saxão - modelo Beveridge) 45

$\begin{array}{ll}\text { 1.4.3 Seguros de saúde privados } & 47\end{array}$

$\begin{array}{ll}1.5 \text { Outras fontes de financiamento } & 48\end{array}$

2 Elementos básicos do financiamento (bem-sucedido) de um sistema de saúde $\quad 52$

2.1 Escassez de recursos versus infinitude da demanda 52

2.2 Os custos do direito à saúde $\quad 60$

2.3 Alocação de recursos sanitários $\quad 66$

2.3.1 O sentido de alocar recursos: equidade na distribuição e

2.3.2 Processos decisórios para alocação de recursos sanitários 71

3 O financiamento do direito à saúde no Brasil (I): precarização do financiamento público da saúde 76

3.1 Panorama histórico: as tendências da atenção à saúde no Brasil anteriormente à Constituição de $1988 \quad 77$

3.2 O SUS e o financiamento privado da saúde 83

3.3 A destinação de recursos à saúde pública no Brasil 95

3.3.1 O rateio da saúde dentro do orçamento da seguridade social 97

$\begin{array}{ll}\text { 3.3.2 Emenda Constitucional 29/00 } & 101\end{array}$

$\begin{array}{ll}\text { 3.3.2.1 Breve histórico } & 101\end{array}$

3.3.2.2 EC 29/00 e LC 141/12 103

3.3.3 Da previsão orçamentária anual para a saúde pública:
planejamento e execução

3.3.4 Descumprimento da EC 29/00 - fazenda versus saúde o caso do Estado do Rio de Janeiro 
4 O financiamento do direito à saúde no Brasil (II): descentralização, regionalização e desinvestimento federal

4.1 Descentralização do SUS

4.1.1 Capilarização político-administrativa do território brasileiro

4.1.2 Insuficiência de apoio financeiro do ente federal à direção municipal do SUS

4.1.2.1 Rateio intergovernamental dos recursos vinculados à saúde: arcabouço normativo que promove o subfinanciamento federal e desigualdades regionais

4.1.2.2 Desvinculação de Receitas da União: um mecanismo adicional para mitigação da responsabilidade da União no custeio do SUS

4.1.3 Regionalização

4.2 A EC 29/00 e o tratamento diferenciado (privilegiado) da União quanto ao custeio do SUS

4.3 As ECs 86/15 e 95/16: nova regra, mesmo enredo, sob o pretexto da recessão econômica

5 Conclusão

6 Referências bibliográficas 


\section{Introdução}

O Sistema Único de Saúde - SUS, instituído no Brasil na Constituição de 1988, configura um dos mais importantes marcos normativos brasileiros. A sua concepção foi fruto de um longo processo de redemocratização política do país e da conquista de valores sociais no campo da medicina a partir de meados da década de 1970 por intermédio do movimento da Reforma Sanitária.

Para além de sua relevância no campo sanitário, o SUS deve ser considerado um dos elementos centrais de toda a transformação político-social a que se submeteu o Brasil na virada do século XX para o século XXI. Após as décadas de ditadura, o Brasil precisou renovar seus votos com a democracia, reorganizando sua estrutura federativa, instrumentalizando seus espaços de controle institucional e social, reinventando a melhor forma de o Poder Público se relacionar com seus cidadãos.

Nessa linha, as diretrizes do SUS estatuídas no art. 198 da CRFB/88 reafirmam os novos paradigmas desta moderna administração pública, tais como a descentralização administrativa em órgãos regionais e locais, a participação do cidadão na tomada de decisões, a transparência na gestão, o financiamento multilateral, com exigência de compartilhamento das responsabilidades e decisões consensuais, a independência e harmonia entre entes públicos que funcionam em regime de colaboração, a ênfase em resultados eficientes etc. ${ }^{1}$

Ousa-se dizer que o SUS representa o macrosistema da Administração Pública com mais ampla envergadura e conexões cruzadas capazes de colocar em prática toda esta nova espécime de administração cooperativa. Os fundamentos constituintes do SUS - universalidade, integralidade com priorização das atividades preventivas, participação comunitária, descentralização regionalizada e hierarquizada etc. - representam tudo aquilo que deveria impulsionar o Brasil para o topo das listas dos sistemas públicos de saúde com maior qualidade e eficiência e das populações mais saudáveis no mundo.

No entanto, apesar da tão elogiosa inovação que foi a instituição do SUS, os esperados resultados não se concretizaram, mesmo quase trinta anos depois da

1 MEDAUAR, Odete apud SANTOS, Lenir; ANDRADE, Luiz Odorico Monteiro de, SUS: o Espaço da Gestão Inovada e dos Consensos Interfederativos: aspectos jurídicos, administrativos e financeiros, 2a ed. Campinas: Saberes, 2009, p. 96. 
promulgação da Constituição de 1988. Apesar de alguns inegáveis avanços, especialmente no âmbito da atenção primária à saúde, uma realidade é notória: o SUS não logrou instituir um sistema de saúde eficiente e igualitário, com acesso amplo e justo às ações e serviços de saúde na linha das mais modernas tendências globais em matéria de saúde coletiva.

O sistema público de saúde brasileiro permanece com índices bastante insuficientes em todos os níveis de atenção à saúde, isso sem falar do grau de desigualdade no acesso aos serviços em oferta. Dito isso, sobressai a indagação: qual o motivo do fracasso dos planos vislumbrados pelos idealizadores do SUS? Por qual motivo a implementação das diretrizes do SUS não foi, até hoje, efetiva e capaz de gerar os resultados positivos para a saúde da população brasileira que dele eram esperados?

A presente dissertação pretende apresentar ao menos uma parcela da resposta a tais indagações. Diz-se apenas uma parcela primeiramente porque grande parte dos problemas de saúde da população brasileira foge ao alcance das políticas sanitárias. Tratam-se de problemas sociais que merecem um enfrentamento muito mais amplo, transbordando o escopo do presente trabalho. Em segundo lugar, o presente estudo avalia apenas os aspectos do financiamento do SUS, por ser este um dos nós críticos de todo o sistema. No entanto, sabe-se que outras diversas perspectivas poderiam ser pautadas, tais como, apenas para citar algumas, a excessiva politização das unidades de saúde públicas, o desestímulo dos profissionais da saúde na rede pública, a influência da indústria farmacêutica na era da globalização, a concentração da atenção à saúde no nível secundário e terciário e a judicialização da saúde. Estes - e outros - são temas de extrema relevância e atualidade, mas que, por opção metodológica, tiveram de ficar de fora do escopo do presente estudo.

Por outro lado, até mesmo a questão do financiamento teve de ter a sua amplitude reduzida para fins de viabilização do seu enfrentamento no nível de pesquisa de Mestrado. Ao longo da elaboração do trabalho, diversas inovações legislativas sucederam, sendo certo que o próprio Ministério da Saúde assumiu a existência de um excessivo número (milhares) de normas para tratar do assunto do financiamento do SUS. Diante da impossibilidade de se examinar todo este arsenal normativo, e considerando o objetivo essencialmente pragmático do presente estudo, tem-se que não se pretendeu aqui examinar todos os 
regulamentos existentes a respeito do financiamento da saúde, mas sim realizar um panorama histórico e crítico a respeito do tema ${ }^{2}$.

Neste viés, o primeiro capítulo apresenta um cenário do estado de artes da disciplina da saúde global, procurando demonstrar quais são as mais modernas linhas e discussões a respeito do tema do financiamento da saúde no contexto internacional. O segundo capítulo percorre alguns esquemas doutrinários a respeito dos aspectos mais intrincados do custo econômico do direito à saúde. Diante da relevância deste direito social e do reconhecimento do alto custo das ações necessárias à sua garantia, é importante a existência de mecanismos concretos para solucionar a dificultosa questão do financiamento justo e adequado de um sistema de saúde. Nestes primeiros dois capítulos, objetiva-se edificar o estudo proposto nos capítulos seguintes. Com o arsenal oferecido, espera-se que possa ser mais fácil compreender toda a análise crítica formulada em seguida.

Os terceiro e quarto capítulos se dedicam, finalmente, ao enfrentamento da questão central da dissertação, qual seja, uma análise crítica sobre o financiamento do sistema de saúde brasileiro. O terceiro capítulo, além de traçar um panorama histórico da atenção à saúde no Brasil até o surgimento do SUS, denuncia a clara tendência brasileira a retrair os gastos públicos - por intermédio de inúmeros artifícios - concomitante a excessivos incentivos à iniciativa privada no campo da saúde. O capítulo seguinte vai além: expõe que o já insuficiente investimento público é, ademais, realizado de forma desordenada. O SUS, que deveria ser um espaço de gestão inovada e de consensos interfederativos ${ }^{3}$ se corporificou em um espaço de disputas federativas, em detrimento da qualidade do sistema e da atenção às necessidades do usuário.

\footnotetext{
2 Apenas para exemplificar um tema que passou ao largo dos comentários expendidos nesta dissertação, Élida Pinto menciona as hipóteses da falta de correção monetária periódica da tabela de serviços e procedimentos do SUS e do cancelamento e contingenciamento de empenhos na área da saúde. PINTO, Élida Graziane, Financiamento dos direitos à saúde e à educação: uma perspectiva constitucional, Belo Horizonte: Fórum, 2015.

3 SANTOS; ANDRADE, SUS: o Espaço da Gestão Inovada e dos Consensos Interfederativos: aspectos jurídicos, administrativos e financeiros.
} 


\section{1 \\ Sistemas de Saúde no Contexto Internacional}

\section{1 \\ Parâmetros e marcos regulatórios supranacionais do direito fundamental à saúde}

\subsection{1}

\section{Definição de saúde}

O conceito de saúde é muitas vezes determinado negativamente, como o estado de "não-doença". Em termos biomédicos é possível extrair utilidade deste conceito, na medida em que o homem saudável é aquele que se encontra no perfeito gozo de suas funções corporais, ausente qualquer deficiência em qualquer um de seus sistemas biológicos.

Em termos sociopolíticos, no entanto, esta conceituação não é suficiente, pois o ser humano saudável, do ponto de vista sociológico, depende não apenas de boas condições corporais. Para além disso, o homem em interação social necessita sentir-se bem neste seu meio, o que inclui um conjunto de fatores, variáveis de sociedade para sociedade. A melhor definição de saúde, nesta linha de raciocínio, encontra-se no preâmbulo da Constituição da Organização Mundial da Saúde (OMS), segundo o qual "saúde é um estado de completo bem-estar físico, mental e social, e não apenas a ausência de doenças".

Talvez a maior dificuldade na efetiva compreensão desta definição esteja na indeterminação do seu conteúdo. Enquanto os parâmetros de "bem-estar físico e mental" podem ser estabelecidos de forma relativamente ${ }^{5}$ objetiva, o significado de "bem-estar social" muda a depender de cada sociedade específica. O cuidado com a saúde é uma questão eminentemente relacional, o que significa dizer que envolve indivíduos e comunidades, bem como seus valores e princípios, e também

\footnotetext{
4 "Health is a state of complete physical, mental and social well-being and not merely the absence of disease or infirmity". ORGANIZAÇÃ̃ MUNDIAL DA SAÚDE, Constituição da Organização Mundial da Saúde.

5 O termo "relativamente" foi empregado aqui pois os avanços da medicina - e dos custos dos tratamentos médicos - ampliou significativamente a margem de ação dos profissionais da área médica. Atualmente, não é possível falar em uma única solução para cada enfermidade em particular. Os níveis de intervenção, a gama de efeitos colaterais, a extensão dos custos e o elenco de potenciais benefícios de cada tratamento são extremamente variáveis, fatores que ampliam a liberdade do próprio paciente quanto à decisão de se submeter a certos procedimentos, considerando a sua concepção subjetiva de bem-estar.
} 
o contexto (social, histórico e econômico) em que se insere o respectivo sistema de saúde ${ }^{6}$.

É justamente em razão deste aspecto subjetivo do conceito de saúde que o parágrafo seguinte do preâmbulo da Constituição da OMS parece ser ainda mais problemático ao consignar que "gozar do melhor estado de saúde possível constitui um dos direitos fundamentais de todo o ser humano, sem distinção de raça, religião, credo político ou condição econômica ou social"’. O real significado de melhor estado de saúde possível é uma das questões mais debatidas na literatura estrangeira a respeito do tema do direito fundamental à saúde.

Para compreender tal significado é preciso inicialmente reconhecer o contexto histórico em que a Constituição da OMS foi elaborada. Trata-se de um marco regulatório datado de 1946, pós-Segunda Guerra Mundial, ocasião em que os países aliados tentavam estabelecer parâmetros mínimos de conduta a serem obedecidos globalmente em prol da paz mundial e da evitação de novos conflitos e barbaridades contra o homem como os que se verificaram durante a guerra. Neste contexto, foi criada a Organização das Nações Unidas (ONU), organismo do qual a OMS é um componente, bem como foi elaborada a Declaração Universal dos Direitos Humanos (DUDH), invocando direitos mínimos de todo ser humano ao redor do mundo. Tal declaração foi fundamento para a celebração do Pacto Internacional dos Direitos Econômicos, Sociais e Culturais (PIDESC), que entrou em vigor em 1976, com força cogente para os países membros que o ratificassem $^{8}$.

Até então, os direitos sociais não costumavam ser vistos como fundamentais ao homem, tampouco o Estado era responsabilizado por sua

\footnotetext{
${ }^{6}$ OLMEN, Josefien van et al, Analysing Health System Dynamics: A Framework, 2a. ed. [s.1.]: Institute for Tropical Medicine, 2012, p. 9. "HS only have a partial influence on the health outcomes of a population. Social, cultural, economic, political, genetic and environmental factors determine people's health. Moreover, many of these factors have a direct influence on the system's functioning".

7 "The enjoyment of the highest attainable standard of health is one of the fundamental rights of every human being without distinction of race, religion, political belief, economic or social condition". ORGANIZAÇÃO MUNDIAL DA SAÚDE, Constituição da Organização Mundial da Saúde.

${ }^{8}$ ORGANIZAÇÃO DAS NAÇÕES UNIDAS, International Covenant on Economic, Social and Cultural Rights.
} 
garantia9. Assim, pode-se dizer que a Constituição da OMS foi um marco regulatório visionário e arrojado para o período ao incluir no conceito de saúde a ideia de bem-estar social, até bem pouco tempo antes desimportante para autoridades públicas. Ao declarar que todo indivíduo possui direito ao melhor estado de saúde possível, considerado este o melhor estado de bem-estar físico, mental e social, a OMS estava se posicionando definitivamente pela responsabilização dos Estados na garantia de uma melhor qualidade de vida a todos os seus cidadãos, proporcionando acesso não somente a tratamentos médicos mas também a condições saudáveis de existência que prevenissem a contração de doenças (moradia, água potável, saneamento, meio ambiente etc.).

No mesmo sentido, o PIDESC exige dos Estados-membros que o ratifiquem o reconhecimento do direito de cada indivíduo ao mais alto padrão de saúde física e mental (art. $12^{10}$ ). Ainda que não tenha mencionado expressamente a ideia de bem-estar social ${ }^{11}$, observa-se aqui o mesmo grau de subjetividade contido nos dizeres do preâmbulo da Constituição da OMS, no que tange ao aspecto superlativo exigido, isto é, quanto ao direito ao melhor e mais alto padrão de saúde.

Uma definição tão ampla de um direito acaba por acarretar uma série de dificuldades práticas na implementação das políticas necessárias à sua garantia efetiva. Ainda que se pondere que este "padrão" de saúde deve ser o melhor e

\footnotetext{
${ }^{9} \mathrm{O}$ chamado "Estado do bem-estar social" (Welfare State), como forma de organização política, era um modelo ainda pouco maduro no período. Seu fortalecimento pós-Segunda Guerra Mundial certamente impactou profundamente a relação Estado-cidadão, especialmente em razão das crises de desemprego geradas pela terceira revolução industrial (revolução tecnológica).

10 "Article 12. 1. The States Parties to the present Covenant recognize the right of everyone to the enjoyment of the highest attainable standard of physical and mental health. 2. The steps to be taken by the States Parties to the present Covenant to achieve the full realization of this right shall include those necessary for: (a) the provision for the reduction of the stillbirth-rate and of infant mortality and for the healthy development of the child; (6) the improvement of all aspects of environmental and industrial hygiene; (c) the prevention, treatment and control of epidemic, endemic, occupational and other diseases; (d) the creation of conditions which would assure to all medical service and medical attention in the event of sickness". ORGANIZAÇÃO DAS NAÇÕES UNIDAS, International Covenant on Economic, Social and Cultural Rights.

${ }^{11}$ Em que pese a carência de menção à ideia de bem-estar social no PIDESC, o General Comment n. 14, documento elaborado pela Comissão dos Direitos Econômicos, Sociais e Culturais da ONU no intuito de conferir interpretação ao artigo 12 do PIDESC, esclareceu que a obrigação dos Estados signatários não se limita à garantia de tratamentos médicos. Segundo o General Comment n. 14, o direito à saúde abrange todos os determinantes sociais que a Constituição da OMS já havia reconhecido. COMITÊ DE DIREITOS ECONÔMICOS SOCIAIS E CULTURAIS DA ORGANIZAÇÃO DAS NAÇÕES UNIDAS, CESCR General Comment No. 14: The Right to the Highest Attainable Standard of Health (Art. 12).
} 
mais alto dentro de um parâmetro de razoabilidade ${ }^{12}$, é preciso haver uma definição minimamente concreta dos aspectos deste direito.

Em nome desta definição, a Comissão dos Direitos Econômicos, Sociais e Culturais da ONU publicou o documento General Comment n. 14: The Right to the Highest Attainable Standard of Health, no intuito de estabelecer aos Estados signatários do PIDESC liames das suas obrigações. Destacadamente, este documento estabelece que a saúde é um direito humano fundamental indispensável para o exercício dos demais direitos humanos ${ }^{13}$, afirmação que deve ser interpretada como o mandamento de que o direito à saúde deve ser tratado como prioritário em relação aos demais interesses em ponderação, quando determinado governo necessitar realizar uma escolha ${ }^{14}$.

Dificuldade adicional se apresenta ao intérprete ou aplicador da norma quando se depara com a necessidade de ponderação entre dois aspectos distintos do direito à saúde. Não raro - sobretudo atualmente, com o avanço dos recursos tecnológicos da medicina - tratamentos médicos e hospitalares são demasiadamente caros para serem custeados indistintamente a todos os cidadãos interessados.

É partindo dessas dificuldades que a presente dissertação lança o seu olhar. Pretende-se examinar a conformação do sistema de saúde público brasileiro - o Sistema Único de Saúde (SUS) - avaliando se a sua forma de organização tem o condão, ou não, de promover uma rede de serviços eficaz e justa do ponto de vista social. Em suma, pretende-se verificar se a forma como o SUS se organiza tem sido capaz de promover o direito à saúde dos cidadãos brasileiros nos padrões

12 GOSTIN, Lawrence O., At Law: The Human Right to Health: A Right to the "Highest Attainable Standard of Health", The Hastings Center, v. 31, n. 2, p. 29-30, 2001.

13 "1. Health is a fundamental human right indispensable for the exercise of other human rights. Every human being is entitled to the enjoyment of the highest attainable standard of health conducive to living a life in dignity. The realization of the right to health may be pursued through numerous, complementary approaches, such as the formulation of health policies, or the implementation of health programmes developed by the World Health Organization (WHO), or the adoption of specific legal instruments. Moreover, the right to health includes certain components which are legally enforceable".1 COMITÊ DE DIREITOS ECONÔMICOS SOCIAIS E CULTURAIS DA ORGANIZAÇÃO DAS NAÇÕES UNIDAS, CESCR General Comment No. 14: The Right to the Highest Attainable Standard of Health (Art. 12).

14 Lawrence Gostin publicou relevante artigo em que enfrentou a dificuldade relacionada à definição do direito à saúde e os critérios para sua efetiva implementação. Destaca-se no texto uma lista dos serviços mínimos que seriam exigidos para garantia de um padrão básico de saúde, segundo o General Comment 14. GOSTIN, At Law: The Human Right to Health: A Right to the "Highest Attainable Standard of Health". 
exigidos internacionalmente, isto é, perseguindo um melhor e mais alto padrão de saúde possível.

\subsection{2}

\section{Sistema de saúde}

A partir dos marcos normativos mencionados no subitem anterior, outros documentos internacionais se sucederam no enfrentamento da problemática do direito à saúde e uma rede de organismos internacionais se estruturou para discutir as questões de racionalidade e equidade na distribuição da saúde em termos globais ${ }^{15}$.

Tal expansão foi importante na medida em que cada país ao redor do mundo possui peculiaridades que derivam do seu próprio contexto histórico, político, social, econômico e cultural. Disto decorre que a frequência, a distribuição e os determinantes dos problemas de saúde, assim como a forma de organização, estruturação e distribuição dos serviços de saúde variam de Estado para Estado, segundo inúmeras variantes.

Com efeito, todo sistema de saúde é uma rede complexa, que reúne pessoas e organizações (cada uma com seus próprios interesses e agendas), governo, serviços e ações diretamente preocupadas com a saúde da população. Esta é a definição presente no Relatório anual da OMS do ano de $2000^{16}$ e dela é possível extrair um pressuposto metodológico para a presente dissertação, qual seja, o de que os sistemas de saúde abrangem apenas as ações e serviços direta ou primariamente preocupados com as melhorias das condições de bem-estar físico e mental da população (saúde propriamente dita, ou saúde corporal - física e mental -, por assim dizer). As ações que venham a beneficiar o bem-estar social do indivíduo, influenciando apenas indireta ou secundariamente a sua saúde corporal (tais como, por exemplo, melhoria em acesso a transporte público, melhoria nas taxas de desemprego, nas condições habitacionais, no desempenho escolar etc.)

\footnotetext{
${ }^{15}$ Vale citar a Organização Pan-Americana da Saúde (OPAS), escritório regional da OMS com a reponsabilidade de atender aos interesses da saúde das populações das Américas.

${ }^{16}$ ORGANIZAÇÃO MUNDIAL DA SAÚDE, The world health report - Health systems: improving performance, 2000 , p. xi. "In this report, health systems are defined as comprising all the organizations, institutions and resources that are devoted to producing health actions. A health action is defined as any effort, whether in personal health care, public health services or through intersectoral initiatives, whose primary purpose is to improve health".
} 
não devem ser consideradas dentro do escopo deste sistema, por mais que todos estes fatores sociais igualmente constituam condições da saúde do ser humano, conforme enfatizado no subitem anterior.

Em resumo, embora o conceito de saúde abranja determinantes sociais, conforme consta do preâmbulo da Constituição da OMS e dos Comentários Gerais ao PIDESC, os sistemas de saúde são responsáveis apenas por aquelas ações diretamente relacionadas ao melhoramento do bem estar físico e mental do ser humano, deixando o seu bem estar social (habitação, educação, transporte, saneamento básico etc.) a cargo de outros aparelhamentos complementares, tais como o sistema de assistência social.

Esta distinção é particularmente importante dentro do tema do financiamento da saúde, na medida em que permite excluir do orçamento do sistema de saúde muitas despesas, ainda que elas sejam indiretamente relevantes para a garantia integral deste direito do cidadão ${ }^{17}$.

Ainda segundo a OMS, todo sistema de saúde seria composto de seis "blocos de sustentação" (building blocks) que funcionariam como as estruturas básicas para organizar o acesso da população às ações e serviços de saúde. A forma de funcionamento de cada um destes blocos seria variável de sistema a sistema e estaria aqui a nota de diferenciação entre eles. Tais "blocos de sustentação", segundo a conceituação da OMS, são: prestação do serviço, força de trabalho, sistema de informação, medicamentos e tecnologia, financiamento e governança ${ }^{18}$.

Neste ponto encontra-se o segundo e mais importante pressuposto metodológico da presente dissertação, qual seja, o de que este trabalho se preocupa particularmente com o "bloco de sustentação" referente ao financiamento das ações e serviços de saúde no sistema de saúde brasileiro. Não

\footnotetext{
${ }^{17}$ Os arts. $3^{\circ}$ e $4^{\circ}$ da Lei Complementar 141/12 definem quais são as despesas que podem ser consideradas como efetiva aplicação de recursos em ações e serviços públicos de saúde. A Lei Complementar 141/12 e o orçamento da saúde no Brasil serão temas do terceiro e quarto capítulos. ${ }^{18}$ ORGANIZAÇÃO MUNDIAL DA SAÚDE, Everybody business: Health Systems to Improve Health Outcomes: WHO's Framework for Action, Genebra: Organização Mundial da Saúde, 2007. Esta estrutura criada pela OMS em 2007 foi posteriormente criticada especialmente por não considerar que os blocos interagem constantemente entre si e com a superestrutura sociopolítica que os cerca, sendo uma concepção muito estanque para explicar o fenômeno dos sistemas de saúde, que é necessariamente dinâmico. Por todos, OLMEN et al, Analysing Health System Dynamics: A Framework, p. 85 e ss.
} 
se pretende aqui a realização de uma análise exaustiva do conceito de saúde, de seu conteúdo e de todas as escolhas políticas fundamentais a este respeito. $\mathrm{O}$ presente estudo pretende verificar tão somente de que forma o Brasil destina recursos financeiros para a promoção de ações e serviços de saúde à sua população.

Finalmente, não é possível deixar de considerar uma importante advertência feita pela OMS no já mencionado relatório anual do ano de 2000:

Enquanto o melhoramento das condições de saúde é claramente o principal objetivo de qualquer sistema de saúde, ele não é o único. O objetivo de uma boa saúde tem dupla perspectiva: o melhor nível possível de atendimento - qualidade e a menor diferença admissível entre indivíduos e grupos - equidade. A qualidade significa que o sistema de saúde responde bem àquilo que a população espera dele; equidade significa que ele responde igualmente bem a todos, sem discriminação. No relatório mundial da saúde 2000, dedicado integralmente aos sistemas de saúde, a Organização Mundial da Saúde expande sua tradicional preocupação com o bem estar físico e mental do ser humano para enfatizar tais elementos de qualidade e equidade ${ }^{19}$ (tradução livre).

A problemática da equidade irá nortear todas as discussões promovidas no presente trabalho, levando em conta não só a preocupação global com esta questão mas sobretudo os altos índices de desigualdade social do Estado brasileiro. Em especial, o terceiro capítulo examinará as injustas consequências do modelo de financiamento da saúde no Brasil à luz da evidente retração dos gastos públicos frente aos gastos privados.

Paralelamente à equidade, todo sistema de saúde deve igualmente se preocupar em ser eficiente. Não raro as discussões a respeito dos investimentos no campo da saúde situam equidade e eficiência em posições diametralmente opostas, como se uma e outra fossem mutuamente excludentes dentro das possíveis decisões políticas a respeito do tema. Tal perspectiva, no entanto, é equivocada. A existência de uma falsa dicotomia entre equidade e eficiência parte

\footnotetext{
19 "But while improving health is clearly the main objective of a health system, it is not the only one. The objective of good health itself is really twofold: the best attainable average level goodness - and the smallest feasible differences among individuals and groups - fairness. Goodness means a health system responding well to what people expect of it; fairness means it responds equally well to everyone, without discrimination. In The world health report 2000, devoted entirely to health systems, the World Health Organization expands its traditional concern for people's physical and mental well-being to emphasize these other elements of goodness and fairness". ORGANIZAÇÃO MUNDIAL DA SAÚDE, The world health report - Health systems: improving performance, p. xi.
} 
de um pressuposto utilitarista que será desmistificado no segundo capítulo, a partir dos arcabouços doutrinários fornecidos por Amartya Sen.

Ao contrário de perturbar, a eficiência na gestão do sistema de saúde promove a equidade deste mesmo sistema, viabilizando uma melhor distribuição dos serviços e ações sanitárias. Amartya Sen explica em Desigualdade Reexaminada que objetivos agregativos e distributivos não estão em rota de colisão $^{20}$.

Todavia, países em desenvolvimento ainda enfrentam muita dificuldade na tarefa de melhorarem os níveis de eficiência de seus sistemas de saúde. A OMS em 2009 elaborou relatório com objetivo de estabelecer parâmetros para o fortalecimento dos sistemas de saúde especialmente nos países em desenvolvimento, relatando que

Apesar do forte consenso mundial sobre a necessidade de fortalecimento dos sistemas de saúde, não há nos países em desenvolvimento um projeto estabelecido a respeito de como conquistar tal objetivo, tampouco fórmula ou pacote de intervenções formulados. Muitos sistemas de saúde simplesmente não possuem capacidade de medir ou compreender suas próprias fraquezas e constrições, fato que deixa gestores públicos à míngua de parâmetros científicos que os apontem o que eles poderiam e deveriam focar em suas ações". ${ }^{21}$ (tradução livre).

É no quarto capítulo desta dissertação que será enfrentado de forma mais direta o aspecto da eficiência do modelo organizacional do SUS, analisando a lógica da descentralização dos serviços em confronto com a excessiva centralização do seu financiamento.

\subsection{3}

\section{Financiamento da saúde}

O financiamento do direito à saúde consiste na atividade de arrecadar, administrar e alocar recursos financeiros em ações e serviços sanitários destinados

\footnotetext{
${ }^{20}$ SEN, Amartya, Desigualdade reexaminada, 2a ed. Rio de Janeiro: Record, 2008, p. 211-212.

21 "Despite strong global consensus on the need to strengthen health systems, there is no established framework for doing so in developing countries, and no formula to apply or package of interventions to implement. Many health systems simply lack the capacity to measure or understand their own weaknesses and constraints, which effectively leaves policy-makers without scientifically sound ideas of what they can and should actually strengthen". Systems thinking for health systems strengthening, 2009, p. 19.
} 
a atender às necessidades epidemiológicas da população. A complexidade desta atividade perpassa diversas nuances, algumas mais objetivas como, por exemplo, a capacidade fiscal do país em análise (quantidade de dinheiro que o país é capaz de gerar para ser investido na produção de serviços de saúde) e outras mais subjetivas como as inclinações político-ideológicas de seus gestores.

Portanto, qualquer discussão a respeito do modelo de financiamento das políticas de saúde em determinado Estado deverá ir além da simples definição do formato como os recursos são arrecadados e alocados. Em uma publicação do ano de 2010 a respeito das estratégias de medição dos indicadores relativos a cada "bloco de sustentação" (building blocks) dos sistemas de saúde, a OMS elucidou que

Financiamento da saúde refere-se à função do sistema de saúde relativa à mobilização, acumulação e alocação de dinheiro para cobertura das necessidades de saúde da sua respectiva população, individual ou coletivamente... o propósito do financiamento da saúde é tornar possível o patrocínio das ações e serviços, assim como gerar o correto incentivo financeiro aos provedores, certificando-se de que todos os indivíduos tenham acesso a uma efetiva saúde pública e atencão personalizada $^{22}$ (tradução livre) (nosso grifo).

Em suma, o que se espera do financiamento da saúde é a promoção do acesso aos serviços de qualidade de forma eficiente e socialmente equitativa. $\mathrm{O}$ financiamento adequado da saúde, isto é, um financiamento que promova uma distribuição justa dos recursos disponíveis, antes de ser visualizado como uma mera despesa primária, deve ser interpretado por gestores públicos como um investimento na proteção dos cidadãos e, por consequência, na diminuição da pobreza e no desenvolvimento econômico do país.

Não por outro motivo que a Resolução 58.33 da OMS, assinada em 2005, estabeleceu a meta da cobertura universal de saúde, consistente na otimização dos sistemas de financiamento da saúde de forma a promover um acesso mais equitativo e que melhor proteja as pessoas das consequências financeiras

\footnotetext{
22 "Health financing refers to the 'function of a health system concerned with the mobilization, accumulation and allocation of money to cover the health needs of the people, individually and collectively, in the health system... the purpose of health financing is to make funding available, as well as to set the right financial incentives to providers, to ensure that all individuals have access to effective public health and personal health care" " ORGANIZAÇÃO MUNDIAL DA SAÚDE, Monitoring the Building Blocks of Health Systems: a handbook of indicators and their measurement strategies, 2010, p. 71.
} 
decorrentes da falta de saúde e do respectivo tratamento médico ${ }^{23}$. O relatório anual da OMS de 2010 apontou três principais problemas para o atingimento deste objetivo, quais sejam, (1) a disponibilidade de recursos, (2) a dependência excessiva dos pagamentos diretos (out-of-pocket money) e (3) o excessivo desperdício, na estimativa, àquela época, de 20-40\% dos recursos de saúde ${ }^{24}$.

Apesar de todos os avanços nos últimos anos no Brasil, ainda há muito a se percorrer e evoluir. É o que o terceiro e o quarto capítulos pretendem demonstrar.

\section{2}

\section{Tendências da saúde global}

Saúde global é a ideia de que algumas preocupações com a saúde transcendem fronteiras nacionais, como doenças epidêmicas, mudanças climáticas globais, pobreza e desigualdades. Muitos problemas de saúde global surgiram com o fenômeno da globalização ${ }^{25}$. Migração de profissionais da medicina e fluxos de pessoas portadoras de doenças transmissíveis são apenas alguns exemplos de fatores a serem enfrentados por esta área de conhecimento.

O estudo da saúde global, portanto, se preocupa com os aspectos generalizados da saúde de toda a população mundial. Não se confunde com as questões referentes às relações internacionais especificamente consideradas, as quais se limitam aos aspectos relacionais entre nações e povos.

A diferenciação é importante, pois são alguns enunciados da saúde global que fornecerão subsídios para o enfrentamento crítico, nos capítulos seguintes, da questão da conformação do sistema de saúde brasileiro e, em particular, do seu modelo de financiamento. Com efeito, noções como compartilhamento de encargos sociais (pooling risk), atenção à saúde verticalizada (versus integrada/horizontalizada), ajustes estruturais, solidariedade social, equidade etc. lideram os tópicos das discussões a respeito dos aspectos mais intrincados do financiamento da saúde no mundo e no Brasil. Compreender tais noções no seu

\footnotetext{
${ }^{23}$ ORGANIZAÇÃO MUNDIAL DA SAÚDE, The world health report: Health systems financing: the path to universal coverage, 2010, p. xi.

${ }^{24}$ Ibid., p. xii-xiii.

${ }^{25}$ KAWACHI, I; WAMALA (Orgs.), Globalization and Health, New York: Oxford University Press, 2007.
} 
contexto mundial é primordial para a efetiva apreensão dos objetivos pretendidos na presente dissertação.

A evolução da saúde global ao longo dos últimos séculos passou por relevantes marcos históricos. De fato, desde a era dos Impérios Europeus e suas respectivas colônias até o período atual as ciências biomédicas passaram por muitas transformações, culminando atualmente nos dilemas de bioética ${ }^{26}$.

Ao longo da era colonial, em que o mundo era eurocentrado, a medicina desenvolvida nas colônias servia exclusivamente aos interesses das metrópoles. Qualquer pesquisa, ação e serviço só era implementado se interessante a salvaguardar os interesses do homem branco europeu ${ }^{27}$. Segundo Greene et al, os atributos da medicina moderna e da atenção à saúde se desenvolveram no período em que se formaram os Impérios Europeus, sendo que a ocupação dos territórios coloniais serviu de grande laboratório para necessários experimentos científicos ${ }^{28}$.

Roy Poter descreve o desenvolvimento da disciplina "Medicina Tropical", no século XIX, com fundamento nas experiências coloniais europeias na Índia, na África e nas Américas. Doenças jamais experimentadas antes e que ficaram conhecidas como doenças "de climas quentes" mataram milhares de europeus e se transformaram num verdadeiro inimigo, desafio aos exploradores, a ser superado em nome do progresso por intermédio de medidas tais como a quarentena e o uso de quinina. Por outro lado, os tratamentos médicos, quando direcionados aos nativos, serviam de pretexto para a evangelização, acarretando a separação de famílias, remoções compulsórias, dizimação da cultura local e imposição dos valores do norte-atlântico ${ }^{29}$. Em suma, a medicina e os cuidados com a saúde eram pretexto para a exploração.

Após a independência das colônias nas Américas ${ }^{30}$, ao longo do século XIX, verificou-se a manutenção de um padrão equivalente ao anteriormente

\footnotetext{
${ }^{26}$ Sobre os recentes dilemas da bioética, leia-se BARBOSA, Swedenberger, Bioética e Direito à Saúde: dilemas, in: ALVES, Sandra Mara Campos; DELDUQUE, Maria Celia; DINO NETO, Nicolao (Orgs.), Direito Sanitário em Perspectiva, Brasilia: ESMPU - Fiocruz, 2013, v. 02.

27 GREENE, J et al, Colonial medicine and its legacies, in: FARMER, P et al (Orgs.), Reimagining Global Health: An Introduction, Berkeley: University of California Press, 2013, p. 38 .

${ }^{28}$ Ibid., p. 34.

${ }^{29}$ PORTER, Roy, The Greatest Benefit to Mankind: a medical history of humanity, New York: W.W. Norton \& Company, 1998, p. 462-468.

${ }^{30}$ Saliente-se que a menção exclusiva às Américas neste ponto do apanhado histórico se deu em razão do escopo do presente trabalho, que se limita ao sistema de saúde brasileiro.
} 
existente, isto é, com foco no controle de doenças transmissíveis (e.g., malária, febre amarela) e políticas sanitárias higienistas ${ }^{31}$ e eminentemente curativas. $\mathrm{O}$ interesse das autoridades públicas permaneceu menos na promoção do bem-estar e mais no desenvolvimento econômico das recém emancipadas Repúblicas. O controle de doenças servia basicamente para impedir que um trabalhador perdesse sua força produtiva em virtude da contração de alguma enfermidade ou que uma praga perturbasse o comércio ${ }^{32}$.

Nesse contexto, doenças evidentemente vinculadas de forma exclusiva a questões socioeconômicas, tais como, por exemplo, a tuberculose, eram frequentemente negligenciadas ${ }^{33,34}$. Na realidade, a atenção à saúde era extremamente verticalizada ${ }^{35}$, isto é, programada para o tratamento de moléstias específicas e seus sintomas, sem se preocupar com métodos preventivos ou tratamentos contínuos e mais abrangentes de con-causas (sociais) determinantes do estado de não-saúde do indivíduo ${ }^{36}$.

Esta tendência se confirmou até meados do século XX, quando então crises econômicas passaram a modificar o contexto econômico mundial. Após a crise do petróleo e a mudança dos padrões de empregabilidade decorrente da revolução pós-industrial (revolução tecnológica), o comércio global, até então superaquecido pelas trocas entre Europa e ex-colônias, passou a sofrer um

\footnotetext{
${ }^{31}$ Higienismo é a política voltada à necessidade de manutenção de padrões de higiene no intuito de se controlar epidemias, sobretudo no espaço urbano.

32 A título de ilustração, pode-se citar o exemplo mencionado por Greene et al, relativo à construção do Canal do Panamá. Entre os anos 1881 e 1889, durante o período de obras promovidas pelos franceses, mais de vinte e um mil trabalhadores morreram, muitos deles de malária ou febre amarela, fazendo com que os planos de construção do canal fossem suspendidos temporariamente. Os trabalhos foram retomados apenas em 1901, sob o comando dos EUA, sendo que desta vez as medidas cabíveis foram adotadas para prevenir o impacto destas doenças (inclusive pela criação do Escritório Sanitário Internacional, embrião da Organização PanAmericana da Saúde). O combate a tais doenças era fruto de estratégicos interesses comerciais existentes na construção do Canal do Panamá, finalmente concluído em 1914. GREENE et al, Colonial medicine and its legacies, p. 53-55.

${ }^{33}$ Ibid., p. 59.

${ }^{34}$ Importante observar, ademais, que certas doenças foram importadas pelos colonizadores, pois os nativos não possuíam resistência às mesmas. Segundo Roy Porter, a tuberculose foi uma doença trazida pelos brancos para as colônias e que foi particularmente devastadora. PORTER, The Greatest Benefit to Mankind: a medical history of humanity, p. 466.

${ }^{35}$ A verticalização da saúde é fenômeno que promove o enfrentamento dos problemas de saúde de forma pontual, mediante intervenções curativas e paliativas e com foco em doenças específicas. Em oposição, a medicina horizontalizada vislumbra uma atenção mais ampla, normalmente preventiva, com olhar na pessoa do paciente e não na enfermidade propriamente dita. Para mais a respeito do assunto, leia-se ATUN, Rifat A.; BENNETT, Sara; DURAN, Antonio, When do vertical (stand-alone) programmes have a place in health systems, 2008.

${ }^{36}$ GREENE et al, Colonial medicine and its legacies, p. 59.
} 
esfriamento. Este novo contexto incentivou uma modificação também na configuração social das populações

Particularmente em relação à América Latina, embora a década de 1970 tenha sido caracterizada pelo desenvolvimento econômico devoto às exportações, as economias latinas sofreram um crescimento reduzido na década seguinte. $\mathrm{O}$ decréscimo nos ganhos individuais dos cidadãos provocou diversos conflitos sociais e inaugurou um período de intensas transformações na região, sendo certo que praticamente todos os países da América Latina mudaram suas Cartas Constitucionais, passando a ampliar o catálogo de direitos nelas previsto incluindo expressamente os direitos econômicos e sociais ${ }^{37}$.

Este novo cenário mundial deu ensejo ao surgimento de uma agenda social cada vez mais influente nas discussões em torno do papel da medicina, viabilizando a emergência de uma nova corrente nesta área do conhecimento - a medicina social -, menos voltada para a cura de doenças específicas e mais interessada na prevenção. Roy Porter relata esta nova tendência, a partir do século XX. Por sua acuidade, suas lições são a seguir transcritas em tradução livre:

A doença após 1900, para além de ser vista apenas como um fenômeno biológico, passou a ser conceituada como uma questão social, a ser compreendida estatisticamente, sociologicamente, psicologicamente - e até mesmo politicamente. O olhar da medicina teve de incorporar questões mais abrangentes, tais como rendimento, hábitos de vida, dieta, condições de moradia, emprego, educação e estrutura familiar - em suma, o complexo psicossocial da economia. Apenas desta forma a medicina poderia enfrentar os desafios postos pela sociedade de massa, suplantando o modelo clínico tradicional e transcendendo visões limitadas da medicina laboratorial preocupada com investigações rápidas da existência de lesões, porém despreocupada com as causas das mesmas. Não foram apenas radicais e profetas que desejaram este novo enfoque $-\mathrm{o}$ de compreender a pessoa por inteiro e no contexto da sociedade; respeitadas figuras da medicina científica, incluindo Kurt Goldstein (1878-1965) e René Dubos (1901-82), autor de Mirage of Health (1959), enfatizaram que o modelo mecânico do corpo e as fórmulas plásticas curativas poderiam, no máximo, cuidar paliativamente uma doença (muito tarde, muito pouco), sem jamais produzir verdadeira saúde.

$\mathrm{O}$ século XX produziu um apanhado de programas e políticas voltados à saúde das pessoas. As ideologias subjacentes a tais programas se estenderam desde a esquerda socialista (medicina estatal deveria ajudar aos desprivilegiados) até a direita fascista (nações deveriam defender-se de tendências socialistas patológicas). De qualquer forma, a sacralização do modelo Hipocrático liberal-

\footnotetext{
${ }^{37}$ MONCAYO S., Héctor-Léon, Las nuevas constituciones en américa latina: algunas reflexiones de contexto., El Otro Derecho, v. 48, 2015, p. 7.
} 
individualista que mistifica o contrato privado existente entre paciente e médico parece ter sido tão superado quanto a política econômica Smithiana na era de Keynes. A medicina se transformou depois de $1900 \mathrm{em}$ um vasto edifício, filosofias mudaram, abraçando uma visão de socialização da medicina. Influenciados pelo inquestionável sucesso da cirurgia Listeriana, da microbiologia de Pasteur etc., a confiança no que a medicina poderia alcançar estava crescente. Em um mundo transformado pela guerra, violência, luta de classes e depressão econômica, a medicina ao menos poderia ser vista como uma força para o bem. Os benefícios eram claros; as desvantagens apareceriam apenas posteriormente (tradução livre) ${ }^{38}$.

Este movimento mencionado por Porter, somado à constatação empírica de que as campanhas de combate a doenças específicas (abordagem "vertical” da medicina) não rendiam resultados suficientemente satisfatórios ${ }^{39}$ acarretou o surgimento de uma campanha pelo enfoque na atenção à saúde básica (primária), inicialmente apenas entre especialistas da área médica, mas que rapidamente ocupou espaço no campo político institucional. Especialistas da medicina e governantes, juntos, passaram a compreender que uma abordagem mais ampla da atenção à saúde (abordagem "horizontal") poderia produzir resultados mais satisfatórios a longo prazo, desviando o foco para a prevenção e para a pessoa do paciente como um ser integral. Os tratamentos deveriam deixar de ser focados na doença propriamente dita, até mesmo em razão do aumento da incidência das comorbidades que exigiam a investigação do homem por inteiro e não apenas no seu aspecto sintomático ou patogênico.

\footnotetext{
${ }^{38}$ PORTER, The Greatest Benefit to Mankind: a medical history of humanity, p. 634-635. "Disease became conceptualized after 1900 as a social no less than a biological phenomenon, to be understood statistically, sociologically, psychologically - even politically. Medicine's gaze had to incorporate wider questions of income, lifestyle, diet, habit, employment, education and family structure - in short, the entire psycho-social economy. Only thus could medicine meet the challenges of mass society, supplanting outmoded clinical practice and transcending the shortsightedness of a laboratory medicine preoccupied with minute investigation of lesions but indifferent as to how they got there. It was not only radicals and prophets who appealed to a new holism - understanding the whole person in the whole society; respected figures within the temple of medical science, including Kurt Goldstein (1878-1965) and René Dubos (1901-82), author of Mirage of Health (1959), were emphatic that the mechanical model of the body and the stickingplaster formula would at best palliate disease (too little, too late) but never produce true health".

${ }^{39}$ Programas de erradicação de doenças como malária e febre amarela nas décadas de 1960 e 1970 obtiveram resultados limitados. O programa da OMS de erradicação da malária (1955-1969) não logrou atingir seus objetivos, embora a campanha contra a varíola (1967-1979) tenha sido um caso único de empreitada bem sucedida, muito possivelmente porque seu tratamento era feito por intermédio de uma vacina de única dose. BASILICO, Matthew et al, Health for All? Competing Theories and Geopolitics, in: FARMER, P et al (Orgs.), Reimagining Global Health: An Introduction, Berkeley: University of California Press, 2013, p. 75.
} 
Segundo Basilico et al, este movimento levou especialistas e gestores a beberem em fontes de conhecimento jamais investigadas anteriormente pelo "mundo desenvolvido". Pioneiramente, nações ditas "civilizadas" e em "avançado estágio de desenvolvimento" lançaram seus olhares para tradições da medicina em países em desenvolvimento. Por exemplo, o especialista em medicina pública Kenneth Newell vangloriou o sistema de saúde ayurvedico e as práticas biomédicas com participação comunitária das áreas rurais na Índia. Outro exemplo mencionado na literatura é o do Sistema Médico Cooperativo, ou movimento dos "médicos descalços" em vilas Chinesas ${ }^{40}$.

Tal movimento culminou na celebração da Conferência Internacional de Alma-Ata, no ano de 1978, a qual se tornou um marco internacional na história do enfrentamento da questão do direito humano à saúde. Tal conferência discutiu os desafios da atenção primária e seus participantes - 134 países, incluindo o Brasil, e 67 organizações internacionais - firmaram o compromisso de atingirem a universalidade da atenção primária até o ano de $2000^{41}$.

A relevância da Convenção da Alma-Ata é indiscutível no cenário da saúde global. Todavia, há um consenso de que, passados quase quarenta anos desde então, os objetivos ali vislumbrados ainda estão longe de serem concretizados. Sobre os problemas de implementação dos objetivos declarados em Alma-Ata, Basilico et al apontam o fato de a Convenção não ter especificado quem iria custear ou ser responsável pela efetiva implementação da atenção primária em escala mundial. De fato, pouco se discutiu a respeito do financiamento das ações ali recomendadas. A crise econômica que se alastrou mundialmente a partir da década de 1980 foi outro importante fator que contribuiu para o fracasso - ao menos parcial - das metas de Alma-Ata ${ }^{42}$.

Em 2008, Rohde et al publicaram importante artigo indicando que, após trinta anos de vigência, Alma-Ata não tinha logrado obter resultados tão satisfatórios quanto se esperava nos países signatários mais pobres. Apesar dos avanços constatados mundialmente em serviços básicos de atenção à saúde

\footnotetext{
${ }^{40}$ Ibid., p. 77. Importante ressaltar que o caso chinês, ao longo dos anos, foi sendo deteriorado e pervertido pela cobrança de taxas por prestação de serviços, como observam Rohde et al. ROHDE, Jon et al, 30 years after Alma-Ata: has primary health care worked in countries?, Lancet, v. 372, p. $950-61,2008$, p. 957.

${ }_{41}$ OMS/UNICEF, Declaração de Alma-Ata.

${ }^{42}$ BASILICO et al, Health for All? Competing Theories and Geopolitics, p. 80-81.
} 
seletivos (e.g., imunização, amamentação natural, hidratação com solução de soro caseiro e monitoramento do crescimento $^{43}$ ), a atenção básica abrangente e compreensiva ou horizontal (e.g., acompanhamento pré e pós-natal, parto assistido por profissionais especializados, vigilância em saúde) não é uma realidade nos países ditos subdesenvolvidos. Os avanços nas estatísticas mundiais de fato demonstram uma melhoria global, todavia esta evolução não foi linear. Melhorias dos índices sanitários na maior parte dos países em desenvolvimento são muito mais comedidas e lentas do que se esperava ${ }^{44}$.

Em se tratando de Brasil, é possível mencionar a importância da criação (em 1994) e expansão do Programa Estratégia Saúde da Família (ESF) em todo o território nacional ${ }^{45}$, considerado um marco na política sanitária brasileira por ampliar o caráter horizontal do atendimento e a coordenação do cuidado, bem como organizar as redes de atenção. A proximidade com a população mais carente também é uma característica marcante do programa, o que para alguns possibilitaria a diminuição da desigualdade no acesso aos serviços de saúde ${ }^{46}$.

No entanto, apesar desta evolução, são enormes os desafios enfrentados, especialmente nos atuais tempos de crise econômica e política no Brasil. Além dos já conhecidos problemas de gestão eficiente, financiamento, resolutividade etc., medidas de austeridade são ainda mais ameaçadoras e submetem o eixo do sistema de saúde brasileiro ao risco de desmantelamento ${ }^{47}$. Detalhes a respeito

\footnotetext{
${ }^{43}$ Ibid., p. 82.

${ }^{44}$ ROHDE et al, 30 years after Alma-Ata: has primary health care worked in countries?

${ }^{45}$ MINISTÉRIO DA SAÚDE, Memórias da Saúde da Família no Brasil, Brasília: [s.n.], 2010.

${ }^{46}$ MALTA, Deborah Carvalho et al, A Cobertura da Estratégia de Saúde da Família (ESF) no Brasil, segundo a Pesquisa Nacional de Saúde, 2013, Revista Ciência \& Saúde Coletiva, v. 21, n. 2, p. 327-338, 2016.

${ }^{47}$ Consigne-se aqui que, recentemente, o Ministério da Saúde alterou a Política Nacional de Atenção Básica (PNAB), tendo a nova política sido aprovada pela Comissão Intergestores Tripartite no dia 31/08/2017. A nova PNAB sofre fortes críticas de especialistas, ao argumento de que está, sub-repticiamente, retirando o Programa Saúde da Família do centro da organização do SUS, instituindo financiamento específico para quaisquer outros modelos na atenção básica que não contemplam equipes multiprofissionais com agentes comunitários de saúde. Em última análise, as reformulações propostas ameaçariam o financiamento adequado da Estratégia de Saúde da Família e incentivaria a seletividade da prestação em detrimento do princípio da universalidade. A influência destes movimentos gerou o Projeto de Decreto Legislativo n. 786/17, do Deputado Mandetta (DEM-MS), com o objetivo de sustar esta Portaria do MS que alterou as diretrizes do PNAB. Por todos, conferir CENTRO BRASILEIRO DE ESTUDOS DE SAÚDE, Contra a reformulação da PNAB - nota sobre a revisão da Política Nacional de Atenção Básica, disponível em: $<$ http://cebes.org.br/2017/07/contra-a-reformulacao-da-pnab-nota-sobre-a-revisao-da-politica-nacional-deatencao-basica/>, acesso em: 21 ago. 2017. e ANTUNES, André, “A nova PNAB é uma volta ao passado”, diz pesquisadora da Fiocruz, disponível em: $<$ https://agencia.fiocruz.br/nova-pnab-e-uma-volta-ao-passadodiz-pesquisadora-da-

fiocruz?utm_source $=$ Twitter\&utm_medium $=$ AFN\&utm_campaign $=$ campaign\&utm_term=term\&utm_conten $\mathrm{t}=$ content $>$, acesso em: 12 set. $201 \overline{7}$.
} 
deste posicionamento austero do governo brasileiro e de suas medidas recentes serão explicitados ao final do quarto capítulo da presente dissertação.

No curso da história, as tendências delineadas em Alma-Ata foram freadas por correntes teóricas neoliberais concebidas nas críticas décadas de 1970 e 1980, quando o cenário político-econômico mundial foi marcado por reformas estruturais impostas especialmente pelo Banco Mundial e pelo Fundo Monetário Internacional (FMI).

Estes organismos financeiros internacionais passaram a ditar programas de austeridade que deveriam ser seguidos por países com dificuldades financeiras, em contrapartida a empréstimos e financiamentos. Estas políticas de ajuste estrutural consistiam na limitação das despesas primárias de governo, aumento das taxas de juros para controle inflacionário, cortes nas importações para ajuste da balança comercial, foco no pagamento de débitos fiscais etc. Tais medidas acabaram acarretando um forte aumento do grau de dependência dos países menos desenvolvidos, elevando gradativamente o grau de endividamento destes governos e prejudicando o desenvolvimento sustentável dos sistemas de saúde nas economias periféricas.

Enquanto países ricos estavam cada vez mais preocupados com causas sociais determinantes da saúde dos seus cidadãos, aumentando assim o grau de proteção e atendimento à demanda, os países mais pobres sucatearam seus sistemas de saúde ao adotarem medidas impostas ou ao menos sugeridas por organismos internacionais. A ordem do dia passou a ser preenchida por ações de austeridade, corte de custos e privatizações. Relatórios e estudos do Banco Mundial recomendaram medidas de cunho neoliberal tais como a implementação da cobrança de tarifas dos usuários de serviços públicos ${ }^{48}$ e o estabelecimento de um pacote básico de serviços públicos, definido com base em índices de custoefetividade das intervenções, concomitante ao incremento do papel do setor privado na assistência à saúde ${ }^{49}$.

Segundo Simms et al, o resultado de tais ajustes estruturais foi catastrófico para os países mais pobres. Em relatório a respeito do efeito das políticas de

\footnotetext{
${ }^{48}$ WORLD BANK, Financing Health Services in Developing Countries: An Agenda for Reform, Washington, D.C.: [s.n.], 1987.

${ }^{49}$ WORLD BANK, World Development Report, 1993.
} 
austeridade para os sistemas de saúde africanos, tais autores apresentaram evidências de que os sistemas de saúde de países como Kenya, Zambia, Madagascar, Tanzania e Senegal entraram em verdadeiro colapso em virtude da ausência de planejamento, suporte e viabilidade da implementação das medidas sugeridas pelo Banco Mundial ${ }^{50}$. As conclusões deste relatório poderiam ser facilmente adaptadas aos países latinos, que também vivenciaram (vivenciam) dificuldades equivalentes e sofreram experiências semelhantes às narradas pelos autores.

Apesar de, como dito anteriormente, a América Latina ter experimentado ao final do século XX décadas permeadas por inspirações socializantes que resultaram na constitucionalização de direitos sociais (dentre eles o direito à saúde), este movimento não foi suficientemente forte para brecar as mencionadas tendências globais neoliberais. Os mesmos direitos sociais que passaram a ser previstos nas Cartas Constitucionais não contaram com suporte material que garantisse ações no sentido da efetiva implementação dos mesmos. A previsão de direitos permaneceu, na maioria das vezes, apenas retórica, pois os governos não investiram recursos financeiros na estruturação de suas redes assistenciais, ao tempo em que a prestação de serviços básicos continuou prioritariamente sob a responsabilidade da iniciativa privada.

Nesse sentido, Laura Soares chama atenção para as ambiguidades desta região, na medida em que, ao mesmo tempo em que se redemocratizava em direção a políticas sociais, foi refreada por um modelo de produção capitalista periférico, dependente e tardio, gerando uma complexidade particular e única frágil, instável e contraditória - em que se situam diferentes estruturas de proteção social $^{51}$.

A respeito da influência da teoria neoliberal na organização dos sistemas de saúde, destaca-se o renomado artigo de Kenneth Arrow, economista vencedor do prêmio Nobel (falecido recentemente, no mês de fevereiro de $2017^{52}$ ),

\footnotetext{
${ }^{50}$ SIMMS, Chris; ROWSON, Mike; PEATTIE, Siobhan, The bitterest pill of all: The collapse of Africa's health systems, 2001.

${ }^{51}$ SOARES, Laura Tavares, Políticas Sociais na América Latina, in: GIOVANELLA, Ligia et al (Orgs.), Políticas e Sistema de Saúde no Brasil, 2a ed. rev. amp. Rio de Janeiro: Fiocruz, 2012, p. 805.

${ }_{52}$ Morre Kenneth Arrow, mais jovem vencedor do Nobel de Economia, Folha de São Paulo, 2017.
} 
intitulado "Uncertainty and the welfare economics of medical care" (em tradução livre, "imprevisibilidade e política-econômica do bem-estar social na atenção à saúde"), que afirma a existência de falhas no mercado de saúde que inviabilizam o seu equilíbrio concorrencial. Segundo Arrow, a imprevisibilidade da incidência de doenças e da eficácia dos tratamentos tornaria inviável a competitividade no setor de serviços de saúde. Fatores adicionais para dificultar a prestação destes serviços por empresas privadas seriam a forte assimetria de conhecimento/informações entre fornecedores e pacientes, a heterogeneidade intrínseca dos produtos médicos, a predominância de "fornecedores-chave", o excesso de regulamentação do mercado etc. ${ }^{53,54}$

Embora sujeito a críticas, em especial em razão dos avanços dos custos tecnológicos da medicina desde o momento em que Arrow escreveu seu artigo, seus fundamentos permanecem atuais e sendo constantemente citados na literatura $^{55}$. Seus ensinamentos merecem atenção porque estas falhas mercadológicas citadas em seu artigo de fato causam uma dissonância entre as pretensões dos prestadores privados dos serviços de saúde (aquilo que eles querem vender) e as necessidades dos usuários/pacientes (aquilo que eles precisam comprar). Por consequência, o serviço ofertado por empresas privadas frequentemente não atende às diretrizes traçadas em políticas sanitárias baseadas em índices epidemiológicos afiançados, mas sim em estratégias mercadológicas interessadas exclusivamente (ou quase exclusivamente) na geração de lucro.

No que tange às necessidades populacionais, é importante destacar que a globalização gerou uma profunda mudança nas questões sociais que afetam a saúde, conforme resume a Comissão da OMS sobre Determinantes Sociais da Saúde (do inglês, Commission on Social Determinants of Health, CSDH). Relatório elaborado por esta Comissão em 2008 relaciona circunstâncias materiais (e.g., condições de vida e de trabalho), comportamentos e circunstâncias biológicas (e.g., nutrição, atividade física, consumo de tabaco e álcool), além de circunstâncias psicossociais (e.g., condições de vida estressantes e

\footnotetext{
${ }^{53}$ ARROW, Kenneth J, Uncertainty and the welfare economics of medical care, The American Economic Review, v. 53, p. 941-973, 1963.

${ }^{54}$ GOTTRET, Pablo; SCHIEBER, George, Health financing revisited: a practitioner's guide, p. 54.

${ }_{55}$ SAVEDOFF, William D, Kenneth Arrow and the birth of health economics, Bulletin of the World Health Organization, v. 82, n. 2, p. 139-140, 2004.
} 
relacionamentos) como atuais fatores sociais que são determinantes na saúde dos indivíduos que vivem em comunidade ${ }^{56}$.

De fato, mais pessoas no mundo estão vivendo em locais sem infraestrutura adequada, saneamento ou água limpa. Além disso, cada vez mais pessoas estão ingerindo álcool e drogas e a queda do fumo de tabaco só veio a ocorrer mais recentemente e ainda de forma bastante tímida. Consequentemente, as taxas de doenças não-transmissíveis aumentaram nas última décadas. Este é um fenômeno também ampliado pelo envelhecimento da população e pelo aumento subsequente das doenças crônicas relacionadas à idade e comorbidades ${ }^{57}$.

Apesar de estas transformações epidemiológicas exigirem uma inovação nos investimentos relativos às políticas de saúde, movimentos por mudanças têm decepcionado, especialmente considerando a força da influência de grandes corporações, tais como indústrias alimentícia e farmacêutica. Em suma, fornecedores privados raramente se interessam em vender soluções para doenças crônicas ou não-transmissíveis. Por exemplo, mais lucrativos do que os investimentos em pesquisas na cura do diabetes, do alcoolismo ou do câncer são os investimentos em campanhas de marketing para promover a venda de alimentos com açúcar adicionado, de bebidas alcoólicas, bem como de tratamentos e medicamentos como quimioterapia e insulina. Considerando que empresas privadas estão particularmente preocupadas com suas margens de lucro, elas naturalmente priorizam as ações mais rentáveis, na maioria das vezes em detrimento da real necessidade da população.

Assim como empresas privadas não vêm se adaptando para atender às mudanças nas demandas de cuidados de saúde resultantes da globalização, da urbanização e do envelhecimento da população, autoridades sanitárias igualmente parecem ignorar tal responsabilidade. Com efeito, o relatório anual da OMS do ano de 2008 revelou que o foco da atenção à saúde na maior parte das nações permanece no cuidado terciário (hospitalocêntrico, isto é, centrado em hospitais), bem como em programas verticalizados (focados no tratamento de doenças específicas), enquanto pouco ou nada está sendo feito para enfrentar o aumento

\footnotetext{
${ }^{56}$ IRWIN, A; SOLAR, O, A conceptual framework for action on the social determinants of health: social determinants of health discussion paper 2 (policy and practice)., 2010, p. 6 .

57 OMS, The World Health Report 2008. Primary Health Care - Now More Than Ever, 2008, p. 7-9.
} 
das doenças crônicas e não-transmissíveis ${ }^{58}$. Esta é uma clara predileção neoliberal, uma vez que os serviços prestados em hospitais e clínicas especializadas são mais caros (e, portanto, mais rentáveis aos seus prestadores) do que aqueles oferecidos nos centros médicos de atenção primária. Quanto mais hospitais e clínicas especializadas houver na rede pública de saúde, maiores são as chances de aquinhoamento dos serviços de saúde a prestadores privados terceirizados, pois estes são geralmente desinteressados na assunção dos serviços (baratos) prestados em pequenos ambulatórios de atenção básica.

O deslocamento das políticas de saúde para as linhas neoliberais ocorrido na década de 1980 causou uma outra notável consequência no campo da assistência, qual seja, a ruptura nos sistemas de saúde consensuais anteriormente existentes, os quais baseavam a atenção à saúde em indicações médicas ou técnicas.

Com efeito, tradicionalmente a medicina era uma prática valorizada pelo capital intelectual de seus profissionais, pela perscrutação profunda dos sintomas e identificação precisa de diagnósticos, bem como pela busca de atendimentos e soluções particularizados para cada paciente, respeitando o ser humano em seu habitat. Tais valores foram sendo perdidos pois as novas políticas de saúde enfatizaram a contenção de custos e a eficiência dos atendimentos segundo critérios de custo-benefício, tornando ainda mais notável a dissonância de interesses entre fornecedores e pacientes (que passaram a ser vistos como simples consumidores). Administradores de empresas e economistas tomaram postos previamente ocupados por médicos; naturalmente, prestadores de saúde, tanto públicos quanto privados, passaram a cobrar cada vez mais taxas dos pacientes por cada serviço prestado ${ }^{59}$.

Dessa forma, os serviços médicos se tornaram cada vez mais caros e a consequência natural dessa trajetória foi o crescimento da desigualdade no acesso aos cuidados de saúde. Isto tem sido claramente verificado ao longo dos últimos trinta anos, particularmente nos países menos desenvolvidos ${ }^{60}$. O já mencionado relatório da OMS, do ano de 2008, é uma excelente evidência disso. Apesar de

\footnotetext{
58 Ibid., p. 9-10.

${ }^{59}$ BASILICO et al, Health for All? Competing Theories and Geopolitics, p. 89.

${ }^{60}$ WALT, Gill; GILSON, Lucy, Reforming the health sector in developing countries: the central role of policy analysis, Health policy and planning, v. 9, n. 4, p. 353-370, 1994, p. 353.
} 
uma melhoria global na qualidade dos cuidados de saúde disponíveis no mundo entre os anos de 1978 e 2008, esses ganhos não foram distribuídos de forma justa. Os países mais pobres do mundo continuam privados de um pacote mínimo de serviços essenciais de saúde para sua população, além do que os indivíduos mais desfavorecidos economicamente não tiveram acesso a tais serviços. Desde 1975 as taxas de queda da mortalidade infantil no mundo e de aumento da expectativa de vida têm sido muito menores nos países subdesenvolvidos ${ }^{61}$.

Em resumo, a desigualdade é consequência do ato de priorizar preocupações econômicas antes das necessidades do ser humano. Os países de alta renda estão gastando trinta vezes mais em cuidados com saúde do que os países em desenvolvimento ${ }^{62}$. Como tal, os que menos necessitam de serviços de saúde são os que mais têm acesso, enquanto os que mais necessitam são os que menos têm acesso. Este dado estatístico ilustra como a desigualdade no financiamento da saúde é uma questão global e que tem por origem uma série de fatores, especialmente a expansão mundial dos ideais capitalistas em detrimento da noção de solidariedade social.

Atualmente, cientistas políticos já reconhecem que a ortodoxia dos padrões neoliberais acarretou o aumento da desigualdade ao redor do mundo e a piora dos padrões de vida humanos em geral. Em junho de 2016, três renomados economistas do FMI, organismo internacional que impulsionou tais padrões ao redor do planeta, publicaram artigo em que afirmam alguns dos fracassos do neoliberalismo e promovem "uma versão mais moderada" deste modelo, baseada na ideia de que, “em vez de gerar crescimento, algumas políticas neoliberais aumentaram a desigualdade" (tradução livre) ${ }^{63}$.

Cabe salientar que a compreensão das tendências narradas no presente subitem tem como objetivo assinalar de que forma elas exerceram influência na organização do sistema de saúde brasileiro. A partir do terceiro capítulo serão expostos os contornos evolutivos do sistema nacional, quando então será possível

\footnotetext{
${ }^{61}$ OMS, The World Health Report 2008. Primary Health Care - Now More Than Ever, p. 2-7.

${ }^{62}$ GOTTRET; SCHIEBER, Health financing revisited: a practitioner's guide, p. viii, 36 .

${ }^{63}$ OSTRY, DJ; LOUNGANI, P; FURCERI, D, Neoliberalism: oversold?, Finance \& development, v. 53, n. 2, p. 38-41, 2016, p. 41 e 38. "Instead of delivering growth, some neoliberal policies have increased inequality, in turn jeopardizing durable expansion".
} 
estabelecer tal relação, suporte para um exame crítico dos padrões de investimento em saúde no Brasil.

\section{3}

\section{Financiamento equitativo do direito à saúde: compartilhamento de encargos sociais e progressividade}

Conforme explicitado anteriormente, o financiamento da saúde consiste na atividade de arrecadar, administrar e alocar recursos financeiros de forma planejada, tornando as ações e serviços sanitários acessíveis à população usuária. Tal atividade conta com, no mínimo, dois personagens: o patrocinador, que realiza um dispêndio financeiro (pagamento), e o provedor, a favor de quem é realizado o pagamento e que, em contrapartida, presta o tratamento ${ }^{64}$.

Ocorre que o patrocinador pode ser o próprio usuário/paciente - e neste caso diz-se que o pagamento é direto (out-of-pocket payment ${ }^{65}$ ) - ou um terceiro, um fundo que se encarrega de arrecadar recursos de diversos contribuintes que se tornam potenciais beneficiários em caso de necessidade de tratamento (pooled funds). Dentro desta última variação são diversos os possíveis arranjos, os quais serão melhor explicitados no próximo item deste capítulo.

São diversos os fatores que influenciam na forma como o financiamento da saúde em um determinado Estado se estrutura: fatores ambientais (e.g., desastres naturais), político-administrativos (e.g., níveis de corrupção, processos políticos, grau de descentralização política, grau de estabilidade política), econômicos (e.g., composição do mercado de trabalho, grau de desemprego, disponibilidades do tesouro público), pressões externas (e.g., imposições do Banco Mundial), valores sociais (e.g., pagamentos informais por serviços públicos, status de profissionais), índices demográficos (e.g., estruturas familiares, gentrificação, urbanização) etc ${ }^{66}$.

A título de exemplo, é possível citar o caso de nações como Grécia e Espanha cujos governos foram forçados, no início do século XXI, a adotarem

\footnotetext{
${ }^{64} \mathrm{O}$ termo tratamento está sendo empregado em sentido lato, significando qualquer espécie de ação, serviço ou mercadoria que envolva os fins do Sistema de Saúde.

${ }^{65}$ Há, ainda, o pagamento direto por intermédio das poupanças individuais (medical savings accounts), de menor importância ao presente estudo por sua diminuta utilização. A hipótese será brevemente explicitada ao final deste capítulo.

${ }^{66}$ GOTTRET; SCHIEBER, Health financing revisited: a practitioner's guide, p. 66-67.
} 
medidas de austeridade e racionalizarem seus serviços públicos de saúde em troca do recebimento de suporte financeiro pelo $\mathrm{FMI}^{67}$. Outro caso passível de menção é o dos países latino-americanos cuja carência de processos políticos efetivamente democráticos e de controle social acarreta uma lógica de transferência de recursos públicos ao setor privado, financiamento regressivo, corrupção na administração dos fundos da saúde, excessiva concentração dos ativos (fragmentação e ausência de economia de escala) etc. ${ }^{68}$

Independentemente das particularidades existentes em cada caso concreto, o que se espera do financiamento de todos os sistemas de saúde, conforme dito outrora, é que seja o mais eficiente e equitativo possível, isto é, aquele que seja capaz de gerar acesso aos serviços de saúde de boa qualidade para o maior número de pessoas possível, sem distinção de classe social e rendimento. Trata-se, em última análise, da busca de um sistema redistributivo, capaz de realocar os recursos de quem tem muito (de sobra) para quem tem pouco (a quem falta).

O assunto será retomado no próximo capítulo; no entanto, considerando que neste momento estão sendo apresentados os elementos básicos das políticas sanitárias segundo padrões globais, esta é a oportunidade adequada para serem apresentados os dois mecanismos de financiamento da saúde úteis ao alcance do objetivo de se promover esta desejada equidade: o compartilhamento de encargos sociais e a progressividade na contribuição.

(a) Compartilhamento de encargos sociais (pooling risk)

Em diversos países ao redor do mundo, inclusive naqueles chamados desenvolvidos, é bastante preocupante a questão da instabilidade das economias familiares. Não é incomum a verificação de casos de famílias inteiras entrarem em insolvência em razão do adoecimento de um de seus membros e da consequente necessidade de mobilização de recursos para custeio do respectivo tratamento. Além disso, a pessoa doente frequentemente deixa de trabalhar e prover o sustento de seus dependentes, prejudicando ainda mais o orçamento familiar.

\footnotetext{
${ }^{67}$ O'CINNEIDE, Colm, Austerity and the Faded Dream of a Social Europe, in: NOLAN, A (Org.), Economic and Social Rights after the Global Financial Crisis, [s.l.]: Cambridge University Press, 2014, p. 185.

${ }^{68}$ SOARES, Políticas Sociais na América Latina, p. 803-808.
} 
Tendo tal cenário em perspectiva, é possível concluir que os pagamentos diretos por tratamentos de saúde (out-of-pocket payments) consistem na mais desastrosa forma de financiamento da saúde, motivo de atraso e desigualdade em diversos países no mundo ${ }^{69}$. Na realidade, trata-se de um sistema que funciona sob a ótica de que os tratamentos de saúde são acessíveis apenas a quem pode pagálos sem prejuízo do sustento próprio e de seus dependentes. Os out-of-pocket payments são a opção lógica dentro de um mercado livre de linha ideológica neoliberal.

Conforme mencionado no item 1.2, os serviços de saúde carecem de algumas características essenciais ao equilíbrio mercadológico, como por exemplo a igualdade de informações entre pacientes e prestadores. O mercado privado de saúde provou ser bastante sensível aos excessos da iniciativa privada na busca por lucros. Para não repetir o que já foi dito anteriormente, basta aqui relembrar a existência de certo consenso na doutrina sanitarista de que o liberalismo ortodoxo provou não ser uma opção bem sucedida no objetivo da distribuição igual dos recursos sociais disponíveis.

A OMS, em seu relatório anual do ano de 2013, tratou do tema da cobertura universal de saúde, reconhecendo o problema das pessoas que não conseguem assumir diretamente os custos dos serviços médicos de que necessitam. Segundo o relatório, este problema pode ser solucionado por intermédio do mecanismo de antecipação do pagamento dos custos de saúde, de forma que os recursos captados antecipadamente possam ser equitativamente distribuídos a quem efetivamente deles necessitar.

Ao exigir que indivíduos paguem pelos serviços de saúde antes mesmo de necessitarem deles o sistema garante a arrecadação de recursos e viabiliza a formação de um fundo que promove a distribuição mais justa dos valores arrecadados. Todos contribuem para o fundo, mas apenas os indivíduos que forem acometidos por alguma moléstia poderão usar os recursos arrecadados. Desta

\footnotetext{
${ }^{69}$ Os países com maior índice de despesas com saúde pagas pelo próprio usuário são os menos desenvolvidos do mundo, em especial os Africanos. ORGANIZAÇÃO MUNDIAL DA SAÚDE, Relatório Mundial da Saúde 2013 - Pesquisa para a cobertura universal de saúde, 2013, p. 14.
} 
forma, tem-se um sistema de compartilhamento dos riscos financeiros inerentes ao adoecimento $^{70}$.

O redirecionamento dos recursos financeiros é uma medida de justiça social, com fundamento no princípio da solidariedade social. No entanto, em última instância, não só o indivíduo é beneficiado por este mecanismo de compartilhamento de riscos, mas a própria sociedade como um todo, eis que a evitação da insolvência familiar é um desejo geral, no intuito de se impedir a pobreza e todas as suas nefastas consequências econômicas e sociais.

Interessante ainda observar que o mecanismo de fundos compartilhados pode ser mais ou menos propenso à redistribuição dos encargos sociais, a depender do quão fragmentado é o sistema de pools. Explica-se: a arrecadação de recursos para composição do fundo para compartilhamento dos encargos sociais pode se dar de três diferentes formas, quais sejam, pela instituição de tributos, pela contribuição compulsória para seguros mandatórios ou pela contribuição voluntária para seguros voluntários (em regra, privados).

Estas três formas de arrecadação de recursos por intermédio de fundos compartilhados serão melhor exploradas no próximo item, pois correspondem aos principais modelos de financiamento dos sistemas de saúde existentes no mundo.

Por ora, importante observar a nocividade da excessiva fragmentação do sistema, ou, em outros termos, os riscos de formação de múltiplos fundos em detrimento do principal objetivo do mecanismo de pooling risk, que é a redistribuição dos encargos a fim de proporcionar a proteção dos indivíduos contra os riscos financeiros decorrentes dos agravos da saúde.

No caso da existência de diversos fundos distintos, como ocorre, por exemplo, quando variados planos de seguro privado disputam no mercado pequenas porções de consumidores, a arrecadação financeira de cada fundo é demasiadamente diluída e, portanto, a proteção financeira dos participantes do fundo é proporcionalmente diminuída.

Pior ainda são duas situações frequentemente observadas nas práticas comerciais e altamente prejudiciais para os consumidores de planos de saúde. A primeira delas diz respeito à seleção hostil (adverse selection) de usuários,

${ }^{70}$ Ibid., p. 7 e 12-14. 
observada quando os preços de planos de saúde são tão altos que apenas pessoas com alta probabilidade de virem a necessitar dos serviços se dispõem a pagar pelo plano. A segunda hipótese consiste na prática de se estabelecer preços diferenciados conforme o risco oferecido pelo consumidor, acarretando a exclusão daqueles potenciais usuários com maior probabilidade de necessitarem da utilização dos serviços médicos cobertos pelo plano (cream-skimming). Nas duas situações, o pool fica extremamente empobrecido e a ideia de redistribuição dos encargos praticamente abolida.

Em conclusão, temos que, quanto maior o pool, maior é a proteção financeira do grupo que o compõe. Por outro lado, quanto menor e mais fragmentado o pool, menor o poder financeiro do fundo e menor é a capacidade de proteção aos seus membros. A existência de planos privados de saúde é um claro exemplo de fragmentação do pool, pois recursos que poderiam ser investidos em um único agregado são desvirtuados para outros (e vários) pequenos grupos, os quais, cada um por si, são mais fracos do que se todos os indivíduos compartilhassem um mesmo fundo de financiamento dos serviços de saúde.

No terceiro capítulo desta dissertação serão avaliadas de forma específica as consequências desta fragmentação no contexto do sistema de saúde brasileiro, sendo identificados os efeitos perversos da pulverização dos investimentos em saúde entre os setores público e privado.

(b) Progressividade na contribuição

Um modelo de financiamento progressivo se funda na ideia de que cada indivíduo deve contribuir financeiramente para o fundo compartilhado na medida da sua capacidade econômica. No sistema progressivo, a proporção da contribuição de cada usuário é diferente, e não guarda qualquer relação com a quantidade de serviços utilizada (real ou potencialmente). É desimportante para o sistema progressivo saber quem vai precisar usar mais os serviços de saúde ofertados pelo sistema de saúde. O fator que importa ao sistema progressivo é a capacidade contributiva de cada membro do pool.

Seguindo lógica similar, é possível falar em progressividade também em relação à potencialidade de uso dos serviços de saúde disponíveis. Dado um certo grupo de pessoas com similar situação financeira, porém desigual risco de 
adoecimento (uns indivíduos com maior potencialidade para o efetivo uso dos serviços de saúde disponíveis que outros), a progressividade do sistema se revelaria na distribuição idêntica do custo do serviço entre todos os indivíduos do grupo. A respeito do tema, o gráfico a seguir, elaborado pela OMS, é bastante elucidativo.

Figure 5.1 Pooling to redistribute risk, and cross-subsidy for greater equity (arrows indicate flow of funds)

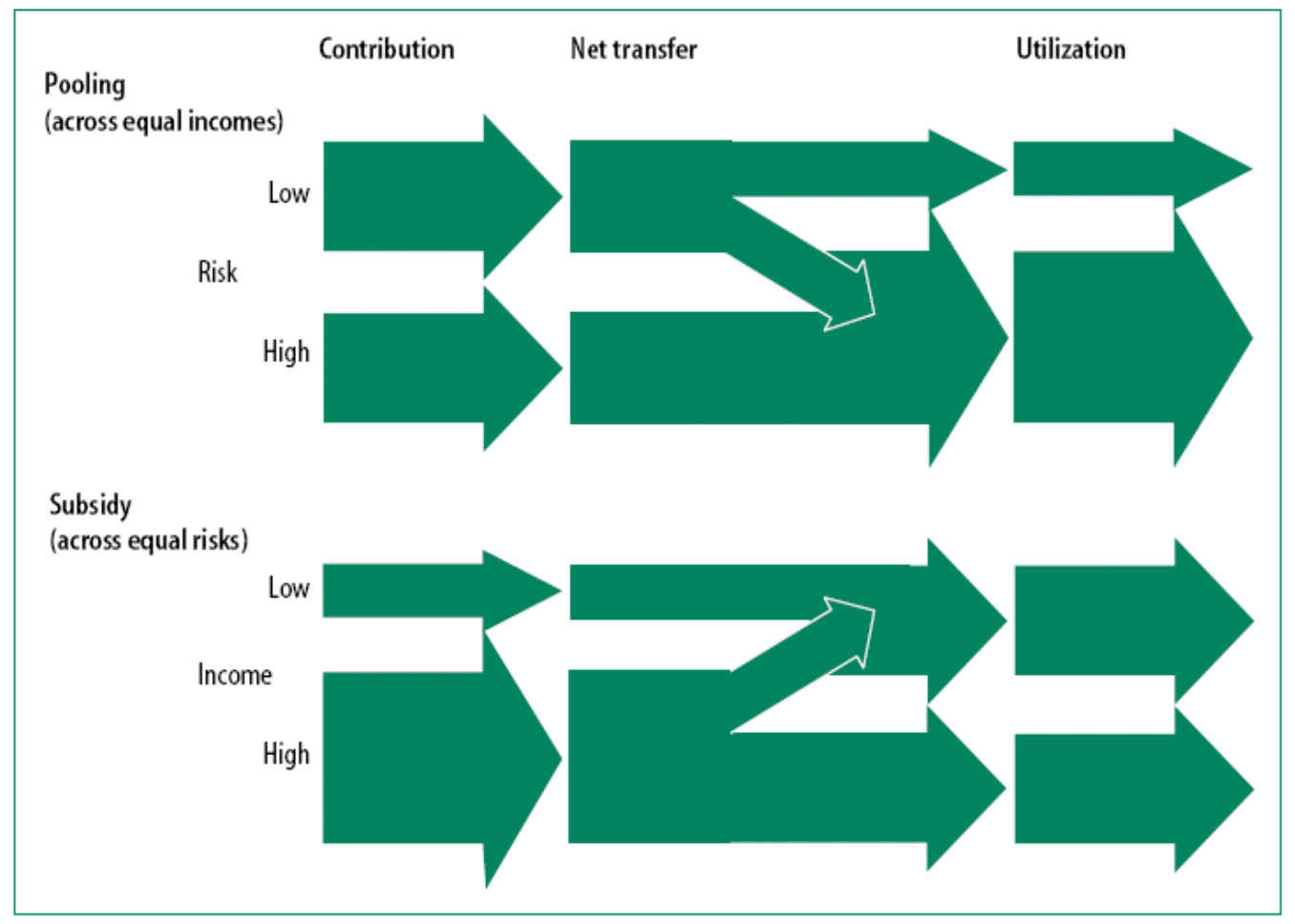

Figura 1

Fonte: Relatório anual OMS 2000. Capítulo 05 "Who Pays for Health Systems?"71

Quanto mais progressivo o sistema de financiamento, mais equitativo ele será, na medida em que pessoas menos vulneráveis (financeira ou em termos de saúde) estarão cobrindo o risco das pessoas mais vulneráveis (redistributividade).

Em conclusão, quanto menos fragmentado e quanto mais progressivo for o financiamento de um sistema de saúde, mais equitativo ele será, sob a ótica da redistributividade. Daí se extrai a conclusão de que o simples aumento do gasto em saúde em termos percentuais do Produto Interno Bruto (PIB) não é um índice

${ }^{71}$ ORGANIZAÇÃO MUNDIAL DA SAÚDE, The world health report - Health systems: improving performance, p. 100. 
suficientemente confiável para concluir que as condições de prestação dos serviços de saúde em um determinado país estão melhorando. É possível, na linha de raciocínio construída, que o aumento do gasto decorra, por exemplo, do incremento de atendimentos de pessoas menos vulneráveis, aumentando ainda mais eventual fosso social existente naquele país especificamente considerado.

Com efeito, dados da Organização para a Cooperação e Desenvolvimento Econômico (do inglês, Organisation for Economic Co-operation and Development - OECD) demonstram que o percentual de gasto em saúde em relação ao PIB dos seus Estados-membros vem gradativamente aumentando ao longo dos anos ${ }^{72}$, fato que evidencia, além de outros aspectos, uma escolha global pela valorização da atenção à saúde ${ }^{73}$. No entanto, o eloquente prêmio Nobel de Economia de 2015, Angus Deaton acredita que "podemos e devemos celebrar conquistas, mas não há base sólida para triunfalismo inconsequente" ${ }^{\text {"74 }}$. Em livro recentemente lançado no Brasil, Deaton afirma que o crescimento econômico sempre foi motivo de ampliação da desigualdade, sobretudo no campo da saúde (como ocorreu no período neolítico, com a mudança das atividades de caça e coleta para a agricultura e igualmente ocorre nas transições do mundo moderno/contemporâneo ${ }^{75}$ ). $\mathrm{O}$ mencionado autor pondera, no entanto, que a solução para esta dicotomia (riqueza versus desigualdade) não é limitar o crescimento econômico, mas sim investir em boas políticas e oferta de bens públicos ${ }^{76}$.

O financiamento equitativo do sistema de saúde vem ao encontro desta ideia, qual seja, a de que os gastos com a atenção à saúde devem ser planejados de forma racional, promovendo o amplo acesso a serviços de qualidade e garantindo proteção financeira a todos os indivíduos contra infortúnios biomédicos.

\footnotetext{
72 OECD, Health expenditure and financing: Health expenditure indicators, OECD Health Statistics (database), disponível em: <http://dx.doi.org/10.1787/data-00349-en>, acesso em: 17 ago. 2017.

${ }^{73}$ São diversas as motivações apontadas por especialistas para justificar o aumento do gasto em saúde, tais como o progressivo aumento dos PIBs dos países, o avanço da tecnologia e, consequentemente, dos custos dos serviços e o envelhecimento populacional. Estas motivações serão melhor discutidas no capítulo 02 .

${ }^{74}$ DEATON, Angus apud ABRAMOVAY, Ricardo, O melhor dos tempos, o pior dos tempos, Revista Quatro cinco um, v. 04, n. 01, p. 04-05, 2017.

75 DEATON, Angus, A grande saída: saúde, riqueza e as origens da desigualdade, [s.1.]: Intrínseca, 2017, p. 81

${ }^{76}$ DEATON, A grande saída: saúde, riqueza e as origens da desigualdade.
} 
O referido planejamento passa pelo reconhecimento de que os recursos a serem investidos em saúde não são infinitos e, por isso, o financiamento das ações e serviços nesta seara precisa ser sustentável. Tal perspectiva é essencial para a longevidade do sistema, evitando-se o seu colapso. No próximo capítulo, o tema da escassez dos recursos de saúde em contraposição à infinitude das demandas no campo sanitário será enfrentado com maior ênfase, oportunidade em que o argumento da equidade será retomado a fim de ser confrontado com o problema da eficiência, outro propósito igualmente relevante para um modelo bem sucedido de financiamento do direito à saúde.

\section{4}

\section{Modelos de financiamento}

A partir das constatações edificadas ao longo dos itens anteriores, é possível concluir que o sistema de saúde de cada país possui suas características particulares, surgidas a partir do contexto histórico, demográfico, político, social etc.

Para os fins do presente trabalho, interessam particularmente as características dos sistemas de saúde que dizem respeito à forma de financiamento das ações e serviços ofertados, o que significa dizer que serão investigados quem são os atores que devem arcar financeiramente com as despesas da saúde e a que custo a assistência à saúde é disponibilizada à população.

Conforme examinado no item 1.3, um determinado sistema de saúde pode ser mais ou menos acessível à sua população a depender da forma como ele é financiado. Nesse sentido, o mecanismo de compartilhamento de encargos sociais (pooling risk) é um dos principais elementos para a promoção da equidade, em contraposição aos pagamentos dos tratamentos diretamente pelos próprios pacientes usuários (out-of-pocket payments).

O presente tópico pretende analisar de que forma os sistemas de saúde podem se organizar para - dentro de suas particulares características providenciarem a proteção social de sua população por intermédio do pooling risk. Serão apresentados, assim, os três principais modos de financiamento dos sistemas de saúde. 
Neste ponto, vale relembrar a tradicional dicotomia entre os paradigmas social e liberal, eis que, no primeiro, o Estado exerce maior influência na economia, enquanto no segundo prevalece a liberdade do mercado

Osmir Antonio Globekner, ao defender sua tese de Mestrado em Direito Público pela Universidade Federal da Bahia (UFBA), posteriormente transformada em obra publicada pela Editora Juruá, sustentou peculiar posicionamento pela relativização desta tradicional dicotomia entre os paradigmas liberal e social, advogando a simbiose de ambos especificamente no campo sanitário. Diz o autor que "a evolução histórica da humanidade determinou a superação de ambos os modelos como alternativas exclusivas, originando a possibilidade de diferentes combinações entre mecanismos de um e outro modelo" $" 77$.

Em que pese a excelência de seu trabalho, tais conclusões merecem ressalvas. Sistemas de saúde são complexos influenciados por uma série de atores, fatores, ações etc. intimamente vinculados aos valores sociais da específica sociedade em que cada sistema se organiza. Nas palavras de Fleury e Ouverney, “cada sociedade responde à necessidade de criar políticas de proteção social de acordo com os valores compartilhados, com suas instituições, com a relação de maior ou menor peso do Estado, da sociedade e da comunidade"78. Assim, o sistema se organiza necessariamente da forma mais conveniente a atender aos interesses sociopolíticos da específica sociedade em que se insere, o que significa dizer que economias liberais e economias sociais conduzirão o financiamento da saúde para caminhos necessariamente distintos.

Não se quer dizer aqui que a iniciativa privada no campo da atenção à saúde não possa conviver com o prestador estatal dentro de um mesmo sistema. Pelo contrário. Mais do que mera convivência, as parcerias público-privadas têm sido um claro exemplo de colaboração bem-sucedida em muitos casos no setor da

\footnotetext{
${ }^{77}$ GLOBEKNER, Osmir Antonio, A Saúde entre o Público e o Privado: o desafio da alocação social dos recursos sanitários escassos, Curitiba: Juruá, 2011, p. 134.

${ }^{78}$ FLEURY, Sonia; OUVENEY, Assis Mafort, Política de Saúde: uma política social, in: GIOVANELlA, Ligia et al (Orgs.), Políticas e Sistema de Saúde no Brasil, 2a ed. rev. e amp. Rio de Janeiro: Fiocruz, 2012, p. 31.
} 
saúde $^{79,80}$. Ainda assim, permanece sendo importante a reflexão a respeito de quais são os valores que organizam o atuar desses personagens interessados, sendo diversas as formas como eles podem se relacionar, de acordo com o tipo de paradigma adotado - liberal ou social. Os exemplos que serão explicitados a seguir comprovam o que ora se defende.

Por fim, vale aqui reproduzir as lições de Ugá et al, segundo as quais "os modelos de financiamento do setor saúde têm forte correspondência com o modelo de sistema de saúde a que pertencem; a lógica que os preside norteia também a do seu financiamento" $"$. De fato, o modelo de financiamento está vinculado à forma de assistência à saúde existente no sistema, a não ser que alguma particularidade seja verificada no caso concreto que subverta esta lógica ${ }^{82}$.

\subsection{1 \\ Modelo de seguro social (germânico - modelo Bismarck)}

O modelo de seguro social desenvolveu-se no final do século XIX e início do século XX, inicialmente na Alemanha (1883) e foi posteriormente copiado por diversos outros países ${ }^{83}$.

Trata-se de um modelo centrado na arrecadação de contribuições cotizadas por empresários e trabalhadores, sendo possível, ainda, a participação do Estado, formando nesse caso um modelo tripartite de financiamento. A partir dessas contribuições, fundos são constituídos para beneficiar apenas aos trabalhadores e seus dependentes, com um pacote pré-fixado de benefícios, cujos valores são em regra equivalentes ao valor das contribuições ${ }^{84}$.

79 MARTIN, Marie H.; HALACHMI, Arie, Public-Private Partnerships in Global Health: Addressing Issues of Public Accountability, Risk Management and Governance, Public Administration Quarterly, v. 36, n. 2, p. 189-237, 2012.

${ }^{80}$ BASTOS, Guaracy Martins, A Aplicabilidade das Parcerias Público-Privadas na Área da Saúde no Brasil, Curitiba: CRV, 2016, p. 101-105.

${ }^{81}$ UGÁ, Maria Alicia D; PORTO, Silvia Marta; PIOLA, Sérgio Francisco, Financiamento e Alocação de Recursos em Saúde no Brasil, in: ESCOREL, Sarah et al (Eds.), Políticas e Sistema de Saúde no Brasil, 2a ed ra. Rio de Janeiro: Fiocruz, 2014, p. 399.

${ }^{82}$ A observação é pertinente, na medida em que, conforme será esclarecido no terceiro capítulo, o Brasil apresenta tal particularidade. Há uma forte tendência à privatização do financiamento do sistema de saúde brasileiro, comportamento este que contraria a promessa de universalização da assistência constante da Constituição.

${ }^{83}$ Tendências do Sistema de Saúde Brasileiro: estudo Delphi, Brasilia: Ipea, 2001, p. 14.

${ }^{84}$ FLEURY; OUVENEY, Política de Saúde: uma política social, p. 35. 
Foi desenvolvido em uma época marcada pelo individualismo, pelo crescimento comercial e industrial e pela expansão das economias globais (século XIX). Naquele contexto histórico, o grande interesse dos Estados era voltado a manter o crescimento econômico, sendo essa a razão pela qual a atenção à saúde voltava-se somente aos trabalhadores, forte no interesse de mantê-los aptos a produzirem riquezas.

Atualmente, o modelo de seguro social é particularmente bem-sucedido em países em que a economia é desenvolvida e os níveis de emprego formal são elevados. Caso contrário, altas taxas de desemprego geram vultosa parcela de excluídos da proteção social à saúde e constituem um grave fator de segregação no acesso aos serviços ${ }^{85}$.

Outra deficiência deste modelo é a sua potencial fragmentariedade, em razão da possível divisão dos recursos arrecadados em diversos fundos, por categorias profissionais ou até mesmo por empresas. Nesses casos, o caráter redistributivo do sistema fica prejudicado.

Ademais, vale mencionar que, em alguns casos, as contribuições sofrem limitações (tetos baseados nos valores das remunerações dos indivíduos), o que limita a progressividade da arrecadação.

Por fim, estudos demonstram que este modelo de financiamento da saúde pode ter efeitos deletérios na economia formal de empregos, em razão do aumento dos encargos trabalhistas ${ }^{86}$.

\subsection{2}

\section{Modelo de seguridade social (anglo-saxão - modelo Beveridge)}

A criação do Sistema Nacional de Saúde britânico (National Health Service - NHS) foi uma estratégia inédita no mundo ocidental, tendo como norte a ideia de cidadania e de amplo acesso aos serviços de saúde a todos os cidadãos ${ }^{87}$, no contexto do Welfare State keynesiano pós-Segunda Guerra Mundial.

\footnotetext{
${ }^{85}$ GOTTRET; SCHIEBER, Health financing revisited: a practitioner's guide, p. 74.

${ }^{86}$ Ibid., p. 9.

87 ALMEIDA, Célia, Reforma de Sistemas de Saúde: tendências internacionais, modelos e resultados, in: GIOVANELLA, Ligia et al (Orgs.), Políticas e Sistema de Saúde no Brasil, 2a ed rev e amp. Rio de Janeiro: Fiocruz, 2012, p. 762.
} 
O sistema britânico foi implementado em 1948 a partir da elaboração do chamado "Relatório Beveridge", documento coordenado pelo economista William Beveridge no final da Segunda Guerra, encomendado pelo primeiro ministro inglês Winston Churchill para planejamento de reformas nos serviços sociais daquele país. O Relatório analisava a situação social da Grã-Bretanha em comparação com diversos outros países, concluindo pela necessidade de se promover uma reforma no sistema de seguros sociais vigente para fins de abarcar uma maior proteção de todos os indivíduos, em igualdade de condições, de forma expandida. Introduziu-se, então, a ideia de universalidade de cobertura:

Mudança 5. Separação do tratamento médico pela administração de simples benefícios fiscais ou transferências de renda, promovendo um serviço médico que atenda a todos os cidadãos, cubra todos os tratamentos e todo tipo de deficiência sob a supervisão de Departamentos de Saúde.

106. Esta é a primeira parte do Compromisso B do Plano, segundo o qual haverá amplos serviços de saúde e reabilitação para todos os cidadãos que precisarem. Este compromisso e algumas das tarefas necessárias para o seu cumprimento são discutidas na Parte VI, parágrafos 426-437 (tradução livre) ${ }^{88}$.

Este sistema adota como estratégia de financiamento a arrecadação tributária de todos os cidadãos com capacidade contributiva, extinguindo a distinção com fundamento na participação no mercado de trabalho. A vantagem desta forma de arrecadação em relação à anteriormente mencionada é a sua magnitude e elasticidade, bem como sua capacidade de ser um modelo de arrecadação progressiva, a depender da forma como forem estabelecidas as regras de incidência tributária.

Neste modelo, o compartilhamento dos encargos sociais é bastante dilatado, na medida em que a rede abrange todos os cidadãos, todos eles igualmente contribuintes e beneficiários ${ }^{89}$.

\footnotetext{
88 "Change 5. Separation of medical treatment from the administration of cash benefits and setting up of a comprehensive medical service for every citizen, covering all treatment and every form of disability under the supervision of the Health Depart-ments.

106. This is the first part of Assumption B of the Plan, namely that there will be comprehensive health and rehabilitation services for all citizens who need them. The assumption and some of the principal problems involved in realizing it are discussed in Part VI, paras. 426-437”. BEVERIDGE, William, Beveridge Report, [s.l.: s.n.], 1942.

${ }^{89}$ Importante observar, todavia, que em países em desenvolvimento geralmente a rede pública de assistência à saúde, por ser deficiente, costuma competir com a rede privada na prestação de serviços, fato que gera uma fragmentação do arranjo pela multiplicação de fontes de financiamento
} 
Quanto ao aspecto negativo, todavia, considerando as diversas outras tarefas a cargo do Estado, este modelo acaba sofrendo com o problema da concorrência com outras possíveis prioridades de agenda do governo. Ademais, este sistema sofre dificuldades em países subdesenvolvidos ou em desenvolvimento, em que grande parte da população não possui qualquer capacidade contributiva. Por fim, ainda é preciso mencionar as dificuldades vinculadas aos aspectos da corrupção e ineficiências, cujos índices são preocupantes em muitos países em desenvolvimento ${ }^{90}$.

\subsection{3}

\section{Seguros de saúde privados}

Segundo Célia Almeida, os sistemas de saúde no mundo - em especial Europa Ocidental e América do Sul - sofreram três 'ondas' (ou gerações) de reformas, assim elencadas:

(i) Primeira onda: iniciada no final do século XIX estendendo-se até as primeiras décadas do século XX, pela implementação do seguro nacional de saúde germânico.

(ii) Segunda onda: iniciada após a Segunda-Guerra Mundial, durando até as crises econômicas que se iniciaram na década de 1970. Criação dos sistemas universalizantes (modelo anglo-saxão) no contexto do Estado do bem-estar social.

(iii)Terceira onda: políticas neoliberais que imputaram a "culpa" pela crise econômica ao Estado do bem-estar social e às suas medidas. Nessa época foram realizados ajustes estruturais e adotadas medidas econômicas privatizantes ${ }^{91}$.

É esta terceira onda que caracteriza o fortalecimento e multiplicação dos seguros de saúde privados, especialmente pela hegemonia norte-americana após o fim das duas grandes guerras mundiais e a influência exercida por seu modelo

e cobertura. Tal questão será destrinchada no terceiro capítulo, que trata especificamente do caso brasileiro.

${ }^{90}$ GOTTRET; SCHIEBER, Health financing revisited: a practitioner's guide, p. 73.

${ }^{91}$ ALMEIDA, Reforma de Sistemas de Saúde: tendências internacionais, modelos e resultados, p. 761-763. 
sanitário hospitalocêntrico (centrado na atenção hospitalar), investido de alta tecnologia e crescente especialização médica ${ }^{92}$.

Vale aqui repetir o que fora dito anteriormente a respeito das consequências do neoliberalismo para a dinâmica do acesso à saúde. Novamente parafraseando Roy Porter no assunto, a medicina, na sua "versão neoliberal", deixou de ser exercida em pequena escala, fundada em relações pessoais entre paciente e médico, para passar a ser uma atividade corporativa, verdadeiro negócio empresarial orientado para o lucro, com crescimento ilimitado. Médicos deixaram de ser o eixo central da medicina, em favor de empresários e outros profissionais que jamais tiveram contato direto com pacientes ou doenças ${ }^{93}$.

Quando comparados com os pagamentos diretos (out-of-pocket payments), os seguros privados de saúde são mais benéficos, pois fornecem proteção financeira aos seus associados, providenciando a antecipação do pagamento e certo compartilhamento dos riscos financeiros inerentes ao adoecimento. No entanto, a depender da forma como os seguros privados se organizam dentro de um sistema de saúde, eles podem causar severas segregações sociais. $\mathrm{O}$ assunto será tratado com rigor no terceiro capítulo.

\section{5 \\ Outras fontes de financiamento ${ }^{94}$}

Os modelos de financiamento apresentados no item anterior raras vezes são encontrados em suas versões "puras". Em regra, elementos desses modelos se misturam dentro de um mesmo sistema de saúde, ainda que seja possível identificar uma linha principal e outra(s) secundária(s) de financiamento ${ }^{95}$.

No presente e derradeiro item deste capítulo são apresentadas outras fontes de financiamento da saúde, utilizadas especialmente em países subdesenvolvidos ou em desenvolvimento, e que podem ou não ser combinadas com os mecanismos "principais" de financiamento anteriormente mencionadas.

\footnotetext{
${ }^{92}$ Ibid., p. 765-766.

${ }^{93}$ PORTER, The Greatest Benefit to Mankind: a medical history of humanity, p. 628-630.

${ }^{94}$ GOTTRET; SCHIEBER, Health financing revisited: a practitioner's guide.

95 SANTOS, Isabela Soares; UGÁ, Maria Alicia D; PORTO, Silvia Marta, O mix público-privado no Sistema de Saúde Brasileiro: financiamento, oferta e utilização de serviços de saúde, Revista Ciência \& Saúde Coletiva, v. 13, n. 5, p. 1431-1440, 2008, p. 1432.
} 
(a) Seguros comunitários

Seguro comunitário é um esquema de seguro centenário, atualmente adotado na África Sub-Sahariana, baseado em planos de pagamentos mínimos, para fundos controlados por pequenas comunidades.

Um caso emblemático, por ser bem-sucedido, é o de Ruanda, em que a implementação do seu "mutuelles de santé" logrou elevar o percentual de alistamento da população em seguro de saúde de 3\% para $73 \%$ apenas entre os anos de 2002 a $2006^{96}$.

A associação a estes planos não é obrigatória e o objetivo do seguro não é lucrativo, mas meramente de ajuda comunitária. A desvantagem deste modelo é sua baixa capacidade financeira em razão da diminuta possibilidade contributiva dos seus membros.

(b) Pagamentos diretos (out-of-pocket payments)

Conforme anteriormente definido, os pagamentos diretos são os dispêndios financeiros realizados diretamente pelos usuários/pacientes aos prestadores dos serviços. Trata-se de uma forma de financiamento extremamente combatida por não privilegiar o compartilhamento dos encargos sociais, focando apenas no individualismo e no poder financeiro de cada um.

Quanto mais uma sociedade estimula os pagamentos diretos, mas ela ficará refém das desigualdades no acesso aos serviços de saúde e aos riscos financeiros decorrentes do adoecimento. Por este motivo, esta fonte de recurso vem diminuindo gradativamente em quase todo o mundo ${ }^{97}$, mas ainda permanece percentualmente muito alta nos países Africanos e Asiáticos. Nesses continentes, a diversidade de países subdesenvolvidos cujos governos são incapazes de prover serviços de saúde torna inviável a diminuição dos pagamentos diretos. Outro motivo para a manutenção desta estatística consiste na alta densidade demográfica

\footnotetext{
${ }^{96}$ LOGIE, Dorothy E; ROWSON, Michael; NDAGIJE, Felix, Rwanda's mutuelles de sante, Lancet, v. 372, p. 256-261, 2008.

${ }^{97}$ FAN, Victoria Y; SAVEDOFF, William D, The Health Financing Transition: a conceptual framework and empirical evidence, Londres: Results for Development Institute, 2012, p. 21.
} 
de diversos países africanos e asiáticos (e.g., Nigéria, Paquistão, Índia, Bangladesh, China), fato que torna interessante às empresas privadas a manutenção do esquema de cobrança diretamente a cada indivíduo usuário, consumidores dos serviços de saúde por elas prestados.

(c) Poupanças individuais (medical savings accounts)

Inicialmente desenvolvido em Singapura ("Medisave Scheme") e atualmente também utilizado nos Estados Unidos, a poupança individual (medical savings account) é um método de financiamento pelo qual um indivíduo contribui obrigatoriamente com um percentual de seu rendimento para uma conta bancária individual em seu próprio nome, cujo saldo será utilizado para eventual necessidade de tratamento médico.

A vantagem deste modelo é a antecipação do pagamento, de forma a criar uma segurança financeira para o indivíduo, contra os riscos financeiros de eventual adoecimento. A desvantagem, todavia, é a ausência de compartilhamento dos encargos sociais (pooling risk), não havendo redistributividade neste esquema de financiamento ${ }^{98}$.

(d) Empréstimos externos

A questão dos empréstimos externos tem levantado diversas discussões atualmente, especialmente no que concerne à capacidade dos países donatários para absorverem os fundos doados e sustentarem as políticas inicialmente financiadas por doações após o término da ajuda financeira.

Doadores internacionais usualmente direcionam os fundos para políticas específicas, verticalizadas, limitando a capacidade de autogoverno dos países donatários. Trata-se de um modelo extremamente invasivo e imperialista, cujos

\footnotetext{
${ }^{98}$ MOSSIALOS, Elias; DIXON, Anna, Funding health care: an introduction, in: MOSSIALOS, Elias et al (Orgs.), Funding health care: options for Europe, Buckingham: Open University Press, 2002, p. 21.
} 
atuais parâmetros vêm sendo crescentemente criticados por organismos internacionais e especialistas no âmbito da academia ${ }^{99,100}$.

${ }^{99}$ GOTTRET; SCHEIBER, Health financing revisited: a practitioner's guide, p. 13, 17.

${ }^{100}$ Por não fazer parte do escopo deste estudo, pois o Brasil não conta com esta fonte de recursos de forma significativa, a temática não será tratada detalhadamente. 


\section{2 \\ Elementos básicos do financiamento (bem-sucedido) de um sistema de saúde}

\section{1 \\ Escassez de recursos versus infinitude da demanda}

O ponto de partida de qualquer discussão a respeito das políticas de financiamento da saúde encontra-se na inafastável premissa de que as necessidades humanas são sempre infinitas enquanto que os recursos disponíveis para atende-las são sempre limitados. Daí decorre a inarredável conclusão de que, independentemente de quão abastado um determinado sistema de saúde for, haverá sempre a necessidade de mediação entre as demandas por serviços e a capacidade financeira da rede prestadora.

Primeiramente, no que tange à infinitude da demanda, é preciso atentar para o fato de que cientistas econômicos e filósofos políticos sempre se ocuparam em discutir as definições de desejo e necessidade humanas e as suas ideais formas de satisfação. Trata-se de uma discussão tão antiga quanto complexa, pois, a depender da posição teórica adotada, respostas absolutamente opostas são possíveis para uma mesma questão.

Do ponto de vista da filosofia política liberal, o indivíduo, a partir de seus desejos, deve ter liberdade para buscar o máximo de satisfação pessoal quanto possível, desde que não viole a lei. Para os liberais, o desejo humano é insaciável, fato que torna quase coincidentes os conceitos de desejo e necessidade. Caberia à economia, por intermédio de seus mecanismos de equilíbrio natural, evitar a situação de excessiva desigualdade entre os homens.

A filosofia política social, por outro viés, preocupa-se menos com a liberdade do indivíduo e mais com as suas necessidades, assim consideradas a partir de uma visão coletiva (ethos). O bem-estar do ser humano é definido na medida do bem comum, por intermédio da coesão social e do princípio de solidariedade ${ }^{101}$.

\footnotetext{
${ }^{101}$ Trata-se de uma definição que, embora simplória, serve genericamente para fazer referência às vertentes das teorias sociais quando o objetivo é compará-las com as teorias liberais sob o aspecto da definição de justiça e bem social, conforme se pretende no presente caso.
} 
Esta síntese, embora simplória, basta, por ora e para os fins do presente trabalho. Para os fins aqui pretendidos, deve-se apenas deixar consignada a existência da dicotomia entre os paradigmas liberal e social, bem como apontar para as dificuldades que a adoção dos preceitos neoliberais geram para a efetiva garantia do direito à saúde, conforme já adiantado no primeiro capítulo e será retomado no terceiro capítulo desta dissertação.

Em segundo lugar, sob a ótica da limitação dos recursos, é de se destacar a respeitada obra de Holmes e Sunstein ${ }^{102}$, publicada nos Estados Unidos às vésperas do século XXI para discutir aquilo que ele considera uma utopia liberal do Estado Mínimo. Já no início da obra os autores provocam seus leitores ao afirmarem que americanos aparentemente esquecem que direitos individuais $e$ liberdades dependem fundamentalmente de uma ação estatal vigorosa (tradução livre $)^{103}$. Por intermédio desta obra, os autores afirmam que todas as espécies de direitos dependem de uma ação estatal (ainda que meramente fiscalizatória) e que esta ação custa dinheiro. Em conclusão, os autores querem dizer que não é possível atender a tudo aquilo que o povo quer/necessita uma vez que não há dinheiro suficiente para custear isso tudo.

Flavio Galdino assume que há cinco modelos teóricos a respeito dos direitos fundamentais a partir da sua clássica tipologia positivos/negativos ${ }^{104}$. Cada um desses modelos representa uma fase da evolução do pensamento jurídico a respeito das concepções de direitos, até que a última delas é representada pela teoria dos custos dos direitos, de Holmes e Sunstein. Galdino apresenta os modelos dogmáticos que se sucederam no tempo da seguinte forma:

\footnotetext{
${ }^{102}$ HOLMES, Stephen; SUNSTEIN, Cass R, The Cost of Rights - Why Liberty Depends on Taxes, New York: W.W. Norton \& Company, 1999.

103 "Americans seem easily to forget that individual rights and freedoms depend fundamentally on vigorous state action” Ibid., p. 14.

${ }^{104}$ Segundo a teoria clássica, os direitos fundamentais são divididos em "gerações", sendo que a primeira delas é a dos direitos negativos, em que caberia ao Estado apenas se abster de impedir o cidadão de exercê-los (direitos civis e políticos) enquanto que a segunda é a dos direitos positivos ou prestacionais, em que o Estado deve promover o acesso ao direito (direitos econômicos, sociais e culturais). Essa teoria vem sendo combatida - se é que já não pode ser considerada superada sendo justamente essa a hipótese de Holmes e Sunstein, qual seja, o de que todos os direitos têm natureza positiva. Para as críticas à teoria clássica, confira-se GALDINO, Flávio, Introdução à teoria dos custos dos direitos: direitos não nascem em árvores, Rio de Janeiro: Lumen Juris, 2005 capítulo VIII.
} 
(I) modelo teórico da indiferença: o caráter positivo da prestação estatal e o respectivo custo são absolutamente indiferentes ao pensamento jurídico.

(II) modelo teórico do reconhecimento: a produção intelectual funda-se no reconhecimento institucional de direitos a prestações (ditos sociais), o que implica reconhecer direitos positivos; ao mesmo tempo afasta-se a pronta exigibilidade desses novos direitos.

(III) modelo teórico da utopia: a crítica ideológica e a crença em despesas sem limite igualam direitos negativos e positivos, a positividade dos direitos sociais permanece reconhecida, mas o elemento custo é desprezado.

(IV) modelo teórico da verificação da limitação dos recursos: o custo assume caráter fundamental, de tal arte que, mantida a tipologia positivo/negativo, tem-se a efetividade dos direitos sociais como sendo dependente da reserva do possível.

(V) modelo teórico dos custos dos direitos: revela a superação dos modelos anteriores; tem-se por superada essa tradicional tipologia positivo/negativo dos direitos fundamentais ${ }^{105}$.

Até os quatro primeiros momentos, a questão do custo dos direitos não era uma preocupação da ciência jurídica. Conforme explica Galdino, a possibilidade material de consecução de um direito garantido normativamente constituiria uma questão meramente eventual, indiferente à definição deste direito.

Em outras palavras, a doutrina tradicional reconhece a possibilidade de um indivíduo ser titular de um direito do qual não pode usufruir em razão da ausência material de uma infraestrutura necessária à sua satisfação. Nesta linha de raciocínio, o Estado poderia se eximir de implementar certas políticas públicas sob o pálio da "reserva do possível", isto é, argumentando a inexistência de recursos orçamentários disponíveis para tanto, pois o Poder Público não é financeiramente capaz de dar conta de todas as demandas de sua população ${ }^{106}$.

A obra de Holmes e Sunstein inaugurou uma nova fase do pensamento doutrinário no campo dos direitos fundamentais. Logo no seu primeiro capítulo, estabelece como hipótese primária o fato de que todos os direitos possuem

\footnotetext{
${ }^{105}$ Ibid., p. 181 e ss.

${ }^{106}$ Importante aqui ressalvar a observação de Osmir Globekner, para quem "como não é apenas contra o Estado que os direitos são exercitados, também não é somente a ele que os custos dos direitos são imputados". Ao tratar especificamente do direito à saúde, Globekner afirma que não apenas o Estado mas também os entes privados seriam responsáveis pela prestação dos serviços necessários à sua satisfação. No caso da prestação por um ente privado, o custo do serviço seria repassado no preço e, portanto, o ônus da implementação do direito seria compartilhado por toda a sociedade. Embora o argumento esteja correto, o tema não foi mencionado no presente texto porque a preocupação primordial deste estudo é com o enfrentamento específico do financiamento da saúde pública no Brasil, considerando que o art. 196 da CRFB/88 estabelece o dever do Estado de garantir o direito à saúde. Trata-se, evidentemente, de uma limitação de escopo. GLOBEKNER, A Saúde entre o Público e o Privado: o desafio da alocação social dos recursos sanitários escassos, p. 66
} 
natureza positiva, isto é, demandam uma prestação estatal em defesa dos mesmos e que tal prestação possui um custo financeiro. Sustentam os autores que a dicotomia direitos positivos/negativos se perpetuou exclusivamente porque ela conta com a simpatia tanto de pensadores conservadores quanto de progressistas. Com efeito, enquanto conservadores defendem que os ditos direitos positivos infantilizam os cidadãos, fisgando a fortuna dos ricos e enfraquecendo a capacidade produtiva dos pobres, os progressistas sustentam que os direitos positivos, ao contrário, representam uma evolução do pensamento político e uma imposição da justiça social. Para ambos, a dicotomia seria não só importante como também necessária para explicar as relações entre Estado e cidadãos ${ }^{107}$.

Holmes e Sunstein censuram tanto conservadores quanto progressistas por ignorarem o fato de que até mesmo os direitos estritamente individuais (dos quais a propriedade é o clássico exemplo) dependem de diversas formas de prestação estatal dispendiosa (e.g., pela implementação de serviços de segurança e proteção patrimonial, pela conservação de remédios administrativos e jurídicos em garantia dos mesmos etc.). Na visão dos autores, ao contrário do que pensam ingenuamente alguns progressistas, a defesa desta dicotomia serve prioritariamente aos interesses conservadores, por dois motivos. Primeiramente, enquanto subsistir a ideia de que os direitos estritamente individuais são mais "baratos" eles continuarão sendo priorizados em detrimento dos investimentos em políticas públicas garantidoras de direitos sociais. Por outro viés, o medo dos progressistas de que a incorporação da discussão sobre os custos dos direitos sociais na pauta política poderia acarretar uma diminuição dos investimentos públicos neste domínio seria ilusório. Pelo contrário, a discussão sobre o custo dos direitos é extremamente necessária para os fins de estabelecer parâmetros mais conscientes e democráticos de escolhas das prioridades dos investimentos, com vistas à redução das desigualdades ${ }^{108}$.

Conforme muito bem explicitado por Galdino ${ }^{109}$, a teoria dos custos dos direitos de Holmes e Sunstein provocou uma verdadeira revisão do conceito de direito subjetivo para nele assimilar o custo financeiro dos serviços necessários à

\footnotetext{
${ }^{107}$ HOLMES; SUNSTEIN, The Cost of Rights - Why Liberty Depends on Taxes, p. 40-43.

${ }^{108}$ Ibid., p. 24-31.

${ }^{109}$ GALDINO, Introdução à teoria dos custos dos direitos: direitos não nascem em árvores, p. 211.
} 
sua garantia ${ }^{110}$. Embora a mencionada obra tenha escopo distinto do pretendido no presente trabalho ${ }^{111}$, tal proposição é extremamente útil pois, na mesma linha do que defende Galdino, é a partir dessa nova perspectiva que se torna possível concluir que nenhum direito - tampouco o direito à saúde - pode ser considerado absoluto. Segundo Galdino,

Os autores [Holmes e Sunstein] recomendam, então, uma revisão do conceito de direito subjetivo (right), no sentido de fazer nele incluir a perspectiva dos custos sugestão acolhida no presente estudo. Talvez pudéssemos nós chama-lo "conceito pragmático de direito subjetivo"(vide item 15.2).

Em primeiro lugar, tais direitos não podem ser considerados absolutos. Afirma-se peremptoriamente: nada que custa dinheiro é absoluto. Não é possível formular uma definição de direito abstraindo da realidade concreta, ou seja, das condições de cada tempo e lugar - daí falarmos nós em conceito pragmático.

Segundo os autores, em vez de considerar direito uma situação ideal e não raro absoluta, é melhor considera-los como poderes de invocar os seletivos investimentos dos escassos recursos públicos de uma dada comunidade. O tempo e o lugar - e por que não dizê-lo, as condições econômicas e financeiras - definem as prioridades dos indivíduos e das comunidades, definindo o que seja direito ${ }^{112}$.

O presente trabalho se alinha a tal ideia. Ao mesmo tempo em que o argumento da "reserva do possível" não pode ser suscitado indiscriminadamente para negar a prestação de um direito fundamental a um cidadão (como faziam as teorias clássicas), a crença na solução inversa, isto é, na impossibilidade de se negar uma prestação de serviço público a um indivíduo por motivações financeiras, conforme vem indistintamente ocorrendo na jurisprudência brasileira a partir de casos paradigmáticos do Supremo Tribunal Federal (e.g., Agravo no Recurso Extraordinário n. 271.286-8), igualmente não é a melhor - tampouco sustentável - alternativa. Galdino pondera:

Embora os custos certamente não sejam o único referencial ou critério para as decisões políticas e judiciais, fato é que eles não podem ser desconsiderados na discussão acerca dos direitos fundamentais, nem servir de fundamento para a

\footnotetext{
${ }^{110}$ Holmes e Sunstein, no capítulo introdutório de sua obra, fazem menção a outras espécies de custos, como por exemplo os custos sociais. Enfrentaremos neste trabalho apenas as questões relativas aos custos financeiros dos direitos, por ser essa a proposta temática aqui sugerida.

${ }^{111}$ A obra de Holmes e Sunstein voltava-se basicamente aos direitos estritamente individuais, aqueles direitos chamados "negativos" pela teoria clássica, enquanto que a presente dissertação trata de um direito social.

${ }^{112}$ GALDINO, Introdução à teoria dos custos dos direitos: direitos não nascem em árvores, p. 211.
} 
tutela integral dos direitos individuais e meramente parcial dos direitos sociais, como se vem fazendo, de forma muitas vezes inaceitável ${ }^{113}$.

De fato, a teoria dos custos dos direitos veio ao encontro da necessidade de se compatibilizar as lógicas das até certo ponto inconciliáveis ciências do Direito e da Economia. Durante muito tempo o Direito se esquivou de levar em consideração dados da realidade econômica, insistindo em regular o comportamento social com base em critérios estritamente normativos/abstratos ${ }^{114}$. A partir do momento em que juristas passaram a observar os dados concretos da realidade os resultados de seus esforços no sentido de ordenar essa realidade se tornaram mais eficazes. A chamada análise econômica do Direito, apesar de ser um fenômeno recente, já conta com diversos adeptos e vem ganhando força na comunidade jurídica. Gico Jr., afirmando a importância desta inovação, salienta que ela pode ajudar na tarefa de concretização dos direitos fundamentais, considerando a necessidade de decisões sobre recursos escassos ${ }^{115}$.

Flávio Galdino também trata desse fenômeno. O autor afirma que Economia e Direito estão em constante rota de colisão porque economistas tendem a descrever o comportamento humano de forma absolutamente racional (com fundamento em critérios objetivos de maximização de interesses/utilidade) enquanto que juristas, pelo contrário, pretendem regular a vida do homem com base em critérios abstratos e desconectados com a realidade. Assim, a análise econômica do Direito, que nada mais seria do que uma "tentativa de incluir no raciocínio jurídico os inolvidáveis resultados das análises econômicas”, sofreria do mal de abstrair princípios éticos e morais, além do que desconsideraria nuances do comportamento humano que fogem aos critérios estritamente racionais econômicos ${ }^{116}$.

\footnotetext{
${ }^{113}$ Ibid., p. 230-231.

114 Não é possível deixar de mencionar, aqui, ainda que meramente em nota de rodapé, a contribuição de Alf Ross, representante da escola realista dinamarquesa, para a evolução da ciência jurídica em direção ao mundo real. Ross defendeu que "toda a ciência está, em última instância, interessada no mesmo corpo de fatos, e todos os enunciados científicos sobre a realidade, isto é, aqueles que não têm cunho puramente lógico-matemático, estão sujeitos à prova da experiência". ROSS, Alf, Direito e Justiça, São Paulo: Edipro, 2000.

${ }^{115}$ GICO JR., Ivo, Introdução ao Direito e Economia, in: TIMM, Luciano Benetti (Org.), Direito e Economia no Brasil, 2a ed. São Paulo: Atlas, 2014, p. 15.

${ }^{116}$ GALDINO, Introdução à teoria dos custos dos direitos: direitos não nascem em árvores capítulo XII.
} 
Data venia, o capítulo XII da obra aqui comentada é demasiadamente sucinto porque faz referência unicamente à visão clássica/utilitarista da ciência econômica, desconsiderando os avanços do pensamento epistemológico neste campo e que já facilitaram o diálogo entre Economia e Direito ${ }^{117}$.

Um excelente exemplo de proposta inovadora é a do prêmio Nobel de Economia em 1998, Amartya Sen, o qual defende que, se cada indivíduo é particular (em diversos sentidos e formas, e.g., religião, gênero, cultura), a distribuição da riqueza deve levar em conta suas diferenças. Circunstâncias individuais e sociais influenciam demasiadamente as escolhas humanas e, portanto, ao contrário do que cientistas econômicos de tradição utilitarista pensam $^{118}$, uma mesma situação pode ser "ótima" para um indivíduo mas não sêla para outro.

Amartya Sen é, portanto, constantemente citado como o autor que desafiou anteriores concepções a respeito da equidade, apresentando um contraponto arrojado àquilo que se pensava até então a respeito da igualdade. Em sua obra Desigualdade Reexaminada, Sen contesta as ideias igualitaristas e a teoria da justiça distributiva de John Rawls, ressaltando as circunstâncias sociais e individuais que influenciam demasiadamente as escolhas humanas. Segundo o autor indiano,

No nível prático, a importância da pergunta "igualdade de quê?" deriva da diversidade real dos seres humanos, de tal modo que exigir a igualdade em termos de uma variável tende a ser incompatível - de fato e não somente em teoria - com querer a igualdade em termos de outra. Somos profundamente diversos em nossas características internas (tais como idade, sexo, habilidades gerais, talentos particulares, propensão à doença, e assim por diante) bem como nas circunstâncias externas (tais como patrimônios disponíveis, ambientes sociais, problemas graves do meio ambiente, e assim por diante). É precisamente devido a tal diversidade que a ênfase no igualitarismo em um campo exige a rejeição do igualitarismo em outro $^{119}$.

\footnotetext{
${ }^{117}$ Um nítido exemplo é o do Prêmio Nobel de Economia Amartya Sen, cujo trabalho, pelas palavras de seu tradutor Ricardo Doninelli Mendes, "se caracteriza pela interdisciplinariedade, rompendo fronteiras entre economia e ética" SEN, Desigualdade reexaminada orelha do livro. Falaremos do autor adiante.

${ }_{118}$ Para utilitaristas, a noção de eficiência se baseia na utilidade individual e na "optimalidade de Pareto". Óptimo de Pareto é um conceito de economia desenvolvido por Vilfredo Pareto, utilitarista para quem a situação da economia é ótima quando não for possível melhorar a situação individual de nenhum agente econômico sem o prejuízo da situação individual de outro.

${ }^{119}$ Ibid., p. 23.
} 
Nesta linha de pensamento, uma vez descartada a ideia de igualdade formal e de distribuição de riqueza baseada em critérios matemáticos de otimização, o mencionado autor indiano trata o conceito de eficiência como essencial ao sucesso da distribuição dos recursos. No que tange à associação entre eficiência e equidade, é rigoroso e critica a ideia da eficiência de Pareto, a qual considera um verdadeiro paradoxo. Em Desigualdade Reexaminada, afirma:

De fato, a dicotomia agregativo-distributivo é uma das questões mais difusas na avaliação social. A igualdade - não importando quão amplamente definida dificilmente pode ser a única consideração em qualquer espaço basal; considerações agregativas (incluindo as exigências de eficiência) tendem a possuir um status irredutível.

Todavia, ao integrar estas distintas considerações, também temos de observar que as próprias considerações agregativas podem, em sua formulação, atribuir um papel crucial à igualdade. Para executarmos uma agregação, há questões sobre o que incluir e que pesos atribuir, e aqui a igualdade é com frequência invocada como uma exigência imposta sobre o exercício da agregação. De fato, é precisamente dando peso igual a cada pessoa no maximando agregativo utilitarista que o utilitarismo adota uma postura firmemente igualitária, cujo significado foi enfatizado particularmente por analistas utilitaristas como Harsanyi $(1955,1982)$ e Hare $(1963,1981,1982)$. A atribuição de peso igual às utilidades de cada pessoa no maximando agregativo faz do utilitarismo uma abordagem igualitária de um modo bastante específico, não somente pela escolha de um espaço particular (as utilidades), mas também pela forma que o requisito de igualdade assume em tal espaço (o de atribuir peso igual a todas as pessoas no objetivo agregado, em vez de, digamos, promover a igualdade de níveis de utilidade). As exigências da igualdade podem ser impostas de diferentes modos, e a igualdade pode ter um papel mesmo na formulação daquilo que inicialmente pode parecer um pouco exercício de agregação.

Portanto, as exigências da igualdade podem surgir em muitos contextos distintos, de muitos modos diferentes. Mas também está claro que nem todas as questões a serem decididas podem ser resolvidas simplesmente usando as exigências de igualdade, ainda que em suas formas mais diversas. Por exemplo, embora a igualdade possa influenciar a forma do objetivo agregativo (p. ex., insistindo numa soma imponderada como maximando apropriado), a exigência de maximizar esse objetivo agregado não é - em si mesma - uma exigência de igualdade. Temos de reconhecer a variedade e amplo alcance das exigências de igualdade, sem buscar nelas uma completude de consideracões que possivelmente não se encontram aí ${ }^{120}$. (nosso grifo)

Em suma, Sen demonstra a inexistência de conflito entre objetivos agregativos e distributivos, afirmando que agregar (ou estimular a eficiência de uma prestação) é atividade intrínseca à distribuição, caso esta seja realizada

${ }^{120}$ Ibid., p. 211-212. 
respeitando-se as diferentes individualidades de cada um. Nesta linha de raciocínio, este autor soluciona de melhor forma o confronto entre a escassez de recursos e a infinitude das demandas, explicando que "a eficiência [assim como a igualdade] também pode ser definida similarmente nos espaços de liberdades, direitos, rendas, e assim por diante. (...) Formalmente, há uma multiplicidade de noções de eficiência...."

Os ensinamentos de Sen servem como norte ao presente trabalho. Por ora, em caráter de conclusão parcial, importa consignar que (i) a teoria do custo dos direitos desenvolvida por Holmes e Sunstein fornece relevante arsenal para o enfrentamento do problema das crescentes demandas da população por tratamentos médicos cada vez mais custosos, problema este que assola todos os sistemas de saúde no mundo e com muito mais gravidade os sistemas de saúde dos países menos ricos, como é o caso do Brasil, país da periferia sul-atlântica e (ii) é com fundamento nas ideias de Amartya Sen, de que equidade e eficiência são objetivos não só conciliáveis como consorciados, que será solucionada a problemática equação da contraposição entre a necessidade de se garantir um direito e o custo financeiro desta tarefa.

\section{2 \\ Os custos do direito à saúde}

Já foi mencionado no primeiro capítulo que os custos dos serviços de saúde no mundo industrializado estão aumentando a cada ano. Costuma-se atribuir este aumento das despesas a três principais fatores: os avanços das tecnologias em medicina, o envelhecimento populacional e as novas tendências epidemiológicas (aumento da incidência de doenças crônicas) ${ }^{122,123}$.

\footnotetext{
${ }^{121}$ SEN, Desigualdade reexaminada, p. 57.

122 FAN; SAVEDOFF, The Health Financing Transition: a conceptual framework and empirical evidence.

${ }^{123}$ É verdade que essas justificativas precisam ser devidamente analisadas e ponderadas em cada caso concreto e não devem ser tomadas genericamente como se fossem todas as causas para o aumento das despesas. Avanços tecnológicos deveriam otimizar os tratamentos, tornando-os mais simples, rápidos, produtivos $\mathrm{e}$, consequentemente, baratos. Ademais, o envelhecimento da população é fenômeno que ocorreu a reboque da melhora das condições de vida (de saúde) das pessoas ao redor do mundo, de forma que o ser humano está cada vez mais saudável por cada vez mais anos em sua vida, exigindo menos intervenções médicas. Por fim, no que tange às alterações dos perfis epidemiológicos, temos que o aumento da incidência de "novas doenças" deveria ser compensado pela diminuição das "antigas doenças" em razão dos avanços em relação ao
} 
A questão não é simples. O aumento das despesas em saúde podem derivar também de motivos não tão nobres como os apresentados. Por exemplo, níveis de corrupção e baixa qualidade da gestão dos serviços de saúde também geram enormes prejuízos e aumentos desnecessários dos gastos ${ }^{124}$. Outros motivos ainda menos evidentes podem ser suscitados, tais como a manutenção de altos custos de tratamentos e medicamentos em favor dos interesses de corporações empresariais (hospitais, indústrias etc.).

Dworkin, em célebre palestra proferida no ano de 1993 na Universidade de Direito McGill, cujo conteúdo foi publicado na revista daquela instituição, discorreu acerca da distribuição da atenção à saúde. Pretendia-se responder a duas indagações: quanto deveria uma sociedade gastar em saúde e de que forma tal quantia deveria ser distribuída ${ }^{125}$.

É verdade que Dworkin falava para uma plateia situada no Canadá e com base em sua experiência dos Estados Unidos e do Reino Unido, realidades bem distintas da brasileira. Por isso mesmo, ele partiu do pressuposto de que o aumento dos custos da saúde decorrem principalmente do aumento massivo de nova tecnologia ${ }^{126}$. No entanto, seus ensinamentos são aplicáveis também ao caso brasileiro, que sofre com o aumento dos custos da saúde, não só pelo incremento da tecnologia mas também pelos diversos outros fatores já mencionados anteriormente (envelhecimento populacional, mudanças no perfil epidemiológico, corrupção, má gestão, desperdício etc.).

Conforme asseverou Dworkin, em se tratando de custos da saúde, é preciso ter em mente a tradicional definição desse direito como um bem absoluto e supremo, o mais importante de todos, sem o qual o ser humano não é capaz de gozar de mais nenhum outro. Já foi esclarecido no capítulo anterior que tal definição, presente tanto na Constituição da OMS quanto no Pacto Internacional

enfrentamento dessas últimas (ao menos nos países mais desenvolvidos, o que não se aplicaria aos países menos desenvolvidos que na realidade só vêm somando os fardos dos novos e antigos perfis epidemiológicos). No entanto, independentemente da crítica contida na presente nota, o argumento contido no texto permanece válido para os fins do presente trabalho, considerando que o aumento dos custos em saúde são de fato uma realidade.

${ }^{124}$ Segundo o relatório anual da OMS do ano de 2010, uma estimativa conservadora apontava para um desperdício de 20 a 40\% dos recursos de saúde no mundo. The WHO Report 2010 (financing to universal coverage), p. 11, xix-xxi, 73-74.

${ }^{125}$ DWORKIN, Ronald, Justice in the Distribution of Healthcare, Mc Gill Law Journal, v. 38, n. 4, p. 883-898, 1993, p. 885.

${ }^{126}$ Ibid., p. 884. 
dos Direitos Econômicos, Sociais e Culturais, instiga inúmeras controvérsias sobre o seu verdadeiro significado. A partir dela, poder-se-ia concluir erroneamente que todo e qualquer recurso material disponível deveria ser investido em ações de saúde, não podendo o Estado declinar qualquer tipo de demanda nesta seara. Evidentemente, tal conclusão não é viável do ponto de vista prático pois qualquer governo possui outras responsabilidades a cumprir, outros serviços a prestar, igualmente custosos ${ }^{127}$.

Diante deste dilema, emerge a inevitável conclusão de que o racionamento dos recursos da saúde é uma necessidade irremediável. A alocação eficiente dos recursos materiais torna-se um mister, cabendo ao Direito regular de que forma isso se dará, selecionando os critérios e métodos que serão aplicados com este objetivo, tudo na linha da mencionada tendência de racionalização econômica da ciência jurídica.

Neste ponto, inevitável concordar com Osmir Globekner quanto à sua afirmação de que, especificamente no campo sanitário, não existe uma distinção óbvia entre o que seja necessidade e o que seja desejo. $\mathrm{O}$ exemplo fornecido pelo autor é clarividente para demonstrar o que se quer dizer: Globekner menciona a questão da fertilidade e sua valoração diferenciada em cada sociedade. Os tratamentos de reprodução assistida podem ser vistos como uma necessidade ou como um mero desejo, a depender dos valores daquela dada sociedade ${ }^{128}$.

Tal exemplo torna evidente a dificuldade adicional que as decisões alocativas no campo sanitário enfrentam. Os critérios alocativos são inúmeros e variam desde padrões técnicos de custo-eficiência dos tratamentos até questões éticas ou morais relacionadas aos valores de dada sociedade. Aliás, é nesse segundo item que se enquadram as decisões de contenção de despesas em serviços de saúde em nome da implementação de políticas austeras, decisões essas tão comuns em tempos de crise econômica.

Sobre a dificuldade particular de alocar recursos sanitários, Globekner pondera que

\footnotetext{
${ }^{127}$ Ibid., p. 886.

${ }^{128}$ GLOBEKNER, A Saúde entre o Público e o Privado: o desafio da alocação social dos recursos sanitários escassos, p. 41.
} 
A questão da hierarquização das necessidades em saúde é bastante complexa. A demanda por atenção em saúde e a gama de serviços voltados a atendê-la são muito amplas. Algumas necessidades se relacionam com a recuperação ou compensação de uma diminuição de capacidades ou funções; outras, com o incremento da qualidade de vida por outros meios.

Por fim, a hierarquização de necessidades em saúde pode ser feita não apenas por sua importância ou natureza intrínseca, mas também por critérios outros, como o da urgência, da repercussão em termos de saúde pública, da proteção de grupos especialmente vulneráveis, para citar apenas alguns exemplos.

(...)

Voltando ao tema do caráter especial da saúde, em relação a outros bens e interesses, não se trata de conferir um valor absoluto à saúde e, por consequência, uma prioridade absoluta ao atendimento das necessidades à saúde. Basta reconhecer que, sob perspectiva individual, para muitas pessoas alguns de seus objetivos, talvez os mais importantes, não são necessariamente comprometidos pela falta de saúde ou pela incapacidade. Outras pessoas, por outro lado, acederiam à diminuição de capacidades em razão de determinados bens ou perspectivas de vida. Trata-se, entretanto, de reconhecer o caráter normalmente preponderante das necessidades de saúde, comparado com os de outra índole ${ }^{129}$.

É patente, portanto, a dificuldade enfrentada por gestores em políticas sanitárias na tarefa de selecionar os melhores investimentos. Trata-se de uma complexidade intrínseca da área da saúde, espécie de atividade com tantas nuances que foge aos padrões ordinários da esfera de decisões alocativas "comuns".

Retornando à palestra de Dworkin, para responder às suas indagações, alguns aspectos devem ser levados em consideração. Qualquer procedimento ou mecanismo tendente a estabelecer parâmetros para as decisões alocativas de recursos em matéria sanitária deve ter em perspectiva o seguinte: (i) a adoção do conceito extensivo de saúde (saúde como bem-estar físico, mental e social e não apenas como estado de não-doença), (ii) o equilíbrio entre os interesses de diversos atores envolvidos (Estado, pacientes, médicos, sociedade, comunidade econômica etc.), (iii) a adoção de processo democrático e transparente, (iv) o estabelecimento de objetivos claros e realizáveis do ponto de vista prático e (v) a explícita renúncia de opções em favor de prioridades objetivas. A seguir serão explicitados detalhes de cada um dos itens elencados.

(i) Conforme explicado no primeiro capítulo, o ser humano saudável depende de um completo bem-estar físico, mental e social. Também nesse capítulo foi pontuado que os sistemas de saúde propriamente ditos são

\footnotetext{
${ }^{129}$ Ibid., p. 43.
} 
responsáveis especificamente pelas ações diretamente relacionadas ao bem-estar físico e mental do ser humano, cabendo a outros setores do governo (sistemas de habitação, educacional, sanitário, meio ambiente etc.) se ocuparem de atividades tendentes à defesa do bem-estar social do indivíduo.

No entanto, isso não quer dizer que os sistemas de saúde devam ignorar o bem-estar social de seus usuários. Pelo contrário, o simples fato de constituir um dos elementos da própria definição do direito à saúde faz com que qualquer ação ou serviço promovido pelo sistema de saúde deva levar em consideração também este elemento. Com efeito, basta notar, por exemplo, que um dos direitos do usuário do sistema de saúde é o de obter tratamento médico humanizado. Isso significa que qualquer atendimento que o paciente receber deve se preocupar com suas condições pessoais, levar em conta o local onde mora (a unidade de saúde que o atende deve se situar o mais próximo possível de sua residência) além de garantir a presença de acompanhantes que possam lhe conferir conforto psicológico durante o procedimento. Tudo isso representa um conjunto de escolhas no nível das ações de saúde que possuem como pano de fundo a consideração do conceito extensivo de saúde.

(ii) Também foi explicado no primeiro capítulo que o sistema de saúde é uma rede complexa que reúne uma gama de pessoas e organizações, cada qual com próprios interesses e agendas. Governos, empresas privadas, médicos, pacientes, instituições financeiras etc., todos se interessam nas decisões políticas que digam respeito à organização do sistema de saúde, pois em cada medida uns e outros ganharão mais ou menos a partir das decisões tomadas. Não é preciso pensar muito sobre o assunto para compreender o que se está expondo. Basta lembrar dos interesses das seguradoras de planos de saúde, da indústria farmacêutica, dos médicos de clínicas particulares, dos pacientes, da indústria de tabaco, dos políticos em ano eleitoral etc. São inúmeros os interesses em contraposição e que precisam ser considerados no momento da tomada de uma específica decisão $^{130}$.

\footnotetext{
${ }^{130}$ Sobre o desvirtuamento dos principais objetivos dos sistemas de saúde em virtude dos diversos interesses ocultos (basicamente financeiros) que os circundam, leia-se SOBRINHO, Luiz Vianna, Medicina Financeira: a ética estilhaçada, Rio de Janeiro: Garamond, 2013.
} 
(iii) Por outro viés - e ao menos em qualquer país livre de ditadura - as decisões alocativas de recursos deverão obedecer a parâmetros democráticos de escolhas. Ampla participação social e transparência são requisitos básicos para a legitimidade da decisão. Este assunto será tratado mais detalhadamente no próximo item deste capítulo.

(iv) Qualquer mecanismo utilizado para auxiliar a tomada de decisão alocativa de recursos deve ter por objetivo a maximização destes recursos. Em outras palavras, a finalidade destas ferramentas é alcançar a máxima eficiência na distribuição dos recursos sanitários. De nada adianta um planejamento de prioridades que sejam irrealizáveis na prática, por conta de circunstâncias da realidade.

Para ilustrar este item, cite-se o caso das comunidades na cidade do Rio de Janeiro tomadas pela violência e dominadas pelo poder do narcotráfico. Muitas destas comunidades são sitiadas a ponto de as ações estatais não alcançarem os seus moradores por força de bloqueios determinados por chefes do tráfico. De nada adianta um estudo sanitário que estabeleça como prioridade a atenção básica nestas comunidades se a implementação deste programa é inviável do ponto de vista prático. Evidentemente que ações de outras áreas do governo (e.g., segurança pública) devem anteceder quaisquer ações no campo sanitário nestas comunidades.

(v) Por fim, é importante que deste processo resultem critérios e parâmetros seguros e objetivos para a tomada da decisão. No fundo, toda escolha acarreta renúncias. Nenhum gestor pode conviver com a hipótese de que tudo seja prioritário na sua agenda de governo. O governante que tende a dar prioridade a todas as demandas termina por não efetivar nenhuma de suas promessas. Em última instância, quando feita de forma segura e seguindo os passos aqui expostos, a racionalização é uma medida que antes de diminuir só tende a aumentar a oferta de garantias.

Também a doutrina sanitarista reconhece ser necessária uma contemporização das demandas em matéria de saúde e um planejamento das políticas públicas, consciente da necessidade de priorização de certas escolhas. Segundo Piola et al, "os sistemas públicos de saúde que estão voltados para um 
atendimento universal e igualitário necessariamente não devem e não podem contemplar todas as necessidades de saúde de seus usuários"131. O reconhecimento deste fato, aliás, é o primeiro passo para a solução do conflito entre a infinitude das demandas e a limitação de recursos.

Neste ponto do presente estudo espera-se que já seja possível perceber que os critérios adotados para a alocação prioritária de recursos reproduzem os alicerces ideológicos do respectivo sistema de saúde, os quais, por sua vez, remontam os valores da sociedade em que se insere. Sobre o tema, os já mencionados autores Holmes e Sunstein indicaram que

A preocupação com os custos dos direitos levanta uma série de outros questionamentos, não apenas sobre o quanto cada direito efetivamente custa, mas também a respeito de quem decide como devem ser alocados os escassos recursos públicos disponíveis para a proteção de quais direitos, e em favor de quem (tradução livre) $^{132}$.

O próximo item deste capítulo trará nuances relacionadas à questão da alocação dos recursos escassos em matéria de saúde, especificamente no que concerne às ferramentas e critérios existentes para a adoção das decisões alocativas.

\section{3}

\section{Alocação de recursos sanitários}

Gustavo Amaral, citando as prestigiosas lições de Guido Calabresi e Philip Bobbitt, esclarece que "as decisões alocativas são, basicamente, de duas ordens: quanto disponibilizar e a quem atender" $" 133,134$.

Nesta linha de ideias, a primeira decisão que uma sociedade precisa adotar é aquela relacionada a quanto deseja investir em ações e serviços de saúde, ou seja, quanto dinheiro quer gastar para manutenção e desenvolvimento do seu

\footnotetext{
${ }^{131}$ PIOLA, Sérgio Francisco et al, Vinte anos da Constituição de 1988: o que significaram para a saúde da população brasileira?, in: Políticas Sociais: Acompanhamento e Análise, Brasília: Ipea, 2009, v. 1, p. 161.

${ }^{132}$ HOLMES; SUNSTEIN, The Cost of Rights - Why Liberty Depends on Taxes, p. 31.

133 AMARAL, Gustavo, Direito, Escassez \& Escolhas - Em busca de critérios jurídicos para lidar com a escassez de recursos e as decisões trágicas, Rio de Janeiro: Renovar, 2001, p. 148.

134 Trata-se, basicamente, da mesma questão posta por Dworkin em sua palestra proferida na Universidade McGill, conforme mencionado no item 2.2.
} 
sistema de saúde. Trata-se de um exercício de ponderação de prioridades entre a saúde e as demais atividades do governo, por vezes até menos urgentes, embora também necessárias (e.g., investimentos em segurança, educação, assistência jurídica, custos da movimentação da máquina burocrática). Indo além, pode-se incluir nesta ordem de decisões alocativas até mesmo a ponderação entre dois serviços de saúde diferentes, pois aquele que for considerado "menos necessário" será excluído do rol de investimentos neste setor.

A segunda ordem de decisões alocativas, aquela relacionada a quem os recursos sanitários devem ser dirigidos, vincula-se à ideia de justiça distributiva, compreendida como a forma mais justa de compartilhar os recursos materiais disponíveis aos indivíduos da sociedade ${ }^{135}$.

$\mathrm{Na}$ realidade, de certa forma ambas as ordens de decisões alocativas acabam se entrelaçando. Como bem observado por Elster, citado por Amaral,

\begin{abstract}
Decisões políticas de primeira ordem relacionam-se com a alocação de recursos fungíveis (monetários) dentre várias atividades. A principal consequência dessas decisões é favorecer certos bens e serviços às custas de outros. Uma consequência secundária pode ser favorecer alguns às expensas de outros, quer dizer, aqueles que podem mais ser beneficiados pelo bem favorecido. Apesar de o efeito nos indivíduos também depender do princípio alocativo de segunda ordem, alguns bens têm características que excluem vários grupos do universo de possíveis beneficiados. Assim, dedicar uma larga parcela de fundos públicos à moradia popular equivale a dar tratamento preferencial aos pobres, a despeito de qual esquema alocativo seja escolhido. Dar prioridade à educação necessariamente ocorre às expensas dos idosos, já que eles não se tornarão jovens novamente. Em contraste, concentrar recursos em equipamentos médicos necessários para salvar vidas, usados principalmente por idoso, pode eventualmente também beneficias os jovens $^{136}$.
\end{abstract}

Dito isso, tem-se que os debates que serão travados a respeito do financiamento da saúde no Brasil nos próximos capítulos desta dissertação dizem respeito a ambas as ordens de decisões alocativas aqui mencionadas.

Por ora, os subitens que seguem aqui neste capítulo especificam alguns mecanismos consagrados no mundo contemporâneo como métodos para ajustamento das prioridades de investimento financeiro no campo da saúde.

\footnotetext{
${ }^{135}$ As teorias da Justiça distributiva encontram guarida em diversos expoentes, desde autores liberais como Dworkin e Rawls até comunitaristas como Walzer, Elster e o já mencionado Sunstein.

${ }^{136}$ Jon Elster apud AMARAL, Direito, Escassez \& Escolhas - Em busca de critérios jurídicos para lidar com a escassez de recursos e as decisões trágicas, p. 149.
} 
Propõe-se uma reflexão a respeito do esforço das sociedades contemporâneas democráticas na tarefa de alocar os recursos de saúde de forma equitativa, eficiente e sustentável.

\subsection{1}

O sentido de alocar recursos: equidade na distribuição e eficiência

O primeiro capítulo desta dissertação já tocou no assunto da equidade no financiamento da saúde. $\mathrm{Na}$ ocasião, foram apresentados dois usuais mecanismos utilizados na promoção deste desejado equilíbrio na alocação dos recursos sanitários, com fundamento em ideais de justiça social/distributiva (são eles, o compartilhamento de encargos sociais e a progressividade na contribuição).

Inúmeras teorias buscam explicar a melhor forma de distribuição dos recursos materiais disponíveis na sociedade. Teorias políticas liberais se apegam aos chamados direitos naturais do ser humano, privilegiando a liberdade e a autodeterminação. Elas se desdobram em diversas correntes como, por exemplo, as teorias utilitaristas que privilegiam a maximização do bem individual. Rawls, um teórico liberal, é frequentemente citado como um dos pais das teorias distributivas ${ }^{137}$. Por outro lado, adotando outro viés, as teorias marxistas enfatizam a necessidade de cada indivíduo em detrimento de suas liberdades.

Quanto às implicações destas diversas teorias na área da medicina, Wagstaff e Van Doorslaer apresentam o sumário elaborado por Gillon em sua obra "Philosophical Medical Ethics". Gillon defende que, em matéria de financiamento na medicina, critérios extra-médicos (como seria o caso da capacidade financeira do indivíduo, por exemplo) nunca deveriam ser levados em conta. Assim, de todas as teorias sobre justiça social, a que melhor se aplicaria à distribuição dos recursos sanitários seria aquela que defende a alocação dos mesmos segundo as necessidades de cada um. Este posicionamento segue a linha

\footnotetext{
${ }^{137}$ As diversas teorias sobre a igualdade e seus desdobramentos (equidade, justiça social etc.) não fazem parte do escopo do estudo aqui desenvolvido, uma vez que a presente dissertação prioriza o aspecto empírico do tema, submetendo o direito positivo brasileiro a uma espécie de "verificação" acerca da sua justeza, partindo do conceito de equidade conforme exposto no texto. Para aprofundamento do tema a respeito dos diversos aspectos da equidade no acesso aos serviços de saúde leia-se GLOBEKNER, A Saúde entre o Público e o Privado: o desafio da alocação social dos recursos sanitários escassos.
} 
do igualitarismo do século $\mathrm{XX}^{138}$, se contrapondo ao liberalismo, que evoca a distribuição dos recursos de acordo com as habilidades natas de cada um, com mínimo de intervenção do Estado ${ }^{139}$.

A respeito deste tema, Travassos e Castro consignam de modo bastante perspicaz a necessidade de serem distinguidos os conceitos de equidade quanto às condições de saúde e equidade quanto ao acesso aos serviços de saúde ${ }^{140}$. É evidente que as camadas menos favorecidas da população terão maiores propensões ao adoecimento, em razão da baixa qualidade das condições sociais em que vivem (moradia, subemprego, nutrição, condições de higiene etc.). Estas condições iníquas, todavia, não são propriamente objeto de preocupação do sistema de saúde, conforme já explicitado. Os sistemas de saúde devem se preocupar com a segunda acepção de equidade mencionada, aquela que é determinada, segundo as autoras mencionadas, conforme "a disponibilidade de serviços e de equipamentos diagnósticos e terapêuticos, a distribuição geográfica, os mecanismos de financiamento dos serviços e a sua organização" ${ }^{\text {141. }}$.

Conforme explicitado no primeiro capítulo, o financiamento dos serviços sanitários abrange a tríplice tarefa de coletar receitas (arrecadar), administrar os fundos e alocar os recursos sanitários (comprar e pagar os serviços). Evidentemente que o planejamento do financiamento deve ser coerente, de forma que essas três atividades devem estar devidamente concatenadas. É por isso que a atividade de alocar deve ser precedida de uma organização, um processo que promova o investimento das receitas arrecadadas de forma responsável, eficiente e, sobretudo, permitindo a distribuição equitativa do acesso aos serviços.

Em excelente resumo, Gottret e Schieber explicam que (tradução livre):

\footnotetext{
${ }^{138}$ Segundo Wagstaff e Doorslaer, Gillon teria feito questão de ressaltar que tal teoria não é um marco exclusivo do Marxismo.

${ }^{139}$ Gillon, Raanan apud WAGSTAFF, Adam; VAN DOORSLAER, Eddy, Equity in Health Care Finance and Delivery, in: CULYER, A; NEWHOUSE, J (Orgs.), North Holland handbook in health economics, Amsterdan: North-Holland, 2000, p. 1808-1809.

${ }^{140}$ TRAVASSOS, Claudia; CASTRO, Mônica Silva Monteiro de, Determinantes e Desigualdades Sociais no Acesso e na Utilização de Serviços de Saúde, in: GIOVANELLA, Ligia et al (Eds.), Políticas e Sistema de Saúde no Brasil, 2a ed. rev. e amp. Rio de Janeiro: Fiocruz, 2012, p. 184. ${ }^{141}$ Ibid.
} 
O sucesso dos sistemas de saúde na execução das três funções do financiamento têm importantes implicações nos seguintes aspectos:

$\checkmark \quad$ quantidade de fundos disponíveis (no presente e no futuro) e nos concomitantes níveis de serviços essenciais ofertados e de proteção financeira aos indivíduos;

$\checkmark \quad$ justiça (equidade) nos mecanismos de coleta de receitas para financiamento do sistema (priorizando o acesso baseado na necessidade em detrimento daquele com base na capacidade financeira);

$\checkmark \quad$ eficiência na coleta de receitas, de forma a não gerar distorções ou perdas econômicas;

$\checkmark \quad$ níveis de compartilhamento de encargos e de antecipação do pagamento (e as implicações disto para as subvenções equitativas de financiamento e de risco);

$\checkmark \quad$ quantidade e variedade de serviços adquiridos e consumidos e respectivos efeitos nos resultados da assistência (eficiência na alocação);

$\checkmark$ eficiência técnica dos serviços (cada serviço produzindo o máximo possível ao seu mínimo custo);

$\checkmark \quad$ acesso financeiro e físico aos serviços (inclusive de forma equitativa) ${ }^{142}$

Deste resumo é possível extrair que equidade e eficiência são as grandes preocupações de qualquer sistema de financiamento da saúde no mundo contemporâneo, seja qual modelo ele adote. Seguindo tal raciocínio, e ao contrário do que uma lógica apressada poderia levar a acreditar, a equidade não está, de forma alguma, em contraposição à eficiência, conforme já esclarecido anteriormente, com fundamento nas lições de Amartya Sen.

Os ensinamentos de Sen servem como norte ao objetivo final da atividade de alocar. Alocar recursos escassos é, necessariamente, pensar que tais recursos serão futuramente distribuídos, afinal esta decisão está intrinsecamente vinculada à escolha do público que será beneficiado. Todavia, tal atividade não é somente distributiva. A alocação de recursos é, também, necessariamente uma decisão que visa à maximizá-los, isto é, a aplica-los da forma mais eficiente possível.

A título ilustrativo, imagine-se que determinado governo opte por investir em atenção terciária, construindo hospitais de alta tecnologia, em detrimento de ações preventivas no nível primário de atenção à saúde. A experiência demonstra

\footnotetext{
${ }^{142}$ GOTTRET; SCHIEBER, Health financing revisited: a practitioner's guide, p. 5. "The success of countries in carrying out these functions has important implications for $\bullet$ funds available (now and in the future) and the concomitant levels of essential services and financial protection, fairness (equity) of the revenue collection mechanisms to finance the system (basing financial access on need rather than ability to pay), • economic efficiency of revenue-raising, in not creating distortions or economic losses in the economy, - levels of pooling and prepayment (and the implications for risk and equity subsidization), - numbers and types of services purchased and consumed and their effects on health outcomes and costs (allocative), technical efficiency of service production (producing each service at its minimum average cost), - financial and physical access to services (including equity in access)".
} 
que esta decisão política certamente acarretará o aumento (ou, pelo menos, estancamento da diminuição) do índice de mortalidade infantil especialmente entre populações mais carentes, uma vez que haverá uma diminuição nos atendimentos a doenças "simples" tais como desnutrição, diarreias etc. É possível, inclusive, que esse aumento do índice de mortalidade infantil ocorra na mesma proporção do aumento dos lucros de grandes empresas de gestão e de tecnologia hospitalar em razão dos novos investimentos deste governo.

Partindo da ideia aqui exposta - de que a alocação de recursos sanitários deve apontar para um duplo objetivo - equidade e eficiência - os próximos capítulos tratarão especificamente do modelo de financiamento do SUS sempre lançando foco em tais aspectos. É com este olhar que serão discutidos temas como, por exemplo, a iniquidade da fragmentação do sistema de saúde brasileiro entre um sistema público para os pobres e um sistema privado para os ricos e, ademais, a ineficiência da gestão do sistema público pelos governos brasileiros, sobretudo o federal, incapazes de instituir uma efetiva política de colaboração federativa.

Por ora, no próximo subitem deste capítulo serão mencionados resumidamente alguns dos principais processos decisórios para alocação de recursos sanitários existentes no mundo.

\subsection{2 Processos decisórios para alocação de recursos sanitários}

Inicialmente, é de se admitir que a questão da alocação de recursos sanitários, apesar de todas as particularidades mencionadas no item 2.2, origina-se das fórmulas já existentes para a implementação de qualquer espécie de política pública.

Celina Souza, em artigo pelo qual expõe os principais conceitos, modelos analíticos e tipologias de políticas públicas, esclarece que “...em democracias estáveis, aquilo que o governo faz ou deixa de fazer é passível de ser (a) formulado cientificamente e (b) analisado por pesquisadores independentes" ${ }^{143}$, significando isso dizer que foi-se o tempo das tomadas de decisão puramente

\footnotetext{
143 SOUZA, Celina, Políticas Públicas: uma revisão da literatura, Sociologias, v. 16, p. 20-45, 2006, p. 22.
} 
discricionárias ou subjetivas, baseadas em mera intuição do gestor público. Decisões são (rectius: deveriam ser) tomadas, atualmente, com base em evidência científica e por intermédio de processos democráticos explícitos e transparentes.

No campo da saúde, é de se reconhecer a existência de toda a gama de dificuldades já mencionadas anteriormente (item 2.2), relacionadas à natureza desse direito e aos crescentes custos dos serviços nesta seara. Ainda assim, a busca por mecanismos cada vez mais criteriosos e justos para a tomada de decisões alocativas permanece seguindo ininterruptamente, evoluindo cada vez mais tanto no ambiente acadêmico quanto no político-institucional.

Um pioneiro e clássico exemplo de processo decisório explícito, bastante citado na literatura internacional, foi o adotado pelo estado americano de Oregon no final da década de 1980. O governo desse estado designou uma comissão Oregon Health Services Comission - para determinar quais seriam as melhores decisões políticas em matéria de saúde a fim de maximizar os objetivos do Programa Nacional US Medicaid. O método utilizado pela experiência de Oregon acabou sendo expandido mundialmente por intermédio do Banco Mundial em seu Relatório de $1993^{144}$, mas o que até então não se percebia era que ele apresentava falhas decorrentes do fato de se basear estritamente em avaliações de rentabilidade. A Oregan Health Services Comission classificava as intervenções médicas seguindo um método que levava em conta critérios estritamente técnicos, desconsiderando a influência de motivos sociais, políticos e econômicos ${ }^{145}$.

Desde então, outros mecanismos e projetos se desenvolveram ao redor do mundo, tais como o Choosing Interventions that are Cost-Effective (CHOICE), da Organização Mundial da Saúde, o Lives Saved Tool, da Johns Hopkins University, a elaboração de listas de medicamentos e/ou tratamentos essenciais, o Accountability for Reasonableness framework (A4R), desenvolvido no contexto das reformas nos Estados Unidos etc. Todos esses exemplos pretendem levar em conta um mix de informações/elementos para fins de adoção de decisões alocativas. No entanto, ainda subsistem muitas dificuldades no mundo inteiro

\footnotetext{
${ }^{144}$ WORLD BANK, World Development Report.

${ }^{145}$ GLASSMAN, Amanda et al, Priority-Setting Institutions in Health: Recommendations from a Center for Global Development Working Group, Global Heart, v. 07, n. 01, p. 13-34, 2012, p. 15-16.
} 
quanto à efetiva implementação destes instrumentos ${ }^{146}$. Ademais, é possível afirmar que não existe um modelo ideal, havendo sempre pontos fortes e fracos em cada um deles ${ }^{147}$.

Um exemplo muito bem sucedido e citado positivamente em diversos estudos é o modelo inglês do National Institute for Health and Care Excellence NICE, copiado por países como Tailândia, China e Brasil ${ }^{148}$. Entretanto, segundo Glassman et al, países em desenvolvimento enfrentam grandes dificuldades na efetiva implementação destes mecanismos, em 06 níveis: (i) complexidade da governabilidade do amplo escopo destes processos, normalmente incompatível com a urgência das demandas de saúde, (ii) carência de recurso humano capacitado, (iii) excessiva fragmentação do sistema e deficiência na definição dos papéis e responsabilidades de agentes políticos e entes, (iv) fraca governança e alta corrupção, (v) sistemas de informações extremamente falhos, (vi) vínculos fracos entre os mecanismos de escolha e os processos para efetiva implementação da decisão ${ }^{149}$.

$\mathrm{Na}$ linha de tais dificuldades, pesquisa realizada no estado de Pernambuco entre os anos de 2007 e 2012 a respeito de mudanças nas políticas da Secretaria de Saúde deste estado concluiu que, no Brasil, critérios técnicos são usualmente preteridos em favor de promessas eleitorais e do desejo de reeleição ou de eleger um sucessor político ${ }^{150}$.

Segundo Ferri-de-Barros et al, o Ministério da Saúde brasileiro define a Conferência Nacional de Saúde (CNS) como o fórum do SUS para o estabelecimento de prioridades democráticas. Na análise dos autores, todavia, este mecanismo está longe de alcançar os "padrões éticos de legitimidade e justiça", havendo uma "má definição do processo de prioridades” no Brasil ${ }^{151}$.

\footnotetext{
${ }^{146}$ Ibid., p. 16.

147 ROBINSON, Suzanne et al, Priority-setting and rationing in healthcare: Evidence from the English experience, Social Science \& Medicine, v. 75, p. 2386-2393, 2012.

148 GLASSMAN et al, Priority-Setting Institutions in Health: Recommendations from a Center for Global Development Working Group, p. 24.

${ }^{149}$ Ibid., p. 26-27.

${ }^{150}$ SANTOS, Francisco de Assis et al, A definição de prioridade de investimento em saúde: uma análise a partir da participação dos atores na tomada de decisão, Revista de Saúde Coletiva, v. 25, n. 4, p. 1079-1094, 2015, p. 1086-1090.

151 FERRI-DE-BARROS, Fabio; HOWARD, Andrew W.; MARTIN, Douglas K., Inequitable Distribution of Health Resources in Brazil: an analysis of national priority setting, Acta Bioethica, v. 15, n. 2, p. 179-183, 2009.
} 
Percebe-se, portanto, que o Brasil se encontra em um estágio muito atrasado de desenvolvimento no que tange à utilização de modelos procedimentais para decisões alocativas. Se em países desenvolvidos já se discute a insuficiência da utilização exclusiva de critérios técnicos, pois fatores sociais e medidas da realidade devem ser igualmente ponderados, o Brasil encontra-se em etapa anterior: ainda se pondera a capacidade dos gestores públicos brasileiros para utilizarem critérios técnicos ou baseados em evidências científicas em suas decisões políticas. Não se pode esquecer, ainda, a patente insuficiência da participação social nas decisões alocativas ${ }^{152}$.

É verdade que as agências reguladoras - a Agência Nacional de Vigilância Sanitária (ANVISA), no caso da saúde - já desempenham relevante papel no caminho da imposição de decisões técnicas. Todavia, é de conhecimento notório o grau de influência política existente no comando de tais agências.

Por fim, deve ainda ser citado o tão intrincado problema da excessiva judicialização das demandas sanitárias no Brasil, questão que vem sendo largamente debatida em inúmeros fóruns, inclusive no contexto internacional. Apesar de não fazer parte do tema desta dissertação, deve ser consignada a preocupação da comunidade jurídica e sanitária com o assunto. Com efeito, o recente crescimento - possivelmente descontrolado - do chamado ativismo judicial vem provocando questionamentos a respeito da sustentabilidade desta solução para a crônica inércia do gestor público em fornecer serviços públicos de saúde de mínima qualidade à população brasileira.

\footnotetext{
${ }^{152}$ Há, no entanto, notícias de boas iniciativas neste campo, como a promovida pelo Departamento de Gestão e Incorporação de Tecnologias em Saúde do Ministério da Saúde - DGITS/SCTIE/MS em parceria com o Hospital Alemão Oswaldo Cruz, o qual promoveu em outubro de 2017 fórum reunindo pacientes e gestores públicos para pensar a questão da participação social no processo de gestão e incorporação de tecnologias em saúde no SUS. O DGITS/SCTIE/MS assiste a Comissão Nacional de Incorporação de Tecnologias no SUS - CONITEC, Comissão criada pela Lei n. 12.401/2011 com o objetivo de assessorar o Ministério da Saúde nas atribuições relativas à incorporação, exclusão ou alteração de tecnologias em saúde pelo SUS, bem como na constituição ou alteração de Protocolos Clínicos e Diretrizes Terapêuticas - PCDT. Todas as recomendações emitidas pelo Plenário da CONITEC são submetidas à consulta pública pelo prazo de 20 dias, exceto em casos de urgência da matéria, quando a consulta será por apenas 10 dias. Todas as contribuições e sugestões angariadas na consulta são inseridas no relatório final e posteriormente encaminhadas pela CONITEC ao Secretário de Ciência, Tecnologia e Insumos Estratégicos (SCTIE) para a tomada da decisão. CONITEC, Fórum discute participação social na incorporação de tecnologias em saúde, disponível em: <http://conitec.gov.br/ultimas-noticias3/16795-forum-discute-participacao-social-na-incorporacao-de-tecnologias-emsaude?platform=hootsuite>, acesso em: 24 out. 2017.
} 
Argumenta-se, de um lado, que a intervenção do Poder Judiciário serve como contraponto democrático à inércia do Poder Executivo. Por outro lado, temse que decisões indiscriminadas e não planejadas provocam verdadeiro caos no orçamento público, prejudicando ainda mais a sustentabilidade do financiamento das ações do Executivo nesta seara.

Independentemente desta discussão - ampla o suficiente para uma dissertação em apartado - é necessário pontuar, uma derradeira vez, que o financiamento da saúde é uma atividade complexa, que envolve a tripla função de arrecadar, administrar e alocar recursos escassos para fazer frente a demandas infinitas. No exercício de tal tarefa, o planejamento adequado é medida essencial a fim de proporcionar o manejo eficiente e equitativo dos recursos sanitários, promovendo justiça na garantia deste direito fundamental.

Nos próximos capítulos será explicitado que o sistema de financiamento da saúde no Brasil foi historicamente planejado de forma descomprometida com tais valores tão relevantes, fato que gerou (e gera) excessivas instabilidade, deformações e privações no sistema de saúde público. 


\section{O financiamento do direito à saúde no Brasil (I): precarização do financiamento público da saúde}

É de conhecimento geral que, no plano interno, o Brasil apresenta histórica dificuldade em se organizar politicamente no intuito de gerir o seu sistema de saúde de forma eficiente. Embora o país tenha acompanhado a tendência dos países em desenvolvimento, melhorando diversos indicadores sanitários nas últimas décadas ${ }^{153}$, ele permanece na lista dos países com maior índice de desigualdade social ${ }^{154}$, possuindo um sistema de saúde iníquo do ponto de vista da distribuição de recursos sanitários ${ }^{155}$.

É verdade que, no plano internacional, o Brasil é reconhecido como uma potência na América Latina, exercendo relevante papel como membro da Organização Pan-Americana de Saúde, assim como colaborando ativamente no Plano Estratégico de Cooperação em Saúde da Comunidade de Países de Língua Portuguesa (CPLP) e no Conselho de Saúde da União de Nações Sul-Americanas (UNASUL Saúde) $^{156,157 .}$

Ademais, do ponto de vista normativo, a exemplo do que ocorreu nos demais países latino-americanos, o país vivenciou um período no final do século $\mathrm{XX}$ influenciado por uma onda social-democratizante, culminando na institucionalização de diversas garantias sociais mediante a inserção de direitos desta natureza no texto da Carta constitucional promulgada em 1988.

Esta tendência socializante, no entanto, não durou muito tempo, tendo sido corrompida pelos ideais neoliberais privatizantes despontados no mundo inteiro logo nos anos seguintes. Desde então, a instabilidade econômica foi reiteradamente suscitada como fundamento para a transferência de serviços públicos para a iniciativa privada, ao mesmo tempo em que políticas públicas

\footnotetext{
153 Brazil Country Profile, [s.l.]: World Bank, [s.d.]. e ORGANIZAÇÃO MUNDIAL DA SAÚDE, Brazil: WHO statistical profile, 2015.

${ }^{154}$ GINI index (World Bank estimate), [s.l.]: World Bank, [s.d.].

155 TRAVASSOS; CASTRO, Determinantes e Desigualdades Sociais no Acesso e na Utilização de Serviços de Saúde, p. 194-199.

${ }^{156}$ ALMEIDA, Célia et al, Brazil's conception of South-South "structural cooperation" in health, RECIIS, v. 4, n. 1, p. 23-32, 2010.

${ }^{157}$ PIRES-ALVES, Fernando A; PAIVA, Carlos Henrique Assunção; SANTANA, José Paranaguá de, A internacionalização da saúde: elementos contextuais e marcos institucionais da cooperação brasileira, Rev Panam Salud Publica, v. 32, n. 6, p. 444-450, 2012.
} 
voltadas a atender às necessidades da população foram frequentemente preteridas em favor de despesas diversas e de políticas fiscais austeras. No mais, sucessivos governos fizeram uso de diversas manobras no intuito de frustrar o satisfatório financiamento das ações públicas em matéria de saúde.

Como resultado dos anos de políticas ineficientes e pouco interessadas em uma verdadeira transformação social, existe no país atualmente um sistema público de saúde notadamente sucateado, necessitando de investimentos e reformas, porém sem contar com um modelo de financiamento propício a tanto.

\section{1 \\ Panorama histórico: as tendências da atenção à saúde no Brasil anteriormente à Constituição de 1988}

Enquanto colônia, inexistia nas terras brasileiras uma estrutura oficial de política sanitária, o que só veio a surgir após a instalação da família real no Rio de Janeiro, no ano de 1808, mesmo assim de forma bastante incipiente. Neste período, e mesmo após a independência, as medidas sanitárias oficiais se resumiam à fiscalização de navios (para impedir a entrada de escravos doentes), à vacinação cautelar em períodos de epidemias e a algumas outras medidas de caráter higienista. A população que residia nestas terras era vítima de parasitas intestinais e doenças determinadas pela carência de nutrientes e transmissão de vetores (tuberculose, varíola, febre amarela etc.) ${ }^{158}$.

As "políticas públicas" em matéria de saúde não passavam de meras medidas paliativas interessadas apenas em sanear as multidões que serviam aos interesses da Coroa ou, após a independência, do senhorio. Na linha do que ocorria em todas as colônias europeias nas Américas ${ }^{159}$, as ações sanitárias no Brasil colonial e nos primeiros anos de república se resumiam a práticas curativas e higienistas para controle de epidemias que representavam um risco ao modelo econômico extrativista (durante a colônia) ou agrário exportador (na recém inaugurada república). Cuidados à saúde dos indivíduos relacionados puramente às suas condições sociais (e.g., tratamentos da tuberculose e de doenças

\footnotetext{
${ }^{158}$ ESCOREL, Sarah; TEIXEIRA, Luiz Antonio, História das Políticas de Saúde no Brasil de 1822 a 1963, in: GIOVANELlA, Ligia (Org.), Políticas e Sistema de Saúde no Brasil, 2a ed rev e amp. Rio de Janeiro: Fiocruz, 2012, p. 280.

${ }^{159}$ Vide item 1.2 do primeiro capítulo.
} 
gastrointestinais) permaneciam ao largo das ações de governo, ficando a população à mercê da ação de instituições filantrópicas como as Santas Casas de Misericórdia. Ademais, as precárias estruturas de saúde pública se concentravam na capital, para atendimento exclusivo das pessoas mais ricas da república, tendência que se confirmou até a segunda década do século XX.

A partir dos processos europeus bolcheviques, surgiram no Brasil diversos movimentos sociais, dentre eles os que lutavam pelo saneamento rural, cujas reivindicações foram determinantes na criação do Departamento Nacional de Saúde Pública (DNSP), primeiro órgão de saúde pública do governo central brasileiro, de caráter eminentemente técnico, fugindo das influências políticas das oligarquias locais e ampliando substancialmente a previsão de serviços públicos de atenção à saúde ${ }^{160}$. Importante observar que, ao mesmo tempo em que atendia aos anseios do movimento pelo saneamento rural, a criação do DNSP também zelava pela manutenção do status quo da chamada "república do café-com-leite", pois a única forma de salvaguardar as fontes de lucro deste sistema já em franco declínio seria expandindo os cuidados sanitários para as regiões rurais do país.

No entanto, a derrocada do arranjo oligárquico da república do café-comleite foi inevitável, concomitante à crescente urbanização liderada pelo movimento operário. A partir deste movimento, novas preocupações passaram a tomar conta das ações do governo central. A lei Eloy Chaves, de 1923, criou o pioneiro sistema securitário de financiamento da saúde no Brasil, implementando as Caixas de Aposentadorias e Pensões (CAPs), limitadas a trabalhadores vinculados ao sistema previdenciário e seus dependentes.

Ao tomar o poder em 1930, Getúlio Vargas preocupou-se especialmente com a regulamentação do trabalho urbano, com a previdência e com a assistência médica do trabalhador. Sob a égide de uma ideologia populista, a era Vargas aumentou a proteção à saúde do trabalhador, transformando gradualmente as CAPs em Institutos de Aposentadorias e Pensões (IAPs), que congregavam os trabalhadores em categorias ao invés de reuni-los por empresas, ampliando assim o pool securitário. A expansão dos seguros sociais, seguindo o modelo bismarckiano $^{161}$, manteve excluída do acesso à saúde grande parcela da

\footnotetext{
${ }^{160}$ ESCOREL; TEIXEIRA, História das Políticas de Saúde no Brasil de 1822 a 1963, p. 293-295.

${ }^{161}$ A respeito do modelo bismarckiano, leia-se item 1.4 do primeiro capítulo.
} 
população, em decorrência dos altos índices de desemprego e de trabalho informal. A saúde não era tratada como um direito da cidadania, mas sim como uma atividade estratégica do Estado no seu plano de governo ${ }^{162}$. Em suma, os serviços de saúde pública serviam basicamente para atender a indivíduos acometidos por doenças que os impedissem de trabalhar. Qualquer atendimento individualizado além disso seria considerado de natureza assistencial.

Da análise desse nascedouro do sistema de saúde brasileiro confirma-se aquilo que Barros et al afirmaram de forma percuciente, isto é, que o sistema de saúde brasileiro desde já se organizava com o fim primordial de garantir que o trabalhador permanecesse dedicado à linha de produção montada em interesse do capital (geração de lucro às empresas privadas), restando aí a origem da sua desigualdade ${ }^{163}$.

Durante o governo centralizador do presidente Eurico Gaspar Dutra (19461951), com o crescimento do papel do Estado, finalmente foi criado um Ministério da Saúde independente. Todavia, a expansão gradativa da rede pública de saúde no Brasil não se traduziu em ampliação do acesso à população mais carente. Pelo contrário, a estrutura da rede foi aumentando no nível terciário (modelo hospitalocêntrico), sobretudo em função das tendências liberais e da revolução tecnológica que se verificavam mundialmente. Nesse mesmo sentido, a expansão global da indústria farmacêutica empurrou o Brasil em direção aos atendimentos médico-hospitalares em detrimento da atenção básica preventiva ${ }^{164}$.

Correntes sanitaristas descontentes com esse modelo da assistência à saúde no Brasil e influenciadas pelas crescentes tendências globais socializantes do período $^{165}$ se lançaram reivindicando a descentralização das políticas públicas de saúde, em nome da maior proximidade dos agentes de saúde com os usuários, das políticas preventivas e da prevalência da autoridade municipal. Este era o mote dos "sanitaristas desenvolvimentistas" que chegaram a influenciar o segundo

\footnotetext{
${ }^{162}$ ESCOREL; TEIXEIRA, História das Políticas de Saúde no Brasil de 1822 a 1963, p. 297-302.

${ }^{163}$ BARROS, Maria Elizabeth; PIOLA, Sérgio Francisco; VIANNA, Solon Magalhãe, Políticas de Saúde no Brasil: diagnóstico e perspectivas, Brasília: Ipea, 1996, p. 26.

${ }^{164}$ ESCOREL; TEIXEIRA, História das Políticas de Saúde no Brasil de 1822 a 1963, p. 308 e 317.

${ }^{165}$ Vide referências a respeito do surgimento da corrente da medicina social a partir do século XX, no item 1.2 do primeiro capítulo.
} 
mandato do governo Vargas e de seus sucessores, até o início da ditadura militar em 1964, quando suas vozes foram sufocadas pelo regime autoritário ${ }^{166}$.

Apesar de o período da ditadura militar ter sido uma fase de grande crescimento econômico, uma série de reformas estruturais geraram cortes nos gastos públicos em políticas sociais. Em 1973, no auge do "milagre econômico", os recursos públicos destinados ao Ministério da Saúde correspondiam a tão somente $1 \%$ do orçamento da União ${ }^{167}$. A promessa de desenvolvimento nunca se traduziu em igualdade social, favorecendo sobretudo a expansão da indústria e a acumulação capitalista. No campo da saúde, foi mantido o modelo de seguro social (previdenciário) implementado por Vargas, bem como o sistema foi reorientado à contratação de serviços terceirizados sob o argumento de que a rede pública não seria capaz de atender à demanda por serviços.

No final da década de 1970, o sistema público de saúde estava organizado em três subsistemas: o previdenciário (organizado pelo então Instituto Nacional de Assistência Médica da Previdência Social - INAMPS), o da administração federal (Ministério da Saúde) e o das administrações estaduais e municipais. Segundo a análise de Melamed, o primeiro era um verdadeiro convite a fraudes e irregularidades, na medida em que sua rede era majoritariamente terceirizada para o setor privado e a remuneração se dava por unidade de serviço prestado; o segundo ocupava-se de ações coletivas sem conseguir efetivamente articular-se regional e localmente; por sua vez, o terceiro não possuía autonomia e recursos para agir ${ }^{168}$. Nenhum deles era devidamente organizado e financiado, o que favorecia o setor privado, seja vendendo soluções para o próprio poder público, seja vendendo serviços privados diretamente aos usuários. Esta (des)organização do sistema incentivou a prática da medicina voltada para o lucro, interessada em procedimentos mais caros em detrimento das ações preventivas. Qualquer alternativa a esta corrente era fortemente condenada e abolida pelo regime

\footnotetext{
${ }^{166}$ ESCOREL; TEIXEIRA, História das Políticas de Saúde no Brasil de 1822 a 1963, p. 305-308.

${ }^{167}$ ESCOREL, Sarah, História das Políticas de Saúde no Brasil de 1964 a 1990: do golpe militar à reforma sanitária, in: GIOVANELLA, Ligia (Org.), Políticas e Sistema de Saúde no Brasil, 2a ed rev e amp. Rio de Janeiro: Fiocruz, 2012, p. 325-329.

${ }^{168}$ MELAMED, C, Regulamentação, Produção de Serviços e Financiamento Federal do Sistema Único de Saúde: dos anos 90 aos 2000, in: MELAMED, C; PIOLA, Sérgio Francisco (Eds.), Políticas Públicas e Financiamento Federal do Sistema Único de Saúde, Brasilia: Ipea, 2011, p. 60-62.
} 
ditatorial, a exemplo do episódio que ficou conhecido como "Massacre de Manguinhos"169.

Não obstante, apesar de toda a repressão imposta pela ditadura, uma corrente de resistência surgiu nas universidades, nos Departamentos de Medicina Preventiva (DMP) criados pela Reforma Universitária de 1968. Com o tempo, esse movimento sanitário foi ganhando larga adesão, sendo que, no final da década de 1970, quando a ditadura militar já entrava em processo de crise, as políticas de saúde eram um campo propício para o crescimento dos oposicionistas-reformistas, conforme restou evidente no I Simpósio sobre Política Nacional de Saúde, na Câmara dos Deputados, em 1979, ocasião em que a oposição apontou a crise no sistema de saúde do país, falando pela primeira vez em uma proposta de sistema universal ${ }^{170}$. Em 1986 foi convocada a $8^{\text {a }}$ Conferência Nacional de Saúde, com o objetivo de concretizar a linha teórica desse movimento, lançando a campanha pela Reforma Sanitária ${ }^{171}$.

Tal movimento foi um importante instrumento de freio ao modelo privatista de assistência médica, fundado em moldes capitalistas, que vinha prevalecendo no Brasil. Sua preocupação com os determinantes sociais da relação saúde-doença introduziu um novo modo de pensar e agir em termos de ciências médicas, propondo uma transformação do sistema de saúde brasileiro, para que passasse a "considerar a determinação da infraestrutura econômica na distribuição desigual das doenças entre as classes sociais ${ }^{\prime 172}$. Nesse sentido, a Reforma Sanitária levantava a bandeira do acesso universal e igualitário aos serviços sanitários.

Todavia, o processo de redemocratização no Brasil sucedeu a um período de forte crise econômica ${ }^{173}$, tendo sido, portanto, acompanhado de diversos planos

\footnotetext{
${ }^{169}$ Em 1964, diversos pesquisadores do Instituto Oswaldo Cruz, no Rio de Janeiro, passaram a ser alvo de falsas acusações e perseguições que culminaram em cortes de financiamentos a pesquisas, cassação dos direitos políticos e aposentadorias compulsórias, tudo porque lutavam em nome do movimento da Reforma Sanitária. LENT, Herman, O Massacre de Manguinhos, Rio de Janeiro: Avenir, 1978.

${ }^{170}$ FALEIROS, Vicente de Paula et al, A Construção do SUS: Histórias da Reforma Sanitária e do Processo Participativo, Brasilia: Ministério da Saúde, 2006, p. 40.

${ }^{171}$ Ibid., p. 46-47.

172 ESCOREL, História das Políticas de Saúde no Brasil de 1964 a 1990: do golpe militar à reforma sanitária, p. 332.

${ }^{173}$ A crise econômica mundial do final do século XX foi causada por múltiplos fatores, dentre os quais destacam-se a crise do petróleo na década de 70, a globalização desenfreada iniciada na
} 
econômicos e políticas de ajustes fiscais. Nesse contexto, as promessas de maior atenção aos direitos sociais foram mais uma vez preteridas. $\mathrm{O}$ então presidente da república José Sarney negociou medidas com setores parlamentares conservadores e o processo constituinte foi marcado por tais influências. Apesar dos avanços das correntes sociais, alcançados especialmente a partir das conclusões da $8^{\mathrm{a}}$ Conferência Nacional de Saúde, tem-se que diversas concessões foram feitas às alas mais conservadoras do Congresso na redação final do texto constitucional. Segundo Faleiros, no processo constituinte

Por entre as diversidades e especificidades de interesses dos vários segmentos sociais envolvidos, o debate se polarizou nos pontos mais polêmicos da regulamentação - a descentralização da gestão, a relação público-privado e o controle social - em dois grandes blocos: os defensores da Reforma Sanitária, no "espírito" da 8 a CNS, organizados na Plenária Nacional de Saúde, defendendo o máximo de regulamentação dos dispositivos constitucionais; e os opositores, organizados na Federação Brasileira de Hospitais - FBH e em outras entidades do setor privado, defendendo uma regulamentação mínima. Os dois grupos se mobilizavam junto às bancadas de parlamentares de diversos partidos ${ }^{174}$.

As concessões mútuas destes dois segmentos sociais geraram dificuldades até hoje enfrentadas pelo sistema, as quais serão objeto dos próximos itens do presente capítulo e do próximo. Especificamente em relação ao financiamento, assunto sobre o qual a presente dissertação se ocupa em particular, não houve um consenso sobre o tema. Segundo Gomes, "é comum a percepção de que os constituintes não previram as fontes dos recursos para implantar as políticas sociais ${ } 175$.

Finalmente, a Constituição de 1988 foi promulgada com a previsão inédita, em seus artigos $6^{\circ}$ e 196 , de que a saúde é direito de todos e dever do

década de 80 e a mudança dos padrões de empregabilidade decorrentes da revolução tecnológica pós-industrial. O'CINNEIDE, Austerity and the Faded Dream of a Social Europe, p. 181.

${ }^{174}$ FALEIROS et al, A Construção do SUS: Histórias da Reforma Sanitária e do Processo Participativo, p. 54.

${ }^{175}$ GOMES, Fábio de Barros Correia, Impasses no financiamento da saúde no Brasil: da constituinte à regulamentação da emenda 29/00, Saúde Debate, v. 38, n. 100, p. 06-17, 2014, p. 8. $\mathrm{O}$ autor menciona o art. 55 do Ato das Disposições Transitórias, o qual estabelece um mínimo de $30 \%$ do orçamento da seguridade social para a saúde. Tal solução, além de não ter sido duradoura, nunca foi efetivamente implementada, ao contrário do que menciona o autor. Este tema será oportunamente comentado no item 3.3.1 do presente capítulo. 
Estado $^{176}$. A partir de então foi instituído um Sistema Único de Saúde (SUS), cujas diretrizes encontram-se previstas no art. 198 do texto constitucional e cuja lei orgânica regulamentadora é a Lei 8.080/90.

\section{2}

\section{O SUS e o financiamento privado da saúde}

O art. 196 da Constituição de 1988 proclama a adoção do modelo beveridgiano de cobertura universal, garantindo a todos os indivíduos acesso aos serviços públicos de saúde. Tal modelo é corolário da consagração da saúde como direito social fundamental (art. $6^{\circ}$ da mesma Carta) bem como do reconhecimento de que sua prestação é um dever do Estado. Por consequência, o art. 198 da Constituição estabelece que o financiamento do sistema de saúde brasileiro terá suporte na arrecadação tributária.

No entanto, apesar desta explícita opção política do constituinte originário, o padrão dos gastos em saúde no Brasil demonstra que, na prática, a lógica beveridgiana vem sendo subvertida.

As planilhas a seguir informam que, historicamente, o gasto privado em saúde (inclui gastos por planos privados de saúde, gastos diretos por particulares e gastos por instituições sem fins lucrativos) é pelo menos igual, sendo quase sempre superior, ao gasto público.

\begin{tabular}{|l|c|r|r|r|r|r|r|r|r|r|r|r|r|r|r|r|r|r|r|r|r|r|r|}
\hline Countries & Indicators & 2014 & 2013 & 2012 & 2011 & 2010 & 2009 & 2008 & 2007 & 2006 & 2005 & 2004 & 2003 & 2002 & 2001 & 2000 & 1999 & 1998 & 1996 & 1995 \\
\hline Brazil & $\begin{array}{c}\text { General government } \\
\text { expenditure on health / \% } \\
\text { Gross domesctic product }\end{array}$ & 4 & 4 & 4 & 4 & 4 & 4 & 4 & 3 & 3 & 3 & 3 & 3 & 3 & 3 & 3 & 3 & 3 & 3 & 3 \\
\hline Brazil & $\begin{array}{c}\text { Private expenditure on } \\
\text { health / \% Gross domestic } \\
\text { product (GDP) }\end{array}$ & 4 & 5 & 5 & 4 & 4 & 5 & 5 & 5 & 5 & 5 & 4 & 4 & 4 & 4 & 4 & 4 & 4 & 4 & 4 \\
\hline
\end{tabular}

Fonte: Organização Mundial de Saúde ${ }^{177}$

\footnotetext{
${ }^{176}$ Art. $6^{\circ}$ São direitos sociais a educação, a saúde, a alimentação, o trabalho, a moradia, o transporte, o lazer, a segurança, a previdência social, a proteção à maternidade e à infância, a assistência aos desamparados, na forma desta Constituição (...) Art. 196. A saúde é direito de todos e dever do Estado, garantido mediante políticas sociais e econômicas que visem à redução do risco de doença e de outros agravos e ao acesso universal e igualitário às ações e serviços para sua promoção, proteção e recuperação.

${ }^{177}$ http://apps.who.int/nha/database/ViewData/Indicators/en, acesso em 10/08/2017
} 


\begin{tabular}{|c|c|c|c|c|c|c|c|c|c|c|c|c|c|c|}
\hline \multicolumn{15}{|c|}{ Retropolação da série de consumo final de bens e serviços de saúde } \\
\hline \multicolumn{2}{|c|}{ Participação do consumo final no PIB (\%) } & \multirow[b]{2}{*}{2012} & \multirow[b]{2}{*}{2011} & \multirow[b]{2}{*}{2010} & \multirow[b]{2}{*}{2009} & \multirow[b]{2}{*}{2008} & \multirow[b]{2}{*}{2007} & \multirow[b]{2}{*}{2006} & \multirow[b]{2}{*}{2005} & \multirow[b]{2}{*}{2004} & \multirow[b]{2}{*}{2003} & \multirow[b]{2}{*}{2002} & \multirow[b]{2}{*}{2001} & \multirow[b]{2}{*}{2000} \\
\hline Ano & 2013 & & & & & & & & & & & & & \\
\hline $\begin{array}{l}\text { Famílias e instituições sem fi } \\
\text { lucro a serviço das famílias }\end{array}$ & 4,4 & 4,4 & 4,3 & 4,4 & 4,7 & 4,5 & 4,7 & 4,7 & 4,7 & 4,7 & 4,7 & 4,8 & 4,9 & 4,7 \\
\hline Governo & 3,6 & 3,4 & 3,5 & 3,6 & 3,7 & 3,5 & 3,5 & 3,6 & 3,4 & 3,5 & 3,5 & 3,7 & 3,5 & 3,5 \\
\hline Total & 8,0 & 7,8 & 7,8 & 8,0 & 8,4 & 8,0 & 8,2 & 8,3 & 8,0 & 8,2 & 8,2 & 8,5 & 8,5 & 8,2 \\
\hline \multicolumn{15}{|c|}{ Variação do volume encadeada (base 100 em 2000) } \\
\hline Ano & 2013 & 2012 & 2011 & 2010 & 2009 & 2008 & 2007 & 2006 & 2005 & 2004 & 2003 & 2002 & 2001 & 2000 \\
\hline $\begin{array}{l}\text { Consumo das famílias e das } \\
\text { instituições sem fins de lucro } \\
\text { das famílias }\end{array}$ & 160,7 & 158 & 156 & 150 & 145 & 140 & 132 & 126 & 122 & 114 & 110 & 109 & 104 & 100 \\
\hline Consumo do governo & 157,3 & 152 & 151 & 148 & 141 & 135 & 127 & 121 & 112 & 111 & 111 & 107 & 104 & 100 \\
\hline Produto Interno Bruto - PIB & 156,6 & 152 & 149 & 144 & 134 & 134 & 127 & 120 & 115 & 112 & 106 & 104 & 101 & 100 \\
\hline
\end{tabular}

Fonte: IBGE - Conta-Satélite de Saúde $e^{178}$

Esta tendência não passou desapercebida ao Banco Mundial, o qual, em relatório publicado no mês de novembro de 2017 por encomenda do governo brasileiro, anunciou que

O gasto total com saúde no Brasil (9,2\% do PIB) é comparável com a média dos países membros da OCDE $(8,9 \%)$ e maior do que a média dos seus parceiros estruturais e regionais $(5,8 \%$ e $7,4 \%$, respectivamente) (Figura 71). Nas duas últimas décadas, o gasto com saúde como parte do PIB aumentou em 1,8 pontos percentuais no Brasil, enquanto que, entre os países da OCDE, o aumento da média foi de 2,3\%. Diferentemente da maioria dos seus parceiros econômicos, mais da metade dos gastos totais com saúde no Brasil são financiados privadamente (individualmente e planos de saúde privados). A despesa pública com saúde como parte da despesa total com saúde $(48,2 \%)$ é significativamente mais baixa do que a média entre os países da $\operatorname{OCDE}(73,4 \%)$ e do que os seus parceiros de renda média, está acima apenas da média entre os países do BRICS $(46,5 \%)^{179}$.

Assim como constatado pelo Banco Mundial, dados da OECD também demonstram que a composição do financiamento da saúde no Brasil em nada se assemelha àquela visualizada nos países desenvolvidos que adotam sistemas nacionais de saúde de cunho beveridgiano. Embora o percentual do gasto total em saúde se assemelhe ao padrão destes demais países no que tange ao seu percentual

\footnotetext{
${ }^{178} \mathrm{http}$ ://www.ibge.gov.br/home/estatistica/economia/economia_saude/css_2010_2013/defaulttab xls.shtm, acesso em 27/09/2017

${ }^{179}$ GRUPO BANCO MUNDIAL, Um Ajuste Justo - Análise da eficiência e equidade do gasto público no Brasil, 2017, p. 110.
} 
médio sobre o PIB, tem-se que a participação do gasto público neste percentual no Brasil não passa dos 50\% enquanto que em países como Inglaterra, Dinamarca e Suécia ultrapassa os $80 \%{ }^{180,181}$.

Os dados contidos nessas análises denotam a tendência do governo brasileiro para se despir de sua autoridade sanitária transferindo grande parte de suas responsabilidades à iniciativa privada. Na realidade, conforme foi possível observar no item anterior deste capítulo, esse movimento privatizante já se desenhava desde antes da promulgação da Constituição de 1988. Nas palavras de Ugá et al,

Correspondendo à estrutura herdada do modelo do sistema de saúde prévio ao SUS no qual o papel do Estado havia sido fundamentalmente o de promover a expansão do setor privado, a estrutura do gasto nacional em saúde está bastante marcada por essa herança. Nosso sistema de saúde, constitucionalmente definido como de acesso universal e integral, exibe estrutura do gasto que em nada se assemelha à dos sistemas nacionais de saúde de cunho beveridgiano, mas se aproxima do padrão estadunidense, tido como sistema típico do modelo liberal do sistema de saúde ${ }^{182}$.

A correta compreensão do fenômeno em comento não pode prescindir da relevância da dicotomia entre os paradigmas político-econômicos liberal e social, já mencionados anteriormente neste estudo. As críticas às conclusões de Globekner, traçadas no primeiro capítulo ${ }^{183}$, serão aqui brevemente retomadas em razão da pertinência temática. O autor de A Saúde entre o Público e o Privado: o desafio da alocação social dos recursos sanitários escassos defende que o surgimento de diferentes arranjos que promovem relações entre o Estado e a iniciativa privada no bojo das sociedades contemporâneas ensejou a superação dessa dicotomia, de forma que, na visão do autor, esses diferentes modelos de pensamento político-filosófico não seriam alternativas excludentes ${ }^{184}$.

\footnotetext{
${ }^{180}$ Fonte: http://apps.who.int/gho/data/node.country, acesso em 27/09/2017

${ }^{181}$ Outros países da América Latina apresentam o mesmo padrão de comportamento dos gastos públicos com saúde, fato que denota ser este um importante aspecto a ser considerado. Ou seja, quanto mais desenvolvido o país maiores são as parcelas públicas dos gastos em saúde em relação ao total das despesas nesse setor.

${ }^{182}$ UGÁ; PORTO; PIOLA, Financiamento e Alocação de Recursos em Saúde no Brasil, p. 402.

${ }^{183}$ Vide item 1.4 do primeiro capítulo.

${ }^{184}$ GLOBEKNER, A Saúde entre o Público e o Privado: o desafio da alocação social dos recursos sanitários escassos, p. 86, 94 e 165.
} 
Discorda-se aqui, conforme já adiantado no primeiro capítulo desta dissertação, das conclusões de Globekner. Apesar de ser evidente a possibilidade - e até mesmo necessidade - de novas formas de relacionamento entre o Estado e a iniciativa privada, permeadas por um caráter mais colaborativo entre estas partes, não é admissível se depreender que a mencionada dicotomia entre os paradigmas liberal e social tenha sido superada. Ao contrário, ainda que a globalização, a escassez de recursos, a democratização política, entre outros fatores, tenham enfraquecido a fronteira existente entre tais posicionamentos políticos, nada disso foi capaz de derrubá-la. A intensidade e as formas de intervenção do Estado na economia continuam sendo circunstâncias extremamente variáveis, ainda que sob novos enfoques e parâmetros ${ }^{185}$. Ademais, os aspectos teóricos que servem de fundamento para a forma de organização da sociedade também variam demasiadamente de acordo com o paradigma adotado. A compreensão das ideias de liberdade, igualdade, bem-comum etc. variam de tal forma que elas continuam sendo vetores que definem diversos aspectos da sociedade e do modo como seus serviços se organizam.

Por exemplo, e segundo dados fornecidos pelo próprio autor em comento, a previsão da universalização da saúde na Constituição brasileira de 1988 acarretou uma debandada de pessoas com melhor poder aquisitivo - e que antes estavam cobertas pelo sistema público de saúde previdenciário - para o sistema privado, mediante contratação de planos e seguros privados de saúde ${ }^{186}$. O autor não critica o fenômeno e até mesmo o justifica como um "ajuste" razoável que “apenas revela a importância da dinâmica da participação pública e privada na configuração de um sistema nacional de saúde"187. Mais uma vez, suas conclusões se distanciam da melhor análise do evento porque, sob a ótica do financiamento da saúde, a segregação dos serviços entre os setores público e privado causa uma ruptura indesejada e uma fragmentação do pool de

\footnotetext{
185 Para um resumo das novas formas como o Estado pode eficientemente vir a conduzir a crescente supremacia do mercado privado no setor da atenção à saúde, visando a corrigir suas falhas mercadológicas, leia-se MONTAGU, Dominic; GOODMAN, Catherine, Prohibit, constrain, encourage, or purchase: how should we engage with the private health-care sector?, Lancet, v. 388, p. 613-621, 2016.

${ }^{186}$ GLOBEKNER, A Saúde entre o Público e o Privado: o desafio da alocação social dos recursos sanitários escassos, p. 148-149.

${ }^{187}$ Ibid., p. 151.
} 
contribuintes que deveriam compartilhar os encargos sociais numa ótica de solidariedade social.

Ao contrário do que defende Globekner, a existência de múltiplas redes não contribui para o acesso à atenção sanitária. Pelo contrário, a polarização acarreta, ao invés de uma ampliação do acesso, aquilo que o próprio autor narrou como "um dos grandes temores do movimento pela reforma sanitária”, ou seja, a ruptura do sistema em dois esquemas, um para os ricos e outro para os pobres, com notórias diferenças de qualidade ${ }^{188}$.

A OMS, em seu relatório anual do ano de 2010, apontou para o problema da fragmentação do financiamento da saúde em diversos fundos:

Cada país precisa de encontrar soluções pragmáticas para pagar aos prestadores e para adquirir serviços; soluções que reflictam as condições locais. Quaisquer que sejam as escolhas, a base do sistema de saúde que melhor serve as necessidades da sua população irá incluir certamente alguma forma de pré-pagamento ou fundos comuns. Quanto maior a partilha de risco, ou seja, a dimensão do fundo comum, melhor. Os grandes fundos têm vantagens diversas, nomeadamente, uma maior capacidade de suportar os custos ocasionais de doenças dispendiosas. Um sistema de saúde mais eficiente evita a fragmentação originada pela multiplicação de fundos, mas também pela canalização e distribuição mais racional de recursos. Como discutido nos capítulos anteriores, a fragmentação limita a possibilidade de solidariedade - entre os mais ricos e os pobres, e os saudáveis e doentes -, que é necessária num sistema de partilha de risco. Nos EUA, a fragmentação na partilha de risco é considerada como uma das razões para o fracasso da cobertura universal, apesar do elevado nível de despesa com a saúde. A fragmentação também pode ser ineficiente. Os sistemas com múltiplos canais de angariação de fundos e fundos comuns, cada um com os seus custos administrativos, esforços duplicados, são dispendiosos e requerem coordenação. De igual modo, a fragmentação noutras partes do sistema - funcionamento dos hospitais, distribuição de medicamentos e equipamentos, manutenção de sistemas laboratoriais - origina desperdício e duplicações desnecessárias ${ }^{189}$.

Alguém poderia argumentar que não importa quanto dinheiro privado é investido em saúde se o setor público permanecesse aplicando largas quantias, ou quantias suficientes para atender à demanda. Trata-se do tão frequente argumento segundo o qual o indivíduo que não se utiliza dos serviços de saúde públicos, pois paga e faz uso de um plano de saúde privado, estaria na realidade "aliviando" os

\footnotetext{
${ }^{188}$ Ibid., p. 157.

189 ORGANIZAÇÃO MUNDIAL DA SAÚDE, The world health report: Health systems financing: the path to universal coverage, p. 83.
} 
recursos do Tesouro público. Tal argumento, todavia, é demasiadamente simplório e, ademais, falacioso.

Explica-se. Embora se acredite que o indivíduo que paga por um plano de saúde privado não gera despesas para o sistema público de saúde, este raciocínio não é perfeito. Planos privados usualmente não cobrem uma série de tratamentos, tampouco investem em qualidade na atenção básica e preventiva à saúde. Por consequência, muitos usuários, mesmo segurados por planos privados, acabam necessitando dos serviços públicos quando são acometidos por doenças não cobertas por seus seguros. Muito mais vantajoso (leia-se, barato) para o poder público seria tratar o indivíduo desde o momento em que surgisse eventual moléstia em seu estágio inicial, prevenindo o seu agravamento, ou até mesmo intervir preventivamente impedindo o seu surgimento. Na realidade, o indivíduo que paga por um plano privado de saúde experimenta uma falsa sensação de que está protegido e, nestas condições, deixa de se prevenir. A situação em exame é agravada quando este cidadão procura cuidados médicos apenas no momento em que sofre uma moléstia já em seu estágio mais avançado, necessitando portanto de tratamento mais caro e muitas vezes não abarcado pelo plano de saúde privado. Daí a busca tardia por atendimento na rede pública, gerando enormes prejuízos ao SUS.

Paul Krugman, ganhador do prêmio Nobel de economia em 2008, escreveu em 2007 o livro The Conscience of a Liberal pelo qual denuncia as políticas atrozes (segundo seu próprio ponto de vista) dos conservadores radicais norte-americanos a partir da segunda metade da década de 1970. Seu livro propõe uma reforma política que pudesse se tratar de um "novo New Deal". A sugestão de Krugman é pela implementação de um programa de saúde universal como ponto central deste plano de reforma. Para tanto, dedica um capítulo inteiro de seu livro ao tema do sistema de saúde americano, partindo da premissa de que "as empresas de seguros privados, entretanto, não ganham dinheiro ao custear a assistência à saúde. Elas ganham dinheiro na medida em que conseguem se safar arrecadando os prêmios e não pagando pela assistência prometida"190. Tal pressuposto, que parece ser bastante lógico e, ao mesmo tempo, aparentemente

${ }^{190}$ KRUGMAN, Paul, A Consciência de um Liberal, Rio de Janeiro: Record, 2010, p. 266. 
inofensivo dentro de uma ideia de livre mercado, denota uma série de consequências perversas para a efetiva garantia do direito à saúde, segundo demonstra o autor.

Não se quer aqui negar a possibilidade de empresas privadas investirem no ramo da saúde como atividade lucrativa. Aliás, trata-se de hipótese garantida na Constituição da República de $1988^{191}$. Trata o presente capítulo desta dissertação de uma crítica à inversão da lógica beveridgiana, eis que a participação da iniciativa privada, neste modelo universalista, deveria ser complementar, e não a principal fonte de financiamento, como vem ocorrendo no Brasil.

Segundo tipologia elaborada pela OECD em $2004^{192}$, há basicamente quatro modos pelos quais os planos ou seguros privados de saúde podem participar da assistência à saúde dentro de um determinado sistema: (i) suplementar, (ii) substitutivo, (iii) complementar ou (iv) primário.

O seguro suplementar é aquele que oferece apenas pequenos diferenciais aos serviços oferecidos pelo Estado, tais como melhorias de hotelaria ou ambulatorial.

O seguro substitutivo existe nos sistemas em que é possível ao indivíduo optar por se excluir do acesso ao sistema público de saúde, desde que adote um plano privado (e.g., Holanda e Chile).

O seguro complementar existe para serviços não cobertos pelo sistema público (e.g., Canadá).

Por fim, o seguro privado é considerado modelo primário do sistema de saúde quando prepondera sobre o sistema público, como ocorre no caso dos Estados Unidos.

Embora Ugá et al afirmem que o caso brasileiro não se enquadra em nenhum dos anteriormente mencionados ${ }^{193}$, o melhor posicionamento sobre este tema é aquele adotado por Santos et al, segundo o qual o modelo brasileiro segue o molde dos seguros suplementares, eis que os planos e seguros privados no Brasil oferecem os mesmos serviços que a rede pública, porém com um ou outro diferencial em termos de qualidade do serviço. Trata-se, na realidade, de uma

\footnotetext{
${ }^{191}$ CRFB/88 Art. 199. A assistência à saúde é livre à iniciativa privada (...)

192 OECD, PROPOSAL FOR A TAXONOMY OF HEALTH INSURANCE, 2017.

${ }^{193}$ UGÁ; PORTO; PIOLA, Financiamento e Alocação de Recursos em Saúde no Brasil, p. 398.
} 
deturpação do sistema universalista, eis que a cobertura se torna duplicada ${ }^{194}$, no final das contas sobrecarregando a estrutura e o financiamento do sistema como um todo.

A duplicação da cobertura e consequente fragmentação do sistema acarreta a quebra do sistema de compartilhamento de encargos sociais, mencionada no primeiro capítulo desta dissertação como um dos mecanismos de financiamento equitativo da saúde ${ }^{195}$. Conforme explicitado outrora, o financiamento da saúde por meio de pools é a forma mais justa (em termos redistributivos) de garantir a todos os cidadãos segurança financeira contra os riscos do adoecimento. Por intermédio do pool (fundo compartilhado), potenciais usuários contribuem antecipadamente na medida de suas capacidades financeiras no intuito de conformar um sistema autossuficiente e capaz de proteger a todos os seus membros. No financiamento por um pool vigora a ideia de compartilhamento de riscos e, em última instância, a noção de solidariedade social.

No entanto, como visto no primeiro capítulo, a ideia de pool é tanto mais eficiente quanto maior e mais heterogênea for a sua composição (no sentido de diferentes capacidades financeiras e níveis de risco de adoecimento entre os seus participantes). A existência de diversos pequenos e homogêneos pools acaba retirando todo o valor redistributivo deste sistema. É exatamente o que acontece com a excessiva fragmentariedade do sistema de saúde brasileiro.

De tudo o que foi dito decorre a conclusão de que o Brasil não vem implementando de forma adequada a promessa que fez à sua população por intermédio da Constituição de 1988. O modelo fragmentado de financiamento do sistema de saúde, que raciona recursos escassos, prejudica em larga escala o alcance da anunciada cobertura universal e integral. O sistema que nasceu para ser único e voltado a atender a toda a população se desmantelou em diversos pequenos esquemas, entre o sucateado SUS e diversos planos privados de saúde.

A problemática se intensifica a partir da constatação de que é o próprio Poder Público quem incentiva a inflação do setor privado de saúde, das mais variadas maneiras.

\footnotetext{
194 SANTOS; UGÁ; PORTO, O mix público-privado no Sistema de Saúde Brasileiro: financiamento, oferta e utilização de serviços de saúde, p. 1432.

${ }^{195}$ Vide item 1.3
} 
Inicialmente, tem-se a crônica falta de investimentos na prestação de ações e serviços públicos de saúde. Esta questão será objeto de análise mais detida nos próximos itens deste capítulo assim como no capítulo seguinte desta dissertação, quando então serão tratadas especificamente as incongruências no financiamento do sistema público de saúde brasileiro. Patente que, enquanto a rede pública não oferecer cuidados à saúde com marcas de qualidade, a iniciativa privada permanecerá encontrando nichos para vender seus bens e serviços a quem puder adquiri-los.

Em seguida, devem ser mencionadas as insistentes renúncias de receitas despropositadamente favoráveis à iniciativa privada. Santos et al mencionam os incentivos fiscais aos prestadores e operadores de planos de saúde filantrópicos, bem como a dedução no imposto de renda relativa aos valores pagos em despesas médicas, hospitalares e com seguro de saúde, valores estes bastante consideráveis segundo dados da Receita Federal ${ }^{196}$.

A respeito desse assunto, Élida Pinto, socorrendo-se à Lei de Responsabilidade Fiscal (LRF - Lei Complementar 101/00), relembra que o seu artigo 14 exige que a validade e o início da vigência de uma renúncia físcal seja condicionada à instituição de uma medida compensatória, com duração de três anos. Assim, a autora sugere um controle mais eficaz sobre a validade dos atos que perpetuam diversas renúncias fiscais para além deste prazo, promovendo situações ilegais. Acrescenta, em tom crítico, que os controles existentes no Brasil na área da responsabilidade fiscal "são frouxos não só sobre as medidas compensatórias que amparam a instituição das renúncias fiscais, como também sobre a compensação dos impactos fiscais causados pelas despesas obrigatórias de caráter continuado (artigo 17 da LRF) ${ }^{\prime 197}$.

Outra forma de incentivo à iniciativa privada por parte do Poder Público consiste na permissão de uso indiscriminado dos recursos do SUS para cuidados da saúde de indivíduos assegurados por planos ou seguros privados. Segundo dados do PNAD 2003, colhidos por Santos, Ugá e Porto, dos pacientes possuidores de plano de saúde internados naquele ano, 15,4\% o foram pelo SUS.

\footnotetext{
${ }^{196}$ Ibid., p. 1438.

197 PINTO, Élida Graziane, Controle judicial dos orçamentos públicos em prol dos direitos fundamentais, Consultor Jurídico, 2016.
} 
Quanto aos atendimentos em geral, os dados revelam que, dos indivíduos segurados $11,8 \%$ foram atendidos pelo SUS ${ }^{198}$. Essa estatística revela a ocorrência de uma seleção egoística da oferta de serviços, fenômeno sobre o qual comenta Globekner na seguinte passagem:

O seguro privado cobre os riscos cuja cobertura se apresenta economicamente rentável, deixando-se para o setor público os não-rentáveis, que irão concorrer, no setor público, com os demais serviços, atinentes aos outros níveis de atenção. É o que ocorre em alguns níveis da atenção básica preventiva, como as campanhas de imunização, com a assistência farmacêutica, não coberta pela empresas de saúde suplementar, e com alguns níveis de atenção que exigem alta tecnologia, por exemplo, os transplantes de órgãos, realizados quase exclusivamente pelo sistema público.

A utilização do serviço público pelos beneficiários de planos e seguros privados, em procedimentos que deveriam ser por estes cobertos, determinou a criação da figura do Ressarcimento ao SUS, através do dispositivo inserto na Lei Federal 9.656 de 03.06.1998. Os dados pertinentes às internações hospitalares e aos procedimentos de alta complexidade realizados no SUS são cruzados com dados dos beneficiários de planos e seguros de saúde, pela Agência Nacional de Saúde (ANS), que, ao identificar a utilização do sistema público pelo beneficiário do plano privado, deverá cobrar da respectiva operadora de seguro-saúde o ressarcimento ao SUS"199.

Percebe-se que, na linha do que foi sublinhado no primeiro capítulo a respeito das falhas mercadológicas do setor da saúde, as empresas privadas ofertam apenas aquilo que lhes gera lucro, deixando seus segurados desassistidos quanto aos tratamentos menos rentáveis. Em relação a esses últimos serviços, indivíduos mesmo segurados por planos privados recorrem ao SUS, sobrecarregando, assim, o sistema público.

O art. 32 da Lei 9.656/98 (Lei dos Planos de Saúde) instituiu a regra de ressarcimento ao SUS nas hipóteses de atendimento a indivíduos segurados por planos privados ${ }^{200}$. Entretanto, Santos, Ugá e Porto revelam dados da ANS que confirmam que desde o final de 1999 até meados de 2006 o Estado raramente realizou tais cobranças, seja porque os valores a serem cobrados (com base na Tabela Única Nacional de Equivalência de Procedimentos - TUNEP) são pouco

\footnotetext{
198 SANTOS; UGÁ; PORTO, O mix público-privado no Sistema de Saúde Brasileiro: financiamento, oferta e utilização de serviços de saúde, p. 1435.

199 GLOBEKNER, A Saúde entre o Público e o Privado: o desafio da alocação social dos recursos sanitários escassos, p. 154.

200 Em fevereiro de 2018 o STF, em decisão de tema com repercussão geral, declarou constitucional o mencionado dispositivo legal. STF, RE 597064
} 
significativos quando individualmente considerados, seja porque os processos de cobrança são longos e em regra não compensam os custos do litígio ${ }^{201}$.

A série de circunstâncias aqui elencadas, consideradas conjuntamente, provocam o fortalecimento do setor privado e consequente enfraquecimento da rede pública. Pior ainda é o fato de que esta postura omissiva do Poder Público brasileiro não parece estar em vias de transformação. Pelo contrário, as condutas mais atuais do governo brasileiro - as quais serão tratadas mais detalhadamente ao final do próximo capítulo - denotam a manutenção deste padrão de conduta impregnado de convicções neoliberais.

Com efeito, em artigo recentemente publicado, Santos analisa a questão da crise econômica brasileira e o processo de transição que o SUS vem enfrentando. Nesse trabalho, a autora compila uma série de fatos recentemente ocorridos e que demonstram que o governo brasileiro atual vem incentivando a diminuição do SUS e a concomitante expansão dos planos privados, em detrimento do próprio desenvolvimento econômico do país.

Como dito, a análise da situação da atual crise político-econômica brasileira e as respectivas medidas de austeridade adotadas pelo governo será realizada ao final do próximo capítulo, quando então as lições do artigo de Santos serão retomadas. No entanto, cabe aqui, desde já, reproduzir sua crítica ao atual Ministro da Saúde, Sr. Ricardo Barros, o qual, no $1^{\circ}$ semestre do ano de 2016, anunciou à imprensa que seria preciso rever o tamanho do SUS, tendo apresentado como solução para sair da crise a criação de 'planos acessíveis' ao custo de R \$ 80,00 (oitenta reais) mensais ao consumidor. Ademais, a Agência Nacional de Saúde estaria estudando um projeto de diminuição dos preços mensais dos planos de saúde, na mesma linha da reforma promovida nos Estados Unidos conhecida por Obamacare. Santos eloquentemente afirma que tais propostas fazem "parte de um sistema de saúde e de políticas públicas que fortalece $[\mathrm{m}]$ o setor privado, aumenta[m] a fragmentação do sistema, não alivia [m] do (sic) SUS e não serve[m] para sociedade alguma ${ }^{202}$.

\footnotetext{
201 SANTOS; UGÁ; PORTO, O mix público-privado no Sistema de Saúde Brasileiro: financiamento, oferta e utilização de serviços de saúde, p. 1438.

${ }^{202}$ SANTOS, Isabela Soares, A solução para o SUS não é um Brazilcare, Revista Eletrônica de Comunicação, Informação e Inovação em Saúde, v. 10, n. 3, 2016, p. 3-4.
} 
Nessa linha, tem-se ainda que atualmente tramita no Congresso Nacional o Projeto de Lei número 7.419/2006, com diversos aditivos ${ }^{203}$, visando a alterar a Lei n. 9.656/98, que dispõe sobre os planos e seguros privados de assistência à saúde. Segundo Bruno Miragem, a tramitação deste projeto no Congresso tem se dado de forma célere e sem a participação efetiva das entidades representativas dos interesses dos consumidores dos planos e seguros, fato que preocupa a comunidade jurídica ${ }^{204}$. Com efeito, o projeto tramita na Câmara dos Deputados sob regime de urgência e, dentre os debates, muitos direitos dos consumidores são deixados de lado em nome de um suposto "alívio" do SUS. Por todos os motivos já expostos até aqui, o risco que esta possível reforma apresenta para a eficiência do sistema e, sobretudo, para a efetiva proteção dos indivíduos mais vulneráveis, é patente.

A Associação Nacional do Ministério Público de Defesa da Saúde AMPASA - resume de forma escorreita aquilo que considera ser o cerne do problema do financiamento do SUS:

Todas as ações que geraram e aprofundaram o sub-financiamento do SUS e ampliaram os subsídios aos planos privados foram capitaneadas pelos ministérios da Fazenda, da Casa Civil e do Planejamento, Orçamento e Gestão. Essa tríade, ao longo dos últimos 25 anos, mantém-se reticente a ampliar os recursos para políticas pró-cidadania e para o cumprimento da Constituição. Sempre com base na mesma argumentação tradicional e economicista ortodoxa: responsabilidade fiscal e falta de recursos ${ }^{205}$.

Feita esta digressão, pretende-se no presente e no próximo capítulos avaliar formas pelas quais o Estado brasileiro provoca o sucateamento do SUS, mantendo esta segregação do sistema público. As crônicas dificuldades no financiamento da saúde pública, fruto de decisões políticas pouco interessadas na proteção deste direito fundamental provocam, em última instância, a valorização

\footnotetext{
203 PLs ns. 664/2007, 1220/2007, 69/2015, 1272/2015, 1564/2015, 1948/2015, 1992/2015, 2582/2015, 3223/2015, 4113/2015, 4477/2016, 4478/2016, 5069/2016 e 5779/2016. Em 12/07/2017 foi aprovado pela Comissão Especial destinada a proferir parecer ao PL o requerimento de realização de Audiência Pública para debater os reajustes de mensalidades dos Planos Privados de Assistência à Saúde Coletivos.

${ }^{204}$ MIRAGEM, Bruno, Reforma da lei dos planos de saúde não pode vulnerar consumidor, Consultor Jurídico, 2017.

${ }^{205}$ ASSOCIAÇÃO NACIONAL DO MINISTÉRIO PÚBLICO EM DEFESA DA SAÚDE, AMPASA assina nota conjunta em favor do Saúde +10 e contra o subfinanciamento da saúde, [s.l.: s.n., s.d.].
} 
dos planos e seguros privados e a preservação da iniquidade que a duplicidade de redes representa.

Entende-se que uma análise crítica do modelo de financiamento do SUS, nos pontos mais suscetíveis a mudanças dentro do cenário político-econômico brasileiro de curto e médio prazo, pode colaborar de forma pragmática para pensar o sistema como um todo e em possíveis formas de torna-lo mais eficiente, equitativo e sustentável.

\section{3}

\section{A destinação de recursos à saúde pública no Brasil}

A partir da inovação contida nos arts. $6^{\circ}$ e 196 da Constituição de 1988, que alçou a saúde a direito social fundamental pertencente a todos, cabendo ao Estado sua garantia por intermédio de políticas públicas tanto preventivas quanto curativas, o Brasil foi obrigado a reformular substancialmente a sua política sanitária.

A mais notória transformação consistiu na implementação do sistema nacional de saúde, de caráter universal, financiado por recursos de arrecadação tributária. No presente capítulo desta dissertação será discutida tal alteração, buscando-se enfrentar aspectos deste novo regime de financiamento do sistema de saúde brasileiro, que deixou de ser de natureza securitária passando a adotar o modelo de tributação universal ${ }^{206}$.

Melamed chama a atenção para outra mudança significativa a partir da promulgação da Carta de 1988, qual seja, a nova definição do direito à saúde, que deixou de ter um aspecto exclusivamente biológico (estado de não-doença) para ganhar um aspecto social. A Constituição faz referência não apenas às ações preventivas e curativas mas também às políticas econômicas e sociais que determinam e condicionam os aspectos do bem-estar: alimentação, moradia, saneamento básico, meio ambiente, transporte, trabalho, renda, lazer, educação etc. ${ }^{207}$ Apesar da importância desta inovação, o alcance do estudo proposto nesta

\footnotetext{
${ }^{206}$ O próximo capítulo se dedica ao tema da organização descentralizada deste sistema, também uma inovação bastante relevante promovida pela CRFB/88.

207 MELAMED, Regulamentação, Produção de Serviços e Financiamento Federal do Sistema Único de Saúde: dos anos 90 aos 2000, p. 62.
} 
dissertação se circunscreve ao sistema de saúde brasileiro, sendo certo que, conforme já delineado no primeiro capítulo, a amplitude da definição de saúde não se confunde com as limitadas funções de um sistema de saúde. Piola et al, em trabalho sobre o sistema de saúde brasileiro, afirmam que

Com o objetivo de garantir que os cidadãos disponham de condições de vida saudáveis, dever-se-ia, adicionalmente, envidar esforços coordenados no âmbito do Estado, articulando-se a política de saúde com outras políticas públicas educação, saneamento, habitação adequada, acesso a alimentos etc. Um sistema que se valha de sua dimensão e potencialidade econômica, atuando de forma articulada com as políticas de educação, desenvolvimento científico e tecnológico e a política industrial, de modo a assegurar a disponibilidade de recursos humanos adequadamente capacitados, insumos, medicamentos e equipamentos.

O desempenho dos serviços de saúde tem forte relação com os determinantes sociais das condições de saúde, que definem, em última instância, as necessidades a serem atendidas. Não obstante, a face mais visível do sistema, sobre a qual incidem mais claramente as demandas, é a oferta de atenção à saúde ${ }^{208}$.

Feita (mais uma vez) tal ressalva, o foco da análise aqui proposta retorna apenas aos aspectos do sistema de saúde brasileiro, sem se preocupar com as demais políticas públicas, ainda que elas venham a influenciar o estado de saúde do brasileiro. Mais especificamente ainda, repita-se que o presente trabalho visa a enfrentar apenas as questões relativas ao financiamento do mencionado sistema. Para tanto, relembre-se que a atividade de financiar não se restringe à arrecadação de recursos, abrangendo também a gestão e a alocação de forma planejada dos recursos arrecadados. É sobre tal assunto que o presente e o próximo capítulos se atêm, procurando demonstrar as deficiências do financiamento da saúde no Brasil, as quais provocam tantas carências no sistema, notadamente no aspecto do acesso à assistência.

Entender a organização do financiamento do SUS é tarefa particularmente importante porque, conforme pontuado no segundo capítulo, o reconhecimento de direitos não mais prescinde do cálculo relativo a quanto isso custa para o indivíduo, para a sociedade e para o Estado. Nenhum direito é gratuito.

Com efeito, a teoria dos custos dos direitos de Holmes e Sunstein ${ }^{209}$ demonstra que qualquer espécie de direito exige uma prestação por parte do

\footnotetext{
${ }^{208}$ PIOLA et al, Vinte anos da Constituição de 1988: o que significaram para a saúde da população brasileira?, p. 163.

${ }^{209}$ HOLMES; SUNSTEIN, The Cost of Rights - Why Liberty Depends on Taxes.
} 
Estado (ou por parte de terceiros, na linha de Globekner ${ }^{210}$ ), bem como que o custo relativo a tal prestação compõe a própria definição do direito. Segundo esta nova visão, não é mais possível defender a ideia de que direitos podem existir independentemente da garantia de seu gozo por seus titulares.

Ademais, relembre-se que um dos maiores desafios do profissional da área jurídica no mundo contemporâneo tem sido o da conciliação da realidade jurídica com a realidade político-econômica. É por esse motivo que conhecimentos sobre Direito Financeiro e sobre o manejo de orçamentos (sobretudo os públicos) ganham cada vez mais relevância no horizonte de quem pretende se aprofundar nos espectros da Justiça e da norma. Essa área do saber, estudada à luz dos preceitos constitucionais, pode ser a grande aliada das desejadas transformações sociais no campo sanitário. A seguir, será investigado se os gestores públicos brasileiros, no manejo do orçamento da seguridade social, têm observado - ou não - essas novas orientações doutrinárias.

\subsection{1 \\ O rateio da saúde dentro do orçamento da seguridade social}

A Constituição de 1988 optou por reunir os orçamentos das ações de saúde, assistência e previdência dentro de um único bloco, o da seguridade social $^{211}$. Sob a ótica estritamente conceitual, tal escolha política de reunir estas três espécies de ações governamentais é compreensível, na medida em que tanto saúde quanto assistência e previdência, em última análise, pretendem promover a segurança financeira e o bem-estar integral do indivíduo ${ }^{212}$.

\footnotetext{
${ }^{210}$ GLOBEKner, A Saúde entre o Público e o Privado: o desafio da alocação social dos recursos sanitários escassos, p. 66 Vide nota de rodapé número 104.

211 Art. 194. A seguridade social compreende um conjunto integrado de ações de iniciativa dos Poderes Públicos e da sociedade, destinadas a assegurar os direitos relativos à saúde, à previdência e à assistência social.

${ }^{212}$ Não se ignora a crítica do movimento sanitarista a esta solução, mencionada por Delgado et al: "Esse novo formato dado ao título da Seguridade Social causou surpresa. Se a integração das políticas de previdência e de assistência já vinha sendo esboçada, o mesmo não ocorria na área de saúde. Sua inserção no Sistema amplo da Seguridade, ao lado da Previdência e da Assistência social, era uma ideia surpreendentemente nova para os militantes do movimento sanitário; tal conformação institucional das políticas de bem-estar jamais havia sido cogitada ao longo das discussões que levaram à formulação do marco doutrinário que foi compilado por ocasião da VIII Conferência Nacional de Saúde. Ao contrário, no âmbito deste movimento, buscava-se ampliação da autonomia da política pública de saúde, incluindo a reserva de um orçamento específico, vinculado percentualmente ao orçamento da União". Delgado, G et al apud PINTO,
} 
Do ponto de vista pragmático, todavia, tal reunião, sem que tivesse sido estabelecida uma mínima reserva orçamentária para cada área, veio a prejudicar a saúde, que passou a disputar recursos com a previdência e a assistência, setores com maior apelo orçamentário.

Com efeito, as ações de assistência social tradicionalmente servem aos governos (especialmente os mais populistas) como meio de propaganda das suas ações para as classes menos favorecidas. As ações assistencialistas são vistas por gestores públicos como um modo de conquistar eleitores de baixa renda para futuras candidaturas a cargos políticos.

Por sua vez, no que diz respeito à previdência social, esta atividade do governo ganha tratamento privilegiado por possuir natureza contributiva. As exigências de fontes próprias de custeio para a previdência são naturalmente mais peremptórias, sob a alegação do risco deste sistema tornar-se deficitário ou até mesmo de entrar em colapso. São crescentes as necessidades de custeio da previdência e frequentes os calotes a esse sistema ${ }^{213}$.

Levando isso em conta, a reunião das áreas de saúde, assistência e previdência dentro de um único bloco orçamentário trouxe inegáveis prejuízos para o financiamento do setor da saúde, sempre visto como menos relevante (ou, no mínimo, menos carente) do que os demais. Vianna corrobora que "ao se integrar à previdência e à assistência social, o SUS entrou em uma competição que lhe é desfavorável"214.

A autora Élida Pinto, tomando por base estudo realizado por Sonia Fleury, esclareceu que a edição das leis 8.080/90, 8.142/90, 8.114/90, 8.212/91, 8.213/91e 8.742/93, que formam um microssistema de proteção social regulamentando o art. 194 da Constituição, “apenas acirrou o processo competitivo por fontes seguras de financiamento entre os direitos fundamentais à saúde, à previdência e à

Financiamento dos direitos à saúde e à educação: uma perspectiva constitucional, p. 96. Segundo Gomes, a inclusão da saúde no orçamento da seguridade foi influenciada pelo Ministério da Previdência Social: "O argumento relacionou-se à obtenção de tratamento diferenciado para o financiamento da seguridade, o que não ocorreria se houvesse sido dado um tratamento separado para a obtenção de recursos para a previdência, saúde e assistência social" GOMES, Impasses no financiamento da saúde no Brasil: da constituinte à regulamentação da emenda 29/00, p. 7 .

${ }^{213}$ PINTO, Financiamento dos direitos à saúde e à educação: uma perspectiva constitucional, p. 88-89.

${ }^{214}$ VIANNA, Solon Magalhães, A Seguridade Social, o Sistema Único de Saúde e a Partilha de Recursos, Revista Saúde e Sociedade, v. 1, n. 1, p. 43-58, 1992, p. 46-47. 
assistência social que formam o tripé da seguridade”. Nas palavras da autora, o processo de reunir os três sistemas em um esquema solidário de financiamento, "ao invés de integrar, revelou-se deveras segregador"215. Adicionalmente, as Leis 8.080/90 e 8.142/90 foram promulgadas com diversos vetos pelo presidente Collor aos artigos que tratavam do financiamento da saúde ${ }^{216}$.

Conscientes das dificuldades acima apontadas, os constituintes originários instituíram uma regra provisória no art. 55 do Ato das Disposições Constitucionais Transitórias - ADCT, prevendo uma reserva de 30\% do orçamento da seguridade social para a área da saúde, até que fosse aprovada a lei de diretrizes orçamentárias ${ }^{217}$. O marco temporal imposto acabou ferindo de morte a intenção constituinte. Segundo leciona Vianna, citando Azeredo e Lobo, tal percentual deveria ter sido aplicado ao menos no ano de 1989, mas efetivamente isso não aconteceu, tampouco nos anos seguintes ${ }^{218,219}$.

As leis de diretrizes orçamentárias (LDOs) para os orçamentos de 1990 e 1991 não repetiram esta regra de vinculação (segundo Melamed, o governo Collor diminuiu os investimentos em saúde por motivos diversos ${ }^{220}$ ). No ano de 1992 o percentual só foi alcançado porque foram contabilizados variados gastos que tradicionalmente não deveriam ser classificados como ações e serviços de saúde $^{221}$. A partir de então, a distribuição de recursos do orçamento da seguridade

\footnotetext{
${ }^{215}$ PINTO, Financiamento dos direitos à saúde e à educação: uma perspectiva constitucional, p. 90.

${ }^{216}$ FALEIROS et al, A Construção do SUS: Histórias da Reforma Sanitária e do Processo Participativo, p. 116-117.

${ }^{217}$ Art. 55. Até que seja aprovada a lei de diretrizes orçamentárias, trinta por cento, no mínimo, do orçamento da seguridade social, excluído o seguro-desemprego, serão destinados ao setor de saúde.

${ }^{218}$ VIANNA, A Seguridade Social, o Sistema Único de Saúde e a Partilha de Recursos, p. 49-51.

${ }^{219}$ Segundo Melamed, o percentual de 30\% deveria ser aplicado "enquanto não fosse aprovada a Lei Orgânica da Saúde", no entanto não há qualquer justificativa para tal posicionamento da autora. MELAMED, Regulamentação, Produção de Serviços e Financiamento Federal do Sistema Único de Saúde: dos anos 90 aos 2000, p. 63.

${ }^{220}$ Ibid., p. 64. Para detalhes sobre os motivos da diminuição dos investimentos em saúde na era Collor, leia-se FALEIROS et al, A Construção do SUS: Histórias da Reforma Sanitária e do Processo Participativo, p. 113-122.

${ }^{221}$ Britto apud VIANNA, A Seguridade Social, o Sistema Único de Saúde e a Partilha de Recursos, p. 49-51. Saliente-se ainda que, até 1999, a Secretaria do Tesouro Nacional apresentava as despesas da União na função saúde sob a rubrica "saúde e saneamento", conforme explica em nota Faleiros et al. FALEIROS et al, A Construção do SUS: Histórias da Reforma Sanitária e do Processo Participativo, p. 205.
} 
social foi realizada não mais com base em percentuais da arrecadação, mas sim com base em fontes de arrecadação ${ }^{222,223}$.

O ano de 1993 foi, segundo Médici, o da pior crise financeira do setor em toda a década de 1990, pois a LDO previa a destinação de um percentual da Contribuição sobre a Folha de Salários (art. 195, I, $a$, CF/88) para o financiamento da saúde, mas compromissos com a previdência impediram o seu cumprimento ${ }^{224}$. Segundo Faleiros et al, nesse ano de 1993 os gastos da saúde também sofreram a sombra da corrupção, tendo sido instalada uma CPI no ano de 1994 com o intuito de apurar irregularidades no INAMPS, que ainda não havia sido extinto ${ }^{225}$.

Élida Pinto explica que essa verdadeira guerra entre as três áreas do governo (saúde, previdência e assistência social) se justifica não apenas pelo contexto político desfavorável (a década de 1990 foi marcada pela busca do crescimento econômico, da estabilização da moeda, da diminuição do papel do Estado... em suma, pelos programas caracteristicamente neoliberais) mas também pela excessiva expansão de contribuições sociais instituídas para financiamento da seguridade social, com fulcro no art. 195, que originalmente permitia a especialização das fontes de financiamento, uma prática predatória, nas palavras da própria autora, pois deixava cada área à mercê desta barganha por uma fonte vinculada e que poderia ser extinta a qualquer momento ${ }^{226}$. Este foi exatamente o caso da instituição da Contribuição Provisória sobre Movimentação Financeira CPMF, em 1996.

A situação aqui retratada só veio a ser amenizada a partir da EC 29/00, a qual finalmente estabeleceu uma cota mínima vinculada à saúde. Segundo

\footnotetext{
${ }^{222}$ MELAMED, Regulamentação, Produção de Serviços e Financiamento Federal do Sistema Único de Saúde: dos anos 90 aos 2000, p. 64.

${ }^{223}$ A instituição da Contribuição Provisória sobre Movimentação Financeira (CPMF), em 1996, serviu não para efetivamente incrementar a arrecadação para a área da saúde - conforme propagandeava o governo que a instituiu - mas sim para resolver o problema da insuficiência de investimento federal, regularizando o aporte de recursos que, segundo dados financeiros do governo, era inferior ao previsto no art. 55 do ADCT. SERVO, Luciana Mendes Santos et al, Financiamento e Gasto Público de Saúde: histórico e tendências, in: MELAMED, Clarice; PIOLA, Sérgio Francisco (Orgs.), Políticas Públicas e Financiamento Federal do Sistema Único de Saúde, Brasilia: Ipea, 2011, p. 87-90.

${ }_{224}$ Médici apud MELAMED, Regulamentação, Produção de Serviços e Financiamento Federal do Sistema Único de Saúde: dos anos 90 aos 2000, p. 65.

${ }^{225}$ FALEIROS et al, A Construção do SUS: Histórias da Reforma Sanitária e do Processo Participativo, p. 126.

${ }^{226}$ PINTO, Financiamento dos direitos à saúde e à educação: uma perspectiva constitucional, p. $92-93$.
} 
Faleiros et al, durante o governo do presidente Fernando Henrique Cardoso (1995-2002),

A saúde, no entanto, foi eleita para ser um lócus de promoção do candidato governamental ao posto de Presidente da República, senador José Serra, merecendo, assim, uma maior atenção e até servindo como palco de divergências entre o "desenvolvimentista" José Serra e o "monetarista" Pedro Malan, ministro da Fazenda

O principal destaque da área foi a aprovação da Emenda Constitucional n. 29, de 13 de setembro de 2000, que estabeleceu mecanismos de financiamento da saúde, com vinculação orçamentária para a área e correção dos valores de acordo com a variação nominal do PIB, conforme Resolução n. 322, do Conselho Nacional de Saúde, de 8 de maio de $2003^{227}$.

De fato, a EC 29/00 teve o mérito de salvaguardar uma fatia do orçamento da seguridade para a saúde, fazendo aumentar o valor dos investimentos no SUS, especialmente a partir do esforço dos entes subnacionais. No entanto, sua estrutura não está livre de críticas - e são muitas -, as quais serão destrinchadas no item seguinte e no próximo capítulo.

Em conclusão, pode-se constatar que a saúde quase sempre foi uma área preterida pelo governo brasileiro. A promulgação da Constituição de 1988 não foi capaz de solucionar o desprezo por investimentos neste setor. De fato, a EC 29/00 pretendeu proteger as necessidades sanitárias, mas as bases desta norma não foram suficientes para alcançar tal objetivo.

\subsection{2}

\section{Emenda Constitucional 29/00}

\subsubsection{1 \\ Breve histórico}

A EC 29/00 foi promulgada durante o governo do presidente Fernando Henrique Cardoso (1995-2002), um governo reconhecidamente voltado a reestruturar o papel do Estado em favor de uma economia de mercado. Já em 1995 foi instituído o Plano Diretor da Reforma do Aparelho do Estado - PDRE, com

\footnotetext{
${ }^{227}$ FALEIROS et al, A Construção do SUS: Histórias da Reforma Sanitária e do Processo Participativo, p. 165.
} 
contornos nitidamente neoliberais e atendendo a orientações do Fundo Monetário Internacional $^{228}$.

Apesar de ter promovido diversas medidas na área da saúde - como dito, esta área foi selecionada para alavancar a candidatura governista à Presidência da República - a conjuntura FHC teve impacto negativo para o setor, segundo a opinião de técnicos sanitaristas.

Com efeito, depoimentos colhidos por Faleiros et al revelam que, em que pese a implementação de algumas medidas importantes, sobretudo no aspecto da promoção da participação social no SUS, a notável diminuição do papel do Estado durante o governo Fernando Henrique representou um verdadeiro abandono das responsabilidades estatais. Nas palavras de Eliane Aparecida da Cruz, Conselheira Nacional de Saúde nos anos de 2001-2002, FHC “devolveu para a sociedade o papel de cuidar dela própria na área da saúde ${ }^{\text {229. }}$.

Essa situação acarretou uma forte comoção e mobilização social, culminando na vitoriosa aprovação da EC 29/00. Segundo Faleiros et al, a aprovação desta emenda foi fruto de uma longa batalha entre governistas e representantes da sociedade mobilizados por sanitaristas. Nelson Rodrigues dos Santos (Nelsão), médico sanitarista coordenador da Secretaria Executiva do Conselho Nacional de Saúde nos anos de 1997-2002, narrou em depoimento que

\begin{abstract}
'As entidades da sociedade e o Conselho Nacional de Saúde foram muito importantes, não pela mobilização do conselho, que eram 32 conselheiros que não têm maior peso em si, mas esses conselheiros na hora que vão para as suas entidades, mobilizam as centrais sindicais, as entidades nacionais de portadores de deficiências e de patologias, mobilizam a CNBB que está no conselho, os empresários da indústria, da agricultura e do comércio, as entidades por eles representadas, nos corredores do parlamento, aí sai de baixo, tanto que foi aprovada $^{230}$.
\end{abstract}

A vitória da aprovação da EC $29 / 00^{231}$, no entanto, não pode ser considerada absoluta. Apesar de ter efetivamente logrado aumentar o valor dos

\footnotetext{
${ }^{228}$ Ibid., p. 157-158.

${ }^{229}$ Ibid., p. 180.

${ }^{230}$ Ibid., p. 183.

${ }^{231}$ Cabe aqui também a referência à influência do Ministério Público nessa vitória, pois, segundo Faleiros et al, naquele período, "O Ministério Público Federal atua próximo às instâncias de controle social do SUS, participando dos fóruns de debate e propondo inquéritos e ações civis
} 
investimentos na área da saúde, a EC 29/00 não conseguiu reduzir desigualdades regionais nem conferiu a tão esperada estabilidade do financiamento da saúde, uma vez que reservou a futura lei complementar a tarefa de regulamentá-la.

\author{
Segundo Élida Pinto,
}

A despeito do caráter adicional de proteção trazido pela Emenda Constitucional n. 29/2000, que dispôs sobre percentual mínimo de gasto público nas ações e serviços públicos de saúde, e nada obstante as contribuições sociais (que expressam fonte vinculada de receita), a política pública de saúde segue, como dantes, marcada pelo signo da instabilidade fiscal provocada, em larga escala, pela União e replicada pelos estados ${ }^{232}$.

\title{
3.3.2.2
}

\section{EC 29/00 e LC 141/12}

A EC 29/00 alterou, além de outros dispositivos, o art. 198 da Constituição para nele introduzir dois parágrafos - os parágrafos $2^{\circ}$ e $3^{\text {o } 233,234}$ - renumerando o então parágrafo único desse artigo.

públicas". Os depoimentos da então Procuradora Regional da República Raquel Dodge (atual Procuradora Geral da República) ilustram tal participação. Ibid., p. 187-195.

${ }^{232}$ PINTO, Financiamento dos direitos à saúde e à educação: uma perspectiva constitucional, p. 103.

${ }^{233}$ Tais parágrafos foram parcialmente reformados, recentemente, pela Emenda Constitucional $\mathrm{n}$. $86 / 2015$, para mais uma vez modificar o sistema de financiamento no que tange à esfera federal. Esta nova reforma será comentada adiante.

${ }^{234} \S 2^{\circ} \mathrm{A}$ União, os Estados, o Distrito Federal e os Municípios aplicarão, anualmente, em ações e serviços públicos de saúde recursos mínimos derivados da aplicação de percentuais calculados sobre:

I - no caso da União, na forma definida nos termos da lei complementar prevista no $\S 3^{\circ}$

I - no caso da União, a receita corrente líquida do respectivo exercício financeiro, não podendo ser inferior a 15\% (quinze por cento); (Redação dada pela Emenda Constitucional no 86, de 2015)

II - no caso dos Estados e do Distrito Federal, o produto da arrecadação dos impostos a que se refere o art. 155 e dos recursos de que tratam os arts. 157 e 159, inciso I, alínea a, e inciso II, deduzidas as parcelas que forem transferidas aos respectivos Municípios;

III - no caso dos Municípios e do Distrito Federal, o produto da arrecadação dos impostos a que se refere o art. 156 e dos recursos de que tratam os arts. 158 e 159 , inciso I, alínea b e $\S 3^{\circ}$

$\S 3^{\circ}$ Lei complementar, que será reavaliada pelo menos a cada cinco anos, estabelecerá

I- os percentmais de que trata 0 \& $2^{\circ}$;

I - os percentuais de que tratam os incisos II e III do $\S 2^{\circ}$; (Redação dada pela Emenda Constitucional $\mathrm{n}^{\mathrm{o}} 86$, de 2015)

II - os critérios de rateio dos recursos da União vinculados à saúde destinados aos Estados, ao Distrito Federal e aos Municípios, e dos Estados destinados a seus respectivos Municípios, objetivando a progressiva redução das disparidades regionais;

III - as normas de fiscalização, avaliação e controle das despesas com saúde nas esferas federal, estadual, distrital e municipal;

IV as normas de cáleulo do montante a ser aplicado pela União

IV - (revogado). (Redação dada pela Emenda Constitucional nº 86, de 2015) 
Tais dispositivos previram a vinculação de uma fatia das receitas de impostos dos três entes federativos à saúde ${ }^{235}$. Trata-se, como dito, de uma vitória dos movimentos sociais e sanitários, mas que foi bastante enfraquecida pelo fato de que o parágrafo $3^{\circ}$ do art. 198 da Constituição delegou a futura lei complementar a tarefa de definir o tamanho desta fatia.

No intuito de preencher esta lacuna legislativa, a EC 29/00 previu regra provisória, introduzindo o art. 77 do ADCT, que deveria viger até fosse editada a legislação regulamentadora ${ }^{236,237}$. A provisoriedade desta norma, por si só, era situação que gerava extrema instabilidade, pelo simples fato de impedir qualquer planejamento de longo prazo. Nenhum gestor (responsável) poderia realizar um investimento muito amplo e visando a benefícios futuros porque ele não poderia

\footnotetext{
${ }^{235}$ Trata-se de uma exceção à regra da não-vinculação da receita de impostos, exceção criada pela própria EC 29/00, por intermédio da alteração do art. 167 da Constituição.

${ }^{236}$ Art. 77. Até o exercício financeiro de 2004, os recursos mínimos aplicados nas ações e serviços públicos de saúde serão equivalentes:

I - no caso da União:

a) no ano 2000, o montante empenhado em ações e serviços públicos de saúde no exercício financeiro de 1999 acrescido de, no mínimo, cinco por cento;

b) do ano 2001 ao ano 2004, o valor apurado no ano anterior, corrigido pela variação nominal do Produto Interno Bruto - PIB;

II - no caso dos Estados e do Distrito Federal, doze por cento do produto da arrecadação dos impostos a que se refere o art. 155 e dos recursos de que tratam os arts. 157 e 159, inciso I, alínea a, e inciso II, deduzidas as parcelas que forem transferidas aos respectivos Municípios; e

III - no caso dos Municípios e do Distrito Federal, quinze por cento do produto da arrecadação dos impostos a que se refere o art. 156 e dos recursos de que tratam os arts. 158 e 159, inciso I, alínea b e $\S 3^{\circ}$.

$\S 1^{\circ}$ Os Estados, o Distrito Federal e os Municípios que apliquem percentuais inferiores aos fixados nos incisos II e III deverão elevá-los gradualmente, até o exercício financeiro de 2004, reduzida a diferença à razão de, pelo menos, um quinto por ano, sendo que, a partir de 2000, a aplicação será de pelo menos sete por cento.

$\S 2^{\circ}$ Dos recursos da União apurados nos termos deste artigo, quinze por cento, no mínimo, serão aplicados nos Municípios, segundo o critério populacional, em ações e serviços básicos de saúde, na forma da lei.

$\S 3^{\circ}$ Os recursos dos Estados, do Distrito Federal e dos Municípios destinados às ações e serviços públicos de saúde e os transferidos pela União para a mesma finalidade serão aplicados por meio de Fundo de Saúde que será acompanhado e fiscalizado por Conselho de Saúde, sem prejuízo do disposto no art. 74 da Constituição Federal.

$\S 4^{\circ} \mathrm{Na}$ ausência da lei complementar a que se refere o art. 198 , $\S 3^{\circ}$, a partir do exercício financeiro de 2005, aplicar-se-á à União, aos Estados, ao Distrito Federal e aos Municípios o disposto neste artigo.

237 No capítulo seguinte, ocasião em que serão apresentadas as questões relativas à descentralização do SUS e o seu crônico subfinanciamento por parte do ente federal, será assinalada especificamente a questão do tratamento diferenciado que a EC 29/00 conferiu à União em detrimento dos entes subnacionais - situação até certa forma mitigada por ocasião da promulgação da EC 86/15. Por ora, no presente capítulo, será pontuado apenas como a EC 29/00 reafirmou a instabilidade do financiamento do SUS ao relegar à legislação infraconstitucional a definição do percentual devido por cada ente federativo à saúde
} 
contar com a manutenção daqueles recursos, previstos em norma meramente transitória. É evidente, portanto, que a solução da EC 29/00 não foi satisfatória.

Para piorar, a lei complementar que deveria ter sido editada até 2004 só veio à luz em 2012. Finalmente, após longos 07 anos de atraso, a Lei Complementar 141/2012 (LC 141/12) praticamente repetiu a norma do ADCT, apenas ajustando a base de cálculo do percentual devido pela União (questão objeto de discussão no próximo capítulo).

Na realidade, o principal mérito desta lei foi estabelecer algo que até então não existia em lugar algum: a definição de quais são as despesas que podem ser contabilizadas dentro do percentual dos recursos vinculados à saúde. Em outras palavras, a LC 141/12 definiu o que é - e o que não é - ação e serviço público de saúde, providência esta que revolucionou de certa forma a questão do financiamento da saúde, impedindo que gestores contabilizassem, por exemplo, custos de obras de saneamento básico como se fossem despesas em saúde ${ }^{238}$.

\footnotetext{
238 Art. 3o Observadas as disposições do art. 200 da Constituição Federal, do art. $6^{\circ}$ da Lei $n^{\circ}$ 8.080, de 19 de setembro de 1990, e do art. 2o desta Lei Complementar, para efeito da apuração da aplicação dos recursos mínimos aqui estabelecidos, serão consideradas despesas com ações e serviços públicos de saúde as referentes a:

I - vigilância em saúde, incluindo a epidemiológica e a sanitária;

II - atenção integral e universal à saúde em todos os níveis de complexidade, incluindo assistência terapêutica e recuperação de deficiências nutricionais;

III - capacitação do pessoal de saúde do Sistema Único de Saúde (SUS);

IV - desenvolvimento científico e tecnológico e controle de qualidade promovidos por instituições do SUS;

V - produção, aquisição e distribuição de insumos específicos dos serviços de saúde do SUS, tais como: imunobiológicos, sangue e hemoderivados, medicamentos e equipamentos médicoodontológicos;

VI - saneamento básico de domicílios ou de pequenas comunidades, desde que seja aprovado pelo Conselho de Saúde do ente da Federação financiador da ação e esteja de acordo com as diretrizes das demais determinações previstas nesta Lei Complementar;

VII - saneamento básico dos distritos sanitários especiais indígenas e de comunidades remanescentes de quilombos;

VIII - manejo ambiental vinculado diretamente ao controle de vetores de doenças;

IX - investimento na rede física do SUS, incluindo a execução de obras de recuperação, reforma, ampliação e construção de estabelecimentos públicos de saúde;

$\mathrm{X}$ - remuneração do pessoal ativo da área de saúde em atividade nas ações de que trata este artigo, incluindo os encargos sociais;

XI - ações de apoio administrativo realizadas pelas instituições públicas do SUS e imprescindíveis à execução das ações e serviços públicos de saúde; e

XII - gestão do sistema público de saúde e operação de unidades prestadoras de serviços públicos de saúde.

Art. 4o Não constituirão despesas com ações e serviços públicos de saúde, para fins de apuração dos percentuais mínimos de que trata esta Lei Complementar, aquelas decorrentes de:

I - pagamento de aposentadorias e pensões, inclusive dos servidores da saúde;

II - pessoal ativo da área de saúde quando em atividade alheia à referida área;

III - assistência à saúde que não atenda ao princípio de acesso universal;
} 
Ainda assim, grandes oportunidades foram desperdiçadas por ocasião da promulgação desta lei. A LC 141/12 não tratou eficientemente das transferências federais de recursos, da descentralização do SUS, da sua regionalização etc., questões extremamente importantes. Conforme bem pontuado por Rosa e Grell,

O SUS não é um plano de saúde, mas um sistema. Como sistema tem como doutrina a universalidade, equidade, integralidade. O problema da EC 29 é que não aborda essas doutrinas. As unidades de saúde do País não têm noção de quais serviços são oferecidos, se existe disponibilidade de medicamentos, se o pessoal tem a capacidade necessária, se possuem os equipamentos mínimos para realizar os serviços, se sua operação funciona 24 horas por dia e se a população é atendida ${ }^{239}$.

Não é necessária nenhuma antecipação, todavia. Os temas da descentralização e da regionalização, bem como a questão da dificuldade de relacionamento entre as três esferas federativas, serão tratados no próximo capítulo.

\subsection{3 \\ Da previsão orçamentária anual para a saúde pública: planejamento e execução}

Até aqui foi dito que, após a promulgação da Constituição de 1988, a unificação do orçamento da seguridade social, integrando previdência, saúde e assistência social em um mesmo sistema solidário, gerou excessiva instabilidade ao financiamento do SUS.

IV - merenda escolar e outros programas de alimentação, ainda que executados em unidades do SUS, ressalvando-se o disposto no inciso II do art. 3o;

$\mathrm{V}$ - saneamento básico, inclusive quanto às ações financiadas e mantidas com recursos provenientes de taxas, tarifas ou preços públicos instituídos para essa finalidade;

VI - limpeza urbana e remoção de resíduos;

VII - preservação e correção do meio ambiente, realizadas pelos órgãos de meio ambiente dos entes da Federação ou por entidades não governamentais;

VIII - ações de assistência social;

IX - obras de infraestrutura, ainda que realizadas para beneficiar direta ou indiretamente a rede de saúde; e

$\mathrm{X}$ - ações e serviços públicos de saúde custeados com recursos distintos dos especificados na base de cálculo definida nesta Lei Complementar ou vinculados a fundos específicos distintos daqueles da saúde.

${ }^{239}$ ROSA, Chennyfer D. P. da; GRELL, Armando Pereira, Financiamento da Saúde no Brasil e a Emenda Constitucional n. 29 de 2000, Revista da Faculdade de Ciências Médicas de Sorocaba, v. 17 , n. 1 , p. 51-52, 2015, p. 52. 
Também foi salientado que a promulgação da EC 29/00 - e sua regulamentação pela LC 141/12 - foi uma mudança necessária, estabelecendo uma vinculação de gasto mínimo nas ações e serviços públicos de saúde. Esta segregação setorial foi um importante marco para o SUS, porém insuficiente, deixando a desejar em diversos aspectos pontuados no item anterior.

No presente subitem será tratado um tema que, diferente dos até aqui suscitados, aflige não apenas o setor da saúde porém todas as políticas públicas que tenham por objetivo a implementação de serviços públicos. Pretende-se discutir de que forma os governos brasileiros, nas três esferas federativas, utilizam indevidamente os seus instrumentos orçamentários, permanecendo insistentemente omissos nas suas obrigações de planejar eficientemente as suas ações, dentre elas as de saúde.

A elaboração de um orçamento público consiste na tarefa de prever receitas e estimar as despesas a serem realizadas ao longo do exercício seguinte ${ }^{240}$. Tal tarefa tem por escopo contemporizar interesses divergentes, unindo em um mesmo instrumento normativo perspectivas de diferentes grupos sociais. $\mathrm{O}$ caráter plural da sociedade torna a tarefa de compor o orçamento anual indubitavelmente complicada, mas os mecanismos democráticos previstos tanto na Constituição quanto na Lei $4.320 / 64^{241}$ facilitam o caminho e deveriam impedir a malversação do orçamento pelo gestor mal intencionado.

Diz-se que 'deveriam' impedir a malversação porque, no que diz respeito à disputa por quinhões do orçamento, o embate supostamente democrático entre propensões opostas pode não ser tão equânime quanto se espera, resultando em possível prejuízo a grupos com menos poder no jogo político. Por exemplo, como visto, ao longo de muitos anos a saúde perdeu esse embate para a previdência e a

${ }^{240}$ CRFB/88 Art. 165. Leis de iniciativa do Poder Executivo estabelecerão: I - o plano plurianual; II - as diretrizes orçamentárias; III - os orçamentos anuais. (...) $\S 5^{\circ}$ A lei orçamentária anual compreenderá: I - o orçamento fiscal referente aos Poderes da União, seus fundos, órgãos e entidades da administração direta e indireta, inclusive fundações instituídas e mantidas pelo Poder Público; II - o orçamento de investimento das empresas em que a União, direta ou indiretamente, detenha a maioria do capital social com direito a voto; III - o orçamento da seguridade social, abrangendo todas as entidades e órgãos a ela vinculados, da administração direta ou indireta, bem como os fundos e fundações instituídos e mantidos pelo Poder Público.

Lei 4.320/64, Art. $2^{\circ}$ A Lei do Orçamento conterá a discriminação da receita e despesa de forma a evidenciar a política econômica financeira e o programa de trabalho do Govêrno, obedecidos os princípios de unidade universalidade e anualidade

${ }^{241}$ Estatui normas gerais de Direito Financeiro para elaboração e controle dos orçamentos e balanços da União, dos Estados, dos Municípios e do Distrito Federal 
assistência social, sendo este o motivo pelo qual necessitou de uma reforma constitucional (EC 29/00) que lhe garantisse um quinhão pré-fixado no orçamento anual de cada ente.

Mas não é só. Lamentavelmente, a reserva orçamentária estabelecida pela EC 29/00 e pela LC 141/12 não foram suficientes para garantir que o dinheiro destinado à saúde fosse alocado de forma bem planejada e eficiente. Pelo contrário. O orçamento público no Brasil sofre uma tradicional manobra de sabotagem por conta do entendimento de que a sua natureza é meramente autorizativa. Em suma, compreende-se que as despesas que são estimadas no orçamento anual consistem em uma mera proposta do governo e, como tal, não vinculam o gestor público, contendo apenas uma autorização para que ele gaste o valor ali previsto. À luz deste entendimento, ao longo do exercício financeiro, por ocasião da execução orçamentária, ajustes (contingenciamentos) podem ser realizados, bastando apenas que o ato seja justificado, tudo com base nas normas dispostas na Lei $4.320 / 64^{242}$.

Ocorre que, por conta desta possibilidade, que deve ser considerada verdadeira "brecha legal", as leis orçamentárias brasileiras são utilizadas por ímpios gestores como instrumento político para incluírem em lei promessas de campanha que sabem previamente serem impossíveis de cumprimento futuro. Explica-se. A lei orçamentária anual é elaborada de forma "simbólica", o que significa dizer que os valores estimados são fictícios, um embuste criado para encobrir a real situação do governo. Posteriormente, ultrapassado o interesse midiático e popular nas promessas de governo, os ajustes à realidade são feitos mediante inúmeros cortes nas ações "planejadas" que não contam com lastro financeiro para serem implementadas.

Não é necessário alongar a descrição das nefastas consequências desta prática. Basta lembrar que qualquer política pública, para que seja bem sucedida, depende de planejamento e continuidade, duas precauções que são absolutamente inviabilizadas pela carência de orçamento anual genuíno e autêntico.

Segundo Élida Pinto,

\footnotetext{
${ }^{242}$ ABRAHAM, Marcus, O orçamento impositivo: uma alternativa possível ao paternalismo judicial, in: RÊGO, Werson (Org.), Segurança Jurídica e Protagonismos Judicial: desafios em tempos de incertezas, Rio de Janeiro: GZ Editora, 2017, p. 672.
} 
A execução cotidiana das políticas públicas definidas nas leis orçamentárias é frágil e instável não porque falte formalmente legalidade e publicidade ao seu regime jurídico. O problema é que, material e pragmaticamente, as leis orçamentárias são, sobretudo, "simbólicas", no sentido propugnado por Neves (2007). Essa nos parece ser a razão pela qual a execução orçamentária de todos os níveis da federação se ressente da falta de motivação, razoabilidade e finalidade para evitar, conter e punir a ocorrência de abusos ${ }^{243}$.

Diante de tal problemática, autores - sobretudo os menos conservadores propõem um novo olhar a respeito do Direito Financeiro e Orçamentário, para interpretá-lo à luz dos princípios constitucionais, especialmente os princípios da Administração Pública insculpidos no art. 37 da CRFB $/ 88^{244}$. Tais autores defendem, inclusive, a possibilidade de sindicabilidade dos orçamentos públicos por parte do Poder Judiciário.

Trata-se de uma verdadeira revisitação do Direito Financeiro e Orçamentário, à luz dos princípios constitucionais, na linha do chamado neoconstitucionalismo, o qual coloca a Carta Constitucional como centro do ordenamento $^{245}$, buscando maior transparência na relação entre o Estado e a sociedade e, ao final das contas, mais justiça social.

Élida Pinto defende que

Em necessária releitura da tradicional autocontenção judicial que, em respeito à separação de poderes, evita decisões de intensivo e amplo impacto no orçamento público, é preciso - cada vez mais - reconhecer que a aludida omissão estatal não só é "insuportável insulto" (a que se referiu o Ministro Celso de Mello), mas, sobretudo, é ato juridicamente nulo e inconstitucional.

Daí porque emerge o controle judicial do ciclo orçamentário como exigência de coerência do sistema jurídico. Se o único modo constitucionalmente adequado e legítimo de alocar os recursos públicos no Brasil passa pela natureza normativa das leis de plano plurianual, diretrizes orçamentárias e orçamento anual, a execução de tais leis não pode desbordar dos limites legais, nem frustrar aquela

\footnotetext{
${ }^{243}$ PINTO, Financiamento dos direitos à saúde e à educação: uma perspectiva constitucional, p. 23.

244 Art. 37. A administração pública direta e indireta de qualquer dos Poderes da União, dos Estados, do Distrito Federal e dos Municípios obedecerá aos princípios de legalidade, impessoalidade, moralidade, publicidade e eficiência e, também, ao seguinte

${ }^{245}$ Importante notar que, recentemente, o Direito Privado passou por larga revisitação a partir dos paradigmas do neoconstitucionalismo, no movimento que ficou conhecido como a "Constitucionalização do Direito Civil". Sobre o neoconstitucionalismo, BARCELLOS, Ana Paula de, Neoconstitucionalismo, direitos fundamentais e controle das políticas públicas., in: QUARESMA, Regina; OLIVEIRA, Maria Lucia de Paula; OLIVEIRA, Farlei Martins Riccio de (Orgs.), Neoconstitucionalismo, Rio de Janeiro: Forense, 2009.
} 
normatividade, impondo-lhe mero sentido retórico, como, aliás, já suscitado pelo Prof. Ingo Sarlet no Prefácio deste livro ${ }^{246}$.

Vale aqui mencionar o julgamento da ADPF n. 347 MC/DF pelo Supremo Tribunal Federal em que esta Corte apontou para a possibilidade de judicialização da questão orçamentária quando recursos legalmente previstos são contingenciados para alcançar metas fiscais, em detrimento da garantia de direitos fundamentais $^{247}$.

${ }^{246}$ PINTO, Financiamento dos direitos à saúde e à educação: uma perspectiva constitucional, p. 22.

247 “O Partido Socialismo e Liberdade - PSOL busca, por meio de arguição de descumprimento de preceito fundamental, com pedido de medida liminar, seja reconhecida a figura do "estado de coisas inconstitucional" relativamente ao sistema penitenciário brasileiro e a adoção de providências estruturais em face de lesões a preceitos fundamentais dos presos, que alega decorrerem de ações e omissões dos Poderes Públicos da União, dos Estados e do Distrito Federal.

O último pedido diz respeito a escolha orçamentária da União e volta-se à imediata liberação das verbas do Fundo Penitenciário Nacional - FUNPEN e à proibição de a União realizar novos contingenciamentos.

O Fundo foi criado pela Lei Complementar $\mathrm{n}^{\circ} 79$, de 1994, sendo destinado, segundo a cabeça do artigo $1^{\circ}$, a "proporcionar recursos e meios para financiar e apoiar as atividades e programas de modernização e aprimoramento do Sistema Penitenciário Brasileiro". A gestão desses recursos cabe ao Departamento Penitenciário Nacional - DEPEN.

Narra-se que esses valores têm sido, desde a criação do Fundo, muito mal aplicados. Relatórios do próprio Departamento dão conta de que a maior parte é contingenciada ou, simplesmente, não utilizada. Para o ano de 2013, por exemplo, a dotação foi de $\mathrm{R} \$ 384,2$ milhões, tendo sido empenhados R \$333,4 milhões. Todavia, apenas R \$ 73,6 milhões foram usados: R \$ 40,7 milhões do orçamento do ano e R $\$ 32,8$ milhões de restos a pagar. Isso significa que mais de $80 \%$ dos valores deixaram de ser utilizados. De acordo com a organização Contas Abertas, o saldo contábil do Fundo, no ano de 2013, chegou a R \$ 1,8 bilhão. Segundo o requerente, ao fim de 2014, o saldo já era de $R \$ 2,2$ bilhões.

A situação levou a senadora Ana Amélia, do Rio Grande do Sul, a apresentar projeto de lei complementar - PLS ${ }^{\circ} 25$, de 2014 - voltado a proibir o contingenciamento, versado de forma genérica na Lei de Responsabilidade Fiscal, dos recursos do mencionado Fundo. Em um dos raros exemplos de preocupação de um agente político com o ocaso do sistema penitenciário brasileiro outro é a própria formalização desta arguição por partido político -, a parlamentar justifica a proposta na necessidade de serem criados meios de garantir "a segurança da população, ao mesmo tempo em que se possibilite a reinserção social daqueles que um dia cometeram um erro".

Não obstante a iniciativa, o que revela tentativa interna de ultrapassar os bloqueios políticos existentes no Congresso, a situação dramática não pode esperar o fim da deliberação legislativa. Protocolado em 6 de fevereiro de 2014, o projeto, sem parecer, encontra-se na Comissão de Constituição, Justiça e Cidadania do Senado, aguardando a designação de novo relator. A existência de propostas legislativas não significa deliberação e decisão política sobre o tema.

A violação da dignidade da pessoa humana e do mínimo existencial autoriza a judicialização do orçamento, sobretudo se considerado o fato de que recursos legalmente previstos para o combate a esse quadro vêm sendo contingenciados, anualmente, em valores muito superiores aos efetivamente realizados, apenas para alcançar metas fiscais. Essa prática explica parte do fracasso das políticas públicas existentes. Como assevera o professor Eduardo Bastos de Mendonça, "políticas públicas são definidas concretamente na lei orçamentária, em função das possibilidades financeiras do Estado", de forma que "a retenção de verbas tende a produzir, na melhor das hipóteses, programas menos abrangentes". Segundo o autor, a medida mostra-se ainda mais problemática tendo em conta "que os cortes têm atingido programas relacionados a áreas em que, 
Marcus Abraham propõe, como via alternativa, o instrumento do orçamento impositivo. Segundo leciona o autor, a natureza autorizativa da lei orçamentária vem sendo cada vez mais questionada no que tange às despesas constitucionalmente delimitadas (despesas vinculadas), tais como as despesas em saúde e educação. Por se tratarem de despesas obrigatórias, vozes doutrinárias passaram a defender a natureza impositiva do orçamento em relação às mesmas. Para Abraham,

O tema do orçamento impositivo merece algumas reflexões. Primeiro, se, por um lado, essa ideia retiraria a flexibilidade de que o administrador público necessita para conduzir sua atividade, mormente pela impossibilidade fática de identificar e prever com antecedência todas as despesas públicas, por outro, resgataria a credibilidade e a importância do orçamento como documento formal de planejamento do governo, que muitas vezes sofre diante dos recorrentes descumprimentos das suas previsões, chegando a ser considerado de forma pejorativa uma simples "carta de intenções".

Há, ainda, aqueles que criticam o modelo autorizativo do orçamento por entenderem haver uma redução de importância no papel do Poder Legislativo nas questões orçamentárias. Justificam a afirmação ao mencionar que o Poder Executivo, além de possuir o poder de veto no orçamento, pode simplesmente não executar determinadas despesas sem ter de submeter a decisão ao debate.

para além de qualquer dúvida, a atuação do Estado tem sido insatisfatória ou insuficiente", como é o caso do sistema penitenciário nacional (MENDONÇA, Eduardo Bastos Furtado de. A Constitucionalização das Finanças Públicas no Brasil. Rio de Janeiro: Renovar, 2010, p. 97-98).

Os valores não utilizados deixam de custear não somente reformas dos presídios ou a construção de novos, mas também projetos de ressocialização que, inclusive, poderiam reduzir o tempo no cárcere. No mais, é de todo duvidosa a possibilidade de limitar despesas dessa natureza ante o disposto no $\S 2^{\circ}$ do artigo $9^{\circ}$ da Lei Complementar $n^{\circ} 101$, de 2000:

Art. $9^{\circ}$. Se verificado, ao final de um bimestre, que a realização da receita poderá não comportar o cumprimento das metas de resultado primário ou nominal estabelecidas no Anexo de Metas Fiscais, os Poderes e o Ministério Público promoverão, por ato próprio e nos montantes necessários, nos trinta dias subseqüentes, limitação de empenho e movimentação financeira, segundo os critérios fixados pela lei de diretrizes orçamentárias.

[...]

$\S 2^{\circ}$. Não serão objeto de limitação as despesas que constituam obrigações constitucionais e legais do ente, inclusive aquelas destinadas ao pagamento do serviço da dívida, e as ressalvadas pela lei de diretrizes orçamentárias.

A cabeça do dispositivo trata da situação em que o Governo deixa de executar, parcialmente, o orçamento, vindo a contingenciar os valores ordenados a despesas, ao passo que, no $\S 2^{\circ}$, consta exceção consideradas obrigações decorrentes de comandos legais e constitucionais. Tratando o Funpen de recursos com destinação legal específica, é inafastável a circunstância de não poderem ser utilizados para satisfazer exigências de contingenciamento: atendimento de passivos contingentes e outros riscos e eventos fiscais imprevistos (artigo $5^{\circ}$, inciso III, alínea "b", da Lei Complementar $\mathrm{n}^{\mathrm{o}}$ 101, de 2000).

Ante o exposto, defiro, parcialmente, a medida liminar requerida, determinando:

$$
\text { (...) }
$$

e) à União - que libere o saldo acumulado do Fundo Penitenciário Nacional para utilização com a finalidade para a qual foi criado, abstendo-se de realizar novos contingenciamentos." (STF, Plenário, ADPF no 347 MC/DF, Relator Ministro Marco Aurélio, Julgado em 09/09/2015) 
Nossa proposta é que, em matéria de políticas públicas sociais para atendimento da população, o orçamento não possa sofrer contingenciamentos, a não ser mediante justificativa razoável do Poder Executivo, a ser votada pelo Poder Legislativo para que seja aceita ${ }^{248}$.

A sugestão de Marcus Abraham deveria ser adotada de forma imediata como meio de moralização da gestão dos recursos do SUS.

\subsection{4 \\ Descumprimento da EC 29/00 - fazenda versus saúde - o caso do Estado do Rio de Janeiro}

Uma intrigante questão a respeito do orçamento da saúde é que, independentemente das vitórias obtidas no nível normativo, longas batalhas no nível institucional continuam sendo enfrentadas.

Mesmo após a promulgação da EC 29/00, até os dias atuais, as esferas governamentais descumprem reiteradamente a vinculação prevista constitucionalmente. Quanto à União, Conceição et al apontam que uma interpretação restritiva sobre o início da vigência da nova regra gerou uma perda de 1,19 bilhões de reais no orçamento de 2001, além do efeito cumulativo para os anos seguintes ${ }^{249}$. Ademais, o próximo capítulo irá esclarecer os mecanismos que o ente federal usa para fugir do peso desta vinculação constitucional ${ }^{250}$.

No plano estadual, o descumprimento da vinculação orçamentária instituída pela EC 29/00 também tem sido reiterado. A falta de apoio financeiro da União, aliada à baixa capacidade administrativa dos entes subnacionais - sem contar motivos tais como desvios ilegais de verbas etc. - tem feito com que o percentual de $12 \%$ previsto no artigo $6^{\text {o251 }}$ da LC 141/12 não seja alcançado.

\footnotetext{
248 ABRAHAM, O orçamento impositivo: uma alternativa possível ao paternalismo judicial, p. 672-673.

${ }^{249}$ CONCEIÇÃO, Tainá Souza; CISLAGHI, Juliana Fiúza; TEIXEIRA, Sandra Oliveira, O financiamento da saúde no Brasil: principais dilemas, Temporalis, v. 23, 2012, p. 110.

${ }^{250}$ Élida Pinto, Procuradora do Ministério Público de Contas do Estado de São Paulo, também aponta outras manobras da União, tais como aquela objeto do Processo TC 031.430/2015-5, quanto aos saldos de restos a pagar adiados indefinidamente esvaziando a proteção das despesas obrigatórias em saúde, bem como o deficit de aplicação em saúde no exercício financeiro de 2016. PINTO, Élida Graziane, Estado de Coisas Inconstitucional na política pública de saúde brasileira, p. 3 nota de rodapé 4 e Governo federal não aplicou mínimo em saúde em 2016, diz MP de Contas, Consultor Jurídico, 2017.

${ }^{251}$ Art. 60 Os Estados e o Distrito Federal aplicarão, anualmente, em ações e serviços públicos de saúde, no mínimo, 12\% (doze por cento) da arrecadação dos impostos a que se refere o art. $155 \mathrm{e}$ dos recursos de que tratam o art. 157, a alínea "a" do inciso I e o inciso II do caput do art. 159,
} 
Neste último subitem do presente capítulo será reportado como exemplo paradigmático o caso do Estado do Rio de Janeiro para ilustrar a situação que se repete em todo o território nacional, afinal o descumprimento dos preceitos contidos na Constituição e na LC 141/12 é histórico, reiterado e ostensivo.

Inicialmente, é importante registrar a existência de uma natural peleja entre as Secretarias de Fazenda e de Saúde de qualquer governo em qualquer ente federativo. É compreensível que o gestor da área de saúde precise de dinheiro para fazer frente às responsabilidades da sua Secretaria de governo enquanto que o gestor do Tesouro, por outro lado, necessite controlar os gastos públicos, impedindo que eles sejam superiores ao que o governo seja capaz de arcar. É em razão deste relacionamento conflituoso que há inúmeras normas, desde o nível constitucional até o infralegal ${ }^{252}$, para regulamentar a disponibilidade financeira dos recursos da saúde.

A exigência de criação de um fundo especial para a saúde pode ser considerada a "regra de ouro" desta sistemática. A metodologia dos fundos especiais está estatuída nos artigos 71 a 74 da Lei 4.320/64, tendo por motivação principal a segregação do valor que tem destinação específica em relação aos demais valores que compõem o patrimônio público. Tal segregação financeira é importante no intuito de facilitar o uso e controle (inclusive social) da verba com destinação específica, evitando que ela se misture com outras verbas destinadas a outras finalidades. É um princípio de boa gestão. A autonomia financeira do Fundo de Saúde está expressamente garantida na Lei $8.080 / 90^{253}$ e na LC $141 / 12^{254}$, salvaguardando a autonomia da administração dos recursos da saúde pelo gestor desta área do governo.

todos da Constituição Federal, deduzidas as parcelas que forem transferidas aos respectivos Municípios.

Parágrafo único. (VETADO).

${ }^{252}$ Tais normas dizem respeito tanto às regras relativas ao regime financeiro (orçamentos públicos e seu manejo) como também àquelas que garantem a autonomia diretiva do gestor da saúde em cada nível federativo.

${ }^{253}$ Art. 32. São considerados de outras fontes os recursos provenientes de: (...) $\S 2^{\circ}$ As receitas geradas no âmbito do Sistema Único de Saúde (SUS) serão creditadas diretamente em contas especiais, movimentadas pela sua direção, na esfera de poder onde forem arrecadadas. Art. 33. Os recursos financeiros do Sistema Único de Saúde (SUS) serão depositados em conta especial, em cada esfera de sua atuação, e movimentados sob fiscalização dos respectivos Conselhos de Saúde

${ }^{254}$ Art. 14. O Fundo de Saúde, instituído por lei e mantido em funcionamento pela administração direta da União, dos Estados, do Distrito Federal e dos Municípios, constituir-se-á em unidade 
Ocorre que, até pelo menos o ano de 2016, o Estado do Rio de Janeiro sequer possuía uma conta bancária específica por onde passassem os recursos da saúde. Os recursos do patrimônio estadual fluminense eram todos geridos em uma conta única ("Conta Única do Tesouro Estadual") e separados apenas contabilmente, tudo a cargo da Secretaria da Fazenda, que estabelecia cotas financeiras ao Secretário de Saúde para as suas despesas. A conta bancária destinada aos recursos vinculados à saúde só veio a ser criada no ano de 2016 por conta de decisão liminar proferida nos autos de Ação Civil Pública proposta pelo Ministério Público Estadual ${ }^{255}$, mas não se tem notícias de que ela esteja sendo devidamente utilizada.

Inexistindo um Fundo de Saúde, a Fazenda Estadual administra todo o dinheiro e, em frontal desobediência à lei ${ }^{256}$, estabelece uma verdadeira "mesada" ao Secretário de Saúde. Cotas financeiras são estabelecidas, determinando quanto este último pode gastar. Evidentemente, tal sistemática suprime toda a margem de liberdade do Secretário de Saúde no manuseio da verba vinculada constitucionalmente.

Um simples exemplo é capaz de tornar definitivamente perceptível o prejuízo desta conduta. Imagine-se que no mês de abril de determinado ano um determinado hospital do Estado tenha que realizar consertos nos seus equipamentos da Unidade de Terapia Intensiva (UTI) pois os mesmos estão apresentando defeitos. Se o dinheiro da saúde estivesse depositado no Fundo da Saúde, ele poderia ser usado pelo Secretário, justificadamente, para tal fim. Acontece que, no caso do Estado Rio de Janeiro, isso não ocorre. Ao invés de os recursos arrecadados serem imediatamente depositados na conta do Fundo de Saúde eles permanecem na Conta Única do Tesouro Estadual, cabendo ao Secretário de Fazenda estabelecer cotas para utilização deste dinheiro. Segundo o governo do Estado do Rio de Janeiro, seria legítima a sua conduta de não gastar absolutamente nada em saúde ao longo de todo o exercício financeiro, desde que,

orçamentária e gestora dos recursos destinados a ações e serviços públicos de saúde, ressalvados os recursos repassados diretamente às unidades vinculadas ao Ministério da Saúde.

Art. 16. O repasse dos recursos previstos nos arts. $6^{\circ}$ a $8^{\circ}$ será feito diretamente ao Fundo de Saúde do respectivo ente da Federação e, no caso da União, também às demais unidades orçamentárias do Ministério da Saúde.

${ }^{255}$ Ação Civil Pública n. 012831-81.2016.8.19.0001

${ }^{256}$ LC 141/12 Art. 28. São vedadas a limitação de empenho e a movimentação financeira que comprometam a aplicação dos recursos mínimos de que tratam os arts. $5^{\circ}$ a $7^{\circ}$. 
ao final do ano, complementasse a "bolada" dos $12 \%$ anuais que são devidos segundo o art. $6^{\circ}$ da LC 141/12. Segundo o Estado do Rio de Janeiro, a UTI do hospital do exemplo aqui mencionado ficaria sem funcionar até o final do ano.

É evidente que esta conduta prejudica em demasiado o planejamento das ações de saúde. Apesar de o art. $6^{\circ}$ da LC 141/12 utilizar o termo "anualmente" no que tange à periodicidade da obrigação de aplicar os recursos na saúde, a teoria governista de que possa a Secretaria de Fazenda reter os recursos vinculados constitucionalmente ao longo dos primeiros 11 meses do ano, em detrimento das necessidades da população, certamente não é a que atende aos seus melhores interesses. O dispositivo em comento merece uma interpretação mais coerente e compatível com as garantias constitucionais do direito social fundamental à saúde.

Aliás, é este o cerne da discussão da Ação Civil Pública proposta pelo Ministério Público anteriormente mencionada.

Nesta ação, argumenta o Ministério Público que:

O raciocínio é simples: para que a Secretaria de Saúde possa planejar as ações e serviços em saúde, promovendo sua oferta contínua, deve celebrar negócios jurídicos que demandam pagamentos periódicos - na maioria das vezes com periodicidade mensal - e, para tanto, necessita ter dinheiro em seu fundo para financiamento destes negócios jurídicos. Este dinheiro é oriundo do Fundo Estadual da Saúde, o qual deveria ser, portanto, periodicamente "alimentado" pela Secretaria de Fazenda Estadual.

Mas não é o que ocorre na prática, eis que a Secretaria de Fazenda não disponibiliza com regularidade a verba arrecadada ao longo do ano, deixando para transferir tais valores apenas em momento posterior, quando a Secretaria de Saúde já se tornou inadimplente e todas as ações e serviços em saúde já entraram em colapso por falta de pagamento.

(...)

Ressalte-se, neste ponto, que não se busca aqui, interferência nas escolhas de prioridades discricionárias pelo Chefe do Executivo, mas apenas que se destina a parcela prevista para a saúde pública na Constituição da República e na Lei Complementar 141/2012.

Vê-se, portanto, que o que é eleito pela Constituição da República como prioridade, ou seja, o pagamento de ASPS - eis que a Constituição define uma cota mínima de despesa na promoção deste direito fundamental - não foi eleito pelo Exmo. Sr. Governador como prioridade neste momento de crise financeira, o que revela a sua postura evidentemente alheia aos interesses sociais mais indisponíveis e caros à sociedade.

Para além de desrespeitar a autonomia do Secretário de Saúde e a disponibilidade financeira dos recursos desta pasta, o Estado do Rio de Janeiro ainda transcende tal irregularidade. Reiteradamente o Estado do Rio de Janeiro descumpre o percentual de $12 \%$, deixando de aplica-lo, ainda que fosse 
considerada legítima a periodicidade anual sustentada pelo governo (interpretação literal do art. $6^{\circ}$ da LC 141/12).

Com efeito, o Tribunal de Contas do Estado do Rio de Janeiro deu parecer pela não aprovação das contas do governador Pezão referente aos anos de $2015 \mathrm{e}$ $2016^{257}$ em razão deste fato, sendo que este governador atualmente responde a processo de improbidade administrativa ${ }^{258}$, ação esta também proposta pelo Ministério Público do Estado do Rio de Janeiro, em razão de tal conduta.

Por fim, deve ser pontuado que até mesmo o Tribunal de Contas vem cometendo o erro de aceitar a conduta do Estado do Rio de Janeiro de contabilizar, para fins de composição do percentual de $12 \%$, despesas empenhadas e não liquidadas, inscritas em restos a pagar ao final do exercício, sem que o Estado tenha disponibilidade de caixa no Fundo de Saúde. Tal prática viola frontalmente o que determina a LC $141 / 12 \mathrm{em}$ seu art. $24^{259}$. Saliente-se que, se não fosse por tal erro da Corte de Contas, também no ano de 2014 o Estado do Rio de Janeiro não teria cumprido o percentual mínimo constitucional.

Com efeito, conforme autoriza o inciso II do art. 24 da LC 141/12, as despesas que são empenhadas no final do exercício fiscal podem ser contabilizadas como despesa de saúde ainda que não tenha sido liquidada (restos a pagar). No entanto, por interpretação lógica, esta autorização legal deve ser condicionada a que tal despesa venha a ser liquidada e paga logo em seguida (no início do exercício seguinte) ${ }^{260}$. Isso porque, se o gestor não realizar a liquidação e pagamento daquela despesa, isso significará que ele, ao final, não terá efetivamente realizado tal despesa. Neste caso, a contabilização do respectivo valor deve ser cancelada, sob pena de o percentual mínimo de vinculação constitucional à saúde estar sendo burlado.

O Conselho Nacional do Ministério Público - CNMP, sensibilizado por esta questão, expediu em 2016 a Recomendação n. 48, de 13 de dezembro de

\footnotetext{
${ }^{257}$ Processo TCE/RJ número 101.576-6/17, fls. 419 e 420

${ }^{258}$ ACP n. 0042427-14.2017.8.19.0001

${ }^{259}$ Art. 24. Para efeito de cálculo dos recursos mínimos a que se refere esta Lei Complementar, serão consideradas:

I - as despesas liquidadas e pagas no exercício; e

II - as despesas empenhadas e não liquidadas, inscritas em Restos a Pagar até o limite das disponibilidades de caixa ao final do exercício, consolidadas no Fundo de Saúde.

${ }^{260}$ Segundo disposto na Lei n. 4.320/64, as despesas públicas são realizadas por intermédio de um processo trifásico: empenho, liquidação e pagamento
} 
2016, para que os membros do Ministério Público com atribuições para atuação na Saúde e no Patrimônio Público se ocupem de realizar ações coordenadas para:

VIII - recomendar dos Chefes do Executivo que as disponibilidades de caixa (saldo financeiro) que ampararam a contabilização dos restos a pagar, para fins de perfazimento do piso em exercícios anteriores, na forma do art. 24 , inciso II e $\S 1^{\circ}$ da LC n. 141/2012, permaneçam depositadas no fundo de saúde do ente, até a sua efetiva liquidação e pagamento;

(...)

$\mathrm{X}$ - cobrar dos gestores a quitação dos restos a pagar que foram contabilizados como ASPS e já tiverem sido liquidados, na sua estrita ordem cronológica e em prazo não superior a 90 (noventa) dias, conforme parâmetro de razoabilidade temporal dado pelo art. 78, inciso XV, da Lei n. 8.666, de 21 de junho de 1993;

XI - apurar a prestação de contas e, se necessário, recomendar o cancelamento dos restos a pagar que, a despeito de contabilizados como ASPS, ainda não tiverem sido processados e, portanto, encontrarem-se pendentes de liquidação há mais de dois exercícios, hipótese em que se impõe a compensação do respectivo montante que houver sido contabilizado no piso constitucional a que se refere o art. $198 \S \S$ $2^{\circ}$ e $3^{\circ}$ da Constituição Federal;",261

De fato, a expedição da mencionada recomendação foi necessária uma vez que tem sido comum a verificação de que gestores brasileiros contabilizam como despesa em saúde valores empenhados no final do exercício, classificados como restos a pagar, e depois não concretizam a liquidação e pagamento destas despesas.

Conclui-se, outrossim, que mesmo tendo a LC 141/12 instituído um mínimo de vinculação a favor da saúde, gestores públicos permanecem avessos ao seu cumprimento e, em última análise, contrários ao melhor interesse de sua população.

\footnotetext{
${ }^{261}$ CONSELHO NACIONAL DO MINISTÉRIO PÚBLICO, Recomendação CNMP n. 48, de 13
} de dezembro de 2016, 2016, p. 7. 


\section{O financiamento do direito à saúde no Brasil (II): descentralização, regionalização e desinvestimento federal}

Desde a sua instauração, por ocasião da proclamação da república, a federação brasileira sempre teve um viés centralizado pois, ao contrário da tradição norte-americana, ela se constituiu por um processo centrífugo, de dispersão de parcela do poder que anteriormente era concentrado no governo central. Intercalando períodos de avanços e retrocessos de centralização e descentralização do poder ao longo da sua história, pode-se dizer que foi por intermédio da Constituição de 1988 que o Brasil, pela primeira vez, de fato planejou uma distribuição do poder de forma democrática e tendente à efetiva melhoria da organização do quadro político-administrativo do país.

No campo sanitário, o arranjo normativo constitucional previu a distribuição de competências entre os três entes federativos - União, Estados e Municípios. Ao mesmo tempo em que o SUS é definido como um sistema único, as suas ações e serviços serão prestados de forma descentralizada, de acordo com as prioridades definidas pelas gestões de cada esfera de governo ${ }^{262}$.

Concomitantemente, a prestação destas ações e serviços deve se organizar de forma regionalizada e hierarquizada, o que significa dizer que, tanto quanto possível, os entes federativos deveriam interagir entre si para que, ao invés de cada um deles funcionar como uma "ilha" que pretenda oferecer todo tipo de assistência à saúde (o que, aliás, seria impossível do ponto de vista prático), a responsabilidade pela oferta de ações e serviços seria repartida entre eles segundo níveis de complexidade crescente (em termos de tecnologia e das modalidades de assistência).

A integração das redes de saúde dos diversos entes federados é um fenômeno cada vez mais indispensável, uma vez verificado o fracasso das políticas de saúde fragmentadas e verticalizadas. As mudanças dos padrões epidemiológicos já mencionadas em outras ocasiões deste trabalho são um nítido exemplo da necessidade de reformulação da atenção à saúde, para que o

\footnotetext{
${ }^{262}$ Art. 198. As ações e serviços públicos de saúde integram uma rede regionalizada e hierarquizada e constituem um sistema único, organizado de acordo com as seguintes diretrizes: I - descentralização, com direção única em cada esfera de governo;
} 
enfrentamento do adoecimento passe a ser realizado de forma integral, integrada e contínua. Daí o surgimento das chamadas "linhas de cuidado" ou "redes temáticas", modelos mais modernos da divisão do cuidado com a saúde. Em cada linha de cuidado (cardiovascular, oncológica etc.) o paciente é atendido desde a atenção primária até eventual atendimento especializado em nível cirúrgico. Nesse ínterim, a integração da rede precisa funcionar de forma eficiente e racional, o que demanda, evidentemente, planejamento e integração dos entes federados não somente no nível da assistência como também no que tange ao financiamento (leia-se: sistemas de transferências de recursos e ressarcimento) das ações e serviços ${ }^{263}$.

Em suma, a descentralização visa a ampliar a participação das esferas subnacionais na gestão do sistema de saúde, de forma a aproximar o gestor do cidadão-usuário. Espera-se desta aproximação a ampliação do aprovisionamento de ações e serviços à população, tanto em termos quantitativos quanto qualitativos. Sabe-se que é o gestor local quem tem maiores condições de avaliar as particularidades epidemiológicas da população atendida.

Por sua vez, a regionalização opera no sentido da interação entre os entes para o sucesso da descentralização. Em que pese a força da regionalização nesse processo, é verdade que o tema da descentralização costuma ganhar mais enfoque dos especialistas da área e esse fenômeno tem um motivo que foi muito bem esclarecido por Lima et al na seguinte passagem:

As razões para o privilegiamento da descentralização estão relacionadas ao contexto de redemocratização do Brasil a partir de 1980. A transferência de recursos, competências e responsabilidades para os governos subnacionais associou-se aos movimentos contra o regime militar e o autoritarismo e a favor da ampliação da democracia e maior eficiência governamental. Sem embargo, outros fatores devem ser considerados...

(....)

Sem a face da regionalização, a descentralização acoplou-se ao desenho federativo brasileiro, desconsiderando o papel das esferas estaduais de governo e acentuando as atribuições dos municípios na provisão de serviços. Em que pesem os resultados positivos do processo de municipalização - entre outros, a ampliação do acesso à saúde, a incorporação de práticas inovadoras no campo da gestão e da assistência à saúde e de novos atores que dão sustentabilidade política e financeira ao setor -,

\footnotetext{
${ }^{263}$ LIMA, Luciana Dias de et al, Regionalização da Saúde no Brasil, in: GIOVANELLA, Ligia et al (Orgs.), Políticas e Sistema de Saúde no Brasil, 2a ed. rev. e amp. Rio de Janeiro: Fiocruz, 2012, p. 823-852.
} 
permanecem, ainda hoje, problemas relativos à intensa fragmentação e à desorganização de serviços, instituições e práticas no território. Além disso, as desigualdades regionais na distribuição e no acesso às ações e aos serviços de saúde são muito significativas no país ${ }^{264}$.

Busca-se no presente capítulo analisar esse processo de reformulação do sistema de saúde brasileiro, demonstrando os motivos pelos quais, apesar de ter sido uma das mais relevantes inovações da Constituição de 1988, a descentralização das ações e serviços sanitários não alcançou, até hoje, os objetivos pretendidos.

São diversas as dificuldades práticas na implementação da proposta contida na Constituição de 1988, conforme argumentam Lima et al no seguinte trecho:

Vários aspectos influenciam a implantação do SUS. Entre eles, as características da federação brasileira, que se distingue pelo reconhecimento dos municípios como entes autônomos a partir da Constituição de 1988, pela multiplicidade de esferas governamentais e por um importante processo de descentralização de encargos e recursos tributários. Existem, por um lado, mais de cinco mil municípios no país, em sua maioria (cerca de 90\%) de pequeno ou médio porte, e com limitadas condições para assumir todas as responsabilidades sobre as políticas públicas que lhes são atribuídas. Por outro lado, $55 \%$ da população brasileira residem em municípios com mais de cem mil habitantes. Também são marcantes as assimetrias políticas e econômicas entre os governos estaduais ${ }^{265}$.

Piola et al ponderam coerentemente que, embora a descentralização promovida pela Constituição de 1988 tenha logrado reduzir as desigualdades inter-regionais no Brasil ${ }^{266}$, alguns problemas subsistem neste campo, dentre os quais destacam-se a intricada relação entre os entes federados (cujos papéis são pobremente definidos, fato que gera querelas tanto no aspecto das

\footnotetext{
${ }^{264}$ Ibid., p. 836-838.

${ }^{265}$ Ibid., p. 823.

${ }^{266} \mathrm{Tal}$ afirmação não é pacífica. Por exemplo, Lucchese afirma, pelo contrário, que "Estudos recentes evidenciam a persistência, ao final dos anos 90, de importantes iniquidades relacionadas 1) à distribuição espacial da oferta de recursos humanos e de capacidade instalada; 2) ao acesso e utilização de serviços (públicos e privados); 3) à qualidade da atenção recebida; e 4) às condições de vida e de saúde da população nas diferentes localidades. O acompanhamento dos debates ocorridos na Comissão Intergestores Tripartite nos últimos anos, no âmbito do Projeto Descentralização On Line (http://www.ensp.fiocruz.br/descentralizar), e os resultados de pesquisa recém-concluída sobre desigualdades intra e inter-regionais no ambiente de gestão pública da saúde, confirmam tal constatação (Lucchese et al, 2002)". Embora o escrito de Lucchese seja 06 anos mais antigo que o de Piola et al, a divergência é digna de registro. LUCCHESE, Patrícia T. R., Equidade na gestão descentralizada do SUS: desafios para a redução de desigualdades em saúde, Ciência e Saúde Coletiva, v. 8, n. 2, p. 439-448, 2003, p. 440.
} 
responsabilidades assistenciais quanto no que tange ao financiamento das ações) e a necessidade de efetiva regionalização do sistema ${ }^{267}$.

De fato, a relação entre os entes federados no Brasil, ao invés de ser harmônica e colaborativa, traduz históricas disputas por poder político e econômico. A tradição política na "república"268 brasileira - fundada em arranjos oligárquicos - reflete uma tradicional postura individualista, interessada antes na partilha do poder (político ou econômico) do que na divisão do bem comum.

Por consequência, a reformulação do modelo de atenção à saúde, mediante repartição das atribuições entre os entes federativos, definindo fluxos e contrafluxos para assegurar disponibilidade de atendimento em todos os níveis de cuidado para toda a população foi - e continua sendo - de fato um dos maiores desafios postos aos entes federados a partir da nova Carta Constitucional.

\section{1 \\ Descentralização do SUS}

O texto da Constituição de 1988 foi exageradamente genérico no que tange às regras de repartição das competências sanitárias dos três entes federativos. Como regra geral, o art. 23, inciso II, estabelece a competência material comum dos três entes para cuidar da saúde pública, assim como o art. 24, inciso XII, prevê a competência legislativa concorrente entre União e Estados nesta matéria (a competência legislativa dos Municípios, conforme regra geral, será exercida de forma suplementar, nos termos do art. 30, inciso II) ${ }^{269}$.

A generalidade dessa repartição de competências sanitárias, somada aos termos literais do art. 196 da Constituição, que responsabiliza o Estado (em termos genéricos) pela garantia do direito à saúde, induziram tanto doutrina quanto jurisprudência no Brasil a sustentarem a existência de solidariedade das obrigações sanitárias entre os entes federativos. Inúmeras decisões judiciais no

\footnotetext{
${ }^{267}$ PIOLA et al, Vinte anos da Constituição de 1988: o que significaram para a saúde da população brasileira?, p. 98.

${ }^{268}$ Optou-se aqui pelas aspas para ressaltar que os valores da política brasileira em nada corroboram os valores republicanos.

${ }^{269}$ Art. 23. É competência comum da União, dos Estados, do Distrito Federal e dos Municípios: (...) II - cuidar da saúde e assistência pública, da proteção e garantia das pessoas portadoras de deficiência; Art. 24. Compete à União, aos Estados e ao Distrito Federal legislar concorrentemente sobre: (...) XII - previdência social, proteção e defesa da saúde; Art. 30. Compete aos Municípios: (...) II - suplementar a legislação federal e a estadual no que couber;
} 
Brasil repetem esse verdadeiro mantra, proferindo condenações indistintamente contra União, Estados e Municípios, obrigando os três entes a cumprirem determinada medida, à míngua de uma definição clara de quem seria o ente verdadeiramente responsável pela prestação no respectivo caso concreto.

$\mathrm{Na}$ prática, todavia, esse posicionamento reiterado acarretou uma verdadeira "corrida aos Tribunais" e uma crescente despesa financeira não planejada no orçamento dos entes federativos. Tal situação tem sido amplamente debatida, tanto na seara acadêmica quanto no próprio âmbito judicial, já havendo vozes defendendo a necessidade de revisão desse entendimento, em nome do equilíbrio orçamentário e financeiro de cada membro da federação ${ }^{270,271}$.

Para ilustrar a situação, em artigo recentemente publicado Lenir Santos criticou uma decisão do Tribunal Regional Federal da $1^{\text {a }}$ Região que condenou a União a ressarcir o pequeno Município de Capim Branco (MG) por despesas em saúde consideradas de alto custo, havidas com um de seus munícipes. Afirmou Santos que

Desrespeita os regramentos constitucionais e legais do SUS impor aos entes federativos responsabilidade solidária, a qual exige de modo igual a garantia de serviços desiguais que se classificam como de baixa complexidade tecnológica e alta complexidade e elevados custos. O sistema de saúde público, de acesso universal e de execução descentralizada e integral, requer conformação a partir da integração dos serviços dos entes em redes de complexidade crescente de serviços. Aplicar no SUS o conceito jurídico de responsabilidade solidária, próprio das competências constitucionais comuns, é desconsiderar as suas especificidades constitucionais e legais que vão além desse conceito. O artigo 198 da Constituição exige que sejam os serviços públicos de saúde integrados em rede regionalizada e hierarquizada exatamente para atender as duas diretrizes constitucionais: garantia do atendimento integral à saúde e descentralização das ações e serviços, com direção única em cada esfera de governo ${ }^{272}$.

\footnotetext{
270 Conforme anteriormente mencionado, a questão da judicialização da saúde no Brasil e suas consequências para o planejamento financeiro-orçamentário das políticas de saúde, bastante problemática, não será objeto do presente estudo, razão pela qual aqui também não se alonga no tema.

${ }^{271}$ Élida Pinto propõe como um possível mecanismo de ajuste deste descompasso a possibilidade de os Municípios e Estados - maiores prejudicados com a crescente judicialização da saúde no Brasil por suportarem majoritariamente as condenações proferidas - ajuizarem ações regressivas em face da União. PINTO, Élida Graziane, Descompasso federativo no financiamento da saúde pública brasileira, Consultor Jurídico, 2015.

272 SANTOS, Lenir, Judicialização da saúde: é preciso rever a responsabilidade solidária,
} Consultor Jurídico, 2017. 
Fugindo deste regramento tão genérico, logrando ser um tanto mais específico, o inciso VII do art. 30 da Constituição ${ }^{273}$ pode ser considerado o arcabouço normativo da descentralização do SUS, ao outorgar aos Municípios a competência para prestar, com cooperação técnica e financeira da União e do Estado, serviços de atendimento à saúde da população. Por intermédio deste dispositivo a Constituição de 1988 transferiu grande parcela da responsabilidade sanitária para os Municípios, os quais se transformaram, nas palavras de Ugá et al, os "atores estratégicos do SUS"274.

A Lei 8.080/90, Lei Orgânica do SUS, procurou estabelecer repartições de competências de forma um pouco mais específica do que fizera a Constituição, obedecendo essa mesma linha de concentração das responsabilidades sanitárias no nível municipal. Assim, o inciso I do art. $18^{275}$ desta lei destina à direção municipal do SUS a competência para planejar, organizar, controlar e avaliar as ações e os serviços de saúde e gerir e executar os serviços públicos de saúde. À União e aos Estados restaram funções suplementares, de coordenação e normativas, bem como a cooperação técnica e financeira e a regulamentação de fluxos e contrafluxos do atendimento aos usuários ${ }^{276}$.

\footnotetext{
${ }^{273}$ Art. 30. Compete aos Municípios: (...) VII - prestar, com a cooperação técnica e financeira da União e do Estado, serviços de atendimento à saúde da população

${ }^{274}$ UGÁ, Maria Alicia D et al, descentralização e alocação de recursos no âmbito do Sistema Único de Saúde, Revista Ciência \& Saúde Coletiva, v. 8, n. 2, p. 417-437, 2003, p. 418.

${ }^{275}$ Art. 18. À direção municipal do Sistema de Saúde (SUS) compete: I - planejar, organizar, controlar e avaliar as ações e os serviços de saúde e gerir e executar os serviços públicos de saúde; II - participar do planejamento, programação e organização da rede regionalizada e hierarquizada do Sistema Único de Saúde (SUS), em articulação com sua direção estadual; III - participar da execução, controle e avaliação das ações referentes às condições e aos ambientes de trabalho; IV executar serviços: a) de vigilância epidemiológica; b) vigilância sanitária; c) de alimentação e nutrição; d) de saneamento básico; e e) de saúde do trabalhador; V - dar execução, no âmbito municipal, à política de insumos e equipamentos para a saúde; VI - colaborar na fiscalização das agressões ao meio ambiente que tenham repercussão sobre a saúde humana e atuar, junto aos órgãos municipais, estaduais e federais competentes, para controlá-las; VII - formar consórcios administrativos intermunicipais; VIII - gerir laboratórios públicos de saúde e hemocentros; IX colaborar com a União e os Estados na execução da vigilância sanitária de portos, aeroportos e fronteiras; X - observado o disposto no art. 26 desta Lei, celebrar contratos e convênios com entidades prestadoras de serviços privados de saúde, bem como controlar e avaliar sua execução; XI - controlar e físcalizar os procedimentos dos serviços privados de saúde; XII - normatizar complementarmente as ações e serviços públicos de saúde no seu âmbito de atuação.

${ }^{276}$ Art. 16. A direção nacional do Sistema Único da Saúde (SUS) compete: I -formular, avaliar e apoiar políticas de alimentação e nutrição; II - participar na formulação e na implementação das políticas: a) de controle das agressões ao meio ambiente; b) de saneamento básico; e c) relativas às condições e aos ambientes de trabalho; III - definir e coordenar os sistemas: a) de redes integradas de assistência de alta complexidade; b) de rede de laboratórios de saúde pública; c) de vigilância epidemiológica; e d) vigilância sanitária; IV - participar da definição de normas e mecanismos de controle, com órgão afins, de agravo sobre o meio ambiente ou dele decorrentes, que tenham
} 
Apesar de todos os esforços dos mencionados arranjos normativos, o processo de descentralização do SUS, quase 30 anos após a promulgação da Constituição, ainda é extremamente falho. Os motivos do fracasso desse projeto constitucional é o que se pretende desvendar no presente capítulo.

Gottret e Schieber, ao analisarem dados relativos aos processos de descentralização da assistência à saúde em diversos países subdesenvolvidos e em

repercussão na saúde humana; V - participar da definição de normas, critérios e padrões para o controle das condições e dos ambientes de trabalho e coordenar a política de saúde do trabalhador; VI - coordenar e participar na execução das ações de vigilância epidemiológica; VII - estabelecer normas e executar a vigilância sanitária de portos, aeroportos e fronteiras, podendo a execução ser complementada pelos Estados, Distrito Federal e Municípios; VIII - estabelecer critérios, parâmetros e métodos para o controle da qualidade sanitária de produtos, substâncias e serviços de consumo e uso humano; IX - promover articulação com os órgãos educacionais e de fiscalização do exercício profissional, bem como com entidades representativas de formação de recursos humanos na área de saúde; X - formular, avaliar, elaborar normas e participar na execução da política nacional e produção de insumos e equipamentos para a saúde, em articulação com os demais órgãos governamentais; XI - identificar os serviços estaduais e municipais de referência nacional para o estabelecimento de padrões técnicos de assistência à saúde; XII - controlar e fiscalizar procedimentos, produtos e substâncias de interesse para a saúde; XIII - prestar cooperação técnica e financeira aos Estados, ao Distrito Federal e aos Municípios para o aperfeiçoamento da sua atuação institucional; XIV - elaborar normas para regular as relações entre o Sistema Único de Saúde (SUS) e os serviços privados contratados de assistência à saúde; XV promover a descentralização para as Unidades Federadas e para os Municípios, dos serviços e ações de saúde, respectivamente, de abrangência estadual e municipal; XVI - normatizar e coordenar nacionalmente o Sistema Nacional de Sangue, Componentes e Derivados; XVII acompanhar, controlar e avaliar as ações e os serviços de saúde, respeitadas as competências estaduais e municipais; XVIII - elaborar o Planejamento Estratégico Nacional no âmbito do SUS, em cooperação técnica com os Estados, Municípios e Distrito Federal; XIX - estabelecer o Sistema Nacional de Auditoria e coordenar a avaliação técnica e financeira do SUS em todo o Território Nacional em cooperação técnica com os Estados, Municípios e Distrito Federal.(Vide Decreto $\mathrm{n}^{\circ}$ 1.651, de 1995) Parágrafo único. A União poderá executar ações de vigilância epidemiológica e sanitária em circunstâncias especiais, como na ocorrência de agravos inusitados à saúde, que possam escapar do controle da direção estadual do Sistema Único de Saúde (SUS) ou que representem risco de disseminação nacional.

Art. 17. À direção estadual do Sistema Único de Saúde (SUS) compete: I - promover a descentralização para os Municípios dos serviços e das ações de saúde; II - acompanhar, controlar e avaliar as redes hierarquizadas do Sistema Único de Saúde (SUS); III - prestar apoio técnico e financeiro aos Municípios e executar supletivamente ações e serviços de saúde; IV - coordenar e, em caráter complementar, executar ações e serviços: a) de vigilância epidemiológica; b) de vigilância sanitária; c) de alimentação e nutrição; e d) de saúde do trabalhador; V - participar, junto com os órgãos afins, do controle dos agravos do meio ambiente que tenham repercussão na saúde humana; VI - participar da formulação da política e da execução de ações de saneamento básico; VII - participar das ações de controle e avaliação das condições e dos ambientes de trabalho; VIII em caráter suplementar, formular, executar, acompanhar e avaliar a política de insumos e equipamentos para a saúde; IX - identificar estabelecimentos hospitalares de referência e gerir sistemas públicos de alta complexidade, de referência estadual e regional; X - coordenar a rede estadual de laboratórios de saúde pública e hemocentros, e gerir as unidades que permaneçam em sua organização administrativa; XI - estabelecer normas, em caráter suplementar, para o controle e avaliação das ações e serviços de saúde; XII - formular normas e estabelecer padrões, em caráter suplementar, de procedimentos de controle de qualidade para produtos e substâncias de consumo humano; XIII - colaborar com a União na execução da vigilância sanitária de portos, aeroportos e fronteiras; XIV - o acompanhamento, a avaliação e divulgação dos indicadores de morbidade e mortalidade no âmbito da unidade federada. 
desenvolvimento, concluíram que não é possível afirmar que a descentralização seja uma estratégia que necessariamente provoque melhorias na performance do sistema de saúde. O sucesso do esquema de descentralização, segundo os autores, depende basicamente de um forte vínculo entre governos central e local, onde ambos possam contar um com o outro, fornecendo suporte mútuo constante. Ademais, os autores apontam para a importância da adoção de providências tais como qualificação política dos gestores, definição clara da divisão de atribuições e implementação de mecanismos de responsabilização eficazes ${ }^{277}$. Lamentavelmente, nenhuma dessas providências foi implementada de forma efetiva no Brasil.

Com efeito, o Brasil sofre de dois graves obstáculos ao sucesso da estratégia de descentralização, os quais estão intimamente ligados às conclusões de Gottret e Schieber, conforme será esclarecido a seguir. São eles: (i) excessiva capilarização político-administrativa do território brasileiro e (ii) inexistência de apoio financeiro do ente federal à direção municipal do SUS. Em última análise, ambos os obstáculos refletem a inexistência de um sistema regionalizado e hierarquizado, permeado por escassez, ineficiência e desigualdades.

\subsection{1 Capilarização político-administrativa do território brasileiro}

Há no Brasil, atualmente, mais de 5.000 Municípios $^{278}$, alguns de diminuta relevância econômico-social no contexto territorial brasileiro. Esta excessiva fragmentação política encontra raízes históricas, eis que no período colonial a terra era cotizada em nome de interesses políticos. A consequência dessa configuração geográfica é a existência de inúmeros Municípios sem capacidade econômica para se autogerirem. Tratam-se de Municípios que não possuem receita suficiente para fazerem frente às suas despesas primárias, de administração e de governo, mesmo contando com os repasses constitucionais que lhes são devidos pelos demais entes federativos. Tais Municípios, portanto, são incapazes financeira e tecnicamente - de implementarem e administrarem suas redes de

\footnotetext{
${ }^{277}$ GOTTRET; SCHIEBER, Health financing revisited: a practitioner's guide, p. 200-201.

${ }^{278}$ Segundo dados do Ministério da Saúde relativos ao ano de 2012, há no Brasil 5.570 Municípios. Fonte: http://sage.saude.gov.br/\#, acessado em 27/09/2017
} 
saúde autonomamente. A esse respeito, o próprio Banco Mundial percebeu o fenômeno em seu estudo denominado "Um Ajuste Justo", publicado em novembro de 2017, em que demonstra que “a eficiência média [na prestação de serviços de saúde] é muito mais baixa entre os municípios com menos de 5.000 habitantes que nos outros grupos ${ }^{279}$.

Este fenômeno também foi avaliado pelo Tribunal de Contas da União TCU no seu paradigmático acórdão 2.888/2015, em que esta Corte apresenta dados da assistência hospitalar no Brasil, afirmando que, apesar de a assistência à saúde competir aos Municípios por força do disposto no inciso VII do art. 30 da CRFB/88, o atendimento no nível de alta complexidade e de alto custo frequentemente se concentra em poucos Municípios, com maios capacidade técnico-financeira e grande parte da rede é ainda gerida pelos Estados e pela própria União $^{280}$.

A excessiva fragmentação político-administrativa também apresenta uma segunda ordem de dificuldades, qual seja, a da formação dos chamados "currais eleitorais", consistentes na influência pessoal dos políticos na vida particular de cada um de seus eleitores. Políticos e eleitores em cidades muito pequenas mantêm vínculos pessoais demasiadamente estreitos, fato que torna a relação de poder muitas vezes antirepublicana e, em alguns (muitos) casos, corrupta. A atenção ao cidadão nestes casos passa a se fundar não no princípio da equidade, mas sim no clientelismo típico das relações privadas.

Rosa e Grell observam que no Brasil

Existe um largo investimento em pequenos hospitais públicos de pequeno porte (menos de 50 leitos espalhados pelo País), com baixa qualidade, taxa de ocupação e eficiência, além de não serem economicamente e operacionalmente viáveis. Entretanto, essa prática nos Estados e Municípios é rotineira, pois envolve uma questão política. O político eleito deve cumprir as promessas feitas durante sua campanha, essa é uma forma de dizer que cumpriu o prometido, investindo os recursos para a saúde em serviços não consistentes, porém que "apresentam-se" sólidos para a população.

A rede hospitalar dispersa acaba tendo uma gestão inadequada com problemas na entrega de serviços e qualidade de operação comprometida, quando não há falta de

\footnotetext{
${ }^{279}$ GRUPO BANCO MUNDIAL, Um Ajuste Justo - Análise da eficiência e equidade do gasto público no Brasil, p. 113.

${ }^{280}$ TRIBUNAL DE CONTAS DA UNIÃO, Acórdão TCU 2.888/2015, p. 8-9.
} 
profissionais qualificados, mas pulverização das atividades clínicas, forte dependência dos usuários e pouca autonomia corporativa dos gestores ${ }^{281}$.

Os autores retrataram de foram irretocável a realidade da descentralização brasileira: a autonomia conferida aos Municípios, ao invés de servir à racionalização do sistema, de modo a organizá-lo de forma hierarquizada e regionalizada, além de mais próxima ao usuário, acaba sendo desvirtuada pelos gestores locais para ser usada de forma demagógica e populista como meio de propaganda político-eleitoral.

Certo seria que Municípios de pequeno porte dessem conta apenas dos serviços da baixa complexidade - via de regra, atenção primária - deixando aos Municípios de maior porte (ou, em alguns casos, aos Estados e à União) a prestação de serviços mais complexos, especializados e hospitalares, prestados em locais racionalmente selecionados para servirem de referência aos munícipes. Infelizmente esta lógica não se observa na realidade brasileira. Pelo contrário, os entes federativos disputam entre si cada serviço, unidade de saúde e leito, pois estes equipamentos representam, no fundo, uma fração do tão cobiçado poder político.

Judith Tendler, no segundo capítulo de sua obra Good Government in the Tropics, apresentou os resultados do programa de saúde preventiva "Programa de Agentes da Saúde/PAS” implementado pelo governo do Estado do Ceará a partir de 1987. O programa obteve tão excelentes resultados que o Ceará foi vencedor em 1993 do prêmio Maurice Pate da UNICEF e passou a ser um exemplo de estudo de caso promovido pelo Banco Mundial a respeito de descentralizações bem-sucedidas. De acordo com a autora da mencionada obra, o programa só logrou êxito porque, apesar da descentralização das atribuições em saúde estabelecida na Constituição brasileira, focada na transferência de responsabilidades sanitárias notadamente aos Municípios, o governo estadual do Ceará decidiu não abrir mão de grande parte das atribuições que lhe eram devidas anteriormente à promulgação da Constituição. Pelo contrário, cientes do forte clientelismo existente nos Municípios cearenses, o governo estadual decidiu comandar o programa de saúde preventiva, liderando a contratação e gestão de

\footnotetext{
${ }^{281}$ ROSA; GRELL, Financiamento da Saúde no Brasil e a Emenda Constitucional n. 29 de 2000, p. $51-52$.
} 
milhares de agentes comunitários. Tal conduta impediu os gestores locais de exercerem sobre tais profissionais seus poderes patronais ${ }^{282}$. Este exemplo evidencia o quão complexa é a descentralização das atividades de saúde no Brasil, uma vez que o sucesso do programa mencionado dependeu de uma atuação extraordinária (e contrária à sistematização do SUS estabelecida na Constituição) do governo do Estado do Ceará.

\subsection{2}

\section{Insuficiência de apoio financeiro do ente federal à direção municipal do SUS}

É no nível do financiamento que a questão da descentralização torna-se ainda mais complexa. A lógica da descentralização consiste, em primeiro lugar, na distribuição de responsabilidades pelas diversas esferas de governo, tendo como objetivo aproximar o gestor do paciente-usuário. Ademais, a descentralização estimula a participação social, na medida em que as comunidades passam a se sentir mais capazes de influenciar nas decisões políticas dos gestores que estão mais próximos a elas.

Todavia, tal estratégia foi bastante frustrada no Brasil, uma vez que gestores locais receberam novas parcelas de responsabilidade na gestão do SUS, passando a ter que executar diversas ações e serviços de saúde sem terem recebido a correspondente parcela financeira que viabilizaria o custeio dessas suas despesas adicionais.

É verdade que a Constituição de 1988 instituiu impostos estaduais ${ }^{283}$ e municipais $^{284}$ anteriormente inexistentes, além do que estabeleceu regras de repartição de receitas tributárias, na tentativa de empoderar financeiramente Estados e Municípios ${ }^{285}$. Tais mecanismos, todavia, não se mostraram suficientes.

\footnotetext{
282 TENDLER, Judith, Good Government in the Tropics, Baltimore: Johns Hopkins University Press, 1997, p. 21-28.

${ }^{283}$ Imposto sobre operações relativas à circulação de mercadorias e prestação de serviços de transporte interestadual (ICMS), imposto sobre a transmisssão causa mortis e por doação de quaisquer bens e direitos (ITD), imposto sobre a propriedade de veículos automotores (IPVA).

${ }^{284}$ Imposto sobre venda de combustíveis a varejo (IVCV) e imposto sobre transmissão de bens imóveis intervivos (ITBI).

${ }^{285} \mathrm{Na}$ realidade, os grandes beneficiados neste processo foram os Municípios pois o incremento relativo aos impostos estaduais foram compensados pelas regras relativas aos repasses financeiros dos Estados para os Municípios.
} 
Os Municípios, desde a promulgação da Constituição de 1988 até os dias atuais, sofrem uma crescente pressão decorrente do aumento de suas reponsabilidades sanitárias em contraste com a falta de apoio financeiro sobretudo do ente central.

Conforme esclarecido linhas acima, o sucesso da política de descentralização dependeria do estabelecimento de um vínculo de suporte e solidariedade mútuo entre governos central e local; no entanto este vínculo nunca se firmou no seio da federação brasileira. Pelo contrário, processos de regionalização são fragilizados e o apoio do ente federal é minguado. A seguir serão esclarecidos os contornos dentro dos quais este cenário se delineou.

No arranjo tributário brasileiro, a União é o ente federativo que detém hegemonia financeira, pois a maior parte dos tributos no Brasil é por ela instituída e arrecadada. Conforme dito anteriormente, a Constituição de 1988 ampliou a capacidade tributária dos entes subnacionais, porém tal medida não alterou o cenário de supremacia econômico-financeira do ente federal, inclusive em razão da propriedade de bens e de certos poderes que denotam supremacia da União em relação aos demais entes nesses diversos aspectos. Trata-se, sem dúvidas, de uma federação bastante voltada para o centro (ao contrário do modelo norte-americano conforme salientado na inauguração deste capítulo).

Diante desse contexto, a descentralização das ações e serviços sanitários exortada no inciso VII do art. 30 da CRFB/88 deveria, logicamente, ser promovida mediante respectiva cooperação técnica e financeira da União (e do Estado, em se tratando de dispositivo que faz referência às atribuições dos Municípios). Daí a necessidade de elaboração de uma norma que regulamentasse de que forma se daria tal cooperação financeira entre os entes federativos, à míngua de qualquer previsão na própria Constituição que estabelecesse tais parâmetros.

A seguir será esclarecido que, lamentavelmente as normas existentes no ordenamento brasileiro não são suficientes para promover esta desejada cooperação financeira. 


\subsubsection{1}

\section{Rateio intergovernamental dos recursos vinculados à saúde: arcabouço normativo que promove o subfinanciamento federal e desigualdades regionais}

A descentralização do SUS tem como finalidade última a distribuição das responsabilidades sanitárias pelos diversos entes federativos, por intermédio do incremento das ações e serviços prestados pelo gestor local. Em nome deste objetivo, recursos devem ser transferidos do ente central aos entes subnacionais.

A Lei $8.080 / 90$ previu no seu art. $35^{286}$ critérios para definir os valores a serem transferidos aos Estados e Municípios para fins de investimento em ações e serviços públicos de saúde. Estados e Municípios receberiam recursos da União $^{287}$, distribuídos segundo critérios de perfil demográfico e epidemiológico, características da rede de saúde, desempenho etc. A Lei 8.142/90 logo veio a esclarecer que, enquanto não fosse regulamentado o art. 35 da Lei 8.080/90, deveria ser observado apenas o seu parágrafo primeiro, que determinava a distribuição dos recursos exclusivamente com base no número de habitantes de cada ente federativo receptor do repasse. Ademais, estabeleceu que ao menos $70 \%$ dos recursos federais deveriam ser destinados aos Municípios ${ }^{288}$.

\footnotetext{
${ }^{286}$ Art. 35. Para o estabelecimento de valores a serem transferidos a Estados, Distrito Federal e Municípios, será utilizada a combinação dos seguintes critérios, segundo análise técnica de programas e projetos: I - perfil demográfico da região; II - perfil epidemiológico da população a ser coberta; III - características quantitativas e qualitativas da rede de saúde na área; IV desempenho técnico, econômico e financeiro no período anterior; V - níveis de participação do setor saúde nos orçamentos estaduais e municipais; VI - previsão do plano qüinqüenal de investimentos da rede; VII - ressarcimento do atendimento a serviços prestados para outras esferas de governo. $\S 1^{\circ}$ Metade dos recursos destinados a Estados e Municípios será distribuída segundo o quociente de sua divisão pelo número de habitantes, independentemente de qualquer procedimento prévio. (Revogado pela Lei Complementar $n^{\circ} 141$, de 2012) $\S 2^{\circ}$ Nos casos de Estados e Municípios sujeitos a notório processo de migração, os critérios demográficos mencionados nesta lei serão ponderados por outros indicadores de crescimento populacional, em especial o número de eleitores registrados. $\S 3^{\circ}$ (Vetado). $\S 4^{\circ}$ (Vetado). $\S 5^{\circ}$ (Vetado). $\S 6^{\circ} \mathrm{O}$ disposto no parágrafo anterior não prejudica a atuação dos órgãos de controle interno e externo e nem a aplicação de penalidades previstas em lei, em caso de irregularidades verificadas na gestão dos recursos transferidos.

${ }^{287}$ É de se pontuar que, ao se falar em rateio/transferências de recursos federais vinculados à saúde, está-se tratando tão somente dos recursos federais passíveis de regionalização, ou seja, estão sendo excluídos os recursos que se refiram a ações federais típicas, consideradas despesas da própria União, pela característica nacional da ação ou serviço. UGÁ et al, descentralização e alocação de recursos no âmbito do Sistema Único de Saúde, p. 424.

${ }^{288}$ Art. $3^{\circ}$ Os recursos referidos no inciso IV do art. $2^{\circ}$ desta lei serão repassados de forma regular e automática para os Municípios, Estados e Distrito Federal, de acordo com os critérios previstos no art. 35 da Lei ${ }^{\circ} 8.080$, de 19 de setembro de $1990 . \S 1^{\circ}$ Enquanto não for regulamentada a aplicação dos critérios previstos no art. 35 da Lei $\mathrm{n}^{\circ} 8.080$, de 19 de setembro de 1990 , será utilizado, para o repasse de recursos, exclusivamente o critério estabelecido no $\S 1^{\circ}$ do mesmo
} 
Na prática, todavia, o art. 35 da Lei 8.080/90 nunca foi regulamentado e a regra transitória estabelecida pela Lei $8.142 / 90$ nunca foi obedecida ${ }^{289}$, tendo prevalecido em seu lugar o previsto em normas infralegais editadas pelo Ministério da Saúde. Um arranjo normativo infralegal orquestrou a distribuição dos recursos arrecadados pelos entes federativos para fins de aplicação em ações e serviços públicos de saúde ${ }^{290}$.

As primeiras Normas Operacionais Básicas - NOBs (01/91 e 01/92) inauguraram o sistema de descentralização, vinculando os repasses de recursos à aferição da estruturação institucional dos sistemas de saúde dos entes subnacionais. A NOB $01 / 91^{291}$ previa como requisitos básicos para as transferências aos Municípios a (a) criação de Conselhos de Saúde, (b) criação de Fundo Municipal de Saúde, (c) criação de Plano Municipal de Saúde, (d) Programação e Orçamentação da Saúde, (e) apresentação de Relatório de Gestão, (f) contrapartida de recursos para a saúde e (g) constituição de Comissão de Elaboração do Plano de Carreiras, Cargos e Salários, critérios esses que certamente serviram para estimular o desenvolvimento dos sistemas de saúde locais, ainda que a fiscalização do preenchimento deles fosse meramente formal.

Por outro lado, estas primeiras NOBs continham regras que deliberadamente violavam a autonomia dos Municípios, estabelecendo repasses

artigo. $\S 2^{\circ}$ Os recursos referidos neste artigo serão destinados, pelo menos setenta por cento, aos Municípios, afetando-se o restante aos Estados. $\S 3^{\circ}$ Os Municípios poderão estabelecer consórcio para execução de ações e serviços de saúde, remanejando, entre si, parcelas de recursos previstos no inciso IV do art. $2^{\circ}$ desta lei.

289 Trata-se de fenômeno tipicamente brasileiro, em que algumas normas legais são ignoradas por seus destinatários e autoridades. É comum referir-se a elas como "normas que não pegam" e são objeto de discussão especialmente no que tange à possibilidade de revogação consuetudinária de leis. Sobre essas regras previstas nas Leis 8.080/90 e 8.142/90, Ugá et al dizem suscintamente que "esses dispositivos legais não vingaram" (UGÁ et al, descentralização e alocação de recursos no âmbito do Sistema Único de Saúde, p. 418.) enquanto que Melamed também de forma abreviada afirma que "Entretanto, as disposições legais relacionadas ao financiamento foram cumpridas apenas parcialmente. O Art. 35 da Lei n. 8.080/90 nunca foi regulamentado e o repasse regular e automático, com base em critério per capita, da totalidade dos recursos transferidos, com $70 \%$ destinados aos municípios, também não". (MELAMED, Regulamentação, Produção de Serviços e Financiamento Federal do Sistema Único de Saúde: dos anos 90 aos 2000, p. 64.)

${ }^{290}$ Registre-se aqui a breve existência do Programa dos Sistemas Unificados e Descentralizados de Saúde (SUDS), instituído pelo Decreto n. 94.656, de 20 de julho de 1987, sob a égide da Constituição de 1967, portanto precursor do SUS ao prever um início de descentralização do sistema de saúde brasileiro. Segundo Santos e Andrade, os repasses de recursos segundo tal programa era realizado por meio de convênios que duraram até a edição da NOB 01/91. SANTOS; ANDRADE, SUS: o Espaço da Gestão Inovada e dos Consensos Interfederativos: aspectos jurídicos, administrativos e financeiros, p. 31-34.

${ }^{291}$ Neste ponto, a NOB 01/92 não apresenta inovações notáveis em relação à NOB 01/91. 
direcionados a atividades especificas, mediante comprovação de produtividade. Segundo tais regras, nenhuma margem de manobra sobrava ao gestor local no intuito de poder alocar os recursos recebidos em ações e serviços que entendesse mais convenientes, segundo suas próprias decisões políticas e com fundamento em necessidades e demandas particulares de sua população.

Ademais, segundo Ugá et al, as transferências destinadas ao financiamento de internações hospitalares e ao financiamento de assistência ambulatorial - os dois grandes fluxos de alocação dos recursos entre os entes federativos no âmbito do SUS - seguiam regras extremamente regressivas, contribuindo para o aumento das desigualdades regionais, pois remuneravam melhor os entes com maior capacidade instalada ${ }^{292,293}$.

Jorge Eri Borges de Medeiros, então Coordenador Executivo da Comissão Organizadora da $9^{\text {a }}$ CNS, Presidente do CONASEMS ${ }^{294}$ entre 1989-1993, entrevistado por Faleiros et al, afirmou sobre a NOB 01/91 que

\begin{abstract}
'Nesse meio tempo, o Ministério da Saúde edita a primeira NOB 91, que continua sendo centralizadora, continua fazendo o município de prestador, mas é o primeiro passo para começar a definir papéis. Naquele momento nem aquilo tinha, o que para nós foi um avanço. A NOB 91, pelo menos, inicia um processo. Nós não tivemos como fazer qualquer tipo de mudança, primeiro porque o governo era mais forte do que nós. A NOB 91 estabelecia um financiamento que era bom para alguns setores, alguns estados, pois ela premiava a rede instalada ${ }^{, 295}$.
\end{abstract}

\footnotetext{
${ }^{292}$ UGÁ et al, descentralização e alocação de recursos no âmbito do Sistema Único de Saúde, p. 419.

${ }^{293}$ Com efeito, a Resolução do INAMPS n. 258, de 07 de Janeiro de 1991 (NOB 01/91), previa que a atividade ambulatorial seria remunerada de acordo com (a) o critério populacional, (b) o empenho global e (c) o índice de reajuste com base na Unidade de Cobertura Ambulatorial - UCA - definido como um valor fixado em resolução da União, que classificaria os Estados dentro dos seguintes critérios: população, capacidade instalada, qualidade e desempenho técnico da rede de serviços de saúde do Estado. A Portaria MS n. 234 de 07 de fevereiro de 1992 (NOB 01/92), por sua vez, passou a definir que a UCA classificaria os Estados dentro dos critérios de população, capacidade instalada, complexidade da rede, desempenho financeiro em 1991 e desempenho da auditoria estadual do ano anterior. Quanto ao financiamento das atividades assistenciais em regime de internação hospitalar, a remuneração dar-se-ia proporcionalmente à população e à quantidade e complexidade dos procedimentos realizados pela unidade da federação, por intermédio da adoção da chamada Autorização de Internação Hospitalar - AIH. Vê-se, portanto, uma supervalorização da produtividade em detrimento do incentivo às redes mais carentes.

${ }^{294}$ Conselho Nacional de Secretários Municipais de Saúde

${ }^{295}$ FALEIROS et al, A Construção do SUS: Histórias da Reforma Sanitária e do Processo Participativo, p. 144.
} 
É inegável que tal estrutura centralizadora do financiamento decorreu da tradição herdada do INAMPS, autarquia federal que, antes da Constituição de 1988, figurava como "centro nervoso" do sistema de saúde brasileiro. Apesar da criação de um Ministério da Saúde, o INAMPS, ainda após a promulgação da Constituição de 1988, continuava sendo tratado como fio condutor do sistema. Tal situação só veio a se modificar com a extinção desta instituição em 1993, mesmo assim sem que resquícios da "cultura inampiana" - para usar a feliz expressão de Santos e Andrade - desaparecessem, em virtude da manutenção do financiamento centralizado e fragmentado ${ }^{296}$.

Os problemas referentes às NOBs 01/91 e 01/92 foram amenizados nas NOBs 01/93 e 01/96, consideradas verdadeiros marcos no processo de descentralização da saúde no Brasil.

A NOB $01 / 93^{297}$ foi a primeira das normas operacionais básicas a levar em consideração para fins de financiamento o fato de que os entes subnacionais encontram-se em estágios diferentes em relação à descentralização do sistema, de forma que não poderiam todos serem tratados de forma igual. $\mathrm{O}$ tratamento diferenciado serviria para ampliar e aprimorar suas condições de gestão com o sentido de efetivar o comando único do SUS nas três esferas de governo. Assim, a NOB 01/93 previu modalidades para as condições de gestão dos entes subnacionais, quais sejam, incipiente, parcial e semiplena (para os Estados, apenas estas duas últimas ${ }^{298}$, criando um mecanismo de transferência direta, fundo a fundo, de um teto global da assistência para estes últimos. A transferência de recursos direta permitiria uma maior autonomia do ente beneficiado e um incentivo à efetiva descentralização sem os vícios das normativas anteriores. Segundo Ugá et al, no entanto, embora a nova regra tenha sido uma iniciativa

\footnotetext{
296 SANTOS; ANDRADE, SUS: o Espaço da Gestão Inovada e dos Consensos Interfederativos: aspectos jurídicos, administrativos e financeiros, p. 38-39.

${ }^{297}$ Portaria MS 545, de 20 de maio de 1993

298 Além destas condições de gestão nomeadas, a NOB 01/93 também previa a situação do ente que não se enquadrasse em nenhuma das hipóteses, estando aquém de todos os critérios mínimos de capacidade de autogestão. Para os Municípios nessa situação, a norma previa um "programa de capacitação" sob responsabilidade do Estado. Quanto aos Estados nessa situação, eles seriam enquadrados na condição de gestão incipiente, descrita na norma.
} 
positiva, em janeiro de 1997 apenas 144 municípios estavam classificados nesta categoria de gestão semiplena ${ }^{299}$.

No campo da participação social e do controle democrático, foi a NOB 01/93 que oficializou a criação da Comissão Intergestores Tripartite (CIT), no âmbito nacional, e das Comissões Intergestores Bipartite (CIBs), no âmbito estadual, compostas paritariamente por gestores dos entes federativos. Juntamente com os Conselhos de Saúde, tais Comissões ampliaram o espaço deliberativo do SUS, estimulando o diálogo democrático. Tratam-se de importantes espaços de negociação, pactuação, articulação e integração entre os entes federados.

Importante ainda ressaltar que a edição da NOB 01/93 ocorreu no mesmo ano da extinção do INAMPS ${ }^{300}$, então mergulhado em denúncias de corrupção. Tratou-se de um importante movimento pela descentralização, naquele conturbado ano de 1993 para o setor da saúde pública brasileira.

Outra norma operacional básica considerada bastante relevante é a NOB $01 / 96^{301}$. O objetivo da norma, no campo estrito do financiamento, era reduzir os fluxos baseados na produtividade, visando à ampliação dos repasses de caráter global, fundo a fundo. Tais repasses se dariam com base na Programação Pactuada Integrada (PPI), instrumento instituído para funcionar como pacto entre os gestores das três esferas de governo, dando o primeiro grande passo à regionalização da saúde. Segundo Ugá et al, todavia, a PPI só se consolidou a partir da vigência da Norma Operacional de Assistência à Saúde (NOAS) 01/01, a qual será tratada mais adiante.

Ademais, a NOB 01/96 deixou explícita a preocupação com a criação de condições elementares e fundamentais para a eficiência e a eficácia gerenciais com qualidade, questão que vai ao encontro da necessidade de conciliação entre os critérios de equidade e eficiência, conforme salientado no segundo capítulo desta dissertação. Segundo a norma em comento,

A ameaça da ocorrência de gastos exagerados, em decorrência de um processo de incorporação tecnológica acrítico e desregulado, é um risco que pode ser

\footnotetext{
${ }^{299}$ UGÁ et al, descentralização e alocação de recursos no âmbito do Sistema Único de Saúde, p. 420.

${ }^{300}$ Lei 8.689/93, Dispõe sobre a extinção do Instituto Nacional de Assistência Médica da Previdência Social (Inamps) e dá outras providências

${ }^{301}$ Portaria MS 2.203, de 05 de novembro de 1996
} 
minimizado pela radicalização na reorganização do SUS: um Sistema regido pelo interesse público e balizado, por um lado, pela exigência da universalização e integralidade com equidade e, por outro, pela própria limitação de recursos, que deve ser programaticamente respeitada.

Esses dois balizamentos são objeto da programação elaborada no âmbito municipal, e sujeita à ratificação que, negociada e pactuada nas instâncias estadual e federal, adquire a devida racionalidade na alocação de recursos em face às necessidades.

Em suma, propunha-se a reformulação do modelo assistencial, para que fosse instituída uma atenção à saúde menos fragmentada (mais integrada) mediante redes regionalizadas e hierarquizadas, além do que para que o modelo clínico fosse menos voltado para a doença e mais voltado para o paciente, na linha daquilo que fora sugerido na Declaração de Alma-Ata ${ }^{302}$, fortalecendo a atenção básica e a atenção aos determinantes sociais da doença em detrimento do atendimento especializado e hospitalar.

Segundo Ugá et al, ao buscar reorganizar o modelo de atenção à saúde no país, a NOB 01/96 realizou tarefa que nenhuma outra norma até então tinha promovido. Para estes autores, o maior benefício da NOB 01/96, nessa linha de raciocínio, foi o estabelecimento de um novo sistema de financiamento para custeio das ações de atenção básica sob gestão municipal, ao criar um valor per capita nacional (PAB fixo) e de incentivos financeiros para o desenvolvimento de outras ações da atenção básica, especialmente a implantação de equipes da saúde da família e de agentes comunitários de saúde (PAB variável). Quanto aos repasses para financiamento das ações de média e alta complexidade, a lógica permaneceu centrada na remuneração por serviços produzidos (exceto para os Municípios de gestão plena, que seriam beneficiados com repasses globais) ${ }^{303}$.

Outra relevante inovação da NOB $01 / 96$ foi a definição explícita de gerência e gestão, de forma a diferenciar estas duas funções dentro do sistema. Segundo dispôs a norma,

....independentemente da gerência dos estabelecimentos prestadores de serviços ser estatal ou privada, a gestão de todo o sistema municipal é, necessariamente, da competência do setor público e exclusiva desta esfera de governo, respeitadas as atribuições do respectivo Conselho e de outras diferentes instâncias de poder.

\footnotetext{
${ }^{302}$ Vide item 1.2 do primeiro capítulo.

${ }^{303}$ UGÁ et al, descentralização e alocação de recursos no âmbito do Sistema Único de Saúde, p. 421.
} 
Assim, nesta NOB gerência é conceituada como sendo a administração de uma unidade ou órgão de saúde (ambulatório, hospital, instituto, fundação etc.), que se caracteriza como prestador de serviços ao Sistema. Por sua vez, gestão é a atividade e a responsabilidade de dirigir um sistema de saúde (municipal, estadual ou nacional), mediante o exercício de funções de coordenação, articulação, negociação, planejamento, acompanhamento, controle, avaliação e auditoria. São, portanto, gestores do SUS os Secretários Municipais e Estaduais de Saúde e o Ministro da Saúde, que representam, respectivamente, os governos municipais, estaduais e federal.

A criação e o funcionamento desse sistema municipal possibilitam uma grande responsabilização dos municípios, no que se refere à saúde de todos os residentes em seu território. No entanto, possibilitam, também, um elevado risco de atomização desordenada dessas partes do SUS, permitindo que um sistema municipal se desenvolva em detrimento de outro, ameaçando, até mesmo, a unicidade do SUS. Há que se integrar, harmonizar e modernizar, com equidade, os sistemas municipais.

No que tange ao trecho destacado, estava o Ministério da Saúde preocupado com as disputas horizontais entre Municípios, bem como as disputas verticais entre estes e o próprio Estado, geradas pelas NOBs anteriores. O sistema de financiamento criado por estas normas acarretou uma política de "salve-se quem puder", onde cada ente disputava por mais recursos para $\mathrm{si}^{304}$. Por consequência, nenhum Município queria receber dentro da sua rede pacientes não residentes, pois isto significaria, na prática, "jogar dinheiro fora".

No mais, as modalidades de gestão dos entes subnacionais foram reduzidas na NOB 01/96 a duas, quais sejam, gestão plena da atenção básica e gestão plena do sistema (para Municípios) e gestão avançada do sistema e gestão plena do sistema (para Estados).

A NOB 01/96 conseguiu efetivamente promover a habilitação dos Municípios aos modelos de gestão avançada. Segundo Ugá et al, até o início do ano de 2000 mais de 4950 Municípios se habilitaram à gestão plena da atenção básica e 564 à gestão plena de seus sistemas ${ }^{305}$.

Uma dificuldade revelada por essa norma, todavia, foi a excessiva segmentação dos repasses, estratégia que cerceia a autonomia dos Municípios que recebem tais repasses ${ }^{306}$. Com efeito, a NOB 01/96 criou diversos tetos financeiros, cada um com uma função (e.g., Teto financeiro da Assistência - TFA, Teto Financeiro da Vigilância Sanitária - TFVS, Teto Financeiro da

\footnotetext{
${ }^{304}$ Ibid.

${ }^{305}$ Ibid., p. 421-422.

${ }^{306}$ Ibid., p. 419-420.
} 
Epidemiologia e Controle de Doenças - TFECD etc.), e que seriam definidos de forma pactuada com base na PPI. A excessiva segmentação abriu margem para a proliferação de incentivos financeiros, isto é, repasses "carimbados" para programas específicos, na linha de ações sanitárias verticalizadas ${ }^{307}$.

Segundo Servo et al, foi em razão dessa excessiva segmentação dos repasses - que enrijecia o poder de decisão das esferas subnacionais e gerava indesejada fragmentação da atenção à saúde - que foi concebido em 2006 o "Pacto pela Saúde"308. Trata-se, na realidade, do conjunto de três pactos, o "Pacto em Defesa do SUS"309, o "Pacto pela Vida"310 e o "Pacto de Gestão"311, sendo este último o que prevê as novas regras de financiamento no que tange às relações intergovernamentais (repasses entre entes federativos), concentrado na Portaria $n$. 204/07. Por intermédio desse novo regramento as transferências de recursos federais passaram a ser automáticas, dependendo exclusivamente de homologação da CIB de cada estado, sendo ordenadas em apenas cinco grandes blocos atenção básica, atenção de média e alta complexidade, vigilância à saúde, assistência farmacêutica e gestão ${ }^{312}$.

Luiz Odorico Monteiro de Andrade escrevera já em 2004 que o problema das NOBs foi pretender articular os entes federados de forma excessivamente burocratizada, sem prestigiar a busca por resultados. Ademais, os Municípios eram tratados como se fossem todos iguais, objetivando um padrão de gestão idêntico para todos eles, independentemente do tamanho de cada um. Assim, segundo o autor, os SUS pós-NOB deveria estabelecer novos pressupostos, quais sejam,

\footnotetext{
${ }^{307}$ Ibid., p. 422.

${ }^{308}$ Portarias GM/MS n. 399/06, 699/06, 3.085/06, 3.332/06 e 204/07.

${ }^{309}$ Segundo definição da Portaria n. 399/06, "O Pacto em Defesa do SUS envolve ações concretas e articuladas pelas três instâncias federativas no sentido de reforçar o SUS como política de Estado mais do que política de governos; e de defender, vigorosamente, os princípios basilares dessa política pública, inscritos na Constituição Federal".

${ }^{310}$ Segundo definição da Portaria n. 399/06, "O Pacto pela Vida está constituído por um conjunto de compromissos sanitários, expressos em objetivos de processos e resultados e derivados da análise da situação de saúde do País e das prioridades definidas pelos governos federal, estadual e municipais. Significa uma ação prioritária no campo da saúde que deverá ser executada com foco em resultados e com a explicitação inequívoca dos compromissos orçamentários e financeiros para o alcance desses resultados".

${ }^{311}$ Segundo definição da Portaria n. 399/06, "O Pacto de Gestão estabelece as responsabilidades claras de cada ente federado de forma a diminuir as competências concorrentes e a tornar mais claro quem deve fazer o quê, contribuindo, assim, para o fortalecimento da gestão compartilhada e solidária do SUS".

${ }^{312}$ SERVO et al, Financiamento e Gasto Público de Saúde: histórico e tendências, p. 97.
} 
Primeiro: respeito ao princípio federativo, à autonomia de cada ente como gestor único do SUS no município;

Segundo: qualificação dos municípios, considerando suas características regionais na operacionalização do seu papel de gestor único do sistema municipal de saúde; $\mathrm{e}$

Terceiro: necessidade de articulação e colaboração dos entes federados - dos municípios entre si com os estados e com a União - com vistas à conquista de melhores resultados de saúde para a população ${ }^{313}$.

De fato, o Pacto pela Saúde seguiu a linha proposta nos comentários deste autor, tendo o novo regramento providenciado uma melhoria no sistema de financiamento, na medida em que deixou de tratar os Municípios como "meros prestadores de serviços" financiados pelo Ministério da Saúde, finalmente emancipando-os em suas funções e responsabilidades. Os Municípios então deixaram de precisar passar por um processo de habilitação como gestores, sendo tal relação subserviente substituída por um vínculo pactuado por intermédio do chamado termo de compromisso, instrumento que passou a formalizar os acordos entre os entes federativos em matéria de saúde, abarcando metas e plano operativo $^{314}$. Em resumo, pretendeu-se avançar no sentido da gestão compartilhada e solidária do SUS.

Apesar dos esforços, todavia, é consenso que o Pacto de Gestão do SUS, de 2006, não logrou alcançar seus objetivos, não tendo sido capaz de eliminar o problema da fragmentação excessiva dos repasses financeiros da União para os entes subnacionais por atividade assistencial. Repasses extremamente vinculados a programas específicos e com normatizações próprias (Política Nacional de Atenção ao Portador de Doença Renal, Política Nacional de Atenção Cardiovascular de Alta Complexidade, Política Nacional de Atenção Integral em Reprodução Assistida, Política Nacional de Atenção ao Portador de Doença Neurológica etc.) continuaram acontecendo, reduzindo imensamente a autonomia dos Municípios e mantendo a insensatez do processo de descentralização do sistema de saúde brasileiro.

\footnotetext{
313 ANDRADE, Luiz Odorico Monteiro de, O SUS pós-NOB II, Revista do CONASEMS, 2004.

314 SANTOS; ANDRADE, SUS: o Espaço da Gestão Inovada e dos Consensos Interfederativos: aspectos jurídicos, administrativos e financeiros, p. 83.
} 
Santos e Andrade foram precisos na crítica ao Pacto pela Saúde 2006 ao afirmarem que

Na realidade, o Pacto pela Saúde 2006, a despeito de ser uma forma eficiente de definir consensualmente a organização, o funcionamento e o financiamento do SUS, traz em seu bojo um tanto do DNA das normas operacionais anteriores, uma vez que mantém todas as modalidades de transferência de recursos da União para os demais entes, vinculadas ao atendimento de determinados programas ${ }^{315}$.

Essa excessiva capilaridade dos repasses financeiros federais tornou dificultosa a fiscalização do sistema sob o aspecto de sua eficiência, especialmente em razão do fato de que as especialidades não são necessariamente estanques. Um paciente cardiovascular, por exemplo, muitas vezes possui outros problemas de saúde conexos. A multimorbidade é uma realidade crescente, especialmente em razão do envelhecimento populacional, e esse fato não pode ser ignorado.

Carvalho et al, no entanto, salientam a vantagem do novo regramento, ressaltando o avanço dos instrumentos democráticos e da regionalização. Segundo os autores,

O foco é dado aos acordos relativos a diretrizes e processos essenciais ao funcionamento do sistema, enfatizando a responsabilidade e as atribuições das diferentes instâncias governamentais com amplas possibilidades de adequação às especificidades regionais, sem exigência explícita de cobrança de quaisquer requisitos de estrutura, de aferimento cartorial ${ }^{316}$.

Insta salientar, por fim, que o Pacto pela Saúde não revogou as normas anteriormente vigentes, considerando que, em relação aos repasses financeiros, caberia aos Municípios aderirem - ou não - ao Pacto de Gestão do SUS. Sem a adesão pela assinatura do Termo de Compromisso permaneceria vigendo a NOB 01/96 bem como a NOAS 01/02 (que será adiante comentada).

Em 2011, a então Presidente da República Dilma Rousseff editou o Decreto n. 7.508/11 que tem por escopo regulamentar a Lei 8.080/90 com a

\footnotetext{
${ }^{315}$ Ibid., p. 87.

${ }^{316}$ CARVALHO, Déa et al, O Sistema Único de Saúde, uma retrospectiva e principais desafios, in: ALVES, Sandra Mara Campos; DELDUQUE, Maria Celia; DINO NETO, Nicolao (Orgs.), Direito Sanitário em Perspectiva, Brasília: Escola Superior do Ministério Público da União: Fiocruz, 2013, v. 2, p. 82.
} 
intenção de finalmente substituir todas as Portarias anteriormente mencionadas (NOBs, NOASs e Pacto pela Saúde). De mais relevante, este Decreto instituiu os chamados Contratos Organizativos da Ação Pública da Saúde (COAP), acordo de colaboração a ser firmado entre entes federativos com a finalidade de organizar e integrar as ações e serviços de saúde, com definição de responsabilidades, indicadores e metas, critérios de avaliação, recursos financeiros etc. (art. $2^{\circ}$, II). Lamentavelmente, todavia, a efetiva implementação deste Decreto ainda não é uma realidade pois, conforme salientam Ouverney et al, as diferenças de contextos de cada ente federativo (capacidade de oferta, recursos financeiros, níveis de conflito político, capacidade institucional e de gestão) faz com que cada Estado tenha implementado o COAP em um ritmo próprio ${ }^{317}$.

Em 2012, em atenção ao comando contido no art. 195, parágrafo $10^{318}$ (introduzido pela EC 20/98), e no art. 198, parágrafo $3^{\mathrm{o} 19}$ (introduzido pela EC 29/00), da CRFB/88, a LC 141/12 entrou em vigor passando a prever novos critérios e metodologia para rateio dos recursos da União e dos Estados, revogando o parágrafo $1^{\mathrm{o}}$ do art. 35 da Lei 8.080/90 e, por força da lógica, também o art. $3^{\circ}$ da Lei 8.142/90. A LC 141/12, sendo genérica nas suas determinações, acabou legitimando a prática de regular a matéria por meio de norma infralegal ${ }^{320}$.

317 OUVERNEY, Assis Mafort; RIBEIRO, José Mendes; MOREIRA, Marcelo Rasga, O COAP e a Regionalização do SUS: os diversos padrões de implementação nos estados brasileiros, Revista Ciência \& Saúde Coletiva, v. 22, n. 4, p. 1193-1207, 2017.

${ }^{318}$ Art. 195. A seguridade social será financiada por toda a sociedade, de forma direta e indireta, nos termos da lei, mediante recursos provenientes dos orçamentos da União, dos Estados, do Distrito Federal e dos Municípios, e das seguintes contribuições sociais: (...) § 10. A lei definirá os critérios de transferência de recursos para o sistema único de saúde e ações de assistência social da União para os Estados, o Distrito Federal e os Municípios, e dos Estados para os Municípios, observada a respectiva contrapartida de recursos.

319 Art. 198. As ações e serviços públicos de saúde integram uma rede regionalizada e hierarquizada e constituem um sistema único, organizado de acordo com as seguintes diretrizes: (...) $\S 3^{\circ}$ Lei complementar, que será reavaliada pelo menos a cada cinco anos, estabelecerá: $(\ldots)$ II - os critérios de rateio dos recursos da União vinculados à saúde destinados aos Estados, ao Distrito Federal e aos Municípios, e dos Estados destinados a seus respectivos Municípios, objetivando a progressiva redução das disparidades regionais

${ }^{320}$ Deve-se pontuar que não se pretende aqui fazer uma crítica a tal opção legislativa. Pelo contrário, segundo Santos e Andrade, as questões relacionadas à descentralização das ações e serviços de saúde, à integralidade da atenção, ao financiamento, e, em suma, à organização da rede hierarquizada e regionalizada, "não podem ser resolvidas pela lei - não há como uma lei definir o que cabe a cada instância de governo diante da diversidade do desenvolvimento econômico social de cada município. (...) Somente as definições periódicas e consensuais poderão dar conta dessa tarefa". SANTOS; ANDRADE, SUS: o Espaço da Gestão Inovada e dos Consensos Interfederativos: aspectos jurídicos, administrativos e financeiros, p. 108. 
A LC 141/12 teve o mérito de estabelecer que a metodologia para cálculo do valor a ser repassado pela União e pelos Estados deverá ser pactuada na CIT ou CIB, respectivamente, bem como ser aprovada pelo Conselho Nacional ou Estadual de Saúde (art. $17 \S 1^{\circ}$, e art. 19, $\S 1^{\mathrm{o} 321}$ ). Trata-se, indubitavelmente, de uma vitória da democracia, mas o fortalecimentos destes órgãos paritários ainda deve enfrentar um longo caminho no Brasil. Tais órgãos ainda estão longe de contarem com a infraestrutura e a força política desejada para construção das decisões alocativas de forma efetivamente democrática. A estruturação tecnológica, técnica e financeira, bem como a capacitação contínua dos gestores e o suporte aos processos eleitorais dos Conselhos de Saúde são medidas essenciais para evolução desses processos no Brasil, permitindo a alocação mais racional dos recursos públicos em saúde e viabilizando escolhas mais conscientes e benéficas a toda a sociedade.

Considerando que o financiamento do SUS permaneceu objeto de normas infralegais, cabe mencionar que, em setembro de 2017, o Ministério da Saúde, consciente do excessivo número de Portarias que regulamentavam os mais diversos temas a respeito da organização do SUS (mais de 17 mil), desenvolveu um projeto que denominou de "projeto do Código do SUS", consistente em 06 atos normativos com o objetivo de facilitar a gestão do sistema. Seis "Portarias de consolidação" foram editadas, cada uma a respeito de um eixo temático, sendo que a Portaria de consolidação n. 06 (DOU n. 190 de 03/10/2017) trata da

\footnotetext{
${ }^{321}$ Art. 17. O rateio dos recursos da União vinculados a ações e serviços públicos de saúde e repassados na forma do caput dos arts. 18 e 22 aos Estados, ao Distrito Federal e aos Municípios observará as necessidades de saúde da população, as dimensões epidemiológica, demográfica, socioeconômica, espacial e de capacidade de oferta de ações e de serviços de saúde e, ainda, o disposto no art. 35 da Lei no 8.080, de 19 de setembro de 1990, de forma a atender os objetivos do inciso II do $\S 30$ do art. 198 da Constituição Federal. §10 O Ministério da Saúde definirá e publicará, anualmente, utilizando metodologia pactuada na comissão intergestores tripartite e aprovada pelo Conselho Nacional de Saúde, os montantes a serem transferidos a cada Estado, ao Distrito Federal e a cada Município para custeio das ações e serviços públicos de saúde. (...) (grifo nosso)

Art. 19. O rateio dos recursos dos Estados transferidos aos Municípios para ações e serviços públicos de saúde será realizado segundo o critério de necessidades de saúde da população e levará em consideração as dimensões epidemiológica, demográfica, socioeconômica e espacial e a capacidade de oferta de ações e de serviços de saúde, observada a necessidade de reduzir as desigualdades regionais, nos termos do inciso II do $\S 3^{\circ}$ do art. 198 da Constituição Federal. §10 Os Planos Estaduais de Saúde deverão explicitar a metodologia de alocação dos recursos estaduais e a previsão anual de recursos aos Municípios, pactuadas pelos gestores estaduais e municipais, em comissão intergestores bipartite, e aprovadas pelo Conselho Estadual de Saúde. (...) (grifo nosso)
} 
Consolidação das normas sobre financiamento e a transferência dos recursos federais para as ações e os serviços de saúde do SUS.

Finalmente, uma última atualização nesta matéria sujeita a tanta instabilidade legislativa aconteceu bem recentemente, em 28 de dezembro do ano de 2017. A Portaria MS 3992/2017 publicada no apagar das luzes deste ano tem a pretensão de novamente reformar o modelo de financiamento do SUS, extinguindo os blocos de financiamento e concentrando os repasses federais em apenas duas categorias: custeio de ação e serviços públicos de saúde e bloco de investimentos. Seria esta nova Portaria uma complementação ao processo iniciado em setembro pela Portaria de consolidação n. 06.

Consta do portal eletrônico do Ministério da Fazenda que

Para o ministro da Saúde, Ricardo Barros, a medida diminui a burocracia e evita que recursos fiquem parados nas contas dos municípios. "Estamos estabelecendo um modelo de repasse onde passaremos recursos apenas para custeio e investimento. Essa ação vai permitir mais flexibilidade ao gestor na aplicação do recurso durante o ano. Com isso, vamos simplificar a prestação de contas, diminuir a burocracia e dá autonomia ao município e ao conselho municipal de saúde", afirmou o ministro.

(...)

Na prática, os gestores estaduais e municipais passam a ter mais autonomia, porém com mais responsabilidade na execução dos recursos para saúde. A aplicação da verba fica interligada ao plano de saúde local, respeitando o cumprimento do orçamento federal, como o financiamento da atenção básica, vigilância em saúde e assistência farmacêutica ${ }^{322}$.

Não obstante as críticas feitas parágrafos acima à fragmentariedade dos repasses em blocos de financiamento e à falta de autonomia dos Municípios, deve-se ter cautela na análise deste "novo modelo" de financiamento proposto. Além de ser ainda muito recente - o que impede um exame mais profundo e abalizado de suas possíveis consequências - o novo regramento veio a lume em um momento emblemático do país, de crise econômica e de reformas constitucionais com tendências a prejudicar o macrofinanciamento do SUS (Emendas Constitucionais 86/15 e 95/16) ${ }^{323}$. A possibilidade de o "novo modelo" ser usado para gerar distorções no sentido de diminuir os investimentos em

\footnotetext{
${ }^{322}$ MINISTÉRIO DA SAÚDE, Novo modelo de financiamento do SUS garante eficiência no uso de recursos, Brasília: Ministério da Saúde, 2017.

${ }^{323}$ Vide item 4.3 neste capítulo.
} 
atenção básica, assistência farmacêutica e vigilância em saúde em favor do incremento dos recursos para média e alta complexidade é muito grande. Caso confirmada tal tendência, apenas os interesses das corporações privadas terá sido valorizado, em razão das margens lucrativas desta espécie de assistência, conforme fora explicado no terceiro capítulo ${ }^{324,325}$.

Feita toda essa digressão histórica a respeito da normatização dos repasses federais para os entes subnacionais - sobretudo para os Municípios - no âmbito do financiamento do SUS, é chegado o ponto crucial da crítica aqui proposta. A respeito do processo de descentralização dos recursos federais em saúde, é importante registrar as observações de Melamed, para quem, apesar de ter sido possível verificar no Brasil um aumento real dos recursos federais aplicados em saúde a partir do ano de 1996 - especialmente pelo incremento dos gastos com Atenção Básica - não há registro da efetiva melhoria na produção do SUS, isto é, do aumento do volume e qualidade da prestação de saúde pelo Poder Público naquele período, especialmente no que tange à média e alta complexidade ${ }^{326}$. Deve ser levado em conta, ademais, que a maioria dos índices sanitários que registram uma melhoria das condições de saúde no Brasil tomam por base indicadores isolados como mortalidade infantil e expectativa de vida ${ }^{327}$. Tais indicadores nunca demonstraram ser os melhores para avaliação do desempenho do sistema de saúde integralmente considerado. Pesquisadores da área da saúde já vem se utilizando de indicadores mais confiáveis, tais como o quality-adjusted life years (QALY), o disability-adjusted life years (DALY) e o health-adjusted life years (HALY), índices esses ainda pouco utilizados pelos bancos de dados brasileiros.

Não se pretende aqui negar as melhorias no atendimento à saúde no Brasil. Conforme diversas vezes afirmado, a atenção básica, por intermédio do Programa Estratégia Saúde da Família (ESF), vivenciou um forte avanço nas últimas duas décadas. Todavia, o avanço da atenção básica retrata justamente o modelo

\footnotetext{
324 FUNCIA, Francisco, Nota introdutória sobre a nova portaria da CIT que trata das transferências SUS fundo a fundo, [s.1.]: CEBES, 2017.

${ }^{325}$ Observe-se que a nova Portaria tem como paradigmas as Reuniões da CIT de 26/01 e 14/12 de 2017.

${ }^{326}$ MELAMED, Regulamentação, Produção de Serviços e Financiamento Federal do Sistema Único de Saúde: dos anos 90 aos 2000, p. 75-76.

${ }^{327}$ ORGANIZAÇÃO MUNDIAL DA SAÚDE, Brazil: WHO statistical profile.
} 
dicotômico do sistema de saúde brasileiro: as clínicas de saúde da família e os agentes comunitários servem basicamente à população mais carente econômica e financeiramente no Brasil, fato que revela que o serviço público de saúde é direcionado a esta camada da população (um sistema "para os pobres").

Já foi afirmado anteriormente neste trabalho a importância da atenção primária à saúde, por meio de ações básicas amplas e abrangentes, conforme preconizava a Conferência de Alma-Ata ${ }^{328}$. A atenção primária à saúde no Brasil ganhou reforço especialmente a partir da NOB 01/96, que instituiu mecanismos de transferências financeiras que incentivaram o desenvolvimento de ações básicas como a implantação de equipes da saúde da família e de agentes comunitários de saúde (PAB variável).

No entanto, conforme observa Giovanella e Mendonça, esse reforço não foi de todo benéfico à universalização da atenção primária. Segundo as autoras, em que pesem as boas intenções do Programa Saúde da Família do governo central,

Ainda assim, [o Ministério da Saúde] mantinha características de uma APS seletiva, pois o PSF incialmente foi implantado como programa focalizado em populações muito pobres, com cesta restrita de serviços e baixa articulação com o restante da rede assistencial.

(...)

$\mathrm{Na}$ trajetória desses programas de estruturação da atenção primária de caráter abrangente no país, observa-se forte associação entre sua experimentação e o processo de descentralização em diferentes dimensões, como na reorientação do modelo médico-assistencial e na revisão da condução da atenção primária. Assim, tais programas possibilitaram às experiências municipais ampliar a cobertura $\mathrm{e}$ melhorar os indicadores de saúde, ao valorizar as ações de promoção e proteção integral e contínua da saúde, as quais transformam gradualmente as práticas sociais em saúde.

Todavia, sua implementação ocorre de diferentes modos, e ainda são poucos os estudos que permitem saber se mudanças substanciais foram efetivamente implementadas no modelo assistencial ${ }^{329}$.

As observações acima levam à conclusão de que, no Brasil, não existe uma prática efetivamente planejada de financiamento sustentável do sistema de saúde. As necessidades sanitárias são mal avaliadas, as escolhas alocativas mal

\footnotetext{
${ }^{328}$ Vide item 1.2 do primeiro capítulo.

${ }^{329}$ GIOVANELLA, Ligia; MENDONÇA, Maria Helena Magalhãe de, Atenção primária à saúde no Brasil, in: ALVES, Sandra Mara Campos; DELDUQUE, Maria Celia; DINO NETO, Nicolao (Orgs.), Direito Sanitário em Perspectiva, [s.1.]: ESMPU - Fiocruz, 2013, v. 2, p. 132-133.
} 
processadas e as decisões implementadas de forma pouco eficientes. Os métodos de supervisionamento dos resultados tampouco resultam em avaliações seguras sobre os efeitos dos investimentos realizados.

Retomando a análise de Melamed, pode-se afirmar que, a partir dos processos de descentralização da saúde, a União precisou elevar os valores nominais destinados à área da saúde mas, concomitantemente, os entes subnacionais também tiveram de aumentar seus investimentos. Sobretudo os Municípios passaram a ser os grandes executores das ações sanitárias porque o dinheiro repassado pela União não era suficiente para lhes garantir um conforto nesta tarefa. Em suma, a direção municipal do SUS era (e continua sendo) subfinanciada em razão da reiterada postura do governo federal de desinvestir na área da saúde.

Ugá et al informam que

Até meados da década de 1990, o gasto público em saúde guardava a marca do período anterior à nova Constituição, caracterizado por forte centralização do sistema de saúde e de seu financiamento em nível federal. Assim, em que pese o processo de descentralização tributária introduzido pela nova Carta Constitucional, que não só ampliou a competência tributária de estados e municípios como também elevou o nível das transferências de tributos federais às esferas subnacionais de governo, o nível federal continuava, em 1990, com aproximadamente a mesma participação do gasto público em saúde que nos anos 80, responsabilizando-se por $73 \%$ dessa despesa. No decorrer dos anos 90 , observou-se ligeira diminuição da participação do governo central nesse gasto, em razão essencialmente do papel mais ativo inicialmente exercido pelo municípios $^{330}$.

O que ocorre é que, a partir da edição das NOBs acima mencionadas, os Municípios (e, especificamente a partir da NOB 01/96, os Estados), aumentaram gradativamente o percentual de suas participações no gasto em saúde. O incentivo de descentralização implementado pelas NOBs acarretou um aumento da participação dos entes subnacionais e consequente diminuição percentual da participação da União. Enquanto no ano de 1993 a União participava com 72\% e os Municípios com 16\% dos gastos em saúde, no ano de 2000 essa situação se

\footnotetext{
${ }^{330}$ UGÁ; PORTO; PIOLA, Financiamento e Alocação de Recursos em Saúde no Brasil, p. 408.
} 
inverteu: a participação da União caiu para $60 \%$ e a dos Municípios elevou para $22 \%{ }^{331}$.

Assim, por mais que seja verdadeiro que, em valores absolutos, os investimentos federais aumentaram, isto não significou um verdadeiro incremento na participação da União no financiamento da saúde. Pelo contrário. Ao mesmo tempo em que a execução das ações e serviços estavam sendo descentralizadas, a União ia gradativamente diminuindo, em termos percentuais, a sua participação no respectivo custeio, deixando Municípios nitidamente desamparados.

Isso tudo agravado pelo fato já mencionado de que o ente federal sempre foi quem tem mais ampla capacidade tributária, sendo aquele que mais arrecada dentre os três entes federativos, possuindo inquestionável supremacia financeira. A autonomia gerencial dos Municípios depende dos repasses dos recursos federais.

Não custa relembrar que o próprio inciso VII do art. 30 da Constituição estabelece que aos Municípios cabe prestar serviços de atendimento à saúde da população com a cooperação técnica e financeira da União e do Estado.

Ademais, o inciso I do art. 198 da Constituição, ao elencar a descentralização como uma das diretrizes do SUS, o faz sob a garantia da direção única em cada esfera de governo ${ }^{332}$. Isso significa dizer que cada ente federativo deve possuir autonomia para gerir suas próprias ações sanitárias, fato que só ocorrerá se o ente possuir disponibilidade de recursos financeiros para fazer frente a tal responsabilidade. No entanto, é cediço que a autonomia de um governo resta absolutamente aniquilada se os seus recursos orçamentários são suprimidos.

No final, tem-se o desinvestimento federal somado à verticalização das ações locais. Políticas feitas com base em campanhas emergenciais (vide as campanhas de controle das epidemias de cólera e demais formas de diarreia, as campanhas anuais contra a dengue, a campanha da Zika etc.), fazendo com que recursos continuem sendo gastos sem qualquer eficiência e violando as diretrizes do SUS de cobertura universal e integral.

\footnotetext{
${ }^{331}$ Ibid.

332 Art. 198. As ações e serviços públicos de saúde integram uma rede regionalizada e hierarquizada e constituem um sistema único, organizado de acordo com as seguintes diretrizes: I - descentralização, com direção única em cada esfera de governo
} 


\subsubsection{2 \\ Desvinculação de Receitas da União: um mecanismo adicional para mitigação da responsabilidade da União no custeio do SUS}

Ao já imbricado cenário de mitigação da participação financeira da União no custeio das ações e serviços de saúde soma-se a chamada desvinculação de receitas da União - DRU, verdadeiro golpe final no sistema de repartições constitucionais das responsabilidades dos entes federativos quanto ao custeio do SUS.

No subitem anterior tratou-se da descentralização do SUS sob o enfoque dos mecanismos de rateio dos recursos vinculados à saúde entre os entes federativos, mediante transferências intergovernamentais.

Além do rateio das verbas da saúde, nos termos das portarias do Ministério da Saúde e conforme os critérios legais previstos na Lei 8.080/90 e na LC 141/12, existe ainda, como suporte à política de descentralização, a regra de repartição de receitas tributárias prevista nos arts. 157 a 159 da CRFB/88.

Não será possível neste estudo um enfrentamento detalhado destas regras de repartição de receitas tributárias, principalmente porque não faz parte do escopo temático aqui proposto as questões de Direito Tributário ou de Direito Financeiro em geral. Interessa ao presente estudo apenas a parcela desta repartição de receitas que seja destinada a ser alocada em ações e serviços de saúde.

De fato, conforme discutido no terceiro capítulo, quando a EC 29/00 entrou em vigor, passou a prever a destinação obrigatória de uma fatia do orçamento dos três entes federativos às ações e serviços de saúde. Tanto o art. 77 do ADCT quanto a LC 141/12 (que regulamentou a EC 29/00) previram que os entes subnacionais teriam que destinar um percentual de suas receitas para este fim, sendo que tal percentual incidiria sobre o produto da arrecadação dos impostos próprios bem como sobre a receita destas transferências tributárias previstas nos artigos 157 a 159 da CRFB/88. É neste ponto - e somente nele - que tais artigos interessam neste estudo. Por consequência da regra prevista nos artigos $6^{\circ}$ e $7^{\circ}$ da LC 141/12, quanto maior for a transferência tributária constitucional, maior será o investimento na saúde pelos entes subnacionais.

No entanto, lamentavelmente, ao mesmo tempo em que a Constituição de 1988 se preocupou com a fixação de transferências de receitas do ente mais rico (União) aos entes mais pobres (subnacionais), o texto constitucional - de certa 
forma contraditoriamente - igualmente permitiu que a União instituísse outras fontes de receitas para o financiamento do SUS, receitas essas que não se submeteriam a tal rateio.

Explica-se. Apesar de os artigos 157 a 159 da CRFB/88 terem estabelecido a repartição de receitas tributárias, eles só trataram da distribuição do produto da arrecadação de impostos e da contribuição de intervenção no domínio econômico (quanto a essa última, somente a partir da EC 42/03). As contribuições sociais para financiamento da seguridade social (incluem ações de saúde), previstas no art. 195 da Constituição, se sujeitam a regramento diverso, não se submetendo à repartição com os entes subnacionais.

Considerando tal circunstância, a União historicamente deu preferência à instituição de novas contribuições sociais, conforme lhe autoriza o parágrafo $4^{\circ}$ do art. 195 da CRFB $/ 88^{333}$, em detrimento da instituição de novos impostos, como poderia fazer de acordo com o disposto no inciso I do art. 154 da mesma Carta $^{334}$.

Arguta é a observação de Élida Pinto, ao perceber que

A União não exerceu a competência residual (art. 154, I) de que é titular no período pós-CR/1988 para criar novos impostos, pois, se o fizesse, 20\% (vinte por cento) de sua arrecadação deveriam ser repartidos com os estados segundo o disposto no art. 157, II, da Constituição. Poder-se-ia arguir que tal omissão decorreria da complexidade da instituição de novos impostos, mas a falta de manejo dessa competência residual deve ser confrontada com o fato de que o Poder Executivo Federal tem instituído novas fontes de receita majoritariamente na forma do que lhe autorizam os arts. 149 e 195, $\S 4$ o, da Constituição ${ }^{335}$.

Um primoroso exemplo do que se está a expor encontra-se na instituição da CPMF, no ano de 1996. Ademais, segundo informam Servo et al, "as contribuições sociais (COFIN, CSLL e CPMF), desde 1997, foram responsáveis

\footnotetext{
333 Art. 195. A seguridade social será financiada por toda a sociedade, de forma direta e indireta, nos termos da lei, mediante recursos provenientes dos orçamentos da União, dos Estados, do Distrito Federal e dos Municípios, e das seguintes contribuições sociais: (...) $\S 4^{\circ} \mathrm{A}$ lei poderá instituir outras fontes destinadas a garantir a manutenção ou expansão da seguridade social, obedecido o disposto no art. 154, I.

${ }^{334}$ Art. 154. A União poderá instituir:

I - mediante lei complementar, impostos não previstos no artigo anterior, desde que sejam nãocumulativos e não tenham fato gerador ou base de cálculo próprios dos discriminados nesta Constituição;

${ }_{335}$ PINTO, Financiamento dos direitos à saúde e à educação: uma perspectiva constitucional, p. $193-194$.
} 
por mais de $70 \%$ do financiamento do MS [Ministério da Saúde], chegando a mais de $90 \%$ em 2005 „336.

Élida Pinto, com base em informações elaboradas pela Assessoria Técnica da Secretaria de Orçamento Federal, do Ministério do Planejamento, Orçamento e Gestão, indica que, de 1988 a 2003, o valor das transferências obrigatórias da União aos Estados e Municípios reduziu-se à metade ${ }^{337}$. Conclui-se que por intermédio do incremento de contribuições sociais a União reduz o percentual de transferências tributárias aos demais entes.

Trata-se de um mecanismo censurável aplicado deliberadamente pelo governo central, reduzindo sensivelmente a sua participação no custeio das ações de saúde e consequentemente sobrecarregando os entes subnacionais, sobretudo os Municípios, já tão limitados orçamentariamente.

Élida Pinto vai além em sua observação crítica:

\begin{abstract}
Nisso não haveria problema algum não fosse a circunstância de, posteriormente à instituição de contribuições sociais, a União desvincular parcialmente - por meio de emendas constitucionais - o produto de sua arrecadação para tredestiná-lo a fins diversos dos que justificaram a instituição daquelas. Ou seja, criaram-se contribuições na forma do que dispõe o art. 149 da CR/1988, assim como houve ampliação da arrecadação das já existentes, porque se sabe ser todo o volume arrecadado integralmente absorvido pela União, para, a seguir, no curso da execução orçamentária, haver tredestinação de tal receita vinculada para finalidades diversas ${ }^{338}$.
\end{abstract}

Além de desmontar o esquema de descentralização vislumbrado pela Constituinte, o governo federal foi ainda mais implacável no desmantelamento do financiamento do SUS, por intermédio da criação das hipóteses de "desvinculação de receitas" criadas em 1994 (Fundo Social de Emergência - FSE), 1996 (Fundo de Estabilização Fiscal - FEF) e 2000 (Desvinculação de Receitas da União DRU), nos artigos 71, 72 e 76 do ADCT.

$\mathrm{Na}$ realidade, apesar de as contribuições sociais serem espécies tributárias que deveriam ser instituídas com destinação específica (art. 149 da CRFB/88), tal característica foi descartada (de forma constitucionalmente duvidosa) pelo

\footnotetext{
${ }^{336}$ SERVO et al, Financiamento e Gasto Público de Saúde: histórico e tendências.

${ }^{337}$ PINTO, Financiamento dos direitos à saúde e à educação: uma perspectiva constitucional, p. 192.

${ }^{338}$ Ibid., p. 193-194.
} 
governo federal, que estabeleceu que os recursos arrecadados sob o nomen iuris de contribuição social para financiamento da seguridade social seriam desviados para outras finalidades "mais relevantes". Ou seja, após instituir a espécie tributária cujo produto deveria ser destinado a investimentos em seguridade social, a União, por meio de emendas constitucionais, transfere os montantes arrecadados para despesas outras. Tal regime, que deveria ser considerado excepcional e provisório, vem sendo prorrogado desde 1994, já tendo contado com 08 emendas de prorrogação.

Notável é o resumo crítico elaborado pela sempre precisa Élida Pinto, reproduzido a seguir integralmente em virtude do seu habitual rigor.

A despeito do caráter adicional de proteção trazido pela Emenda Constitucional $\mathrm{n}$. 29/2000, que dispôs sobre percentual mínimo de gasto público nas ações e serviços públicos de saúde, e nada obstante as contribuições sociais (que expressam fonte vinculada de receita), a política pública de saúde segue, como dantes, marcada pelo signo da instabilidade fiscal provocada, em larga escala, pela União, e replicada pelos estados.

Dito de forma muito genérica, o que a União tem feito, desde a instituição da desvinculação de receitas em 1994, especialmente no âmbito da seguridade social, é:

a) arrecadar mais por meio de tributos dotados de destinação específica que, em função disso, estão alheios à sistemática constitucional de repartição obrigatória entre os entes (de que tratam os arts. 157 a 159). No caso da saúde, trata-se das contribuições sociais destinadas ao financiamento solidário da seguridade social, à luz do art. 195 da CR/1988;

b) descentralizar para estados e municípios mais ações de diversas políticas públicas prestacionais, como, de fato, sucedeu-se com o SUS, com o que, a própria União se desincumbe, correspondentemente, da execução direta de tais despesas;

c) não distribuir o produto da arrecadação majorada com estados e municípios em nome da aludida destinação dos tributos que deram ensejo ao maior volume de ampliação de receitas tributárias; e

d) paradoxalmente, não aplicar a totalidade daqueles recursos onde constitucionalmente eles deveriam ser aplicados, por força de mecanismo transitório de desvinculação de receitas insistentemente prorrogado no ADCT. $^{339}$

${ }^{339}$ Ibid., p. 103-104. 


\subsection{3 \\ Regionalização}

Todos os desafios da descentralização apontados nos subitens anteriores poderiam ser mitigados por intermédio da implementação de uma política focada em medidas de cooperação mútua.

O TCU apontou no seu acórdão 2.888/2015 a importância dos processos colaborativos, mediante a "organização dos serviços de saúde em redes e em regiões de saúde, de modo a otimizar o uso dos recursos por municípios próximos e possibilitar a integralidade no atendimento dos cidadãos de cada região"340

O processo de regionalização na conformação de sistemas universais de saúde não é recente e foi vislumbrado pioneiramente na Inglaterra, no Relatório Dawson, documento produzido após a Primeira Guerra Mundial e que tinha por objetivo organizar os serviços de saúde daquele país por região, definindo bases territoriais e redes regionalizadas de serviços de saúde ${ }^{341}$.

Melamed registra que, no Brasil, mesmo após a edição das NOBs 01/93 e 01/96, os Estados e Municípios enfrentaram diversas dificuldades neste processo de descentralização das atividades assistenciais e de assunção de funções adicionais em seus sistemas de saúde, mormente em razão de suas incapacidades gerenciais. As deficiências eram (e, de certa forma, continuam sendo) de diversas dimensões, especialmente no que tange à incapacidade dos entes subnacionais de gerarem diagnósticos analíticos de suas redes, bem como quanto aos mecanismos de interação interestadual ou intermunicipal (particularmente as referências na oferta de serviços de média e alta complexidade) $)^{342}$.

Destas dificuldades surgiu a necessidade de ampliação do papel dos Estados como entes responsáveis pela coordenação regional dos serviços, mediador dos conflitos entre Municípios e gerente do sistema na esfera regional. Agora já sob a égide da EC 29/00 a Portaria GM-MS 95/2001 (Norma Operacional de Assistência à Saúde - NOAS 01/01) deu início ao processo de regionalização, propondo ainda um Plano Diretor de Regionalização. A NOAS

\footnotetext{
340 TRIBUNAL DE CONTAS DA UNIÃO, Acórdão TCU 2.888/2015, p. 9.

${ }^{341}$ LIMA et al, Regionalização da Saúde no Brasil, p. 831.

342 MELAMED, Regulamentação, Produção de Serviços e Financiamento Federal do Sistema Único de Saúde: dos anos 90 aos 2000, p. 69.
} 
01/01 organizou o sistema geograficamente, estabelecendo novos conceitos de território base para planejamento da atenção à saúde, regionalizando e hierarquizando de forma mais efetiva a prestação. Os fluxos de referência ficaram mais claros e lógicos, melhorando o acesso da população.

A maior dificuldade enfrentada é a resistência de gestores estaduais em transferir o comando de unidades de saúde (e respectivos leitos) para os gestores dos municípios habilitados para gestão plena do sistema municipal. Por outro lado, os gestores municipais desconfiam do elenco de procedimentos financiados, indagando sobre a conveniência do acordo. Por fim, disputas locais permanecem existindo na definição dos municípios referência (consequentemente, municípios com comando sobre leitos) ${ }^{343}$. O que se tem aqui é, basicamente, uma reprodução das disputas herdadas do histórico oligárquico brasileiro e que permanece exercendo suas influencias até os dias atuais.

Estas resistências acarretaram a revisão da NOAS 01/01, provocando a edição da NOAS $01 / 02^{344}$ com algumas adaptações que conferiram maiores comandos a certos Municípios. Sobre o assunto, Melamed assevera

\begin{abstract}
Contudo, nunca é demais frisar que pouco se avançou em relação à reorganização efetiva da rede de média e alta complexidade e seus respectivos provedores públicos, filantrópicos ou privados credenciados ao SUS em todo o País. Pode-se até mesmo dizer que, a partir da mal-sucedida evolução deflagrada por ambas as NOAS, o processo de discussão e organização do conjunto do sistema sofre ruptura metodológica ainda não devidamente analisada pela literatura sobre o assunto.

O conteúdo de um conjunto de portarias editadas pelo Ministério da Saúde entre 2003 e 2009, que permanecem em vigor, confirma nova orientação implícita na modelagem de programas de saúde nacionais e, na prática, propõem um diálogo com a reorganização inconclusa implementada a partir da NOAS 01/2001 e $01 / 2002$. No período citado, foram propostas desde a criação de novas políticas referentes a tratamentos e/ou procedimentos até a (re)estruturação de políticas e programas já tradicionais do SUS ${ }^{345}$.
\end{abstract}

Percebe-se que a tentativa de organização de forma descentralizada, regionalizada e hierarquizada do sistema por intermédio de normas infralegais foi

\footnotetext{
${ }^{343}$ Ibid., p. 70-71.

${ }^{344}$ Portaria GM/MS373/2002

345 MELAMED, Regulamentação, Produção de Serviços e Financiamento Federal do Sistema Único de Saúde: dos anos 90 aos 2000, p. 70-71.
} 
frustrada por diversas dificuldades vinculadas à própria fragilidade da federação brasileira.

Em 2011, o Decreto 7.508 que dispõe sobre a articulação interfederativa no planejamento e execução dos serviços de saúde, criou novos mecanismos que poderiam colaborar neste aspecto. O Contrato Organizativo da Ação Pública da Saúde (COAP) é o novo instrumento de pactuação entre os entes, porém, conforme explicitado anteriormente, a implementação deste Decreto até hoje não foi bem sucedida ${ }^{346}$.

De tudo o que foi dito até aqui - considerando inclusive o exposto no capítulo precedente -, pode-se concordar com a crítica de Faleiros, para quem

\begin{abstract}
A disputa por verbas, entre os ministros da Saúde e da Previdência, entre os ministros da Saúde e da Fazenda, entre secretários estaduais e municipais de saúde e o ministro da Saúde, entre governos estaduais e governo federal, entre secretários municipais e secretários estaduais de saúde, entre governos municipais e governos estaduais, caracteriza a dinâmica institucional de relações no setor. Por outro lado, o usuário sofre, no cotidiano, as consequências do sucateamento dos serviços com longas filas, falta de material, pessoal desmotivado, infra-estrutura desgastada, fraudes constantes. Não há como negar a existência de funcionários "missionários" que, apesar das dificuldades, tentar superar os problemas para atender à população ${ }^{347}$.
\end{abstract}

\title{
4.2 \\ A EC 29/00 e o tratamento diferenciado (privilegiado) da União quanto ao custeio do SUS
}

Adicionalmente a tudo o que foi dito até aqui, pode-se afirmar que o lastimável cenário de subfinanciamento federal do SUS restou consolidado a partir da EC 29/00. Além dos fatos mencionados no item anterior, a redução da parcela federal no custeio do SUS também ocorreu em razão da forma de cálculo dos recursos mínimos obrigatórios que deveria a União despender em ações e serviços de saúde, segundo previsão contida nos parágrafos $2^{\circ}$ e $3^{\circ}$ do art. 198 da $\mathrm{CRFB} / 88$.

\footnotetext{
${ }^{346}$ Segundo acórdão TCU 2.888/2015, até o fechamento daquele relatório (dezembro de 2016), os COAPs haviam sido formalizados em apenas 24 regiões de saúde em apenas dois estados (Ceará e Mato Grosso do Sul). TRIBUNAL DE CONTAS DA UNIÃO, Acórdão TCU 2.888/2015, p. 10.

${ }^{347}$ FALEIROS et al, A Construção do SUS: Histórias da Reforma Sanitária e do Processo Participativo, p. 119-120.
} 
Conforme adiantado no capítulo anterior, a EC 29/00 introduziu os mencionados parágrafos do art. 198 da Constituição, passando a dispor sobre um mínimo de gasto em ações e serviços públicos de saúde mas deixando a cargo do legislador ordinário a fixação dos respectivos percentuais que deveriam ser aplicados por cada ente federativo. Enquanto não fosse editada a mencionada lei o que efetivamente só veio a ocorrer no ano de 2012 (LC 141/12), a regra aplicável seria aquela prevista no art. 77 do Ato das Disposições Constitucionais Transitórias (ADCT), também introduzido pela mesma emenda.

Segundo o art. 77 do $\mathrm{ADCT}^{348}$, os valores aplicados em saúde deveriam ser (i) para a União, o valor apurado no ano anterior, corrigido pela variação nominal do PIB, (ii) para os Estados, o percentual de $12 \%$ do produto da arrecadação dos impostos estaduais e das suas receitas decorrentes da regra constitucional de repartição de receitas tributárias e (iii) para os Municípios, o percentual de $15 \%$ do produto da arrecadação dos impostos municipais e das suas receitas decorrentes da regra constitucional de repartição de receitas tributárias.

Élida Pinto defende que a diferença dos critérios estabelecidos para a União, de um lado, e para Estados e Municípios, de outro (enquanto estes últimos

\footnotetext{
${ }^{348}$ Art. 77. Até o exercício financeiro de 2004, os recursos mínimos aplicados nas ações e serviços públicos de saúde serão equivalentes:

I - no caso da União:

a) no ano 2000, o montante empenhado em ações e serviços públicos de saúde no exercício financeiro de 1999 acrescido de, no mínimo, cinco por cento;

b) do ano 2001 ao ano 2004, o valor apurado no ano anterior, corrigido pela variação nominal do Produto Interno Bruto - PIB;

II - no caso dos Estados e do Distrito Federal, doze por cento do produto da arrecadação dos impostos a que se refere o art. 155 e dos recursos de que tratam os arts. 157 e 159, inciso I, alínea a, e inciso II, deduzidas as parcelas que forem transferidas aos respectivos Municípios; e

III - no caso dos Municípios e do Distrito Federal, quinze por cento do produto da arrecadação dos impostos a que se refere o art. 156 e dos recursos de que tratam os arts. 158 e 159, inciso I, alínea b e $\S 3^{\circ}$.

$\S 1^{\circ}$ Os Estados, o Distrito Federal e os Municípios que apliquem percentuais inferiores aos fixados nos incisos II e III deverão elevá-los gradualmente, até o exercício financeiro de 2004, reduzida a diferença à razão de, pelo menos, um quinto por ano, sendo que, a partir de 2000, a aplicação será de pelo menos sete por cento.

$\S 2^{\circ}$ Dos recursos da União apurados nos termos deste artigo, quinze por cento, no mínimo, serão aplicados nos Municípios, segundo o critério populacional, em ações e serviços básicos de saúde, na forma da lei.

$\S 3^{\circ}$ Os recursos dos Estados, do Distrito Federal e dos Municípios destinados às ações e serviços públicos de saúde e os transferidos pela União para a mesma finalidade serão aplicados por meio de Fundo de Saúde que será acompanhado e fiscalizado por Conselho de Saúde, sem prejuízo do disposto no art. 74 da Constituição Federal.

$\S 4^{\circ} \mathrm{Na}$ ausência da lei complementar a que se refere o art. 198 , $\S 3^{\circ}$, a partir do exercício financeiro de 2005, aplicar-se-á à União, aos Estados, ao Distrito Federal e aos Municípios o disposto neste artigo.
} 
deveriam aplicar um percentual sobre suas receitas, a União ficaria vinculada ao valor despendido no ano anterior, apenas atualizado pelo resultado do produto interno bruto) tinha por objetivo privilegiar o ente federal. Segundo a autora,

(...) o critério de cálculo do patamar mínimo de gasto da União (seja tal como definido no ADCT, seja na LC n. 141/2012) preocupou-se apenas com a variação nominal do PIB, desconhecendo a necessidade de manter alguma referência de proporção com o crescimento da própria Receita Corrente Líquida federal.

$\mathrm{Na}$ forma do art. 77 do ADCT e dos arts. $5^{\circ}$ a $8^{\circ}$ da LC n. 141/2012, enquanto os estados e municípios devem gastar com a política pública de saúde determinado percentual fixo da receita de impostos e transferências constitucionais, a União não tem qualquer vinculação de gasto com o comportamento progressivo, ou não, de sua receita.

Isso, por si só, tem permitido ao Governo Federal despregar-se de qualquer proporção histórica de gasto em saúde em face do volume total das suas receitas. Como se verá adiante, o crescimento das receitas correntes federais tem sido, na média, consideravelmente superior à variação do PIB. Por essa razão é que se fala, desde já, em regressividade do gasto federal em saúde, quando observada a proporção de tal gasto sobre o volume anual da Receita Corrente Líquida ${ }^{349}$.

Não há como negar que, no geral, a EC 29/00 significou de fato um acréscimo no volume de recursos destinados à saúde, protegendo esse setor da histórica disputa com os orçamentos da assistência e previdência ${ }^{350}$. Este acréscimo na destinação à saúde, todavia, concentrou-se basicamente no aporte de recursos pelos entes federativos subnacionais, deixando a União cada vez mais confortável quanto à sua responsabilidade no financiamento do $\mathrm{SUS}^{351}$.

De fato, a União foi a grande privilegiada não só pela emenda como também pela sua regulamentação por intermédio da comedida LC 141/12 $2^{352}$.

\footnotetext{
${ }^{349}$ PINTO, Financiamento dos direitos à saúde e à educação: uma perspectiva constitucional, p. 206-207.

${ }^{350}$ Vide itens 3.3.1 e 3.3.2 no terceiro capítulo.

${ }^{351}$ Segundo o Relatório do Banco Mundial "Um Ajuste Justo", de novembro do ano de 2017, "a expansão do setor público de saúde ao longo da última década levou a aumentos nos gastos. $O$ Brasil realizou investimentos significativos na expansão da cobertura de seu Sistema Único de Saúde (SUS) com o objetivo de expandir a rede de prestação de serviços. Nos dez anos até 2014, as despesas públicas com saúde cresceram a uma taxa real média de 7\%, o que aumentou os gastos públicos com saúde proporcionais ao PIB em 0,5 ponto percentual. No entanto, a maior parte desse aumento nos gastos públicos ocorreu na esfera subnacional. As despesas com saúde do Governo Federal aumentaram levemente, de 1,6\% para 1,7\% do PIB entre 2004 e 2014". GRUPO BANCO MUNDIAL, Um Ajuste Justo - Análise da eficiência e equidade do gasto público no Brasil, p. 109.

352 Quanto à regra prevista na LC 141/12, deve-se registrar que ela modificou pontualmente a redação contida no art. 77, I, $b$, do ADCT, a qual previa que à União caberia aplicar em saúde $o$ valor apurado no ano anterior, corrigido pela variação nominal do Produto Interno Bruto. Diante da dificuldade revelada em se interpretar o real conteúdo do vocábulo "apurado", a LC 141/2012,
} 
Segmentos sociais defendiam, à época da regulamentação da EC 29/00, que o volume do investimento federal ao SUS deveria ser fixado também com base em um percentual da receita deste ente federativo - tal como a regra prevista para os entes subnacionais -, como forma de obrigar a União a efetivamente canalizar seus ganhos para financiar ações sanitárias ${ }^{353}$. Todavia, a postulação não foi atendida e a LC 141/2012 manteve a mesma lógica do regramento do art. 77 do ADCT.

Os dados arrecadatórios dos anos de 2000 em diante demonstram que, em regra, a variação nominal do PIB brasileiro se situa em patamar notadamente inferior à variação nominal da receita corrente líquida da União ${ }^{354}$. Assim, a fixação da regra de participação federal no financiamento das ações e serviços de saúde com base na variação nominal do PIB nitidamente privilegiou este ente federativo. Seus investimentos, em última análise, tornaram-se regressivos, isto é, desproporcionais à sua real capacidade contributiva (considerando o volume da receita arrecadada no mesmo período) ${ }^{355}$.

Ademais, a partir do momento em que o piso da despesa em saúde leva em consideração o valor aplicado em saúde no ano anterior, este piso acaba se tornando o que comumente se chama de "piso-teto", isto é, um piso que nunca é excedido na prática, pois qualquer elevação do valor das despesas em saúde iria influenciar o próprio piso do ano seguinte. Assim, apesar de a União ter demonstrado durante anos seguidos capacidade fiscal para investir em ações e serviços de saúde, ela nunca o fez, para não correr o risco de, no ano seguinte, ficar vinculada a um piso mais elevado.

De fato, não havia qualquer razoabilidade nesse dispositivo, que representava verdadeiro privilégio concedido ao ente federal e merecia reforma.

sem alterar a racionalidade do dispositivo, passou a prever que tal valor seria o correspondente ao empenhado no exercício financeiro anterior [Art. 5o A União aplicará, anualmente, em ações e serviços públicos de saúde, o montante correspondente ao valor empenhado no exercício financeiro anterior, apurado nos termos desta Lei Complementar, acrescido de, no mínimo, o percentual correspondente à variação nominal do Produto Interno Bruto (PIB) ocorrida no ano anterior ao da lei orçamentária anual. (...) § 20 Em caso de variação negativa do PIB, o valor de que trata o caput não poderá ser reduzido, em termos nominais, de um exercício financeiro para o outro].

${ }^{353}$ UGÁ; PORTO; PIOLA, Financiamento e Alocação de Recursos em Saúde no Brasil, p. 407.

354 PINTO, Financiamento dos direitos à saúde e à educação: uma perspectiva constitucional, p. 179-181.

355 Ibid., p. 181. 
Por consequência desse cenário normativo, os Municípios sofreram uma severa sobrecarga financeira ao longo de anos. Além disso, tais entes, com menos potencial arrecadatório, são os primeiros a suportar as pressões sociais e judiciais por melhorias na assistência à saúde ${ }^{356}$.

A planilha a seguir demonstra a queda vertiginosa da proporção federal nos investimentos em saúde desde a promulgação da emenda n. 29/00.

\begin{tabular}{|r|r|r|r|r|r|r|r|r|}
\hline \multirow{2}{*}{ Ano } & \multicolumn{3}{|c|}{ R\$ milhões } & \multicolumn{3}{|c|}{ \% } \\
\cline { 2 - 11 } & \multicolumn{1}{|c|}{ Total } & União & Estados & Municípios & Total & União & Estados & Municípios \\
\hline $\mathbf{2 0 0 0}$ & $\mathbf{6 4 . 7 9}$ & 38.74 & 12.02 & 14.03 & 100 & $59.8 \%$ & $18.6 \%$ & $21.7 \%$ \\
\hline $\mathbf{2 0 0 1}$ & $\mathbf{7 1 . 3 2}$ & 40.04 & 14.73 & 16.55 & 100 & $56.1 \%$ & $20.7 \%$ & $23.2 \%$ \\
\hline $\mathbf{2 0 0 2}$ & $\mathbf{4 7 . 5 2 4}$ & 24.737 & 10.757 & 12.03 & 100 & $52.1 \%$ & $22.6 \%$ & $25.3 \%$ \\
\hline $\mathbf{2 0 0 3}$ & $\mathbf{5 4 . 2 6 4}$ & 27.181 & 13.318 & 13.765 & 100 & $50.1 \%$ & $24.5 \%$ & $25.4 \%$ \\
\hline $\mathbf{2 0 0 4}$ & $\mathbf{6 6 . 3 8 7}$ & 32.704 & 17.273 & 16.41 & 100 & $49.3 \%$ & $26.0 \%$ & $24.7 \%$ \\
\hline $\mathbf{2 0 0 5}$ & $\mathbf{7 7 . 0 9 7}$ & 37.146 & 19.664 & 20.287 & 100 & $48.2 \%$ & $25.5 \%$ & $26.3 \%$ \\
\hline $\mathbf{2 0 0 6}$ & $\mathbf{8 7 . 2 9 7}$ & 40.75 & 22.978 & 23.569 & 100 & $46.7 \%$ & $26.3 \%$ & $27.0 \%$ \\
\hline $\mathbf{2 0 0 7}$ & $\mathbf{9 6 . 7}$ & 44.303 & 25.97 & 26.427 & 100 & $45.8 \%$ & $26.9 \%$ & $27.3 \%$ \\
\hline $\mathbf{2 0 0 8}$ & $\mathbf{1 1 2 . 1 1 7}$ & 48.67 & 30.976 & 32.471 & 100 & $43.4 \%$ & $27.6 \%$ & $29.0 \%$ \\
\hline $\mathbf{2 0 0 9}$ & $\mathbf{1 2 5 . 0 7 2}$ & 58.27 & 32.259 & 34.543 & 100 & $46.6 \%$ & $25.8 \%$ & $27.6 \%$ \\
\hline $\mathbf{2 0 1 0}$ & $\mathbf{1 3 8 . 5 2}$ & 61.965 & 37.264 & 39.291 & 100 & $44.7 \%$ & $26.9 \%$ & $28.4 \%$ \\
\hline $\mathbf{2 0 1 1}$ & $\mathbf{1 5 9 . 8 2 5}$ & 72.332 & 41.487 & 46.006 & 100 & $45,3 \%$ & $26.0 \%$ & $28.8 \%$ \\
\hline $\mathbf{2 0 1 2}$ & $\mathbf{1 7 8 . 1 5 7}$ & 80.063 & 46.054 & 52.04 & 100 & $44,9 \%$ & $25.9 \%$ & $29.2 \%$ \\
\hline $\mathbf{2 0 1 3}$ & $\mathbf{1 9 5 . 4 1 3}$ & 83.053 & 52.435 & 59.925 & 100 & $42,5 \%$ & $26.8 \%$ & $30.7 \%$ \\
\hline $\mathbf{2 0 1 4}$ & $\mathbf{2 1 6 . 8 2 6}$ & 91.899 & 57.542 & 67.385 & 100 & $42,4 \%$ & $26.5 \%$ & $31.1 \%$ \\
\hline $\mathbf{2 0 1 5}$ & $\mathbf{2 3 3 . 2 1 3}$ & 100.46 & 60.538 & 72.215 & 100 & $43,1 \%$ & $26.0 \%$ & $31.0 \%$ \\
\hline $\mathbf{2 0 1 6}$ & $\mathbf{2 4 7 . 7 3 4}$ & 106.718 & 63.312 & 77.704 & 100 & $43,1 \%$ & $25.6 \%$ & $31.4 \%$ \\
\hline
\end{tabular}

Fontes: SPO/MS e SIOPS

Nota: Os valores relativos aos anos de 2000 e 2001 foram copiados de tabela elaborada por Servo et al, com base em dados obtidos no SPO/MS (para a esfera federal) e no RIPSA e SIOPS (para as esferas estadual e municipal) e cujos valores estão deflacionados de 2010 pela média do IPCA ${ }^{357}$. Do ano de 2002 em diante os dados foram extraídos do SIOPS, consultado em setembro de 2017. Os valores são correntes.

A tendência de queda dos investimentos federais retrata o nítido desinteresse da União no financiamento adequado e sustentável do sistema público de saúde, na mesma linha da falta de apoio no processo de descentralização retratada no item anterior, tudo em detrimento do usuário do sistema público de saúde.

Mas nem tudo no campo do financiamento é má notícia. Felizmente, movimentos sociais são bastante atuantes nesse campo e se intensificaram nos anos de 2012 e 2013, sob o título do movimento "Saúde+10", buscando a

\footnotetext{
${ }^{356}$ Ibid., p. 182.

${ }^{357}$ SERVO et al, Financiamento e Gasto Público de Saúde: histórico e tendências, p. 93.
} 
alteração dessa regra para que passasse a obrigar a União à aplicação mínima de $10 \%$ da sua receita corrente bruta em ações e serviços públicos de saúde e $^{358,359}$.

Embora essa reivindicação não tenha sido atendida, a EC 86/15 trouxe uma inovação favorável, ao modificar mais uma vez o art. 198 da CRFB/88, passando a instituir uma nova regra de financiamento para a União, qual seja, a de que o percentual dos recursos federais vinculados à saúde deveria, a partir de então, ser aplicado sobre a receita corrente líquida do ente central.

No item seguinte será analisado o inteiro teor desta emenda, além do teor da EC 95/16, que criou um "Novo Regime Fiscal" a vigorar no Brasil por 20 anos (ao menos). Será esclarecido, no entanto, que, assim como sempre ocorreu na história do sistema de saúde brasileiro, a máxima proteção deste direito fundamental foi preterida em nome de políticas voltadas a outros interesses, sobretudo aqueles protegidos por políticas neoliberais.

\section{3}

\section{As ECs 86/15 e 95/16: nova regra, mesmo enredo, sob o pretexto da recessão econômica}

Duas emendas constitucionais agitaram o cenário do financiamento do SUS nesta segunda década do século XXI. A EC 86/15 novamente alterou os parágrafos $2^{\circ}$ e $3^{\circ}$ do art. 198 da Constituição, naquilo que toca a parcela federal do financiamento da saúde. A EC 95/16, por sua vez, alterou dispositivos do ADCT instituindo um "Novo Regime Fiscal", com vigência pelo prazo de 20 anos financeiros. No que tange ao financiamento da saúde, o art. 110 do ADCT passou a prever que, durante a vigência do Novo Regime Fiscal, os investimentos federais no SUS serão "congelados", isto é, o valor será o mesmo todos os anos, apenas atualizado monetariamente pela variação do Índice Nacional de Preços ao Consumidor Amplo - IPCA.

\footnotetext{
${ }^{358}$ Tal movimento apresentou ao Congresso Nacional, em 2013, projeto de lei complementar de iniciativa popular, contendo 2,2 milhões de assinaturas, com o objetivo de alterar o art. $5^{\circ}$ da LC 141/12. Trata-se do Projeto de Lei Complementar 321 de 2013. FUNCIA, Francisco, Implicações da Emenda Constitucional n. 86/2015 para o processo de financiamento do Sistema Único de Saúde, Revista Consensus - CONASS, n. 15, .

359 ASSOCIAÇÃO NACIONAL DO MINISTÉRIO PÚBLICO EM DEFESA DA SAÚDE, AMPASA assina nota conjunta em favor do Saúde +10 e contra o subfinanciamento da saúde.
} 
Tais emendas, evidentemente, geraram inúmeras reações entre especialistas.

Para compreender tais alterações, é preciso, inicialmente, perceber que do ano de 2014 em seguida o Brasil mergulhou em um profundo período de recessão econômica do qual ainda não se recuperou. Dados do IBGE demonstram uma diminuição do crescimento seguido de vertiginosa queda do Produto Interno Bruto - PIB - brasileiro desde então. A crise revelada pelos índices econômicos foi certamente influenciada por sucessivos escândalos políticos que desvendaram esquemas de corrupção dentro de instituições e do gabinete do governo federal, culminando com a decretação do impedimento da então presidente Dilma Rousseff, em 2016. A instabilidade política do país prejudicou as suas já então fragilizadas finanças.

Nesse contexto, se é certo que movimentos sociais lograram influenciar a modificação da redação do $\S 2^{\circ}$ do art. 198 da Constituição no intuito de prever uma nova forma de cálculo do piso da aplicação de recursos federais em saúde, esta vitória dos movimentos sanitários foi prejudicada por regras transitórias que, na prática, retiraram toda a eficácia do novo regramento.

De fato, a modificação da redação do $\S 2^{\circ}$ do art. 198 da CRFB/88 para que a aplicação de recursos em saúde pela União passasse a ser calculada com base na sua receita corrente anual e não mais com base no montante empenhado no exercício anterior atualizado pela variação nominal do PIB (regra prevista no art. $5^{\circ}$ da LC 141/12) foi, em tese, uma alteração benéfica ao financiamento do SUS, por todos os motivos já delineados no item anterior deste capítulo. No entanto, a EC 86/15 não se limitou a tanto, tendo criado, por intermédio de seu art. $2^{0360}$, uma regra transitória que, na realidade, causou a redução dos valores que

\footnotetext{
${ }^{360}$ Art. $2^{\circ} \mathrm{O}$ disposto no inciso I do $\S 2^{\circ}$ do art. 198 da Constituição Federal será cumprido progressivamente, garantidos, no mínimo:

I - 13,2\% (treze inteiros e dois décimos por cento) da receita corrente líquida no primeiro exercício financeiro subsequente ao da promulgação desta Emenda Constitucional;

II - 13,7\% (treze inteiros e sete décimos por cento) da receita corrente líquida no segundo exercício financeiro subsequente ao da promulgação desta Emenda Constitucional;

III - 14,1\% (quatorze inteiros e um décimo por cento) da receita corrente líquida no terceiro exercício financeiro subsequente ao da promulgação desta Emenda Constitucional;

IV - 14,5\% (quatorze inteiros e cinco décimos por cento) da receita corrente líquida no quarto exercício financeiro subsequente ao da promulgação desta Emenda Constitucional;

$\mathrm{V}-15 \%$ (quinze por cento) da receita corrente líquida no quinto exercício financeiro subsequente ao da promulgação desta Emenda Constitucional.
} 
seriam destinados à saúde caso fossem calculados segundo as regras anteriormente vigentes.

O novo cálculo do piso do financiamento federal da saúde sofreu uma suspensão da sua eficácia, pois do ano 2016 ao ano 2020 deveriam ser aplicados os percentuais previstos nos incisos do art. $2^{\circ}$ da EC 86/15, chamados de "subpisos provisórios" a serem aplicados por 05 anos sucessivos. A justificativa para essa regra transitória seria o estágio de recessão econômica e a necessária adaptação orçamentária. No primeiro ano (2016) o "subpiso" seria de 13,2\% da RCL e este percentual iria crescendo gradativamente até alcançar o patamar de $15 \%$, em 2020 .

Contra tal dispositivo se insurgiu o Ministério Público Federal, propondo Ação Direita de Inconstitucionalidade ${ }^{361}$, cujo pedido liminar foi recentemente deferido. Alega-se, com base em representação dirigida à Procuradoria Federal dos Direitos do Cidadão pela Procuradora do Ministério Público de Contas do Estado de São Paulo, Dra. Élida Graziane Pinto - frequentemente citada no presente estudo - que a regra transitória prevista no art. $2^{\circ}$ da EC 86/15 acabou gerando uma perda estimada para o SUS de, no mínimo, R\$ 10 bilhões, somente no ano de 2016.

Segundo cálculos realizados ${ }^{362}$ comparando quanto deveria ser aplicado em saúde pela União caso fossem seguidas as regras vigentes antes da entrada em vigor da EC 86/15 (ou seja, segundo as regras previstas no art. $5^{\circ}$ da LC 141/12) e quanto deveria ser aplicado em saúde segundo as regras do subpiso previstas no art. $2^{\circ}$ desta Emenda, conclui-se que o subpiso provocou uma redução dos investimentos em saúde. Portanto, tal regra violaria a cláusula pétrea que protege o direito fundamental à saúde. É por esse motivo que a ADI 5.595 foi proposta e teve sua liminar deferida em 31 de agosto de 2017, pelo Min. Ricardo Lewandowski, ao fundamento que "alterações que impliquem retrocesso no

\footnotetext{
${ }^{361}$ Ação direta de inconstitucionalidade 5.595/DF

${ }^{362}$ FUNCIA, Implicações da Emenda Constitucional n. 86/2015 para o processo de financiamento do Sistema Único de Saúde.
} 
estágio de proteção por eles [direitos e garantias fundamentais] alcançado não são admissíveis, ainda que a pretexto de limites orçamentário-financeiros" ${ }^{\text {363,364. }}$.

A propósito do argumento destacado, contido na decisão liminar, reitera-se a compreensão já destacada anteriormente neste estudo de que limites fiscais são uma realidade que deve ser ponderada pelo aplicador do Direito, intérprete da lei. Não pode o jurista ignorar a vida prática, a necessidade de haver dinheiro em caixa do Tesouro para que as demandas sociais possam ser atendidas. No entanto, ainda em tempos de recessão econômica - como são os atuais - devem ser observadas quais são as escolhas prioritárias segundo critérios de eleição democráticos. Tudo o que foi dito no segundo capítulo desta dissertação serve nesse momento para identificar que o Brasil, neste atual momento de recessão econômica, tem elegido realizar cortes nos montantes a serem despendidos em ações e serviços de saúde em detrimento de políticas austeras de reajuste físcal. Não é, todavia, essa a orientação de nossa "Constituição Cidadã". Tal opção vai de encontro à opção democraticamente realizada ao longo da história política do país, fruto de movimentos e lutas sociais liderados por sanitaristas.

O que já era bastante ruim acabou piorando bastante ao final do ano de 2016. Em 15 de dezembro de 2016 foi promulgada a EC 95/16, já sob a égide do governo Michel Temer, marcadamente neoliberal, impondo aquilo que chamou de "Novo Regime Fiscal", a perdurar por 20 anos financeiros, no suposto intuito de recuperar o crescimento econômico da nação.

A EC 95/16 tratou de revogar o art. $2^{\circ}$ da EC 86/15 pois instituiu uma outra regra transitória, agora para vigorar entre 2017 e 2036. Segundo o inciso I art. 110 do ADCT, no ano de 2017 deveria a aplicação de recursos federais em saúde ser calculada segundo a regra geral do $\S 2^{\circ}$ do art. 198 da CRFB/88, isto é, de acordo com a receita corrente líquida da União. Até aqui, a regra aparentemente seria favorável em relação à EC 86/15, pois estaria anulando a regra transitória então combatida pela ADI 5.595 e que trouxe uma diminuição do montante a ser destinado à saúde. Mas isso não passa de uma mera impressão.

\footnotetext{
${ }^{363}$ A ADI ainda discute a regra do art. 3o da EC 86/15, que trouxe outro retrocesso ao passar a incluir no cálculo do mínimo obrigatório previsto na Constituição aqueles gastos em saúde realizados com receitas de exploração do pré-sal.

${ }^{364}$ PINTO, Élida Graziane, STF reconhece o "direito a ter o custeio adequado de direitos" na ADI 5.595, Consultor Jurídico, 2017.
} 
Explica-se. Além de a receita corrente líquida do ano de 2017 ser uma quantia expectada como módica por conta da recessão, o inciso II do mesmo art. 110 do ADCT estabelece o congelamento desta quantia pelos 19 anos seguintes para fins de aplicação em saúde. Em outras palavras, este seria o montante a ser aplicado por 20 anos sucessivos, devendo apenas sofrer um reajuste monetário pelo Índice Nacional de Preços ao Consumidor Amplo - IPCA.

Em face deste dispositivo também foi proposta Ação Direta de Inconstitucionalidade, pelo Partido Democrático Trabalhista - PDT $^{365}$, considerando o autor da demanda que

O que se tem é o entrincheiramento de um mecanismo de controle de gastos públicos, que retira do campo da política ordinária a decisão sobre os meios necessários ao atingimento do equilíbrio fiscal - a partir da EC 95/16, os próximos cinco governos eleitos não poderão sequer elevar os gastos em patamar equivalente ao crescimento das receitas. Com isso, esvazia-se um dos principais aspectos da democracia: a decisão sobre a adequada alocação dos recursos públicos. Ainda que o país recupere sua capacidade de crescimento e eleve substancialmente suas receitas, nenhum governo, nos próximos vinte anos, independentemente do programa apresentado e apresentado nas eleições, poderá incrementar o nível de investimento de recursos públicos para além da inflação. (...)

De outro lado, o congelamento estabelecido pela Emenda Constitucional n. 95/2016 abarca também os gastos com educação e saúde. O aumento da população fará com que os gastos públicos per capita nas áreas de saúde e educação sejam, na verdade, progressivamente reduzidos. Como se demonstrará ao longo da presente petição, as projeções econômicas e financeiras demonstram que a perspectiva é de sério comprometimento das bases materiais que permitem a efetivação desses direitos, providos de máxima fundamentalidade. As promessas contidas na Constituição, relativas à promoção da dignidade da pessoa humana, perdem sua normatividade e tendem a se converter em meros artifícios simbólicos ${ }^{366}$.

Importante notar, neste ponto, que o Novo Regime Fiscal visou a estabelecer tetos de gastos públicos como forma de conter a recessão físcal. No entanto, especialistas observam com curiosidade a completa ausência de qualquer teto de gastos na gestão da dívida pública. Segundo Mendes, Graziane e Funcia, "a dívida bruta do governo geral tem sido desproporcionalmente onerada pela política monetária, bem como pelo expressivo e opaco custo das opções das

\footnotetext{
${ }^{365}$ Ação Direta de Inconstitucionalidade 5.658/2017

${ }^{366}$ ADI 5.658, petição inicial, p. 7-8
} 
políticas cambial e creditícia”, enquanto que os cortes e sacrifícios são basicamente direcionados às políticas sociais e investimentos ${ }^{367}$.

Não é apenas a dívida pública que tem sido desproporcionalmente onerada. Mesmo em tempos de recessão fiscal, análises do orçamento público federal indicam gastos elevados também em propaganda institucional, locomoção de servidores e serviços de consultoria, despesas que sustentam interesses públicos meramente secundários, conforme bem observou Marcos Abraham, para quem "a racionalização do gasto público, sobretudo em um país que ainda apresenta várias demandas sociais a serem satisfeitas, passa também por uma análise criteriosa da prioridade da despesa a ser executada ${ }^{\text {} 368}$.

Diante deste quadro, a Procuradora do Ministério Público de Contas do Estado de São Paulo Dra. Élida Graziane Pinto propõe em seu mais recente artigo o ajuizamento de uma arguição de descumprimento de preceito fundamental $\mathrm{ADPF}$, a fim de questionar o "estado de coisas inconstitucional" na política pública de saúde do país. Segundo a iminente professora,

\begin{abstract}
No caso do direito fundamental à saúde, parece-nos ser inadiável o diagnóstico do Estado de Coisas Inconstitucional quanto à fragilidade e à descontinuidade das políticas públicas que deveriam lhe assegurar efetividade, até para que se evidenciem impasses e omissões históricas na federação brasileira, bem como para que sejam implementadas rotas de pactuação intergovernamental que não sejam preteridas ou fraudadas ${ }^{369}$.
\end{abstract}

Segundo Graziane Pinto, pretender-se-ia por intermédio desta ação, chamar o STF a (i) fixar que o piso constitucional de financiamento da saúde não é apenas uma equação matemática, mas uma garantia material que prime pela redução das disparidades regionais e pelo rateio equitativo das responsabilidades sanitárias e (ii) fixar que os repasses de recursos devem ser tempestivos, de forma que se deem de forma estável, com periodicidade mensal, proporcional à receita efetivamente arrecadada, de forma a assegurar o cumprimento dos compromissos financeiros assumidos por cada $e^{370}$ e (iii) fixar sanções efetivas para

\footnotetext{
367 MENDES, Áquila; GRAZIANE, Élida; FUNCIA, Francisco, O desrespeito à saúde constitucional, Estadão, 2016.

368 ABRAHAM, O orçamento impositivo: uma alternativa possível ao paternalismo judicial, p. 668-669.

${ }^{369}$ PINTO, Estado de Coisas Inconstitucional na política pública de saúde brasileira, p. 7.

${ }^{370}$ Vide item 3.3.4 do terceiro capítulo.
} 
responsabilização de gestores em caso de descumprimento do piso da saúde (e.g., à míngua de qualquer sanção prevista em norma para a União para o caso de deixar de cumprir as regras de transferências obrigatórias, elas acabam sendo constantemente desobedecidas na prática; ademais, quando Estados deixam de cumprir suas metas e são sancionados com a perda das transferências federais nos termos do art. 160, parágrafo único, da $\mathrm{CRFB} / 88$, é o usuário quem acaba sofrendo: melhor seria haver sanção ao gestor e que à União coubesse prestar o custeio não realizado pelo Estado transgressor ${ }^{371}$ ).

Em resumo, o que se percebe no Brasil é que, em quase 3 décadas de uma Constituição que nitidamente se inclina pela proteção dos direitos sociais dos cidadãos, sucessivos governos se recusam a cumprir suas parcelas de responsabilidade no intuito de fazerem valer este compromisso. Padrões neoliberais de incentivo ao livre mercado continuam prevalecendo em detrimento do preceito expressamente contido nos artigos 6 $6^{\circ}, 196$ e 198 da CRFB/88, no sentido de que o Sistema Único de Saúde brasileiro é universal, integral e gratuito, sendo dever do Estado a garantia do direito à saúde, com participação da iniciativa privada apenas em caráter complementar (art. 199, $\S 1^{\circ}, \mathrm{CRFB} / 88^{372}$ ).

Conforme já ressaltado no terceiro capítulo, o sistema brasileiro tem invertido o que é universal para torná-lo suplementar e vice-versa. Isabela Soares Santos bem descreveu esse fenômeno em seu artigo "A solução para o SUS não é um Brazilcare”, confrontando o que vem acontecendo no Brasil com o programa de saúde norteamericano. De forma bastante perspicaz, a autora aponta o equívoco do governo federal em incentivar a proliferação de planos de saúde privados "populares", a baixo custo e com assistência básica. Tal metodologia transfere à iniciativa privada apenas os serviços mais lucrativos e menos custosos, mantendo a cargo do poder público tudo aquilo que for mais dispendioso. A estratégia serve apenas para fragmentar o sistema, quebrando a solidariedade no custeio da saúde e segregando ricos e pobres, como, afinal, sempre ocorreu neste país das

\footnotetext{
${ }^{371}$ PINTO, Estado de Coisas Inconstitucional na política pública de saúde brasileira, p. 7-10.

372 Art. 199. A assistência à saúde é livre à iniciativa privada. $\S 1^{\circ}$ - As instituições privadas poderão participar de forma complementar do sistema único de saúde, segundo diretrizes deste, mediante contrato de direito público ou convênio, tendo preferência as entidades filantrópicas e as sem fins lucrativos.
} 
desigualdades sociais ${ }^{373}$. Ao invés de economizar e gerar crescimento econômico, o governo brasileiro está cultivando resultado diametralmente oposto por intermédio da dita estratégia.

É necessária uma conscientização de que as políticas de austeridade, muito utilizadas durante a década de 1990 e a primeira década do século XXI atualmente já passaram por revisitação dentro até mesmo de instituições como o Banco Mundial e o Fundo Monetário Nacional. O Brasil ainda se encontra bastante atrasado em termos de política econômica e não acompanha novas tendências para determinar o reequilíbrio das economias.

Recente relatório da Conferência da ONU para Comércio e Desenvolvimento (Unctad), lançado em 2017, apontou as políticas de austeridade como um dos motivos para a ausência de crescimento econômico ${ }^{374}$.

Élida Graziane Pinto aponta uma série de exemplos de políticas que poderiam ser implementadas no lugar das políticas austeras que vêm sendo elaboradas pelo governo brasileiro, a exemplo das recentes ECs 86/15 e 95/17, tais como (i) o contingenciamento de despesas discricionárias menos importantes (do que as despesas obrigatórias em saúde e educação) enquanto perdurar a trajetória de receitas decrescentes em face das despesas autorizadas na lei orçamentária anual: e.g., publicidade institucional e shows artísticos, (ii) redução da assunção de novas despesas com novos serviços e obras sem que estejam assegurados os recursos destinados a cumprir obrigação formal preexistente ou situação de emergência, (iii) melhor controle sobre as renúncias de receitas sem lastro, (iv) esgotamento das vias para execução da dívida ativa, com maiores controles sobre os prazos prescricionais e (v) manejo solidário das relações federativas mediante desoneração das prefeituras da responsabilidade por despesas com pessoal temporário e material de consumo destinadas, por exemplo, ao apoio de delegacias de polícia etc. ${ }^{375}$.

Tratam-se de soluções simples e que, se implementadas, conjuntamente com outras medidas (dentre elas as já indicadas ao longo dos capítulos deste

\footnotetext{
${ }^{373}$ SANTOS, A solução para o SUS não é um Brazilcare.

${ }^{374}$ ONU quer fim da austeridade e ousadia para reequilibrar economia, Valor Econômico, 2017.

${ }^{375}$ PINTO, Controle judicial dos orçamentos públicos em prol dos direitos fundamentais.
} 
trabalho), poderiam evitar os históricos desmontes ao SUS que provocam o seu notório sucateamento. 


\section{Conclusão}

A pesquisa desenvolvida por intermédio do presente trabalho teve como pano de fundo a preocupação com os rumos de um sistema de saúde extremamente arrojado para o seu próprio tempo. A instituição do SUS na Constituição da República de 1988 tornou-se um dos marcos regulatórios mais importantes da democracia brasileira, porém ainda carece de implementação efetiva, à míngua de suficientes estruturas políticas e sociais partidárias do seu fortalecimento.

Surgido em um momento de redemocratização do país recém egresso de décadas de ditadura militar, o SUS pretendeu modificar o sistema de saúde brasileiro de forma radical, introduzindo elementos até então completamente estranhos ao modelo vigente, tais como acesso universal, atenção integral, prioridade à prevenção, constituição de redes descentralizadas e regionalizadas etc. Anteriormente, a atenção à saúde era restrita a certas camadas populacionais, voltada a um modelo de prestação biomédico (medicina especializada e concentrada em hospitais) e gerida de forma centralizada e predominantemente terceirizada ao capital privado. Esta tendência de transferência dos serviços de saúde à iniciativa privada, mais interessada em serviços médicos de alta tecnologia (e consequentemente alto custo), mostrou-se incapaz de dar conta de problemas fundamentais de saúde, tais como desnutrição, mortalidade infantil, certas doenças não-transmissíveis (e.g., diabetes) e outros tantos que decorrem das condições sociais, econômicas e culturais do país.

Indubitavelmente, a saúde do ser humano na era contemporânea enfrenta uma série de desafios que passam ao largo de discussões exclusivamente biomédicas. A par das questões enfrentadas pelas ciências da natureza, as políticas de saúde ao redor do mundo são influenciadas sobretudo por questões relacionadas ao modo como o ser humano vive e as sociedades se organizam, não sendo mais possível, em pleno século XXI, raciocinar a respeito dos sistemas de garantias do direito à saúde sem cogitar o imbricado conjunto destas questões.

É neste sentido que a presente pesquisa se utilizou de ensinamentos interdisciplinares, trazendo à ciência jurídica concepções da realidade estudadas tanto pela Medicina Sanitária quanto pela Economia. Demonstrou-se que a 
alocação de recursos financeiros em políticas públicas sanitárias não é uma questão meramente conceitual mas, sobretudo, pragmática, e que portanto depende de processos decisórios planejados, eficientes, transparentes e, principalmente, democráticos.

O limitado espaço de diálogos democráticos no Brasil gera o natural enfraquecimento das diretrizes coletivas do SUS, conquistadas pelo Movimento da Reforma Sanitária e instituídas na $\mathrm{CRFB} / 88$. Consequentemente, a força vinculante dessas diretrizes - sobretudo o acesso universal e o atendimento integral - é sobreposta pelos interesses do capital privado, dentro de uma vertente neoliberal da economia.

Ao investigar os motivos pelo qual o SUS, 30 anos após a sua criação, ainda não gera efetivos resultados positivos em termos de melhoria da qualidade da saúde do cidadão brasileiro, o presente trabalho estampa a delicada situação da democracia brasileira. O Brasil sofre pela carência de processos pré-definidos e democraticamente legítimos para tomada de decisões alocativas de recursos sanitários. Tal fragilidade, conforme demonstrado ao logo do texto, remonta a tradicional forma como o poder é instituído - e mantido - no Brasil. São então apresentadas duas principais respostas para este fracasso do SUS, quais sejam, (i) a precarização do financiamento público da saúde e (ii) a fragilidade do pacto interfederativo na governança do sistema de saúde público.

No que se refere ao financiamento público da saúde, em primeiro lugar, logrou-se demonstrar a excessiva fragmentariedade do sistema de saúde brasileiro, na medida em que há demasiados pools de financiamento decorrentes da existência de planos de saúde privados com oferta de cobertura duplicada à cobertura do sistema público. Este fenômeno é inclusive incentivado pelo poder público, por intermédio de diversos mecanismos, como por exemplo subsídios fiscais para empresas privadas prestadoras de serviços de saúde bem como para despesas privadas em saúde por particulares.

Dentro de uma ótica econômica neoliberal, o papel do Estado se reduz em favor da transferência da responsabilidade pela prestação do serviço de saúde à iniciativa privada. Apesar de a Carta Constitucional prever que a saúde é um direito social que deve ser garantido pelo Estado a todo e qualquer cidadão, na prática os governos brasileiros repassam tal responsabilidade a entidades privadas sem exercer o devido controle sobre este esquema. Ao final, o sistema de saúde é 
fragmentado em dois, um para os ricos que possam pagar por serviços privados e outro para os pobres que dependam do SUS, por sua vez sucateado pela falta de investimentos financeiros.

Em suma, há no Brasil uma completa desvalorização do financiamento público da saúde, sendo certo, ainda, que os processos políticos relacionados ao financiamento do SUS são marcados pela falta de planejamento adequado, por contingenciamentos de despesas ao longo do ano fiscal, pelo descumprimento do percentual mínimo constitucional de vinculação às despesas em saúde etc. São diversos os fatores para a retração dos gastos públicos em saúde.

O segundo fator pontuado neste trabalho como principal motivo da frustração dos objetivos do SUS encontra-se na insuficiência (senão ausência) de uma rede colaborativa entre os entes federados. Apesar de a CRFB/88 ter inaugurado uma forma descentralizada de organização do Estado, fundada em um federalismo cooperativo no intuito de fazer frente às necessidades populacionais dentro de um país com gigantescas dimensões territoriais e desigualdades regionais, tal objetivo não foi alcançado em razão de diversas deficiências de interação entre os entes.

Com efeito, o SUS foi estruturado na Constituição como uma rede regionalizada e hierarquizada de ações e serviços públicos de saúde, o que significa que cada ente federativo deveria contar não só com sua rede própria mas também com a disponibilidade dos serviços existentes na rede de outros entes federativos. Para facilitar esta simbiose, deveria o país ser repartido em regiões de saúde e os serviços serem planejadamente distribuídos pelos entes destas regiões.

No entanto, alguns efeitos negativos do federalismo ganham contornos acentuados no Brasil em virtude de particularidades histórico-culturais deste país (e.g., formação política aristocrática, multiplicidade excessiva de centros de poder), fato que prejudica o sucesso da proposta de regionalização do SUS. São excessivas as disputas federativas por repasses de recursos federais, assim como é praticamente inexistente o diálogo entre gestores para planejamento dos fluxos de pacientes.

Os aspectos problemáticos do financiamento do SUS, evidenciados essencialmente ao longo dos capítulos três e quatro desta dissertação, traduzem um fenômeno notável que provoca uma ampliação da reflexão: ao longo de diversas gerações, desde a formação política deste país, os gestores brasileiros 
mantém um padrão de comportamento que se repete e se reproduz, qual seja, uma forma de governança frágil e de abstenção Estatal, adotando-se uma cultura mercadológica de prestação dos serviços de saúde. São constantes nas políticas de saúde brasileiras a falta de planejamento, a desassociação das ações de saúde aos orçamentos do respectivo ente e o baixo nível de consenso e cooperação federativa.

Tudo isso ressoa na qualidade da assistência ao usuário. A consequência direta deste comportamento inerte dos governantes brasileiros acaba sendo o sucateamento do sistema que, nascido para uma prestação de ponta, permanece no limbo.

É verdade que uma transformação como a pretendida pelo SUS não poderia ser conquistada do dia para a noite, afinal ambicionava-se uma completa transformação dos padrões anteriormente existentes. No entanto, é preciso atentar para o fato de que já se vão 30 anos desde a criação do SUS, sem que muito tenha evoluído (não se nega a evolução quanto à atenção primária, porém ainda insuficiente).

É necessário que esquemas de controle democrático sejam fortalecidos, seja no nível institucional, por intermédio de órgãos de controle como o Tribunal de Contas e o Ministério Público - quanto no nível social, por intermédio da qualificação da participação dos Conselhos de Saúde e demais espaços de diálogo democrático. Sobretudo, faz-se necessário que a saúde seja efetivamente tratada como o bem mais importante do ser humano, sem o qual nenhum outro direito pode ser exercido, e que tal noção seja conciliada com a ideia de que a distribuição de recursos da saúde pode e deve ser feita de forma eficiente pois, conforme ensinou Amartya Sen, distribuir não se contrapõe ao conceito de agregar. Em última análise, é preciso ter em mente que quanto mais saudável uma população for mais rica (inclusive economicamente) ela será, ideia muitas vezes recusada por detentores de poder decisório. Não é possível combater antigos problemas com os remédios de sempre. É necessários uma mudança do padrão de comportamento do gestor público para que sejam alcançados novos (e melhores) resultados em termos de qualidade do sistema de saúde brasileiro. 


\section{6 \\ Referências bibliográficas}

ABRAHAM, Marcus. O orçamento impositivo: uma alternativa possível ao paternalismo judicial. In: RÊGO, Werson (Org.). Segurança Jurídica e Protagonismos Judicial: desafios em tempos de incertezas. Rio de Janeiro: GZ Editora, 2017, p. 655-677.

ABRAMOVAY, Ricardo. O melhor dos tempos, o pior dos tempos. Revista Quatro cinco um, v. 04, n. 01, p. 04-05, 2017.

ALMEIDA, Célia. Reforma de Sistemas de Saúde: tendências internacionais, modelos e resultados. In: GIOVANELLA, Ligia; ESCOREL, Sarah; LOBATO, Lenaura de VAsconcelos Costa; et al (Orgs.). Políticas e Sistema de Saúde no Brasil. 2a ed rev e amp. Rio de Janeiro: Fiocruz, 2012.

ALMEIDA, Célia; CAMPOS, Rodrigo Pires de; BUSS, Paulo; et al. Brazil's conception of South-South "structural cooperation" in health. RECIIS, v. 4, n. 1, p. 23-32, 2010 .

AMARAL, Gustavo. Direito, Escassez \& Escolhas - Em busca de critérios jurídicos para lidar com a escassez de recursos e as decisões trágicas. Rio de Janeiro: Renovar, 2001

ANDRADE, Luiz Odorico Monteiro de. O SUS pós-NOB II. Revista do CONASEMS, 2004.

ANTUNES, André. “A nova PNAB é uma volta ao passado”, diz pesquisadora da Fiocruz. Disponível em: <https://agencia.fiocruz.br/nova-pnab-e-uma-voltaao-passado-diz-pesquisadora-da-

fiocruz?utm_source $=$ Twitter\&utm_medium $=$ AFN\&utm_campaign $=$ campaign $\& u t$ m_term=term\&utm_content $=$ content $>$. Acesso em: 12 set. 2017.

ARROW, Kenneth J. Uncertainty and the welfare economics of medical care. The American Economic Review, v. 53, p. 941-973, 1963.

ASSOCIAÇÃO NACIONAL DO MINISTÉRIO PÚBLICO EM DEFESA DA SAÚDE. AMPASA assina nota conjunta em favor do Saúde + 10 e contra o subfinanciamento da saúde. [s.1.: s.n., s.d.]. Disponível em: $<$ http://www.ampasa.org.br/templates/_176/noticia_visualizar.jsp?idNoticia=1444 2\&idUser=320413\&idEmpresa=50>. Acesso em: 8 nov. 2017. 
ATUN, Rifat A.; BENNETT, Sara; DURAN, Antonio. When do vertical (standalone) programmes have a place in health systems. 2008. Disponível em: $<$ When do vertical (stand-alone) programmes have a place in health systems $>$.

BARBOSA, Swedenberger. Bioética e Direito à Saúde: dilemas. In: ALVES, Sandra Mara Campos; DELDUQUE, Maria Celia; DINO NETO, Nicolao (Orgs.). Direito Sanitário em Perspectiva. Brasilia: ESMPU - Fiocruz, 2013, v. 02. (Pós Graduação).

BARCELLOS, Ana Paula de. Neoconstitucionalismo, direitos fundamentais e controle das políticas públicas. In: QUARESMA, Regina; OLIVEIRA, Maria Lucia de Paula; OLIVEIRA, Farlei Martins Riccio de (Orgs.). Neoconstitucionalismo. Rio de Janeiro: Forense, 2009.

BARROS, Maria Elizabeth; PIOLA, Sérgio Francisco; VIANNA, Solon Magalhãe. Políticas de Saúde no Brasil: diagnóstico e perspectivas. Brasília: Ipea, 1996.

BASILICO, Matthew; WEIGEL, Jonathan; MOTGI, Anjali; et al. Health for All? Competing Theories and Geopolitics. In: FARMER, P; KIM, JY; KLEINMAN, A; et al (Orgs.). Reimagining Global Health: An Introduction. Berkeley: University of California Press, 2013.

BASTOS, Guaracy Martins. A Aplicabilidade das Parcerias Público-Privadas na Área da Saúde no Brasil. Curitiba: CRV, 2016.

BEVERIDGE, William. Beveridge Report. [s.1.: s.n.], 1942. Disponível em: $<$ https://www.sochealth.co.uk/national-health-service/public-health-andwellbeing/beveridge-report/>. Acesso em: 29 ago. 2017.

CARVALHO, Déa; MERCHAN-HAMANN, Edgar; PEREIRA, Márcio Florentino; et al. O Sistema Único de Saúde, uma retrospectiva e principais desafios. In: ALVES, Sandra Mara Campos; DELDUQUE, Maria Celia; DINO NETO, Nicolao (Orgs.). Direito Sanitário em Perspectiva. Brasília: Escola Superior do Ministério Público da União : Fiocruz, 2013, v. 2, p. 71-86.

CENTRO BRASILEIRO DE ESTUDOS DE SAÚDE. Contra a reformulação da PNAB - nota sobre a revisão da Política Nacional de Atenção Básica. Disponível em: <http://cebes.org.br/2017/07/contra-a-reformulacao-da-pnab-notasobre-a-revisao-da-politica-nacional-de-atencao-basica/>. Acesso em: 21 ago. 2017. 
COMITÊ DE DIREITOS ECONÔMICOS SOCIAIS E CULTURAIS DA ORGANIZAÇÃO DAS NAÇÕES UNIDAS. CESCR General Comment No. 14: The Right to the Highest Attainable Standard of Health (Art. 12). Disponível em: $<$ http://tbinternet.ohchr.org/_layouts/treatybodyexternal/Download.aspx?symboln $\mathrm{o}=\mathrm{E} \% 2 \mathrm{fC} .12 \% 2 \mathrm{f} 2000 \% 2 \mathrm{f} 4 \&$ Lang=en $>$. Acesso em: 6 set. 2017.

CONITEC. Fórum discute participação social na incorporação de tecnologias em saúde. Disponível em: <http://conitec.gov.br/ultimas-noticias-3/16795-forumdiscute-participacao-social-na-incorporacao-de-tecnologias-emsaude?platform=hootsuite>. Acesso em: 24 out. 2017.

CONSELHO NACIONAL DO MINISTÉRIO PÚBLICO. Recomendação CNMP n. 48 , de 13 de dezembro de 2016. 2016.

DEATON, Angus. A grande saída: saúde, riqueza e as origens da desigualdade. Trad. Marcelo Levy. [s.1.]: Intrínseca, 2017.

DWORKIN, Ronald. Justice in the Distribution of Healthcare. Mc Gill Law Journal, v. 38, n. 4, p. 883-898, 1993.

ESCOREL, Sarah. História das Políticas de Saúde no Brasil de 1964 a 1990: do golpe militar à reforma sanitária. In: GIOVANELLA, Ligia (Org.). Políticas e Sistema de Saúde no Brasil. 2a ed rev e amp. Rio de Janeiro: Fiocruz, 2012.

ESCOREL, Sarah; TEIXEIRA, Luiz Antonio. História das Políticas de Saúde no Brasil de 1822 a 1963. In: GIOVANELLA, Ligia (Org.). Políticas e Sistema de Saúde no Brasil. 2a ed rev e amp. Rio de Janeiro: Fiocruz, 2012.

FALEIROS, Vicente de Paula; SILVA, Jacinta de Fátima Senna; VASCONCELLOS, Luiz Carlos Fadel; et al. A Construção do SUS: Histórias da Reforma Sanitária e do Processo Participativo. Brasilia: Ministério da Saúde, 2006.

FAN, Victoria Y; SAVEDOFF, William D. The Health Financing Transition: a conceptual framework and empirical evidence. Londres: Results for Development Institute, 2012.

FERRI-DE-BARROS, Fabio; HOWARD, Andrew W.; MARTIN, Douglas K. Inequitable Distribution of Health Resources in Brazil: an analysis of national priority setting. Acta Bioethica, v. 15, n. 2, p. 179-183, 2009.

FLEURY, Sonia; OUVENEY, Assis Mafort. Política de Saúde: uma política social. In: GIOVANELLA, Ligia; ESCOREL, Sarah; LOBATO, Lenaura de 
VAsconcelos Costa; et al (Orgs.). Políticas e Sistema de Saúde no Brasil. 2a ed. rev. e amp. Rio de Janeiro: Fiocruz, 2012.

FUNCIA, Francisco. Implicações da Emenda Constitucional n. 86/2015 para o processo de financiamento do Sistema Único de Saúde. Revista Consensus CONASS, $\quad$ n. 15, Disponível em: $<$ http://www.conass.org.br/consensus/implicacoes-da-emenda-constitucional-n862015-para-o-processo-de-financiamento-sistema-unico-de-saude/>. Acesso em: 7 nov. 2017.

FUNCIA, Francisco. Nota introdutória sobre a nova portaria da CIT que trata das transferências SUS fundo a fundo. [s.1.]: CEBES, 2017. Disponível em: $\quad<$ http://cebes.org.br/2017/01/nota-introdutoria-sobre-a-nova-portaria-da-citque-trata-das-transferencias-sus-fundo-a-fundo/> . Acesso em: 29 dez. 2017.

GALDINO, Flávio. Introdução à teoria dos custos dos direitos: direitos não nascem em árvores. Rio de Janeiro: Lumen Juris, 2005.

GICO JR., Ivo. Introdução ao Direito e Economia. In: TIMM, Luciano Benetti (Org.). Direito e Economia no Brasil. 2a ed. São Paulo: Atlas, 2014.

GIOVANELLA, Ligia; MENDONÇA, Maria Helena Magalhãe de. Atenção primária à saúde no Brasil. In: ALVES, Sandra Mara Campos; DELDUQUE, Maria Celia; DINO NETO, Nicolao (Orgs.). Direito Sanitário em Perspectiva. [s.1.]: ESMPU - Fiocruz, 2013, v. 2, p. 115-146.

GLASSMAN, Amanda; CHALKIDOU, Kalipso; GIEDION, Ursula; et al. Priority-Setting Institutions in Health: Recommendations from a Center for Global Development Working Group. Global Heart, v. 07, n. 01, p. 13-34, 2012. GLOBEKNER, Osmir Antonio. A Saúde entre o Público e o Privado: o desafio da alocação social dos recursos sanitários escassos. Curitiba: Juruá, 2011.

GOMES, Fábio de Barros Correia. Impasses no financiamento da saúde no Brasil: da constituinte à regulamentação da emenda 29/00. Saúde Debate, v. 38, n. 100, p. 06-17, 2014.

GOSTIN, Lawrence O. At Law: The Human Right to Health: A Right to the "Highest Attainable Standard of Health". The Hastings Center, v. 31, n. 2, p. 29 $30,2001$.

GOTTRET, Pablo; SCHIEBER, George. Health financing revisited: a practitioner's guide. Disponível em: 
$<$ http://siteresources.worldbank.org/INTHSD/Resources/topics/HealthFinancing/HFRFull.pdf>. Acesso em: 9 jun. 2017.

GREENE, J; THORP, Basilico M; KIM, H; et al. Colonial medicine and its legacies. In: FARMER, P; KIM, JY; KLEINMAN, A; et al (Orgs.). Reimagining Global Health: An Introduction. Berkeley: University of California Press, 2013. GRUPO BANCO MUNDIAL. Um Ajuste Justo - Análise da eficiência e equidade do gasto público no Brasil. 2017. Disponível em: $<$ http://documents.worldbank.org/curated/en/884871511196609355/pdf/121480REVISED-PORTUGUESE-Brazil-Public-Expenditure-Review-OverviewPortuguese-Final-revised.pdf>. Acesso em: 22 nov. 2017. HOLMES, Stephen; SUNSTEIN, Cass R. The Cost of Rights - Why Liberty Depends on Taxes. New York: W.W. Norton \& Company, 1999.

IRWIN, A; SOLAR, O. A conceptual framework for action on the social determinants of health: social determinants of health discussion paper 2 (policy and practice). 2010. Disponível em: $<$ http://apps.who.int/iris/bitstream/10665/44489/1/9789241500852_eng.pdf>. Acesso em: 6 nov. 2017.

KAWACHI, I; WAMALA (Orgs.). Globalization and Health. New York: Oxford University Press, 2007.

KRUGMAN, Paul. A Consciência de um Liberal. Trad. Alexandre Oliveira Kappaun. Rio de Janeiro: Record, 2010.

LENT, Herman. O Massacre de Manguinhos. Rio de Janeiro: Avenir, 1978.

LIMA, Luciana Dias de; MACHADO, Cristiani Vieira; ALBUQUERQUE, Mariana Vercesi de; et al. Regionalização da Saúde no Brasil. In: GIOVANELLA, Ligia; ESCOREL, Sarah; LOBATO, Lenaura de VAsconcelos Costa; et al (Orgs.). Políticas e Sistema de Saúde no Brasil. 2a ed. rev. e amp. Rio de Janeiro: Fiocruz, 2012, p. 823-852.

LOGIE, Dorothy E; ROWSON, Michael; NDAGIJE, Felix. Rwanda's mutuelles de sante. Lancet, v. 372, p. 256-261, 2008.

LUCCHESE, Patrícia T. R. Equidade na gestão descentralizada do SUS: desafios para a redução de desigualdades em saúde. Ciência e Saúde Coletiva, v. 8, n. 2, p. 439-448, 2003.

MALTA, Deborah Carvalho; SANTOS, Maria Aline Siqueira; STOPA, Sheila Rizzato; et al. A Cobertura da Estratégia de Saúde da Família (ESF) no Brasil, 
segundo a Pesquisa Nacional de Saúde, 2013. Revista Ciência \& Saúde Coletiva, v. 21, n. 2, p. 327-338, 2016.

MARTIN, Marie H.; HALACHMI, Arie. Public-Private Partnerships in Global Health: Addressing Issues of Public Accountability, Risk Management and Governance. Public Administration Quarterly, v. 36, n. 2, p. 189-237, 2012.

MELAMED, C. Regulamentação, Produção de Serviços e Financiamento Federal do Sistema Único de Saúde: dos anos 90 aos 2000. In: MELAMED, C; PIOLA, Sérgio Francisco (Eds.). Políticas Públicas e Financiamento Federal do Sistema Único de Saúde. Brasilia: Ipea, 2011.

MENDES, Áquila; GRAZIANE, Élida; FUNCIA, Francisco. O desrespeito à saúde constitucional. Estadão, 2016. (Blogs Fausto Macedo). Disponível em: $<$ http://politica.estadao.com.br/blogs/fausto-macedo/o-desrespeito-a-saudeconstitucional/>. Acesso em: 8 nov. 2017.

MINISTÉRIO DA SAÚDE. Memórias da Saúde da Família no Brasil. Brasília: [s.n.], 2010. (História da Saúde no Brasil). Disponível em: $<$ http://bvsms.saude.gov.br/bvs/publicacoes/memorias_saude_familia_brasil.pdf $>$. MINISTÉRIO DA SAÚDE. Novo modelo de financiamento do SUS garante eficiência no uso de recursos. Brasília: Ministério da Saúde, 2017. Disponível em: <http://portalms.saude.gov.br/noticias/agencia-saude/42263-novo-modelo-definanciamento-do-sus-garante-eficiencia-no-uso-de-recursos>. Acesso em: 29 dez. 2017.

MIRAGEM, Bruno. Reforma da lei dos planos de saúde não pode vulnerar consumidor. Consultor Jurídico, 2017. Disponível em: $<$ http://www.conjur.com.br/2017-set-13/garantias-consumo-reforma-lei-planossaude-nao-vulnerar-consumidor>. Acesso em: 14 set. 2017.

MONCAYO S., Héctor-Léon. Las nuevas constituciones en américa latina: algunas reflexiones de contexto. EI Otro Derecho, v. 48, 2015.

MONTAGU, Dominic; GOODMAN, Catherine. Prohibit, constrain, encourage, or purchase: how should we engage with the private health-care sector? Lancet, v. 388, p. 613-621, 2016.

MOSSIALOS, Elias; DIXON, Anna. Funding health care: an introduction. In: MOSSIALOS, Elias; DIXON, Anna; FIGUERAS, Josep; et al (Orgs.). Funding health care: options for Europe. Buckingham: Open University Press, 2002. 
O'CINNEIDE, Colm. Austerity and the Faded Dream of a Social Europe. In: NOLAN, A (Org.). Economic and Social Rights after the Global Financial Crisis. [s.1.]: Cambridge University Press, 2014.

OECD. Health expenditure and financing: Health expenditure indicators. OECD Health Statistics (database). Disponível em: $<$ http://dx.doi.org/10.1787/data-00349-en>. Acesso em: 17 ago. 2017.

OECD. PROPOSAL FOR A TAXONOMY OF HEALTH INSURANCE. 2017. Disponível em: $<$ https://www.oecd.org/els/health-systems/31916207.pdf $>$. Acesso em: 10 ago. 2017.

OLMEN, Josefien van; CRIEL, BArt; VAN DAMME, Wim; et al. Analysing Health System Dynamics: A Framework. 2a. ed. [s.1.]: Institute for Tropical Medicine, 2012.

OMS. The World Health Report 2008. Primary Health Care - Now More Than Ever. 2008.

OMS/UNICEF. Declaração de Alma-Ata. Disponível em: $<$ http://www.who.int/publications/almaata_declaration_en.pdf $>$.

ORGANIZAÇÃO DAS NAÇÕES UNIDAS. International Covenant on Economic, Social and Cultural Rights. Disponível em: $<$ https://reaties.un.org/Pages/ViewDetails.aspx?src=TREATY\&mtdsg_no=IV3\&chapter=4\&lang=en $>$. Acesso em: 16 ago. 2017.

ORGANIZAÇÃO MUNDIAL DA SAÚDE. Brazil: WHO statistical profile. 2015. Disponível em: <http://www.who.int/gho/countries/bra.pdf?ua=1>. Acesso em: 10 abr. 2017.

ORGANIZAÇÃO MUNDIAL DA SAÚDE. Constituição da Organização Mundial da Saúde. Disponível em: $<$ http://apps.who.int/gb/bd/PDF/bd47/EN/constitution-en.pdf $>$. Acesso em: 6 set. 2017.

ORGANIZAÇÃO MUNDIAL DA SAÚDE. Everybody business: Health Systems to Improve Health Outcomes: WHO's Framework for Action. Genebra: Organização Mundial da Saúde, 2007.

ORGANIZAÇÃO MUNDIAL DA SAÚDE. Monitoring the Building Blocks of Health Systems: a handbook of indicators and their measurement strategies. 2010. Disponível em: 
$<$ http://www.who.int/healthinfo/systems/WHO_MBHSS_2010_full_web.pdf $>$.

Acesso em: 29 dez. 2017.

ORGANIZAÇÃO MUNDIAL DA SAÚDE. Relatório Mundial da Saúde 2013 Pesquisa para a cobertura universal de saúde. 2013. Disponível em: $<$ http://apps.who.int/iris/bitstream/10665/85761/26/9789248564598_por.pdf?ua= 1>. Acesso em: 19 set. 2017.

ORGANIZAÇÃO MUNDIAL DA SAÚDE. The world health report - Health systems: improving performance. 2000. Disponível em: $<$ http://www.who.int/whr/2000/en/>. Acesso em: 6 out. 2017.

ORGANIZAÇÃO MUNDIAL DA SAÚDE. The world health report: Health systems financing: the path to universal coverage. 2010. Disponível em: $<$ http://www.who.int/whr/2010/en/>. Acesso em: 6 set. 2010.

OSTRY, DJ; LOUNGANI, P; FURCERI, D. Neoliberalism: oversold? Finance \& development, v. 53, n. 2, p. 38-41, 2016.

OUVERNEY, Assis Mafort; RIBEIRO, José Mendes; MOREIRA, Marcelo Rasga. O COAP e a Regionalização do SUS: os diversos padrões de implementação nos estados brasileiros. Revista Ciência \& Saúde Coletiva, v. 22, n. 4, p. 1193-1207, 2017.

PINTO, Élida Graziane. Controle judicial dos orçamentos públicos em prol dos direitos fundamentais. Consultor Jurídico, 2016. Disponível em: $<$ http://www.conjur.com.br/2016-ago-17/elida-pinto-controle-orcamentario-proldireitos-fundamentais>. Acesso em: 19 set. 2017.

PINTO, Élida Graziane. Descompasso federativo no financiamento da saúde pública brasileira. Consultor Jurídico, 2015. Disponível em: $<$ https://www.conjur.com.br/2015-abr-04/elida-pinto-descompasso-federativofinanciamento-saude $>$. Acesso em: 8 nov. 2017.

PINTO, Élida Graziane. Estado de Coisas Inconstitucional na política pública de saúde brasileira.

PINTO, Élida Graziane. Financiamento dos direitos à saúde e à educação: uma perspectiva constitucional. Belo Horizonte: Fórum, 2015.

PINTO, Élida Graziane. STF reconhece o "direito a ter o custeio adequado de direitos" na ADI 5.595. Consultor Jurídico, 2017. Disponível em: $<$ https://www.conjur.com.br/2017-set-12/contas-vista-stf-reconhece-direitocusteio-adequado-direitos-adi-5595>. Acesso em: 8 nov. 2017. 
PIOLA, Sérgio Francisco; MARIA ELIZABETH BARROS; NOGUEIRA, Roberto Passos; et al. Vinte anos da Constituição de 1988: o que significaram para a saúde da população brasileira? In: Políticas Sociais: Acompanhamento e Análise. Brasília: Ipea, 2009, v. 1, p. 97-172. 17v. (Série Vinte anos da Constituição Federal).

PIRES-ALVES, Fernando A; PAIVA, Carlos Henrique Assunção; SANTANA, José Paranaguá de. A internacionalização da saúde: elementos contextuais e marcos institucionais da cooperação brasileira. Rev Panam Salud Publica, v. 32, n. 6, p. $444-450,2012$.

PORTER, Roy. The Greatest Benefit to Mankind: a medical history of humanity. New York: W.W. Norton \& Company, 1998.

ROBINSON, Suzanne; WILLIAMS, Iestyn; DICKINSON, Helen; et al. Prioritysetting and rationing in healthcare: Evidence from the English experience. Social Science \& Medicine, v. 75, p. 2386-2393, 2012.

ROHDE, Jon; COUSENS, Simon; CHOPRA, Mickey; et al. 30 years after AlmaAta: has primary health care worked in countries? Lancet, v. 372, p. 950-61, 2008 .

ROSA, Chennyfer D. P. da; GRELL, Armando Pereira. Financiamento da Saúde no Brasil e a Emenda Constitucional n. 29 de 2000. Revista da Faculdade de Ciências Médicas de Sorocaba, v. 17, n. 1, p. 51-52, 2015.

ROSS, Alf. Direito e Justiça. Trad. Edson L. M. Bini. São Paulo: Edipro, 2000.

SANTOS, Francisco de Assis; JÚNIOR, Garibaldi Dantas Gurgel; GURGEL, Idê Gomes Dantas; et al. A definição de prioridade de investimento em saúde: uma análise a partir da participação dos atores na tomada de decisão. Revista de Saúde Coletiva, v. 25, n. 4, p. 1079-1094, 2015.

SANTOS, Isabela Soares. A solução para o SUS não é um Brazilcare. Revista Eletrônica de Comunicação, Informação e Inovação em Saúde, v. 10, n. 3, 2016. Disponível em: <www.reciis.icict.fiocruz.br/index.php/reciis/article/ viewFile/1191/pdf1191>. Acesso em: 2 ago. 2017.

SANTOS, Isabela Soares; UGÁ, Maria Alicia D; PORTO, Silvia Marta. O mix público-privado no Sistema de Saúde Brasileiro: financiamento, oferta e utilização de serviços de saúde. Revista Ciência \& Saúde Coletiva, v. 13, n. 5, p. 14311440, 2008. 
SANTOS, Lenir. Judicialização da saúde: é preciso rever a responsabilidade solidária. Consultor Jurídico, 2017. Disponível em: $<$ http://www.conjur.com.br/2017-ago-26/lenir-santos-preciso-reverresponsabilidade-solidaria-saude>. Acesso em: 30 ago. 2017. SANTOS, Lenir; ANDRADE, Luiz Odorico Monteiro de. SUS: o Espaço da Gestão Inovada e dos Consensos Interfederativos: aspectos jurídicos, administrativos e financeiros. 2a ed. Campinas: Saberes, 2009.

SAVEDOFF, William D. Kenneth Arrow and the birth of health economics. Bulletin of the World Health Organization, v. 82, n. 2, p. 139-140, 2004.

SEN, Amartya. Desigualdade reexaminada. Trad. Ricardo Doninelli Mendes. 2a ed. Rio de Janeiro: Record, 2008.

SERVO, Luciana Mendes Santos; PIOLA, Sérgio Francisco; PAIVA, Andrea Barreto de; et al. Financiamento e Gasto Público de Saúde: histórico e tendências. In: MELAMED, Clarice; PIOLA, Sérgio Francisco (Orgs.). Políticas Públicas e

Financiamento Federal do Sistema Único de Saúde. Brasilia: Ipea, 2011.

SIMMS, Chris; ROWSON, Mike; PEATTIE, Siobhan. The bitterest pill of all: The collapse of Africa's health systems. 2001. Disponível em: $<$ http://www.eldis.org/vfile/upload/1/document/0708/DOC8889.pdf>.

SOARES, Laura Tavares. Políticas Sociais na América Latina. In: GIOVANELLA, Ligia; LOBATO, Lenaura de VAsconcelos Costa; NORONHA, José Carvalho de; et al (Orgs.). Políticas e Sistema de Saúde no Brasil. 2a ed. rev. amp. Rio de Janeiro: Fiocruz, 2012.

SOBRINHO, Luiz Vianna. Medicina Financeira: a ética estilhaçada. Rio de Janeiro: Garamond, 2013.

SOUZA, Celina. Políticas Públicas: uma revisão da literatura. Sociologias, v. 16, p. 20-45, 2006.

TENDLER, Judith. Good Government in the Tropics. Baltimore: Johns Hopkins University Press, 1997.

TRAVASSOS, Claudia; CASTRO, Mônica Silva Monteiro de. Determinantes e Desigualdades Sociais no Acesso e na Utilização de Serviços de Saúde. In: GIOVANELLA, Ligia; ESCOREL, Sarah; LOBATO, Lenaura de VAsconcelos Costa; et al (Eds.). Políticas e Sistema de Saúde no Brasil. 2a ed. rev. e amp. Rio de Janeiro: Fiocruz, 2012, p. 183-205.

TRIBUNAL DE CONTAS DA UNIÃO. Acórdão TCU 2.888/2015. 
UGÁ, Maria Alicia D; PIOLA, Sérgio Francisco; PORTO, Silvia Marta; et al. descentralização e alocação de recursos no âmbito do Sistema Único de Saúde. Revista Ciência \& Saúde Coletiva, v. 8, n. 2, p. 417-437, 2003.

UGÁ, Maria Alicia D; PORTO, Silvia Marta; PIOLA, Sérgio Francisco. Financiamento e Alocação de Recursos em Saúde no Brasil. In: ESCOREL, Sarah; LOBATO, Lenaura de VAsconcelos Costa; NORONHA, José Carvalho de; et al (Eds.). Políticas e Sistema de Saúde no Brasil. 2a ed ra. Rio de Janeiro: Fiocruz, 2014, p. 395-425.

VIANNA, Solon Magalhães. A Seguridade Social, o Sistema Único de Saúde e a Partilha de Recursos. Revista Saúde e Sociedade, v. 1, n. 1, p. 43-58, 1992.

WAGSTAFF, Adam; VAN DOORSLAER, Eddy. Equity in Health Care Finance and Delivery. In: CULYER, A; NEWHOUSE, J (Orgs.). North Holland handbook in health economics. Amsterdan: North-Holland, 2000.

WALT, Gill; GILSON, Lucy. Reforming the health sector in developing countries: the central role of policy analysis. Health policy and planning, v. 9, n. 4, p. 353-370, 1994.

WORLD BANK. Financing Health Services in Developing Countries: An Agenda for Reform. Washington, D.C.: [s.n.], 1987.

WORLD BANK. World Development Report. 1993. Disponível em: $<$ https://openknowledge.worldbank.org/handle/10986/5976>.

Brazil Country Profile. [s.l.]: World Bank, [s.d.]. Disponível em: $<$ http://databank.worldbank.org/data/Views/Reports/ReportWidgetCustom.aspx? Report_Name $=$ CountryProfile $\& I d=b 450 f d 57 \&$ tbar $=y \& d d=y \& i n f=n \& z m=n \& c o u$ ntry $=$ BRA $>$. Acesso em: 27 set. 2017.

GINI index (World Bank estimate). [s.1.]: World Bank, [s.d.]. Disponível em: $<$ https://data.worldbank.org/topic/poverty>. Acesso em: 27 set. 2017.

Governo federal não aplicou mínimo em saúde em 2016, diz MP de Contas. Consultor Jurídico, 2017. Disponível em: <https://www.conjur.com.br/2017-abr30/governo-nao-aplicou-minimo-saude-2016-mp-contas>. Acesso em: 8 nov. 2017.

Morre Kenneth Arrow, mais jovem vencedor do Nobel de Economia. Folha de São Paulo, 2017. Disponível em: $<$ http://www1.folha.uol.com.br/mercado/2017/02/1860916-morre-kenneth-arrowmais-jovem-vencedor-do-nobel-de-econo>. Acesso em: 24 ago. 2017. 
ONU quer fim da austeridade e ousadia para reequilibrar economia. Valor Econômico, 2017. Disponível em: <http://www.valor.com.br/brasil/5122156/onuquer-fim-da-austeridade-e-ousadia-para-reequilibrar-economia>. Acesso em: 17 set. 2017.

Systems thinking for health systems strengthening. 2009.

Tendências do Sistema de Saúde Brasileiro: estudo Delphi. Brasilia: Ipea, 2001 .

The WHO Report 2010 (financing to universal coverage). Disponível em: $<$ http://apps.who.int/iris/bitstream/10665/44371/1/9789241564021_eng.pdf>. Acesso em: 10 jun. 2017. 